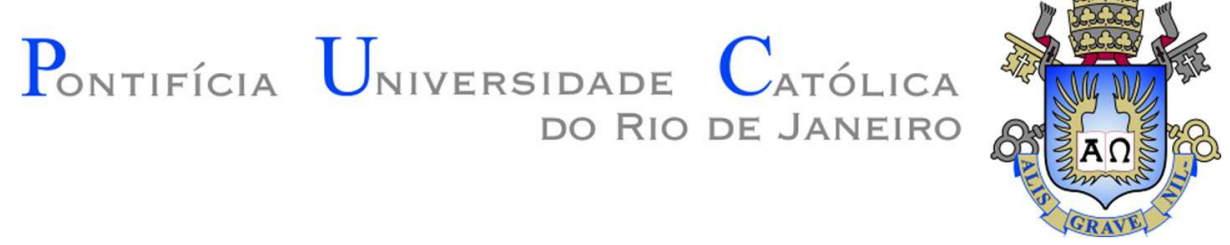

Alessandra Pazini

Derivados de benzotiadiazola arilóxisubstituídos: uma nova classe de emissores orgânicos para OLEDs

Dissertação de Mestrado

Dissertação apresentada ao Programa de PósGraduação em Química da PUC-Rio como requisito parcial para obtenção do grau de Mestre em Química.

Orientador: Prof. Jones Limberger

Rio de Janeiro

Fevereiro de 2019 
Todos os direitos reservados. É proibida a reprodução total ou parcial do trabalho sem autorização da universidade, da autora e do orientador.

\section{Alessandra Pazini}

Graduou-se em Engenharia Química pela UFRGS em 2017. Possui experiência em Química Orgânica com ênfase em reações de acoplamento e reações de acoplamento cruzado catalisadas por paládio.

Ficha Catalográfica

Pazini, Alessandra.

Derivados de benzotiadiazola arilóxisubstituídos: uma nova classe de emissores orgânicos para OLEDs/ Alessandra Pazini; orientador: Jones Limberger. - 2019.

119 f. : il. color. ; $30 \mathrm{~cm}$

Dissertação (mestrado)-Pontifícia Universidade Católica do Rio de Janeiro, Departamento de Química, 2019.

Inclui bibliografia

1. Química - Teses. 2. Reações de acoplamento. 3. BTD. 4. Fluorescência. 5. OLED. 6. Poliarilação. I. Limberger, Jones. II. Pontifícia Universidade Católica do Rio de Janeiro. Departamento de Química. III. Título. 


\section{Agradecimentos}

À minha família, pelo apoio, por entenderem a distância física, e mesmo não entendendo o que faço se sentem muito orgulhosos.

Às minhas amizades, pelo suporte mesmo que via WhatsApp, pela paciência de me ouvir reclamar e vibrarem com as minhas conquistas.

Ao meu Jones, por tudo.

Ao Prof. Dr. Jones Limberger pela incansável vontade de ensinar, pela paciência e pelo apoio durante o desenvolvimento dessa dissertação.

À Prof. Cristiane Schwalm (UFGD) pela amizade e ajuda na revisão.

Ao nosso grupo de pesquisa LaSOQF pela parceria e ajudas diárias, em especial ao aluno de iniciação científica Felipe Valente.

À todos os colaboradores que contribuíram para a realização dessa dissertação: Prof. Fabiano Rodembush (UFRGS) pelos experimentos de rendimento quântico de fluorescência no estado sólido e de fluorescência resolvida no tempo; Prof. Jairton Dupont (UFRGS) pela disponibilidade do equipamento HRMS; Prof. Davi Back (UFSM), pelas estruturas de raio-X; Central analítica do departamento de Química da Puc-Rio pelas análises de RMN; Prof. Ricardo Aucélio (Puc-Rio) pelo empréstimo do fluorímetro e espectrofotômetro; Prof. Marco Cremona (Puc-Rio) pela contribuição nos dispositivos OLED; Dr. Luis Maqueira (Puc-Rio) pelos ensinamentos e os cálculos de DFT, TD-DFT e Lippert-Mataga; Dra. Joseany Almeida que me ensinou a técnica de voltametria cíclica e todos do LabSint pela amizade, troca de conhecimento e empréstimo de vidrarias, reagentes e solventes.

À PUC-Rio e à Vice-Reitoria.

Ao CNPq. 


\section{Resumo}

Pazini, Alessandra; Limberger, Jones. Derivados de benzotiadiazola arilóxi-substituídos: uma nova classe de emissores orgânicos para OLEDs. Rio de Janeiro, 2019. 119 p. Dissertação de Mestrado Departamento de Química, Pontifícia Universidade Católica do Rio de Janeiro.

O planejamento racional e a obtenção de novos compostos luminescentes com aplicações específicas continua sendo um importante desafio em síntese orgânica. Derivados do núcleo benzotiadiazola (BTD) com conjugação $\pi$ estendida têm sido amplamente sintetizados e aplicados em diferentes aspectos da tecnologia da luz. Em geral, na estrutura desses derivados, grupos doadores de elétrons (D) são ligados ao anel BTD, que tem caráter aceptor de elétrons (A). Até o presente momento não haviam sido descritos derivados de BTD cuja porção doadora é um grupamento arilóxi. No presente trabalho foi desenvolvida uma rota sintética para derivados de BTD arilóxi-substituídos. Os compostos se mostraram altamente luminescentes em solução ( $\phi$ de até 74\%) e com band gap adequado para aplicação em camadas emissoras de OLEDs. O desenvolvimento/otimização dos compostos foi dividido em duas partes. Na primeira parte, foram determinadas as condições reacionais para a obtenção dos novos derivados e foi avaliada qual a melhor configuração dos compostos: arilóxi-BTD-aceptor ou arilóxi-BTD-doador. Um composto com característica arilóxi-BTD-doador se mostrou mais emissivo, assim, construiu-se um dispositivo OLED verde utilizando-o como camada emissora, como uma prova de conceito. Na segunda parte do trabalho, foi realizada uma otimização estrutural mais abrangente, onde oito novos derivados foram sintetizados e caracterizados. Através dessa nova otimização chegou-se no composto líder 4-(4-metoxifenóxi)-7-o-toluilbenzo[c][1,2,5]tiadiazol, que apresentou band gap eletroquímico de 3,2 eV, máximo de emissão em $471 \mathrm{~nm}$ (azul), emissão induzida por agregação e 83 \% de rendimento quântico de fluorescência no estado sólido. A partir desse emissor puramente orgânico otimizado serão construídos novos dispositivos OLED.

\section{Palavras-chave}

Reações de acoplamento; benzotiadiazola; fluorescência; OLED. 


\section{Abstract}

Pazini, Alessandra; Limberger, Jones (Advisor). Aryloxy-substituted benzothiadiazole derivatives: a new class of organic emitters for OLEDs. Rio de Janeiro, 2019. 119 p. Dissertação de Mestrado Departamento de Química, Pontifícia Universidade Católica do Rio de Janeiro.

The rational planning and obtention of new luminescent compounds with specific applications can be considered an important challenge in organic synthesis. Benzothiadiazole (BTD) derivatives with extended $\pi$ conjugation have been widely synthesized and applied in different aspects of light technology. In general, in the structure of these derivatives, electron donor groups (D) are bound to the BTD ring, which has electron acceptor character (A). To date, BTD derivatives in which the donor moiety is an aryloxy group have not been described. In the present work a synthetic route for aryloxy-substituted BTD derivatives has been developed. The compounds are highly luminescent in solution ( $\phi$ up to $74 \%$ ) and display suitable band gaps for application as emitting layers in OLEDs. The development/optimization of the compounds was divided into two parts. In the first part, the reaction conditions were optimized and the best architecture of the compounds was evaluated: aryloxy-BTD-acceptor or aryloxy-BTD-donor. A compound with aryloxy-BTD-donor design displayed more intense emission, thus, a green OLED device was constructed using it as a emitting layer, as a proof of concept. In the second part of the work, a more comprehensive structural optimization was performed, and eight novel derivatives were synthesized and characterized. By means of this new optimization, the lead compound 4-(4methoxyphenoxy)-7-o-tolylbenzo[c][1,2,5]thiadiazole was obtained, which showed an emission maximum at $471 \mathrm{~nm}$ (blue), band gap of 3,2 eV, aggregation emissioninduced and $83 \%$ of photoluminescence quantum yield in the solid state. This new leader compound will be explored as emissive layer in novel OLED devices.

\section{Keywords}

Coupling reactions; benzothiadiazole; fluorescence; OLED. 


\section{Sumário}

1 Introdução 14

2 Revisão bibliográfica $\quad 16$

2.1. Reações de acoplamento catalisadas por metais de transição 16

2.1.1. Reação de Suzuki 17

2.1.2. Aminação de Buchwald-Hartwig 19

2.2. Derivados de benzotiadiazola (BTD) 23

2.3. Aplicação de reações de acoplamento carbono-carbono e carbonoheteroátomo na obtenção de derivados de BTD 23

2.4. OLEDs 28

2.4.1. Funcionamento do dispositivo 31

2.4.2. Parâmetros de um dispositivo OLED 33

2.4.3. OLEDs baseados em materiais TADF 34

2.5. Aplicação de derivados de BTD em OLEDs 36

3 . Objetivos 40

4 . Resultados 41

4.1. Síntese do intermediário fenóxi-BTD e avaliação de grupos doadores e aceptores de elétrons $\quad 41$

4.1.1. Síntese e caracterização estrutural 41

4.1.2. Caracterização fotofísica dos compostos 43 e 44

4.1.3. Estudo dos compostos 43 e 44 através da teoria funcional da densidade (DFT) 49

4.1.4. Aplicação do derivado de BTD 43 como camada emissora de OLED 50

4.2. Otimização estrutural de derivados de BTD arilóxi-substituídos para aplicação em camadas emissoras de OLEDs 56

4.2.1. Síntese de novos derivados BTD substituídos 56

4.2.2. Caracterização fotofísica e eletroquímica dos novos derivados de BTD 65

5 . Conclusões 78

6 . Perspectivas $\quad 80$

7. Procedimentos experimentais $\quad 81$ 
7.1. Materiais e métodos

7.2. Síntese dos intermediários ArO-BTD-Br (compostos 42 e 53)

7.3. Síntese dos cromóforos fenóxi e naftóxi-substituídos via acoplamento de Suzuki (43-48, 54 e 55)

7.4. Síntese dos derivados de BTD arilóxi-substiuidos via aminação de Buchwald-Hartwig (49 e 50)

86

7.4.1. Síntese dos compostos diarilados 56 e 57 via acoplamento de Suzuki 88

7.5. Síntese dos compostos simétricos 58 e 59 via Aminação de BuchwaldHartwig

7.6. Preparo de soluções 90

7.6.1. Soluções para experimento de absorção 90

7.6.2. Soluções para experimento de emissão 90

7.6.3. Soluções para rendimento quântico de fluorescência 90

7.7. Cálculo de Rendimento quântico em solução 90

7.8. Experimentos de Voltametria Cíclica 91

8. Referências bibliográficas 92

9. Anexos 97

9.1. Espectros de RMN ${ }^{1} \mathrm{He}^{13} \mathrm{C} \quad 97$

9.2. Voltametria cíclica 113

$\begin{array}{ll}\text { 9.3. Dados de difratometria de raios -X } & 117\end{array}$ 


\section{Lista de abreviaturas}

$\varepsilon$ : Absortividade molar

$\tau$ : Tempo de decaimento de fluorescência

$\left(t-\mathrm{Bu}_{3} \mathrm{PH}\right) \mathrm{BF}_{4}$ : Tetrafluoroborato de tri-terc-butilfosfônio

$\phi_{\text {sólido }}$ : Rendimento quântico de fluorescência no estado sólido

$\phi_{\text {solucão }}$ : Rendimento quântico de fluorescência em solução

$\phi_{\mathrm{w}}$ : Função trabalho

$\Delta \lambda_{\mathrm{ST}}:$ Deslocamento de Stokes

$\Delta \mathrm{E}_{\mathrm{ST}}$ : Diferença energética entre os níveis de energia singlete e triplete $\mathrm{Alq}_{3}$ : Tris-(8-hidroxiquinolinato) de alumínio

Ar: Arila

ArO: Arilóxi

BCP: 2,9-Dimetll-4,7-difenil-1,10-fenantrolina

BINAP: 2,2'-bis(difenilfosfino)-1,1'-binaftila)

BTD: Benzotiadiazola

CE: Camada emissora

CIB: Camada injetora de buracos

CIE: Camada injetora de elétrons

CTB: Camada transportadora de buracos

CTE: Camada transportadora de elétrons

dba: Dibenzilidenoacetona

DFT: Teoria funcional da densidade, do inglês functional density theory

DMF: Dimetilformamida

DMSO: Dimetilsulfóxido

DPE-Phos: Bis[2-(difenilfosfino)feniléter

DPPF: 1,1'-Bis(difenilfosfino)ferroceno

EL: Eletroluminescência do inglês electroluminescence.

EQE: Máxima eficiência quântica externa do inglês External quantum efficiency

ESIPT: Transferência intramolecular de próton no estado excitado do inglês excited state intramolecular proton transfer

HOMO: Orbital molecular ocupado de mais baixa energia do inglês highest occupied molecular orbital

ICT: Transferência de carga intramolecular do inglês intramolecular charge transfer

ITO: Óxido de estanho dopado com índio

IZO: Óxido de índio dopado com zinco 
J: Constante de acoplamento

LUMO: Orbital molecular não ocupado de mais baixa energia do inglês lowest unoccupied molecular orbital

Naft: Naftila

NHet: Heterociclo de nitrogênio.

NPB: N,N'-difenil-N,N'-bis(3-metilfenil)-(1,1'-bifenil)-4,4'diamina

NPs: Nanopartículas

OLED: Diodo emissor de luz orgânica do inglês organic light-emitting diode

ONaft: Naftóxi

PEDOT:PSS: Poli(3,4-etilenodioxitiofeno) poli(estirenosulfonato)

PhMe: Tolueno

PL: Fotoluminescência do inglês photoluminescence

RISC: Cruzamento reverso intersistema do inglês reverse intersystem crossing

S-Phos: 2-Diciclohexilfosfino-2',6'-dimetoxibifenil

t.a.: Temperatura ambiente

TADF: Fluorescência atrasada ativada termicamente do inglês Thermally activated delayed fluorescence

TBS: Terc-butildimetilsilano

TD-DFT: Teoria funcional da densidade dependente do tempo do inglês Timedependent density functional theory

THF: Tetrahidrofurano

TPD: N,N'-bis(1-naftil)-N,N'-difenil-1,1'-bifenil-4,4'-diamina

TTF: Fluorescência triplete-triplete

$\mathrm{V}_{\text {on: }}$ Tensão de acendimento

DPA: difenilamina

CZ: $9 H$-carbazol

DMAC: 9,9-Dimetil-9,10-dihidroacredina 


\section{Lista de figuras}

Figura 1: Exemplos de aplicação da reação de acoplamento de Suzuki-Miyaura em compostos comerciais.

Figura 2: Monofosfinas biarílicas ativas como ligantes da aminação de

Buchwald-Hartwig.

Figura 3: Exemplos de aplicação da reação de aminação de Buchwald-Hartwig.

22

Figura 4: Núcleo 2,1,3-benzotiadiazola.

23

Figura 5: Estrutura química do intermediário 4,7-dibromo-BTD e as possíveis configurações de substituição nas posições 4,7 de 9 .

Figura 6: Esquema da arquitetura comercial de um OLED típico. Imagem adaptada de Volz e colaboradores. (2015).

Figura 7: Exemplos selecionados das moléculas utilizadas nas diversas camadas em um OLED.

Figura 8: Diagrama esquemático de energia de um OLED de três camadas ilustrando os processos básicos de eletroluminescência. Adaptado de W. Bruwtting e colaboradores (2013).

Figura 9: Classificação dos dispositivos OLED quanto à sua camada emissiva. Imagem adaptada de Chen e colaboradores (2018).

Figura 10: Esquema do cruzamento intersistemas que é necessário para ter característica TADF. Imagem adaptada de Volz e colaboradores (2015)...35

Figura 11: Exemplos de estratégias para adquirir característica TADF..............36

Figura 12: Derivados de BTD aplicados em OLED já descritos na literatura......39

Figura 13: Espectro de $\mathrm{RMN}^{1} \mathrm{H}\left(400 \mathrm{MHZ}, \mathrm{CDCl}_{3}\right)$ do intermediário 42. ...........43

Figura 14: Espectro de $\mathrm{RMN}^{1} \mathrm{H}\left(400 \mathrm{MHz}, \mathrm{CDCl}_{3}\right)$ do composto $43 \ldots \ldots \ldots \ldots . . . . . .44$

Figura 15: Estrutura molecular do intermediário 42 ..................................... 44

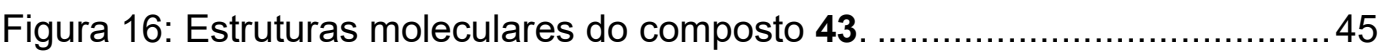

Figura 17: Absorção (superior) e espectro de emissão de fluorescência (inferior) dos compostos 43 e 44 em vários solventes. Ciclohexano (-), tolueno $(-)$, acetona $(-)$ e acetato de etila $(-)$.

Figura 18: Deslocamento de Stokes $\left(\mathrm{cm}^{-1}\right)$ dos luminóforos 43 e 44 em função dos valores de $\Delta f$ para diferentes solventes. $43\left(R^{2}>0,88\right), 44\left(R^{2}>0,24\right)$. Concentração: $10 \mu \mathrm{mol} \mathrm{L}{ }^{-1}$.

Figura 19: Distribuição HOMO e LUMO calculada para os estados fundamentais de 43 e 44 . 
Figura 20: Estrutura do composto 32 sintetizado por Pazini e colaboradores (2017).

Figura 21: Voltamogramas cíclicos de (a) medição de referência; (b) ferroceno;

(c) 43; e (d) 32 .

Figura 22: Diagrama de energia do dispositivo construído com a seguinte estrutura: ITO/PEDOT:PSS $(40 \mathrm{~nm}) / 43$ ou 32 (30 nm)/TPBi $(25 \mathrm{~nm}) / \mathrm{LiF}$ $(0.1 \mathrm{~nm}) / \mathrm{Al}(100 \mathrm{~nm})$. 53

Figura 23: Caracterização OLEDs A e B. 54

Figura 24: OLED verde fabricado utilizando o composto 43 como camada emissora. 55

Figura 25: Estrutura geral dos derivados de BTD arilóxi-substituídos de segunda geração. 56

Figura 26: Espectro de $\mathrm{RMN}{ }^{1} \mathrm{H}\left(400 \mathrm{MHz}, \mathrm{CDCl}_{3}\right)$ do produto 47. 58

Figura 27: Materiais TADF que possuem o grupo fenoxazina e são comercializados como materiais para camadas emissoras de OLEDs.......59

Figura 28: Espectro de $\mathrm{RMN}{ }^{1} \mathrm{H}\left(400 \mathrm{MHz}, \mathrm{CDCl}_{3}\right)$ do produto $50 \ldots \ldots \ldots \ldots \ldots \ldots . . . . . . . .60$

Figura 29: Fenóis testados para a síntese de novos derivados de BTD.............60

Figura 30: Espectro de $\mathrm{RMN}^{1} \mathrm{H}\left(400 \mathrm{MHz}, \mathrm{CDCl}_{3}\right)$ do produto $54 \ldots \ldots \ldots \ldots \ldots . . . . . . . . .62$

Figura 31: Espectro de $\mathrm{RMN}^{1} \mathrm{H}\left(400 \mathrm{MHz}, \mathrm{CDCl}_{3}\right)$ do produto $57 \ldots \ldots \ldots \ldots \ldots \ldots . .63$

Figura 32: Espectro de $\mathrm{RMN}^{1} \mathrm{H}\left(400 \mathrm{MHz}, \mathrm{CDCl}_{3}\right)$ do produto $59 . \ldots \ldots \ldots \ldots \ldots . . . . . . . .65$

Figura 33: Voltamograma cíclico do composto 50........................................66

Figura 34: Espectros UV-Vis dos derivados de BTD arilóxi-substituídos. Tolueno (-), ciclohexano (-), diclorometano (-) e isopropanol (-)......67 Figura 35: Espectros de fluorescência dos novos derivados de BTD. Tolueno (-), ciclohexano (-), diclorometano (-) e isopropanol (-). 70

Figura 36: Distribuição eletrônica do HOMO e LUMO dos novos derivados de

BTD através de cálculos teóricos de DFT. .73

Figura 37: Curvas de fluorescência resolvida no tempo dos compostos em ciclohexano. 75

Figura 38: Requisitos estruturais propostos para derivados de BTD arilóxisubstituídos apresentarem EIA.

Figura 39: Variação da intensidade de fluorescência dos compostos 46, 47, 56 e 57 em diferentes frações de água. 


\section{Lista de tabelas}

Tabela 1: Principais reações de acoplamento cruzado C-C e seus respectivos reagentes. Adaptado de Batalha e colaboradores $(2014)^{14}$. 17

Tabela 2: Dados de otimização da reação de formação do fenóxi-BTD.

Tabela 3: Comprimentos de onda máximo para absorção e emissão e os deslocamentos de Stokes de $\mathbf{4 3}$ e $\mathbf{4 4}$ em diferentes solventes.

Tabela 4: Dados de inclinação Lippert-Mataga, mudança de dipolo no estado fundamental, no estado excitado e a diferença entre os estados (em Debye, D).

Tabela 5: Níveis de energia HOMO e LUMO para os compostos 43 e 32.

Tabela 6: Acoplamento de Suzuki entre o intermediário 42 e ácidos arilborônicos

Tabela 7: Dados de otimização da reação de formação do segundo intermediário BTD-naftóxi (53).

Tabela 8: Dados eletroquímicos de oxidação e redução dos compostos 45-50 e 54-59

Tabela 9: Dados do máximo de absorção $\left(\lambda_{\text {abs }}\right)$, absortividade molar $(\varepsilon)$ e band gap óptico (em eV) dos compostos estudados.

Tabela 10: Comprimento de onda máximo $\left(\lambda_{\mathrm{em}}\right)$ para emissão dos novos derivados de BTD em diferentes solventes

Tabela 11: Deslocamentos de Stokes $\Delta \lambda_{\mathrm{ST}}$ dos novos derivados de BTD em diferentes solventes.

Tabela 12: Rendimento quântico de fluorescência em solução ${ }^{80-82}$ em ciclohexano.

Tabela 13: Estimativas da diferença energética (eV) entre os estados $S_{1}$ e $T_{1}$ por TD-DFT.

Tabela 14: Dados da fluorescência resolvida no tempo, onde $\tau$ é o tempo de decaimento de fluorescência.

Tabela 15: Rendimento quântico de fluorescência no estado sólido. ${ }^{87,88}$ 76 


\section{Lista de esquemas}

Esquema 1: Esquema geral da primeira parte dos resultados. ....................... 15

Esquema 2: Esquema geral da segunda parte dos resultados. ....................... 15

Esquema 3: Esquema geral de um acoplamento de Suzuki-Miyaura................. 18

Esquema 4: Ciclo catalítico da reação de acoplamento C-C. Os ligantes

auxiliares foram omitidos para melhor visualização.................................. 18

Esquema 5: Esquema geral de um acoplamento de Buchwald-Hartwig.............21

Esquema 6: Ciclo catalítico da reação de acoplamento C-N............................21

Esquema 7: Rotas sintéticas utilizadas por $\mathrm{Ni}$ e colaboradores para a síntese

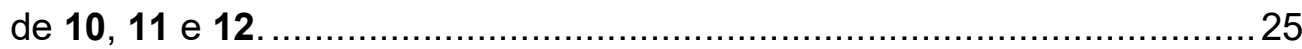

Esquema 8: Esquema de rota sintética desenvolvida por Neto e colaboradores (2012).

Esquema 9: Exemplo de acoplamento de Buchwald-Hartwig para a síntese 15.

Esquema 10: Exemplos de reações de BTD com tiofenóis sintetizados por Balaguez e colaboradores (2016) ..................................................27

Esquema 11: Procedimento sintético para os emissores de Fang e

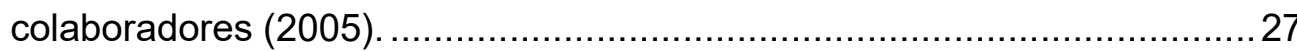

Esquema 12: Condições de síntese elaborada por Neto e colaboradores (2005).

Esquema 13: Condições de síntese elaborada por Pazini e colaboradores (2017). 28

Esquema 14: Síntese dos derivados BTD fenóxi-substituídos 43 e 44 43

Esquema 15: Síntese de derivados de BTD $N$ - e O-substituídos via acoplamento de Buchwald-Hartwig. ................................................... 59

Esquema 16: Acoplamento de Suzuki no intermediário 53 61

Esquema 17: Acoplamento de Suzuki na síntese de derivados simétricos em 9.

Esquema 18: Reação de aminação Buchwald-Hartwig para obtenção de derivados simétricos no dibromo-BTD. 


\section{Introdução}

As reações de acoplamento carbono-carbono e carbono-heteroátomo catalisadas por metais de transição (reações de Suzuki, Heck, Sonogashira, Negishi, Ullmann, Buchwald-Hartwig, etc.) estão entre as formas mais simples e efetivas para a obtenção de compostos poliarilados. A inserção de grupos arila, ariloxi e arilamina em diferentes esqueletos orgânicos permite a construção racional de compostos luminescentes com características doador-aceptor (D-A).

Derivados do núcleo 2,1,3-benzotiadiazola (BTD) com conjugação $\pi$ estendida têm sido extensivamente sintetizados e aplicados em variados aspectos da luminescência. ${ }^{1,2}$ Nesse contexto, o anel BTD tem sido funcionalizado nas posições 4 e 7 com grupos arila ${ }^{3-5}$, aminas aromáticas ${ }^{6-8}$ e tiofenóis $^{9,10}$ - através de reações catalisadas por metais de transição, ou através de protocolos livres de metais - levando a derivados de BTD altamente luminescentes. No entanto, até o presente momento, a funcionalização do anel BTD com fenóis, levando a derivados de BTD arilóxi-substituídos, não foi descrita.

Nessa dissertação é descrita pela primeira vez a obtenção de derivados de BTD arilóxi-substituídos. Para a obtenção desses compostos, a porção ArO- foi ligada à BTD através de uma metodologia isenta de metal, e, a partir de intermediários ArO-BTD-Br, novos derivados altamente luminescentes foram obtidos através de acoplamentos C-C e C-N. A estrutura desses luminóforos foi otimizada visando a aplicação em dispositivos OLEDs e os resultados foram divididos em duas partes:

1. Obtenção do primeiro derivado de BTD arilóxi-substituído e otimização da arquitetura do luminóforo ( $D-A-D$ ou $A-A-D)$.

2. Otimização estrutural de derivados de $B T D$ arilóxi-substituído $D-A-D$ visando propriedades TADF.

No Esquema 1 é mostrado um resumo gráfico da primeira parte dos resultados, onde dois derivados de BTD não simétricos foram sintetizados a partir do intermediário ArO-BTD-Br. O primeiro derivado com arquitetura D-A-D e o segundo com design A-A-D. O composto com arquitetura $D-A-D$ apresentou maior 
rendimento quântico de fluorescência e, por isso, foi aplicado como camada emissora em um OLED, como uma prova de conceito.

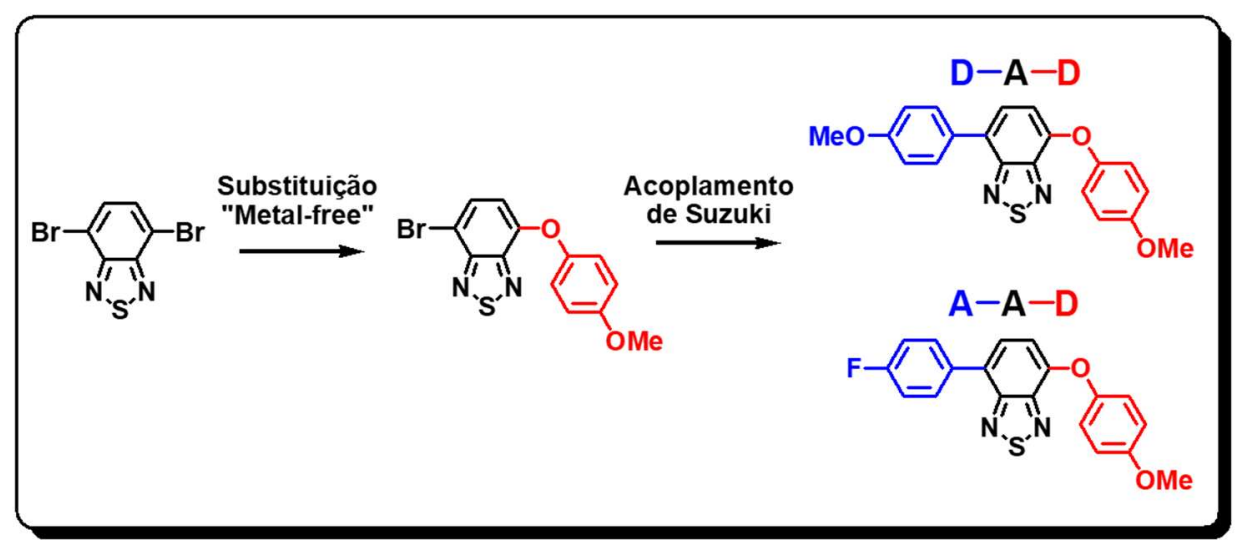

Esquema 1: Esquema geral da primeira parte dos resultados.

No Esquema 2 é mostrado o resumo gráfico da segunda parte dos resultados. Nessa parte do trabalho foi realizada uma otimização estrutural mais abrangente, obtendo-se diversos derivados de BTD arilóxi-substituídos com arquitetura D-A-D. Buscou-se nessa otimização compostos com alto grau de separação entre HOMO e LUMO, visando baixa diferença energética entre $S_{1}$ e $T_{1}$ e, consequentemente características de TADF (fluorescência atrasada ativada termicamente). Utilizando essa estratégia, desenvolveu-se um composto líder, com emissão azul, emissão induzida por agregação e $83 \%$ de rendimento quântico de fluorescência no estado sólido.

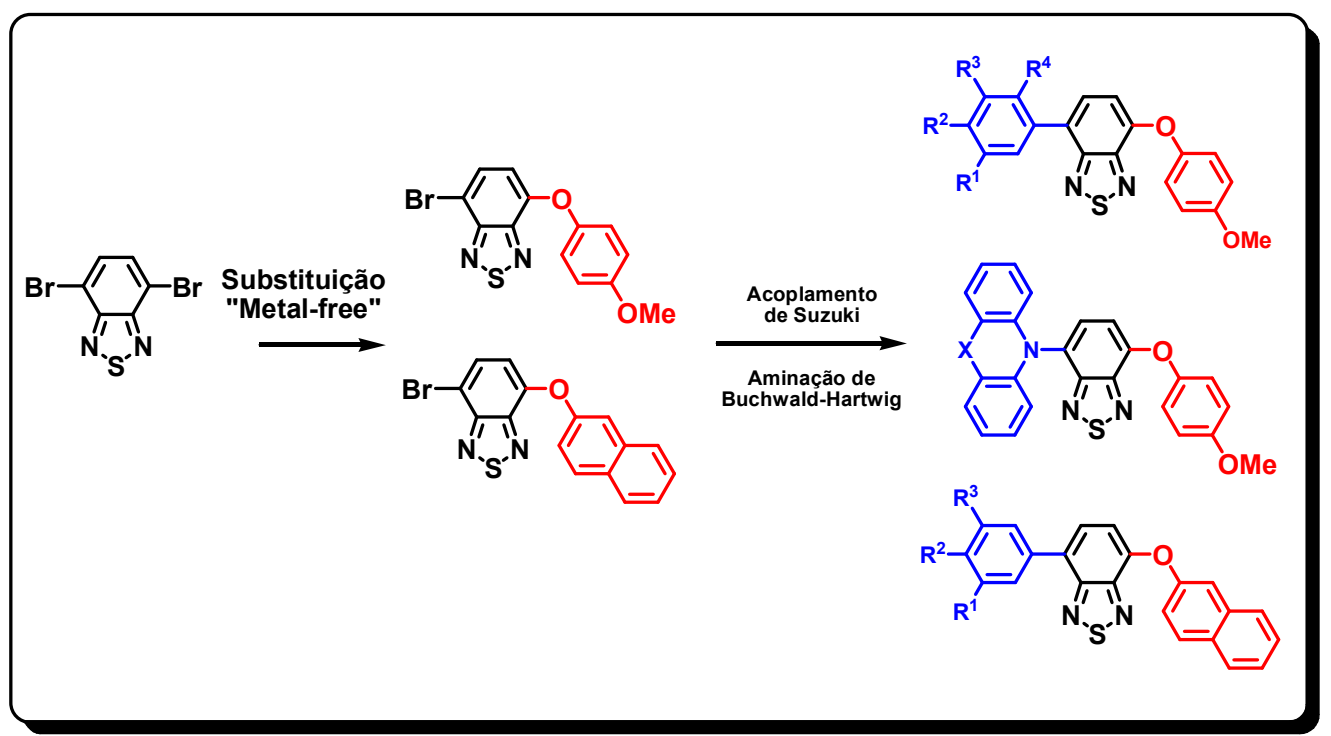

Esquema 2: Esquema geral da segunda parte dos resultados. 


\section{Revisão bibliográfica}

\subsection{Reações de acoplamento catalisadas por metais de transição}

As reações de acoplamento carbono-carbono ou carbono-heteroátomo compreendem uma gama de metodologias sintéticas catalisadas por metais de transição. Foram desenvolvidas para obter-se compostos que antes não poderiam ser sintetizados no segmento da química fina. As áreas que foram mais favorecidas com esse avanço foram a síntese total, processos químicos e químico-medicinais, assim como nanotecnologia e química biológica. Hoje em dia é muito raro encontrar uma edição de um periódico no campo da química orgânica ou organometálica sem que haja alguma contribuição que aborde algum aspecto das reações de acoplamento cruzado. ${ }^{11-14}$

Pesquisas pioneiras e fundamentais foram publicadas na década de 70 , a partir das quais foram desenvolvidas as reações de Mizoroki-Heck ${ }^{15}$, KumadaTamao-Corriu $^{16,17}$, Sonogashira ${ }^{18}$, Negishi ${ }^{19}$, Stille ${ }^{20}$, Suzuki-Miyaura ${ }^{21}$, entre outras. Cada uma dessas metodologias reacionais é específica para o acoplamento de algum organometálico/organometaloide (olefina no caso da reação de Mizoroki-Heck) com haletos/pseudohaletos orgânicos. Um resumo dos principais substratos, reagentes e aditivos de cada uma das reações de acoplamento $\mathrm{C}-\mathrm{C}$ é mostrado na Tabela 1. Como pode-se observar, a maioria desses trabalhos foram desenvolvidos aplicando-se complexos de paládio como catalisadores, demostrando o amplo repertório e importância desse metal de transição. Atualmente, além do paládio, diversos metais de transição têm sido aplicados em reações de acoplamento $\mathrm{C}-\mathrm{C}$, entre eles, $\mathrm{Ni}^{16,17}, \mathrm{Rh}^{22}, \mathrm{Cu}^{23} \mathrm{e} \mathrm{Fe}^{24,25}$.

Considerando que no presente trabalho foram utilizados o acoplamento C-C de Suzuki-Miyaura e o acoplamento C-N de Buchwald-Hartwig, nas próximas seções, essas metodologias serão abordadas mais detalhadamente. 
Tabela 1: Principais reações de acoplamento cruzado C-C e seus respectivos reagentes. Adaptado de Batalha e colaboradores (2014) ${ }^{14}$.

\begin{tabular}{|c|c|c|c|c|}
\hline \multirow{2}{*}{ Reação } & \multicolumn{2}{|c|}{$\begin{array}{c}\text { Substratos dos trabalhos } \\
\text { originais }\end{array}$} & \multirow{2}{*}{ Catalisador original } & \multirow{2}{*}{$\begin{array}{l}\text { Aditivos } \\
\text { originais }\end{array}$} \\
\hline & Nucleófilo & Eletrófilo & & \\
\hline $\begin{array}{l}\text { Mizoroki- } \\
\text { Heck }\end{array}$ & $\underset{\mathrm{R}=\mathrm{Ph} ; \mathrm{CO}_{2} \mathrm{Me}}{\mathrm{R}} \overbrace{}^{\mathrm{H}}$ & Ph-I & $\mathrm{Pd}(\mathrm{OAc})_{2}$ & $\begin{array}{l}(n-\mathrm{Bu})_{3} \mathrm{~N}, \\
\text { como base }\end{array}$ \\
\hline $\begin{array}{c}\text { Kumada- } \\
\text { Tamao-Corriu }\end{array}$ & $\begin{array}{c}\mathrm{R}-\mathrm{MgBr} \\
\mathrm{R}=\text { alquil; } \mathrm{Ph}\end{array}$ & $\overbrace{\mathrm{Cl}}^{\mathrm{Ph}-\mathrm{Cl}}$ & $\mathrm{Ni}(\text { acac })_{2}$ & - \\
\hline Sonogashira & $\begin{array}{r}\mathrm{R} \\
\mathrm{R}=\mathrm{H} ; \mathrm{\overline { \textrm {Ph } } ;} \mathrm{CH}_{2} \mathrm{OH}\end{array}$ & $\begin{array}{c}\mathrm{R}-\mathrm{X} \\
\mathrm{X}=\mathrm{I} ; \mathrm{Br} \\
\mathrm{R}=\mathrm{Ph} ; \text { piridil; } \\
\text { vinil }\end{array}$ & $\mathrm{PdCl}_{2}\left(\mathrm{PPh}_{3}\right)_{2}$ & $\begin{array}{l}\text { Cul como } \\
\text { co- } \\
\text { catalisador }\end{array}$ \\
\hline Negishi & $\begin{array}{l}\mathrm{R}=\mathrm{D} \equiv \mathrm{CZnCl} \\
\mathrm{R}=\mathrm{H} \text {; alquil }\end{array}$ & $\begin{array}{c}\mathrm{X} \\
\mathrm{X}=\mathrm{Br} ; \mathrm{I} \\
\mathrm{R}^{1} ; \mathrm{R}^{2} ; \mathrm{R}^{3}=\mathrm{H} ; \\
\text { alquil; } \\
\mathrm{CO}_{2} \mathrm{Me} \\
\end{array}$ & $\begin{array}{c}\mathrm{Pd}\left(\mathrm{PPh}_{3}\right)_{4} \\
\mathrm{Cl}_{2} \mathrm{Pd}\left(\mathrm{PPh}_{3}\right)_{2} \\
\mathrm{Ni}\left(\mathrm{PPh}_{3}\right)_{4}\end{array}$ & - \\
\hline Stille & $\begin{array}{c}\mathrm{R}_{4} \mathrm{Sn} \\
\mathrm{R}=\text { alquil; } \mathrm{Ph}\end{array}$ & $\begin{array}{c}\mathrm{Cl} \\
\mathrm{R}=\text { alquil;aril }\end{array}$ & $\mathrm{PhCH}_{2} \mathrm{Pd}\left(\mathrm{PPh}_{3}\right) \mathrm{Cl}$ & - \\
\hline $\begin{array}{l}\text { Suzuki- } \\
\text { Miyaura }\end{array}$ & $\begin{array}{l}\mathrm{R}^{1} ; \mathrm{R}^{2}=\mathrm{H} ; \text { alquil } \\
\mathrm{R}^{2}\end{array}$ & $\begin{array}{c}\mathrm{R}^{2} \\
\mathrm{R}^{1} ; \mathrm{R}^{2} ; \mathrm{R}^{3}=\mathrm{H} ; \\
\text { alquil } \\
\text { Ar-X } \\
\mathrm{X}=\mathrm{I} ; \mathrm{Br} ; \mathrm{Cl} \\
\mathrm{Ar}=\text { aril; } \\
\text { heteroaril }\end{array}$ & $\mathrm{Pd}\left(\mathrm{PPh}_{3}\right)_{4}$ & $\begin{array}{l}\mathrm{NaOH} ; \\
\text { EtONa } \\
\text { como } \\
\text { bases }\end{array}$ \\
\hline
\end{tabular}

\subsubsection{Reação de Suzuki}

Em 1979, verificou-se que as reações de acoplamento cruzado de compostos organoboro, onde o passo chave é a transmetalação com halogenetos de paládio, foram bem sucedidas na presença de uma base aquosa. A metodologia desenvolvida por Suzuki e Miyaura provou ser uma reação geral para uma ampla gama de formações seletivas de ligações carbono-carbono, juntamente com reações de acoplamento relacionadas de organomagnésio, organozinco e organoestanho. ${ }^{21,26}$ Além disso, em comparação com essas metodologias, os regentes organoboro tem as vantagens da baixa toxicidade, maior inércia à agua e ao oxigênio e a alta estabilidade térmica. ${ }^{26}$ No Esquema 3 é mostrado um esquema geral do acoplamento de Suzuki-Miyaura, onde um organoboro é reagido com um haleto orgânico na presença de um catalisador de 
paládio e de uma base, levando à formação de uma nova ligação $C$-C entre os fragmentos $R^{1}$ e $R^{2}$.

$$
\mathrm{R}^{1}-\mathrm{X}+\mathrm{R}^{2}-\mathrm{BY} Y_{2} \underset{\text { ligante }}{\stackrel{[\mathrm{Pd}] \text {, base }}{\longrightarrow}} \mathrm{R}^{1}-\mathrm{R}^{2}+\mathrm{XBY}_{2}
$$

Esquema 3: Esquema geral de um acoplamento de Suzuki-Miyaura.

O mecanismo clássico para o acoplamento de Suzuki-Miyaura é mostrado no Esquema 4. Quando precursores de Pd(II) são utilizados, o processo inicia pela pré-ativação do precursor, com a formação de uma espécie de $\operatorname{Pd}(0)$. Essa espécie entra no ciclo catalítico, sofrendo adição oxidativa do haleto orgânico e gerando um intermediário $\mathrm{R}^{1} \mathrm{Pd} \mathrm{d}^{\prime \prime} \mathrm{X}$. Essa etapa normalmente é a etapa lenta da reação. Em seguida, esse intermediário reage com o derivado organoboro previamente ativado pela base, em uma etapa elementar chamada de transmetalação. $O$ intermediário $R^{1} \mathrm{Pd}^{\prime \prime} \mathrm{R}^{2}$ sofre, então, eliminação redutiva, efetivamente formando a nova ligação $\mathrm{C}-\mathrm{C}$ e regenerando a espécie de $\mathrm{Pd}(0) .^{26,27}$

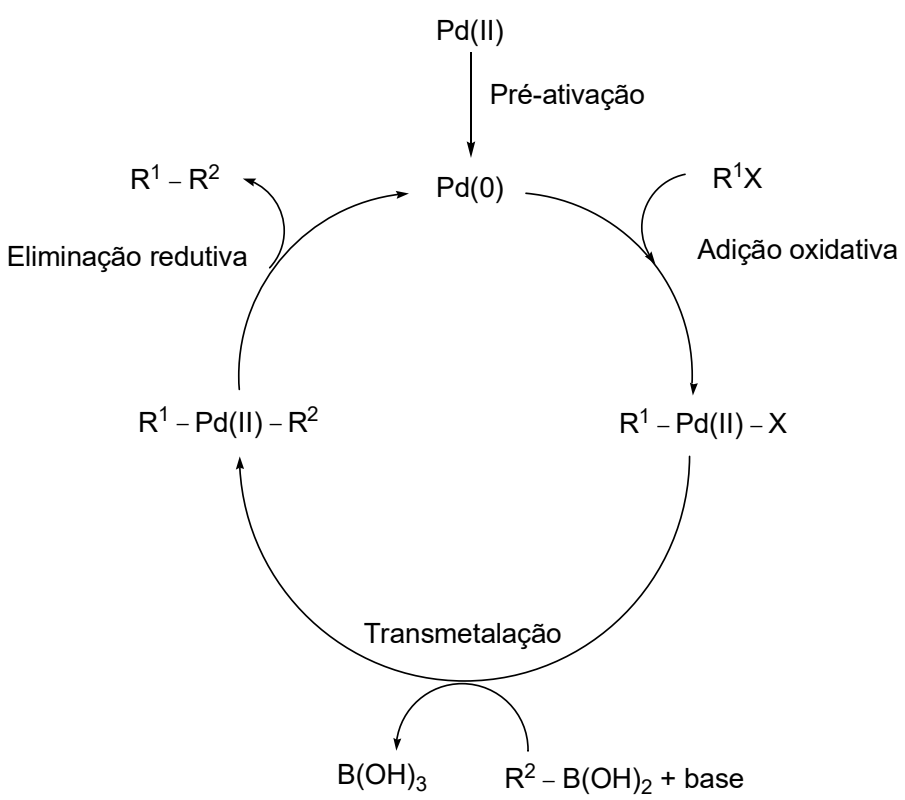

Esquema 4: Ciclo catalítico da reação de acoplamento C-C. Os ligantes auxiliares foram omitidos para melhor visualização.

Atualmente, como já descrito, o acoplamento de Suzuki tem grande aplicação tanto em ambiente acadêmico, quanto em ambiente industrial, tendo papel essencial no desenvolvimento de rotas sintéticas para compostos de alto valor agregado. Na Figura 1 são mostrados alguns exemplos da aplicação 
industrial do acoplamento de Suzuki na obtenção de fármacos e agroquímicos, onde a ligação formada através do acoplamento de Suzuki está ressaltada.

Em 1994, Larsen e colaboradores, da Merck, publicaram uma abordagem altamente eficiente e convergente para a síntese do antagonista do receptor de angiotensina II Losartan ${ }^{28}$ (1). A síntese foi desenvolvida empregando uma combinação das metodologias direcionadas de orto-metalação e acoplamento de Suzuki. A aplicação desta metodologia proporcionou um procedimento de alto rendimento ( $80 \%$ de rendimento global), que superou todas as abordagens anteriores. Uma metodologia alternativa pode ser aplicada na síntese da valsartana(2) e outras "sartanas" também utilizadas como anti-hipertensivos. Nessa rota, é realizado o acoplamento de Suzuki entre a 2-clorobenzonitrila o ácido 4-toluilborônico levando a um intermediário sintético biarílico.

O agroquímico Boscalid $®(3)$, sintetizado e comercializado pela BASF, teve sua rota sintética encurtada em várias etapas pela substituição de uma metodologia sintética clássica por uma abordagem envolvendo a reação de Suzuki para a obtenção de um intermediário biarílico ${ }^{29-31}$. Essa é atualmente a maior planta comercial envolvendo reações de Suzuki. ${ }^{31}$
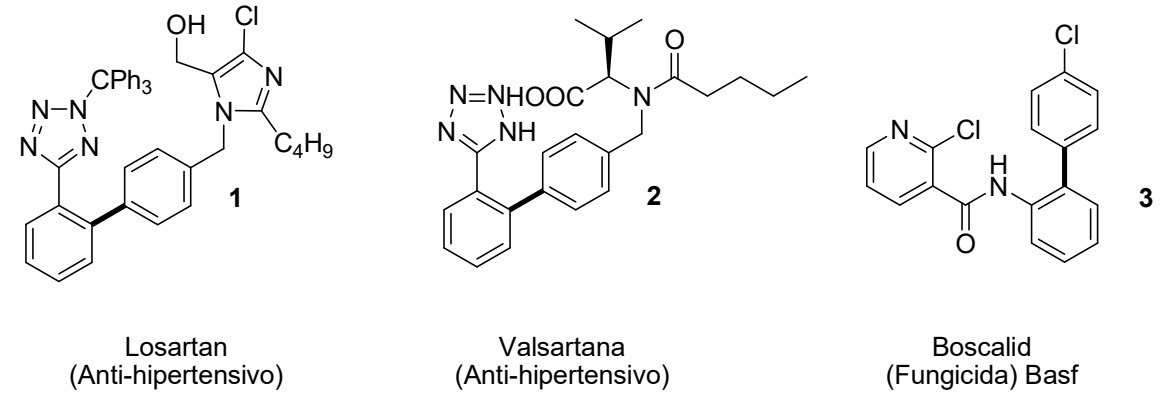

Figura 1: Exemplos de aplicação da reação de acoplamento de Suzuki-Miyaura em compostos comerciais.

\subsubsection{Aminação de Buchwald-Hartwig}

O avanço das reações de acoplamento cruzado catalisadas por paládio na formação de ligações C-C, iniciadas na década de 70 , estimulou a busca de métodos análogos de acoplamento cruzado para a formação de ligações C-N. Apesar de existirem técnicas úteis para a preparação de arilaminas a partir de haletos de arila (acoplamento de Ullmann, por exemplo), ainda era desejável ter um método geral que pudesse ser empregado para converter um único substrato diretamente em uma gama de anilinas $N$-substituídas sob condições brandas. ${ }^{32}$ 
O estudo das reações de acoplamento C-N iniciou-se com Mijita e Kosugi ${ }^{33}$, que, apesar dos esforços desenvolveram um protocolo de reação limitado em suas aplicações devido ao uso de uma quantidade estequiométrica de amida de estanho e da sensibilidade hidrolítica dos reagentes. Após importantes contribuições de Panek $^{34}$ e Buchwald ${ }^{35}$, em 1995, os grupos de Buchwald ${ }^{36}$ e Hartwig ${ }^{37}$, em trabalhos independentes, desenvolveram um método efetivo para a formação de ligação entre carbono e nitrogênio catalisado por paládio, que era livre de estanho.

O método consistia em utilizar $\mathrm{Pd}_{2}(\mathrm{dba})_{3}$ ou $\mathrm{Pd}(\mathrm{OAc})_{2}$ como fontes de $\mathrm{Pd}(0)$, e $\mathrm{P}(\mathrm{o}-\mathrm{Tol})_{3}$ como ligante. Entretanto, esta metodologia aplicada por Buchwald e Hartwig apresentou algumas deficiências, uma vez que brometos de arila com grupos doadores de elétrons resultaram em produtos de $\beta$-eliminação e, acoplamentos com aminas acíclicas levaram a rendimentos insatisfatórios. Inicialmente, esses problemas foram resolvidos com o uso de ligantes fosfínicos bidentados: Buchwald e colaboradores descreveram o uso de um sistema baseado em $\mathrm{Pd}_{2}(\mathrm{dba})_{3}$, BINAP e NaOtBu${ }^{38}$, enquanto que Hartwig e colaboradores empregaram as mesmas condições, substituindo o ligante por DPPF ${ }^{39}$. Apesar do sucesso atingido com os ligantes bidentados, em seguida percebeu-se que ligantes quelantes não são necessários para que a reação leve a altos rendimentos, uma vez que ligantes biarílicos ${ }^{40} \operatorname{como} 4$ e 5, Figura 2, e até mesmo $\mathrm{P}(t-\mathrm{Bu})_{3}$ levaram a sistemas altamente ativos, mesmo com cloretos de arila como substratos.

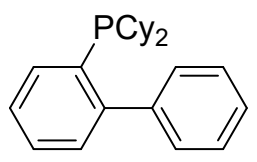

4

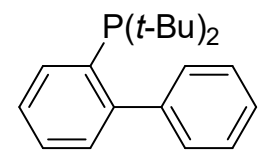

5

Figura 2: Monofosfinas biarílicas ativas como ligantes da aminação de BuchwaldHartwig.

No Esquema 5 é mostrado um esquema geral da aminação de BuchwaldHartwig, onde uma amina reage com um haleto de arila na presença de uma fonte de paládio, uma base e um ligante apropriado, levando à arilação da amina. 


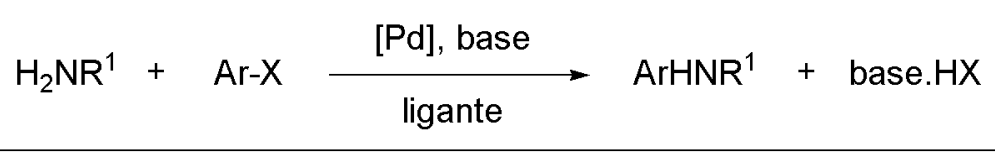

Esquema 5: Esquema geral de um acoplamento de Buchwald-Hartwig.

Em termos de mecanismo (Esquema 6), assim como as reações de acoplamento $\mathrm{C}-\mathrm{C}$, a reação inicia pela adição oxidativa de $\operatorname{ArX}$ a uma espécie de $\operatorname{Pd}(0)$. Em seguida, acontece a coordenação da amina, seguida de desprotonação mediada pela base. O Intermediário ArPdNRR' sofre então eliminação redutiva, formando a nova ligação $\mathrm{C}-\mathrm{N}$ e regenerando a espécie ativa. Cabe ressaltar que a correta escolha do ligante é imprescindível tanto para acelerar a adição oxidativa, quanto para evitar a formação de subprodutos de $\beta$-eliminação (imina e ArH). ${ }^{32}$

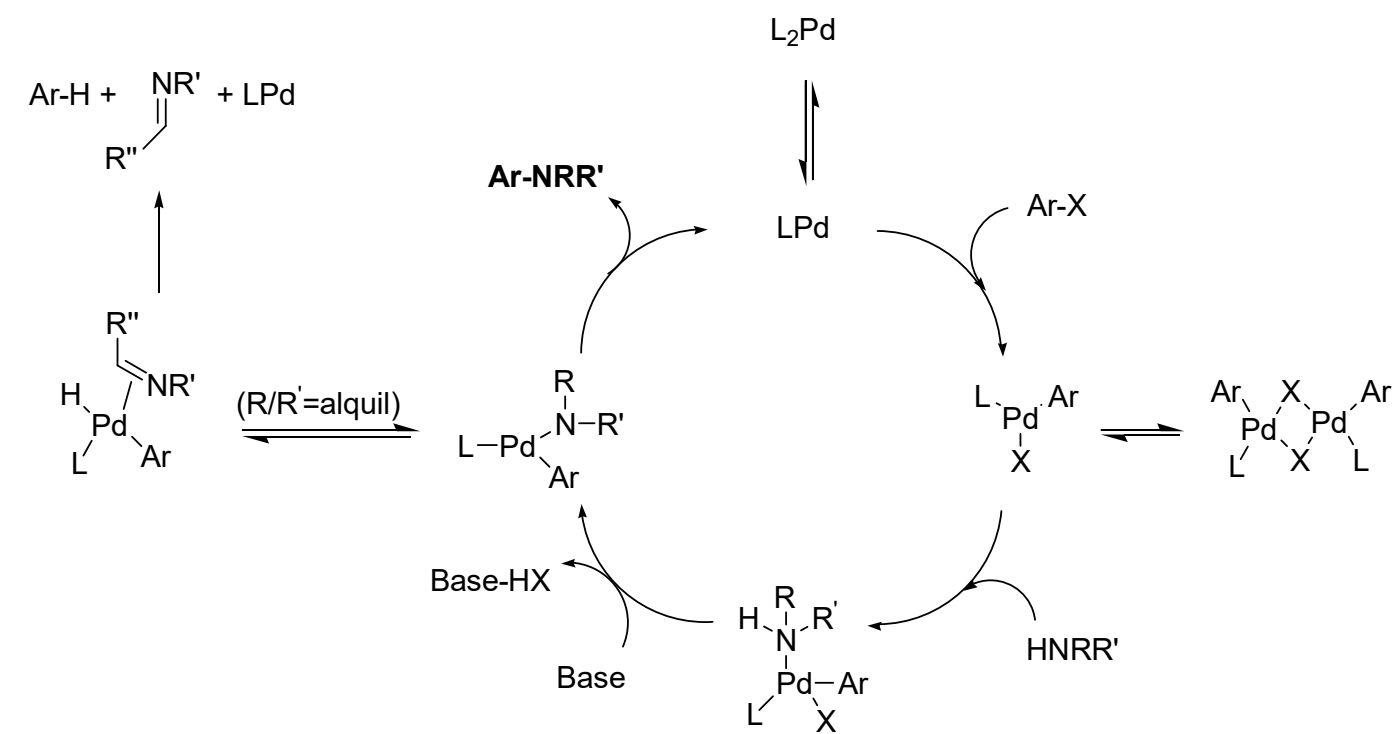

Esquema 6: Ciclo catalítico da reação de acoplamento C-N.

A generalidade combinada com a ampla disponibilidade de nucleófilos (aminas) e halogenetos de arila torna os métodos catalisados por Pd uma alternativa atraente aos métodos mais tradicionais para a síntese de arilaminas. Comparativamente, a substituição nucleofílica aromática $\left(S_{N} A r\right)$ e o acoplamento de Ullmann catalisados por cobre, têm um escopo mais limitado e condições menos brandas quando comparado com a aminação de Buchwald-Hartwig. ${ }^{32}$

O acoplamento de Buchwald-Hartwig mesmo sendo mais recente que o acoplamento de Suzuki, apresenta uma grande importância em aplicações tanto em ambiente acadêmico, quanto em ambiente industrial, tendo papel essencial no 
desenvolvimento de rotas sintéticas para compostos de alto valor agregado. ${ }^{42} \mathrm{Na}$ Figura 3 são mostrados alguns exemplos de aplicação do acoplamento de Buchwald-Hartwig na obtenção de fármacos e de camadas emissoras em OLEDs. A ligação formada através de Buchwald-Hartwig está ressaltada na Figura 3.

Goodyear e colaboradores (2012) desenvolveram uma nova rota sintética e estudo do scale up para o candidato a fármaco 6, um inibidor não nucleosídico da transcriptasse reversa (NNRTI) de segunda geração a ser desenvolvido como um potencial tratamento do HIV. Isolou-se o fármaco em seis passos com um rendimento global de $35 \%$, contra $5 \%$ da rota antiga, a partir de materiais de partida disponíveis comercialmente ou de fácil síntese. A nova síntese de $\mathbf{6}$ foi desenvolvida e demonstrada em escala de quilogramas. A chave para o sucesso desta rota foi a formação do núcleo de indazol através de uma $N$-alquilação regiosseletiva de um derivado de benzofenona, além disso na etapa do acoplamento $\mathrm{C}-\mathrm{N}$ foi realizada uma varredura de diferentes complexos de paládio variando o ligante empregado, assim como também testando várias bases de diferentes forças. O sistema que levou ao maior rendimento e inibiu quase totalmente a formação de subprodutos foi $\mathrm{PdCl}_{2}$ (DPPF) $\cdot \mathrm{CH}_{2} \mathrm{Cl}_{2}, \mathrm{~K}_{3} \mathrm{PO}_{4} \mathrm{e}$ tolueno. ${ }^{43}$

Um OLED de alta EQE foi desenvolvido usando um derivado de benzofuro [2,3-b]piridina modificado na posição 6 como material dopante. O composto 7 foi sintetizado através do acoplamento C-N entre o 6-clorobenzofuro[2,3-b]piridina e o carbazol utilizando $\mathrm{Pd}_{2}(\mathrm{dba})_{3}$ como catalisador, S-Phos como ligante, $t$-BuONa como base, e xileno como solvente durante $36 \mathrm{~h}$ na temperatura de $140^{\circ} \mathrm{C}$ com um rendimento de $53 \%$. Com o material sintetizado foi obtido um dispositivo de alta eficiência quântica (19\%), valor muito bom para compostos puramente orgânicos. ${ }^{44}$

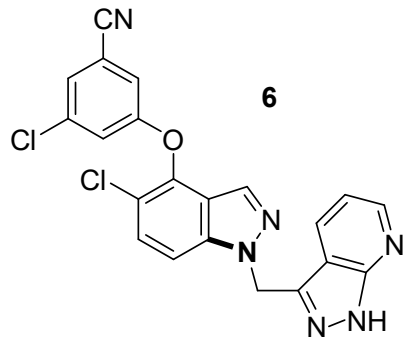

Inibidor HIV
Merck

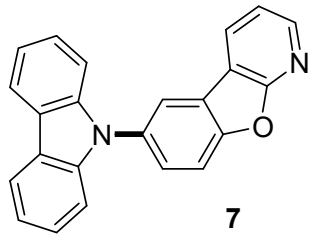

Dopante azul de OLED LG Display R\&D Center

Figura 3: Exemplos de aplicação da reação de aminação de Buchwald-Hartwig. 


\subsection{Derivados de benzotiadiazola (BTD)}

Muitos esforços têm sido feitos no desenvolvimento e síntese de novas moléculas conjugadas com propriedades luminescentes. Essa busca é estimulada pelo grande número de aplicações desses compostos em diferentes áreas da tecnologia de luz, incluindo: constituintes em OLEDs ${ }^{45,46}$; sondas luminescentes para química biológica ${ }^{2,47}$ e analítica ${ }^{48,49}$; sensibilizadores orgânicos para células solares $^{50}$, entre outros. Neste contexto, os derivados do núcleo 2,1,3benzotiadiazola 8 (Figura 4), mais conhecido pela sua abreviação BTD, surgem como compostos com muito destaque, graças a diversas propriedades desse anel.

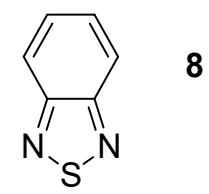

Figura 4: Núcleo 2,1,3-benzotiadiazola.

Dentre as propriedades que fazem com que derivados do núcleo BTD tenham destaque em termos de aplicações na tecnologia da luz estão ${ }^{1,2}$ :

- Derivados de BTD normalmente são fluoróforos estáveis, mesmo no estado excitado.

- Derivados de BTD fluorescentes normalmente exibem grandes deslocamento de Stokes, que a diferença entre o máximo de absorção e de emissão. Que é uma característica que comprova a estabilidade da molécula no estado excitado

- Derivados de BTD são uma das classes mais importantes de sistemas conjugados devido aos seus relativamente altos potencial de redução e afinidade eletrônica.

- O núcleo BTD apresenta uma alta capacidade retiradora de elétrons o que facilita a transferência de carga intramolecular.

- Geralmente, os derivados de BTD apresentam estruturas cristalinas bem ordenadas.

\subsection{Aplicação de reações de acoplamento carbono-carbono e carbono-heteroátomo na obtenção de derivados de BTD}

Uma forma fácil de funcionalizar o núcleo BTD e produzir compostos conjugados e fluorescentes é através de reações de acoplamento carbonocarbono ou carbono-heteroátomo no intermediário 9, Figura $5 a .{ }^{51}$ Dessa forma, o 
anel BTD tem sido funcionalizado com sucesso nas posições 4 e 7 com aminas aromáticas $^{6-8}$ e tiofenóis ${ }^{9,10}$ (Figura $5 \mathrm{~b}$ ) - via acoplamentos carbono-heteroátomo catalisados por metal ${ }^{6-9,52}$ ou via protocolos isentos de metal ${ }^{10}$ - fornecendo derivados de BTD altamente luminescentes. Além disso, diversos derivados arilados de BTD têm sido obtidos via acoplamentos de Suzuki ${ }^{3-5}$.

a)

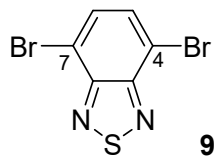

b)

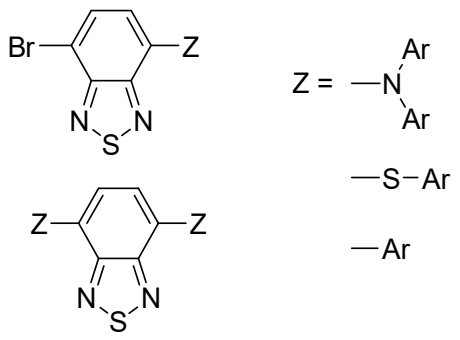

Figura 5: Estrutura química do intermediário 4,7-dibromo-BTD e as possíveis configurações de substituição nas posições 4,7 de 9 .

$\mathrm{Ni}$ e colaboradores (2017) sintetizaram derivados de BTD (Esquema 7) através da reação de acoplamento C-N entre 9 e aminas aromáticas (DPA, CZ e DMAC) e aplicaram o derivado de DMAC em dispositivos OLEDs ${ }^{6}$. O derivado de BTD 10 foi primeiramente sintetizado através de uma reação de acoplamento C$\mathrm{N}$ catalisada por cobre com um rendimento razoável de $22 \%$. No entanto, as mesmas condições de reação levaram a rendimentos baixos (aproximadamente $10 \%)$ para os compostos 11 e 12. Para melhorar os rendimentos, as condições reacionais foram trocadas para o acoplamento $\mathrm{C}-\mathrm{N}$ catalisado por $\mathrm{Pd}$ e os correspondentes rendimentos atingiram aproximadamente 80\% para 11 e 12 . 

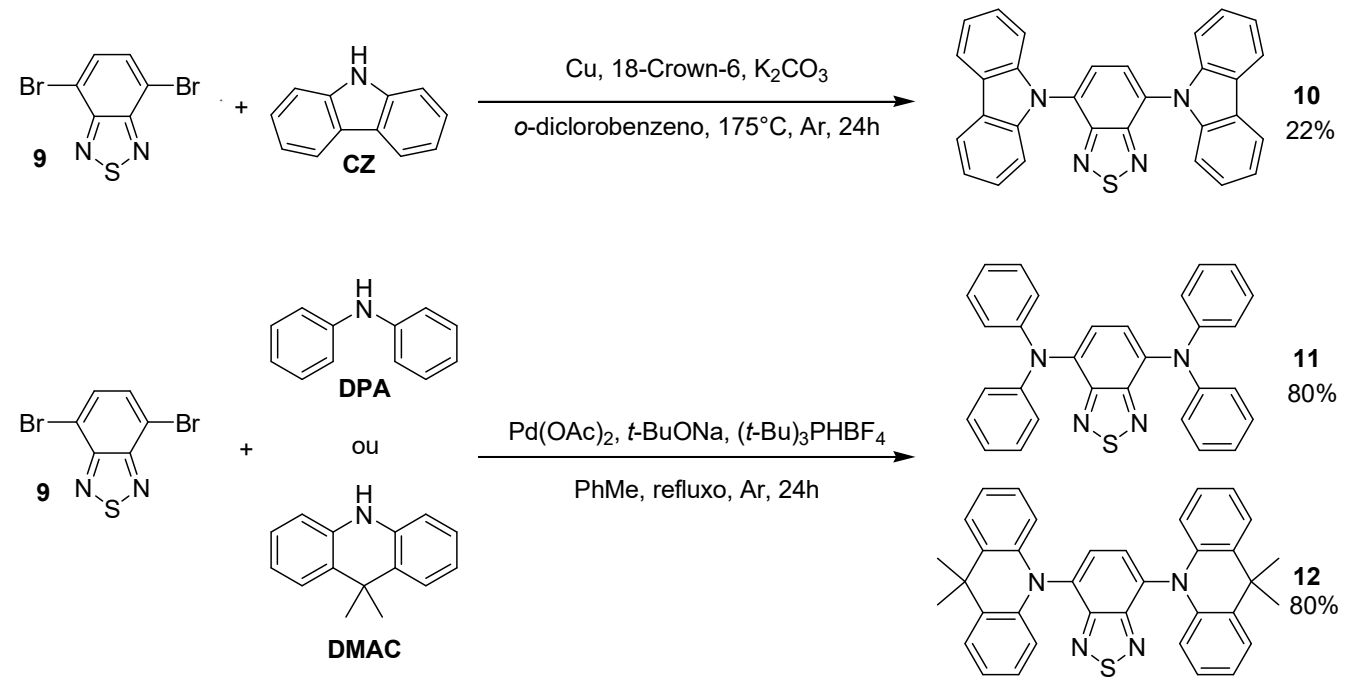

Esquema 7: Rotas sintéticas utilizadas por Ni e colaboradores para a síntese de 10, 11 e 12.

Em 2012, Neto e colaboradores sintetizaram dois novos derivados do núcleo benzotiadiazola, 13 e 14 ${ }^{8}$, seguindo a rota sintética mostrada no Esquema 8. O fluoróforo 13 foi obtido através do procedimento de aminação de BuchwaldHartwig, utilizando a 2-aminopiridina, sendo que o produto foi isolado com $47 \%$ de rendimento após purificação cromatográfica. 14 foi sintetizado a partir de $13 \mathrm{com}$ $23 \%$ de rendimento após a purificação. A arquitetura molecular desses compostos foi projetada para que eles apresentassem boa planaridade, possibilidade de ligação de hidrogênio intramolecular (com os nitrogênios da piridina e da BTD) e conformação rígida, buscando-se fluoróforos que apresentem tanto transferência intramolecular de próton no estado excitado (ESIPT) quanto transferência de carga intramolecular (ICT). Segundo os autores, a presença de um nitrogênio básico na porção piridina é crucial, prevendo-se uma segunda ligação de $\mathrm{H}$ intramolecular, consequentemente aumentando a rigidez e planaridade desses compostos.
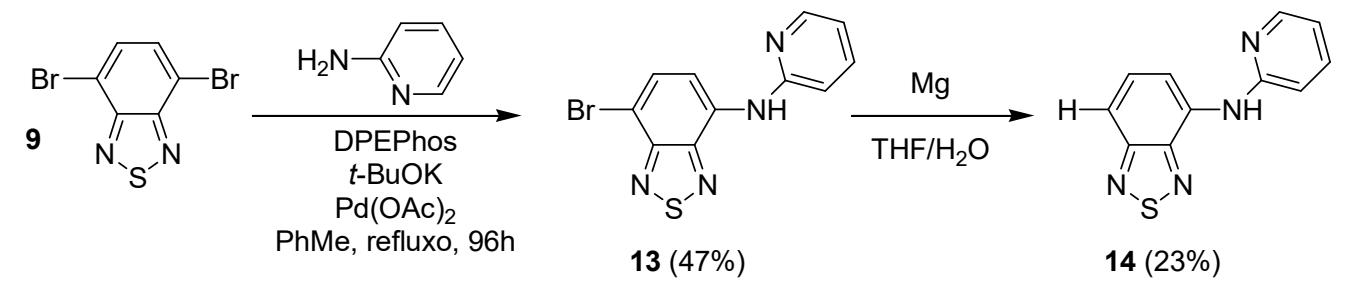

Esquema 8: Esquema de rota sintética desenvolvida por Neto e colaboradores (2012).

Cruz e colaboradores (2014) descreveram a síntese de um híbrido BTDlapachona (15) e sua aplicação como sonda fluorescente para marcação celular 
seletiva em células tumorais ${ }^{7}$. No planejamento do híbrido buscou-se um fluoróforo capaz de realizar ESIPT. Para tanto, a posição 4 da BTD foi substituída com a 2-aminoanilina via reação de aminação de Buchwald-Hartwig, e a posição 7 foi substituída com um derivado azido-substituído de lapachona via click chemistry, Esquema 9. No híbrido, o anel triazol atua como um espaçador entre o núcleo BTD e o derivado de lapachona. Esse composto mostrou-se eficiente para a marcação celular de citoplasma, não sendo detectado no núcleo de células cancerígenas.
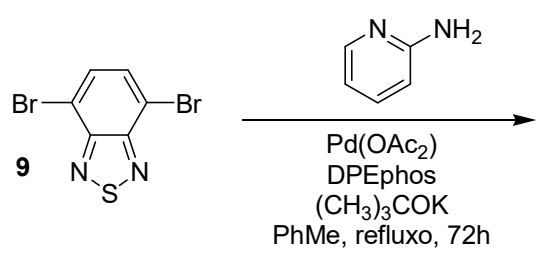<smiles>Brc1ccc(Nc2ccccn2)c2nsnc12</smiles>
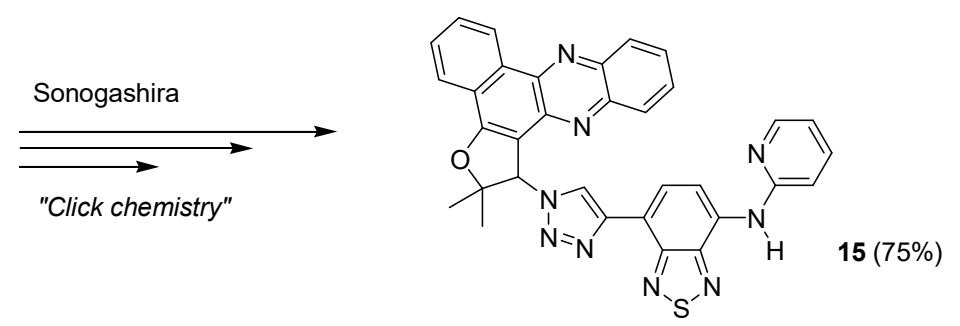

Esquema 9: Exemplo de acoplamento de Buchwald-Hartwig para a síntese 15.

Em relação às sínteses de derivados de BTD com tiofenóis se destaca o trabalho de Balaguez e colaboradores (2016). Nesse trabalho foram sintetizados seis derivados de BTD simétricos com variações de ariltiofenóis através de reações de acoplamento C-S de Ullmann catalisados por nanopartículas de óxido de cobre (II) ${ }^{9}$. Os derivados de BTD foram obtidos com rendimentos entre $80 \mathrm{e}$ 90\% (Esquema 10). Os compostos obtidos emitem na faixa de 510-570 nm, apresentando rendimentos quânticos de fluorescência de até 0,37 . 


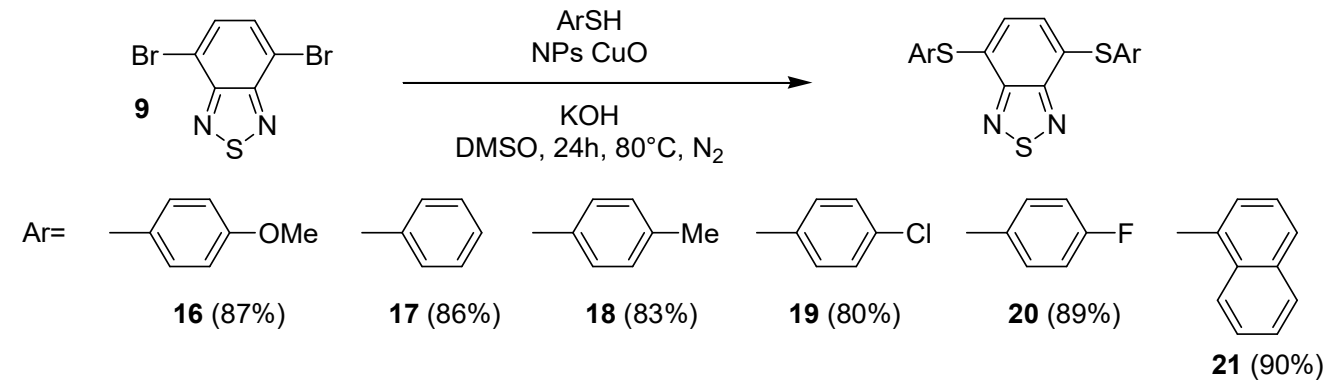

Esquema 10: Exemplos de reações de BTD com tiofenóis sintetizados por Balaguez e colaboradores (2016).

Em 2005, Fang e colaboradores apresentaram uma nova classe de materiais fluorescentes vermelhos a base de BTD ${ }^{4}$ (Esquema 11). Os derivados foram sintetizados de uma forma simples e usados como emissores vermelhos não dopados em dispositivos OLED. Os compostos foram sintetizados e obtidos com alto rendimento (entre 57 e $77 \%$ ) usando um protocolo convencional de acoplamento C-C de Suzuki entre o ácido $N$-terc-butildimetilsilil-3-indolil borônico e 9.

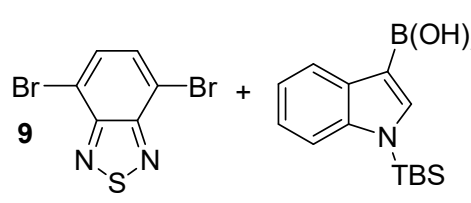

(i) (a) $\mathrm{Pd}\left(\mathrm{PPh}_{3}\right)_{4}, \mathrm{Na}_{2} \mathrm{CO}_{3}$, PhMe, refluxo, 24h (b) TBAF, t.a., $8 \mathrm{~h}$

(ii) DMF, NaH, RX, t.a., $2 \mathrm{~h}$

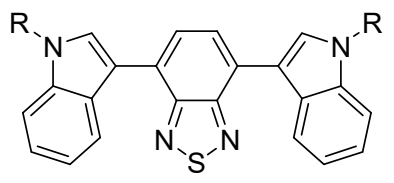

$\mathrm{R}=$ metil (22), etil (23) ou benzil (24)

Esquema 11: Procedimento sintético para os emissores de Fang e colaboradores (2005).

Em 2005, Neto e colaboradores descreveram a reação de 9 com diversos ácidos arilborônicos na presença de quantidades catalíticas do paladaciclo NCP (25), CsF como base e dioxano como solvente como está demonstrado no Esquema 12. Nessas condições diversos derivados de BTD diarilados com conjugação $\pi$-estendida fotoluminescentes foram obtidos em altos rendimentos $(92 \text { a 99\% })^{5}$. Os compostos apresentaram rendimentos quânticos de fluorescência entre 0,15 e 0,86; altas afinidades eletrônicas e valores adequados de band gap para testes como OLEDs. 


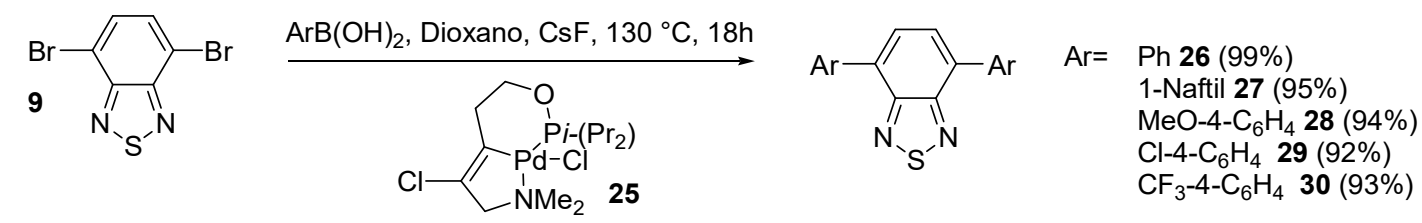

Esquema 12: Condições de síntese elaborada por Neto e colaboradores (2005).

O nosso grupo de pesquisa descreveu em 2017 a síntese do composto 32 através de reações de acoplamento sequenciais ${ }^{3}$. A estratégia proposta para obter o produto alvo (Esquema 13) foi realizada através do acoplamento cruzado de Suzuki entre o 9 e o ácido 4-metoxifenilborônico. Esta reação foi realizada utilizando condições descritas na literatura ${ }^{5}$ (NCP-paladaciclo 25, CsF, dioxano $130{ }^{\circ} \mathrm{C}$ ) levando ao intermediário monobromado $31 \mathrm{com} 81 \%$ de rendimento em 24 h. Para obter o composto luminescente 32, o intermediário monobromado foi reagido com o éster MIDA do ácido 4-piridilborônico, utilizando outro protocolo Suzuki, com um sistema composto por $\mathrm{Pd}\left(\mathrm{PPh}_{3}\right)_{4}, \mathrm{~K}_{2} \mathrm{CO}_{3}$ aquoso e tolueno. Esta reação produziu $32 \mathrm{com} 49 \%$ de rendimento e $40 \%$ de rendimento global.<smiles>Brc1ccc(Br)c2nsnc12</smiles>

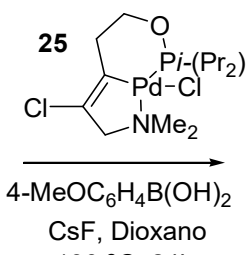

$130^{\circ} \mathrm{C}, 24 \mathrm{~h}$

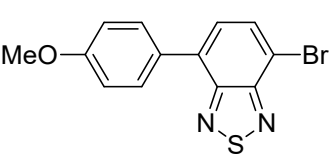

$31(81 \%)$
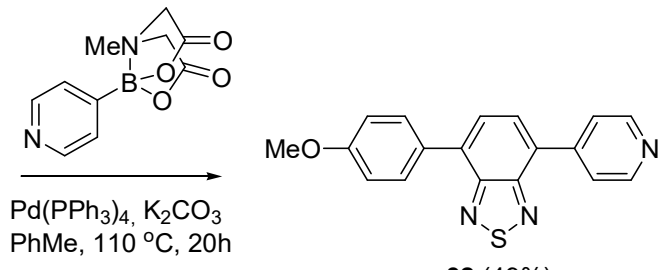

$32(49 \%)$

Esquema 13: Condições de síntese elaborada por Pazini e colaboradores (2017).

Em resumo, há na literatura vários exemplos da funcionalização da 4,7dibromo-BTD através de reações de acoplamento C-C, C-N e C-S. Entretanto, até a presente Dissertação, não havia sido descrita a obtenção e o estudo das propriedades fotofísicas de derivados de BTD arilóxi-substituídos, obtidos pela funcionalização de 9 com fenóis.

\subsection{OLEDs}

Organic light emitting diodes or devices (OLEDs) são dispositivos composto por apenas camadas orgânicas capazes de transformar energia elétrica em luz. ${ }^{53}$ Eles podem apresentar diversas configurações, com uma, duas ou várias camadas (Figura 6). Na configuração clássica, além do cátodo e do ânodo, temse a camada transportadora de elétrons (CTE), a camada emissora (CE) e a 
camada transportadora de buracos (CTB). Em configurações mais robustas, podem ser adicionadas camadas injetoras de buracos (CIB) e/ou camadas injetoras de elétrons (CIE) ${ }^{54}$ Geralmente, cada camada em um OLED é bem fina, e o total de espessura do dispositivo é menor que $1 \mu \mathrm{m}$, sendo que o substrato não está incluído nessa medida. Sabendo disso podemos afirmar que um OLED é candidato perfeito para telas flexíveis. ${ }^{55}$

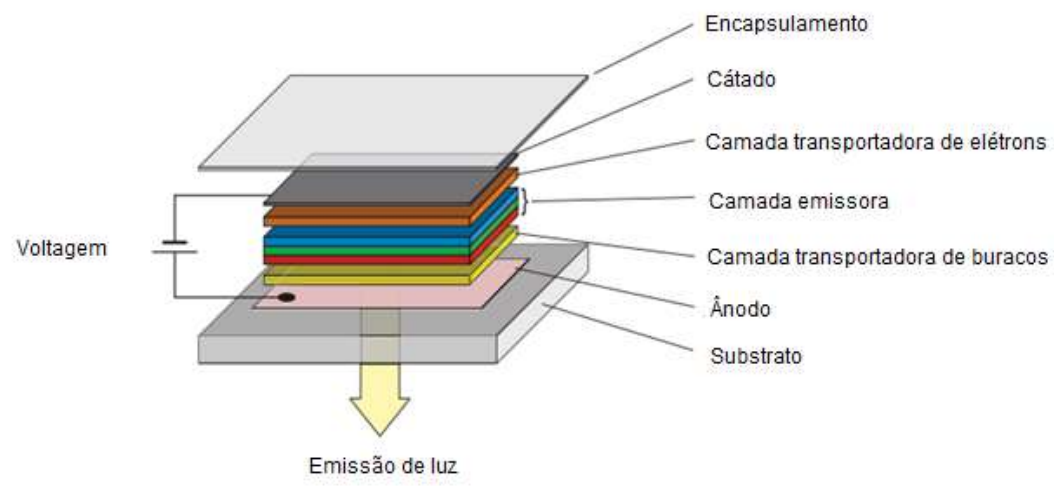

Figura 6: Esquema da arquitetura comercial de um OLED típico. Imagem adaptada de Volz e colaboradores. (2015).

A camada do substrato, que geralmente é feita de plástico, vidro ou folhas de metal deve apresentar aspecto transparente e uma ótima condutividade. Sua função de trabalho $\left(\varphi_{w}\right)$ deverá estar entre 4,7- 4,9 eV. O ânodo, que tem como função servir como eletrodo que injeta buracos nas camadas orgânicas, deve ser transparente e apresentar baixa rugosidade e alta função de trabalho. Os principais materiais utilizados como ânodo atualmente são o ITO (óxido de indio dopado com estanho) e o IZO (óxido de índio dopado com zinco). ${ }^{54}$

$\mathrm{Na}$ camada injetora de buracos (CIB), geralmente, utiliza-se PEDOT:PSS ${ }^{56-58}$ (Figura 7a). Esse material é solúvel em água e é composto por uma mistura de politiofenos conjugados e poliestireno sulfonado. Essa camada tem como função compensar a rugosidade dos óxidos e reduzir a barreira de energia entre a camada do ânodo e o HOMO da camada subsequente ${ }^{45}$.

A camada transportadora de buracos (CTB) desempenha um papel importante no transporte desse portador de carga e no bloqueio de elétrons, evitando que os mesmos atinjam o eletrodo oposto sem recombinar com os buracos. ${ }^{54}$ Os materiais empregados nessa camada devem ser compostos ricos em elétrons como por exemplo derivados de carbazol ou triarilaminas. ${ }^{45}$ Os compostos já estabelecidos na literatura para o uso como CTB são o NPB e o TDP $^{59}$ (Figura $7 b$ ). 
A camada emissora (CE) deve ser um ótimo emissor de fótons. Os materiais que compõem essa camada podem ser moléculas orgânicas, polímeros ou complexos metálicos com alta eficiência, extensa vida útil e pureza de cor. ${ }^{54}$ Exemplos de materiais empregados nessa camada podem ser vistos na Figura 7c. ${ }^{45}$ Muitas vezes a camada emissora é diluída em uma matriz, com concentrações de dopante por volta de $10 \%$ em massa, o qual chama-se de "hostmaterials" que geralmente são materiais iguais ou similares às moléculas das camadas transportadoras de elétrons e buracos, sendo ambipolares.

A camada transportadora de elétrons (CTE) deve apresentar ótimas propriedades para o transporte de elétrons e bloquear buracos. Geralmente as moléculas são heterocíclos aromáticos pobres em elétrons, como derivados de fenantrolina, piridina, triazol, entre outros. Outros grupos funcionais relevantes podem ser as sulfonas e os óxidos de fosfinas. Os compostos mais tradicionais empregados nessa camada são o $\mathrm{Alq}_{3}$ e o BCP (Figura 7d). ${ }^{45,54}$

A camada do cátodo é tipicamente uma liga de metal com baixa função de trabalho $\left(\phi_{\mathrm{w}} \approx 2,9-4,0 \mathrm{eV}\right)$. É transparente nos principais dispositivos emissores. Deve ser estável às camadas orgânicas abaixo dela. Na maioria dos dispositivos fabricados atualmente utiliza-se alumínio como cátodo. ${ }^{54}$ 
a) CIB

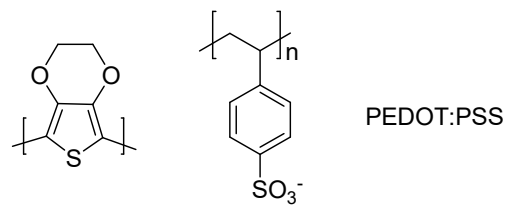

b) CTB
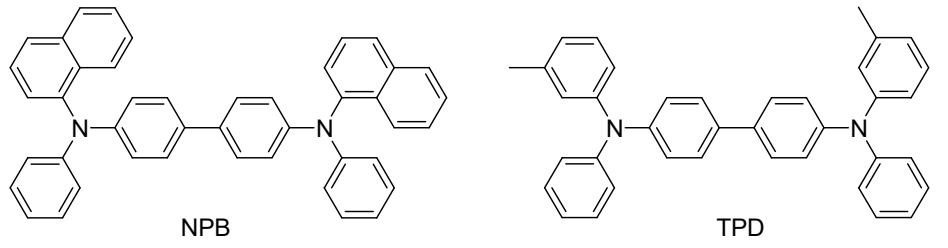

c) $\mathrm{CE}$

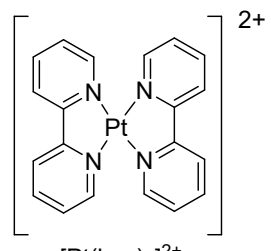

$\left[\mathrm{Pt}(\mathrm{bpy})_{2}\right]^{2+}$<smiles></smiles>

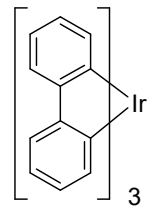

$\operatorname{Ir}(\mathrm{ppy})_{3}$

d) CTE

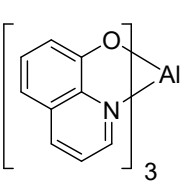

$\mathrm{Alq}_{3}$

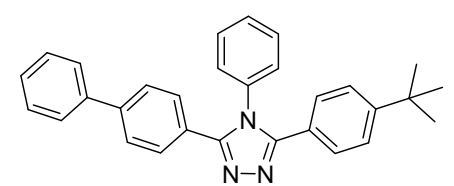

TAZ

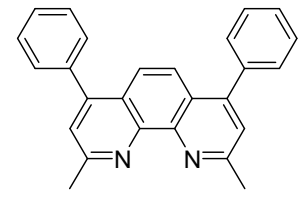

BCP

Figura 7: Exemplos selecionados das moléculas utilizadas nas diversas camadas em um OLED.

\subsubsection{Funcionamento do dispositivo}

De forma resumida há 4 passos básicos para o funcionamento de um OLED. São eles:

1. Injeção de portadores de cargas nos materiais orgânicos;

2. Transporte dos portadores de cargas;

3. Formação dos pares elétron-buraco (éxcitons);

4. Decaimento radiativo dos éxcitons e emissão da luz;

Na Figura 8 está representado um esquema de como é o funcionamento de um OLED. Primeiro, as cargas positivas e negativas (elétrons e buracos, respectivamente) são geradas (1). Os elétrons são injetados partir do cátodo para o LUMO do composto que age como transportador/injetor de elétrons. Já os buracos, são injetados a partir do ânodo para o HOMO do composto que age como transportador/injetor de buracos. Os elétrons vão em direção ao ânodo e os buracos em direção ao cátodo, essas cargas migram sob efeito do campo elétrico aplicado e pela atração de Coulomb entre as cargas opostas (2). Nesse meio 
tempo irá ocorrer a recombinação entre os buracos e elétrons (3) e vários processos de transferência de energia acontecerão para formar éxcitons singletes e tripletes (pares elétrons-buraco no estado excitado) dentro da camada emissora (CE) e assim há a emissão de luz (4). 1,53,55

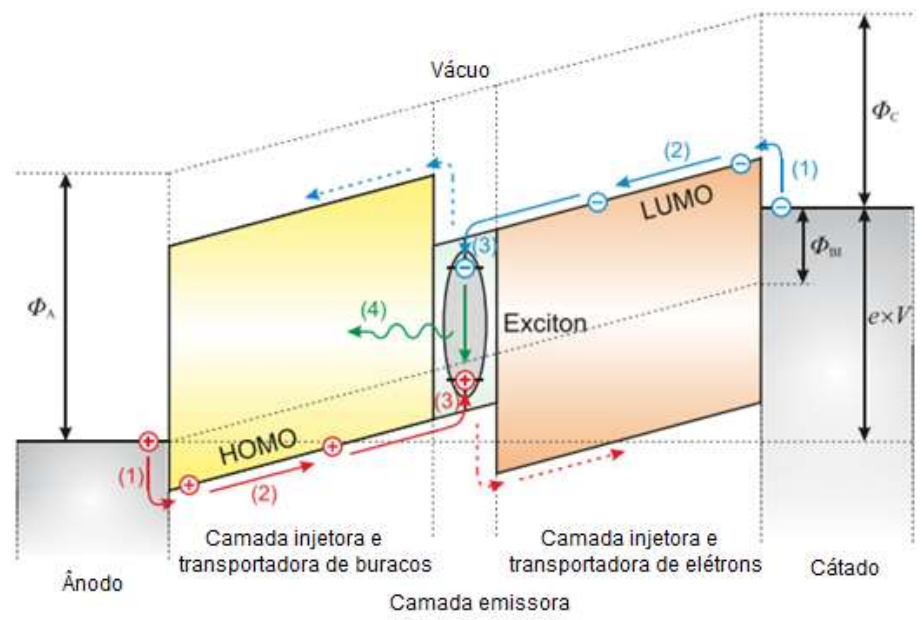

Figura 8: Diagrama esquemático de energia de um OLED de três camadas ilustrando os processos básicos de eletroluminescência. Adaptado de W. Bruwtting e colaboradores

(2013).

Baseado na camada emissora, os OLEDs podem ser classificados em quatro tipos: fluorescente, fluorescência triplete-triplete (TTF), fosforescente e com fluorescência atrasada ativada termicamente (TADF), conforme mostrado na Figura 9. Em um dispositivo em que a camada emissora é baseada no fenômeno da fluorescência, é utilizado apenas o decaimento radiativo dos estados singletes, quando submetido a uma excitação elétrica, com um tempo de vida de aproximadamente nanossegundos, o que por sua vez proporciona um limite teórico de apenas 25\% na eficiência quântica interna (EQI) (Figura 9a). Já nos dispositivos TTF ocorre a fusão de dois éxcitons tripletes para formar um singlete, e o decaimento ocorre desse singlete diferenciado o que proporciona um aumento da EQI para 62,5\% (Figura 9b). Por outro lado, com a introdução de metais pesados na camada emissora pode-se fabricar dispositivos OLEDs fosforescentes. Devido ao forte acoplamento spin-orbita dos metais, normalmente usa-se nesses dispositivos complexos de irídio e platina, com os quais se reduz para microssegundos o tempo de vida no estado triplete, resultando em um eficiente emissor fosforescente. Nesses dispositivos tem-se a possibilidade de $100 \%$ de EQI, pois ocorre cruzamento intersistema entre o estado singlete e triplete. O decaimento radiativo, nesse caso, se dá pelo estado triplete (Figura 9c). Finalmente, os dispositivos de maior interesse dessa pesquisa são os que 
apresentam na camada emissora a característica TADF. Um composto com esse atributo possui baixa diferença de energia entre o estado singlete e o triplete, o que facilita a troca de energia entre esses estados. Dessa maneira o elétron deslocado ao estado triplete pode retornar ao estado singlete por meio de energia térmica, através de um fenômeno conhecido como cruzamento reverso intersistema (RISC), para, assim, ocorrer a emissão de fluorescência (via $S_{1}$ ) (Figura 9d). Esse dispositivo é interessante pois pode-se atingir um EQI de 100\% com um material puramente orgânico, que não apresenta átomos pesados. Aspectos mais detalhados de materiais TADFs serão discutidos a seguir. ${ }^{55}$

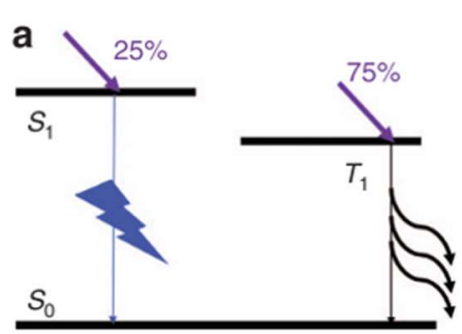

Fluorescente

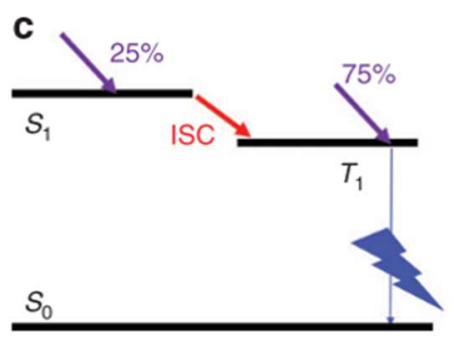

Fosforescente

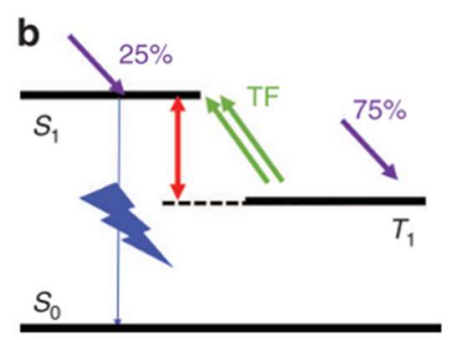

TTF

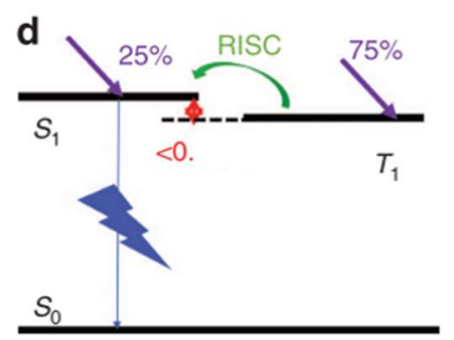

TADF

Figura 9: Classificação dos dispositivos OLED quanto à sua camada emissiva. Imagem adaptada de Chen e colaboradores (2018).

\subsubsection{Parâmetros de um dispositivo OLED}

Abaixo são descritos alguns parâmetros básicos utilizados na avaliação de um OLED:

O diagrama de cromaticidade apresenta um colorímetro padrão tridimensional de todas as cores visíveis. Foi desenvolvido como resultado das investigações experimentais realizadas pela CIE (Comission Internacionale l'Eclairage). ${ }^{60}$

Luminância é uma medida de intensidade de luminosidade por unidade de área, isto é, descreve a quantidade de luz que passa, que é emitida ou refletida em uma área. Sua unidade no SI é candela por metro ao quadrado $\left(\mathrm{cd} \mathrm{m}^{-2}\right)$. Esse parâmetro está diretamente relacionando ao quanto de claridade é percebida pelo 
observador, assim, sendo muito importante na avaliação da confecção de um dispositivo opticoeletrônico. Já a irradiância é o fluxo radiante (potência) recebido por uma superfície por unidade de área. A unidade de irradiância do SI é o watt por metro quadrado $\left(\mathrm{W} \mathrm{m}^{-2}\right)$.

Eletroluminescência (EL) é a conversão de energia elétrica em radiação luminosa por um meio, que pode ser sólido, gasoso ou plasma. No caso de fabricação de OLEDs a EL é produzida em sólidos, filmes finos de moléculas orgânicas. ${ }^{61}$ Outra característica é a tensão de acendimento $\left(V_{o n}\right)$ que deve ser alcançada para superar as barreiras para injetar cargas nos materiais orgânicos.

Além de suas características espectrais, o parâmetro mais importante que caracteriza um OLED é a eficiência quântica de eletroluminescência externa (EQE) que descreve a razão entre o número de fótons emitidos e os portadores de carga injetados. ${ }^{62}$

\subsubsection{OLEDs baseados em materiais TADF}

A camada emissora da maioria dos dispositivos OLEDs é, atualmente, composta por complexos de irídio ou platina. A grande vantagem desses complexos vem do fato que eles apresentam maior eficiência, pois podem apresentar luminescência baseada tanto no estado singlete, quanto no estado triplete. A desvantagem está relacionada ao alto custo desses materiais e a fatores ambientais relacionados à aplicação desse tipo de metal..$^{53}$ Tendo essas desvantagens em mente, na última década, muito tem se buscado compostos puramente orgânicos capazes de atuarem como emissores em OLEDs que apresentem alta eficiência, brilho e durabilidade. ${ }^{53}$

O inconveniente da utilização de compostos puramente orgânicos reside no fato que a maioria deles é capaz de utilizar apenas a fluorescência baseada no estado singlete, limitando a eficiência teórica do dispositivo em $25 \%$. No entanto, dependendo das características estruturais inseridas no emissor orgânico, podese obter compostos onde a diferença energética entre os estados $\mathrm{S}_{1}$ e $\mathrm{T}_{1}\left(\Delta \mathrm{E}_{\mathrm{ST}}\right)$ é baixa (Figura 10). Nesses compostos pode haver cruzamento reverso intersistema, o que faz com que os compostos possam utilizar também a luminescência baseada no estado $T_{1}$. Compostos que possuem essas características são chamados de TADFs (thermally activated delayed fluorescence). ${ }^{6,53,63}$ 


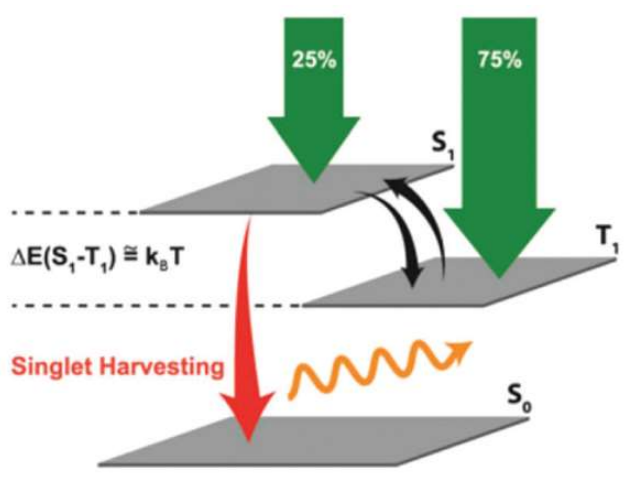

Figura 10: Esquema do cruzamento intersistemas que é necessário para ter característica TADF. Imagem adaptada de Volz e colaboradores (2015).

Em termos de planejamento de novos emissores TADFs, o que se busca são compostos que apresentem baixa sobreposição orbitalar entre o HOMO e o LUMO e para isso, deve haver uma ruptura na conjugação entre a porção doadora (D) e a porção aceptora (A). Uma das formas de romper essa conjugação é impedir a coplanaridade entre essas porções. ${ }^{63}$ Duas principais estratégias têm sido usadas para impedir essa coplanaridade. A primeira é o desenvolvimento de espirocompostos e a segunda é a inserção de grupos que promovam um alto ângulo diedro na junção D-A.

O espirocomposto 33 (Figura 11) foi desenvolvido por Méhes e colaboradores $^{64}$ (2012). Em 33 a triarilamina é a porção doadora de elétrons enquanto que a porção inferior, dicianobifenila, age como a porção aceptora. A junção do tipo espiro rompe com eficiência a conjugação- $\pi$ entre as porções doadoras e aceptoras levando a uma orientação ortogonal. Além disso, através de cálculos de TD-DFT observou-se que toda densidade eletrônica do HOMO está localizada sobre a triarilamina, enquanto que o LUMO está localizado na porção dicianobifenila. A diferença de energia entre os estados singlete e triplete ( $\left.\Delta \mathrm{E}_{\mathrm{ST}}\right)$ é de apenas 0,0083 eV. Então, com (i) uma ótima separação entre o HOMO e o LUMO, (ii) não-coplanaridade, (iii) baixa $\Delta \mathrm{E}_{S T} \mathrm{e}$, (iv) decaimento de fotoluminescência na ordem de $\mu$ s, a molécula mostrou-se um eficiente emissor TADF. Utilizando 33 na camada emissora, produziu-se um dispositivo OLED de alto valor de $\operatorname{EQE}(10,1 \%)$, operando em uma baixa densidade de corrente $\left(3,3 \times 10^{-4} \mathrm{~mA} \mathrm{~cm}^{-2}\right)$.

Zhang e colaboradores ${ }^{65}$ (2014) sintetizaram uma série de moléculas simétricas com a arquitetura $D-\pi-A-\pi-D(34)$, no qual a antraquinona atua como porção aceptora, a difenilamina como doadora e a fenila age como uma ponte de conjugação $\pi$ entre as partes (Figura 11). Nesse caso os compostos foram 
planejados para que aja um alto ângulo diedro entre as porções $\mathrm{D}$ e $\mathrm{A}$. Como esperado, a predição dos cálculos de TD-DFT mostrou que o HOMO está concentrado na difenilamina e o LUMO na antraquinona. O ângulo diedro entre a fenila e a difenilamina foi calculado em torno de $29-39^{\circ}$, considerado um valor baixo. Esse emissor apresentou um bom rendimento quântico de fluorescência $(0,55)$, com um máximo de emissão em $614 \mathrm{~nm}$, um tempo de vida TADF de 120 $\mu$ e e $\Delta \mathrm{E}_{\mathrm{ST}}$ de $0,22 \mathrm{eV}$ em filme dopado (10\% em CBP). O OLED construído com este filme dopado como CE alcançou um EQE de até 8,1\% a uma luminância de $100 \mathrm{~cd} / \mathrm{m}^{2}$, com um máximo de emissão a $624 \mathrm{~nm}$, que é comparável aos melhores OLEDs fosforescentes vermelhos.
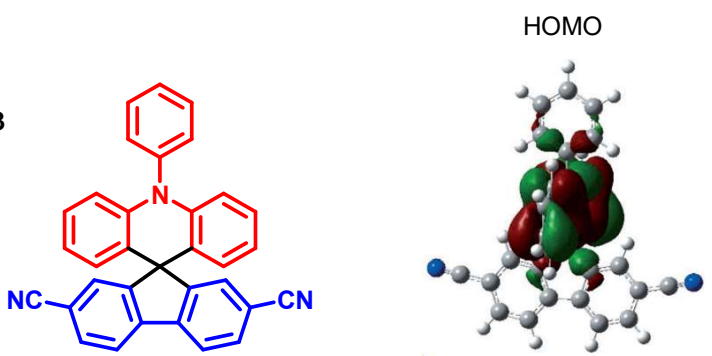

LUMO
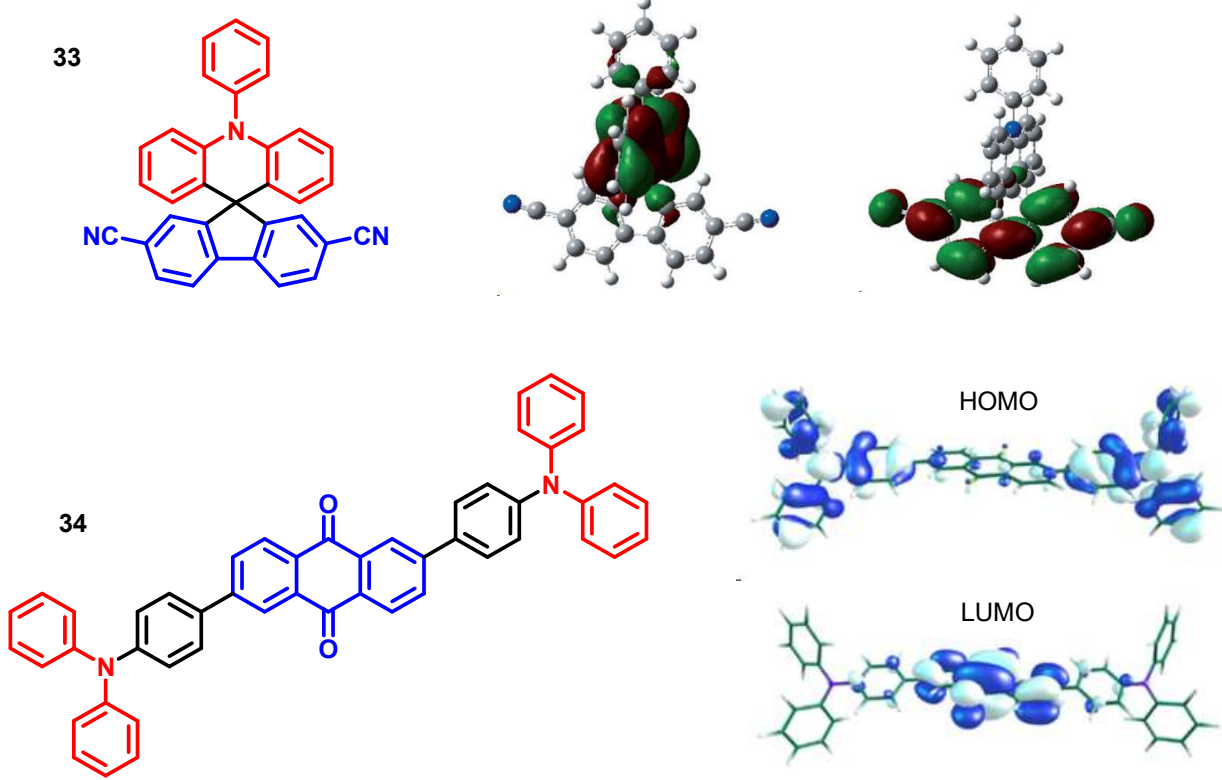

Figura 11: Exemplos de estratégias para adquirir característica TADF.

$\mathrm{Na}$ literatura, há alguns exemplos de derivados de BTD que já foram aplicados como emissores em OLEDs, no entanto, há apenas um exemplo onde esse emissor apresenta características TADF, como será descrito a seguir.

\subsection{Aplicação de derivados de BTD em OLEDs}

Na Figura 12 são mostradas as estruturas dos derivados de BTD que já foram aplicados como emissores na estrutura de OLEDs. O composto bisindol 35 - emissor no vermelho - foi sintetizado através de um acoplamento de Suzuki. A partir dele, foi produzido um dispositivo com a configuração vidro/ITO/CuPc/NPB/35/Alq $/ 2 / \mathrm{LiF} / \mathrm{Al}$, por deposição térmica. O dispositivo começa 
a emitir luz vermelha (máximo em $650 \mathrm{~nm}$ ) em aproximadamente 4,8 V. O maior brilho obtido foi de $1600 \mathrm{~cd} \mathrm{~m}^{-2}$, operando a uma voltagem de $11 \mathrm{~V}$. A eficiência observada foi de $0,2 \mathrm{~L} \mathrm{~m} \mathrm{~W}^{-1}$. As coordenadas de cromaticidade CIE 1931 foram $x=0,64, y=0,33 .^{4}$

O fluoróforo 36 foi obtido através de uma reação de aminação de BuchaldHartwig utilizando a $\mathrm{H}_{2} \mathrm{~N}-\mathrm{BTD}$. O composto apresenta fotoluminescência no vermelho tanto em solução (tolueno $=643 \mathrm{~nm}$; THF $=673 \mathrm{~nm}$ ) quanto na forma de filme fino (643 nm). O espectro de eletroluminescência apresentou máximo de emissão em $635 \mathrm{~nm}$. O rendimento quântico de fluorescência determinado no filme foi de $10 \%$. Com esse composto foi construído um dispositivo com a seguinte arquitetura: ITO/PEDOT/PSS/36/BAlq/LiF/AI. As camadas de PEDOT:PSS e a camada emissora foram depositadas por spin coating em atmosfera aberta. As camadas de BAlq e LiF/Al foram depositadas por evaporação. As coordenadas de cromaticidade $\mathrm{CIE}$ foram dependentes da densidade de corrente. A eficiência quântica externa foi de $0,60 \%$ a $100 \mathrm{~cd} \mathrm{~m}^{-2} .58$

O emissor verde 37 foi obtido através de um acoplamento de Suzuki na dibromo-BTD. Esse composto apresentou $81 \%$ de rendimento quântico de flurescência em filme. Dois dispositivos foram produzidos utilizando 37 como emissor. A arquitetura que levou aos melhores resultados foi ITO/DPAlnT 2 /DPAInF/TCTA/37/LiF/Al, onde DPAlnT 2 e DPAlnF são respectivamente a camada injetora de buracos e a camada transportadora de buracos, sendo compostos também sintetizados no trabalho. Com esse dispositivo foram obtidos eficiência quântica externa de 3,7\% $\left(12,9 \mathrm{~cd} \mathrm{~A} \mathrm{~A}^{-1}\right)$, máximo brilho de $168000 \mathrm{~cd} \mathrm{~m}^{-2}$, uma luminância de $8000 \mathrm{~cd} \mathrm{~m}^{-2}$ e densidade de corrente de 100 $\mathrm{mA} \mathrm{cm}{ }^{-2} .66$

Já para o composto 38 a síntese foi feita através de um acoplamento de Heck seguido de um acoplamento de Suzuki. Esse derivado de BTD foi aplicado como camada emissora (via spin coating) em um OLED com a seguinte arquitetura: ITO/PEDOT:PSS/PVK:poly-TPD/38/Ca/Al. Com uma baixa voltagem de acendimento (2,0 V), apresentou um máximo de luminância de $12192 \mathrm{~cd} \mathrm{~m}^{-2} \mathrm{e}$ $1,66 \mathrm{~cd} \mathrm{~A}^{-1}$ de eficiência máxima de corrente. Segundo os autores, os dados obtidos com o composto 38 estão entre os melhores para os OLEDs de emissão vermelha processados por solução. ${ }^{56}$

O derivado de BTD 39 - multitrifenilamino-substituído - foi obtido a partir de reações de acoplamento sequenciais. O fluoróforo apresenta emissão no vermelho. A partir dele foi construído um dispositivo com a arquitetura ITO/PEDOT/:PSS/39/BCP/LiF-Al com eficiência de $6,25 \mathrm{~cd} \mathrm{~A}^{-1}$ à $4,1 \mathrm{~mA} \mathrm{~cm}{ }^{-2}$, 
baixa voltagem de acendimento ( $3,0 \mathrm{~V})$ e uma emissão pura no vermelho (656 nm, $\mathrm{CIE}(\mathrm{x}, \mathrm{y})=0,67,0,33) \cdot{ }^{57} \mathrm{O}$ Composto 40 , com estrutura bastante simples foi obtido através de um acoplamento de Suzuki. Ele foi aplicado na construção de um OLED branco. A emissão branca foi explicada pela formação de um exciplex na interface da camada emissora com a camada transportadora de buracos (TPD). A configuração do dispositivo foi ITO/Cul/TPD/40/BCP/Ca/Al, que apresentou máxima eficiência de corrente de $6,5 \mathrm{~cd} \mathrm{~A}^{-1}$, brilho máximo de $5219 \mathrm{~cd} \mathrm{~m}^{-2}$, boa qualidade de cor, com coordenadas CIE 1931 0,38 e 0,45 à $15 \mathrm{~V} .{ }^{67}$

Um grande avanço na utilização de BTD como camadas emissoras em OLEDs foi descrito recentemente. O composto 41 - sintetizado via aminação de Buchwald-Hartwig - apresentou características de TADF, sendo um emissor vermelho de alta eficiência. A característica de TDAF foi corroborada através de experimentos de DFT, que apontaram uma pequena diferença de energia entre os níveis $\mathrm{S}_{1}$ e $\mathrm{T}_{1}$ e através de experimentos de fluorescência resolvida no tempo, que apontaram um decaimento de $29 \mu$ s em tolueno e um decaimento de $448 \mu$ s em filme, ambos na ausência de oxigênio (valores característicos de TADF). $O$ rendimento quântico de fluorescência determinado para o fluoróforo em filme fino foi de 56\%. A partir de 41 foi construído um dispositivo com a seguinte configuração: ITO/ $\mathrm{MoO}_{3} / \mathrm{TAPC} / \mathrm{mCP} / 41: \mathrm{CBP} / \mathrm{TmPyBP} / \mathrm{LiF} / \mathrm{Al}$. Esse dispositivo levou a ótimos resultados: luminância máxima de $2980 \mathrm{~cd} \mathrm{~m}^{-2}$ à $11,2 \mathrm{~V}$; máxima eficiência de corrente: $11,0 \mathrm{~cd} \mathrm{~A}^{-1}$; eficiência energética máxima $=10,8 \mathrm{Im} \mathrm{W}^{-1}$; máxima eficiência quântica externa (EQE) de 8,8\% a uma luminância de 1,06 cd $\mathrm{m}^{-2}$. Esse valor de EQE nunca seria observado para um emissor puramente orgânico sem características de TADF. ${ }^{6}$ 
<smiles>c1ccc(Cn2cc(-c3ccc(-c4cn(Cc5ccccc5)c5ccccc45)c4nsnc34)c3ccccc32)cc1</smiles>

35

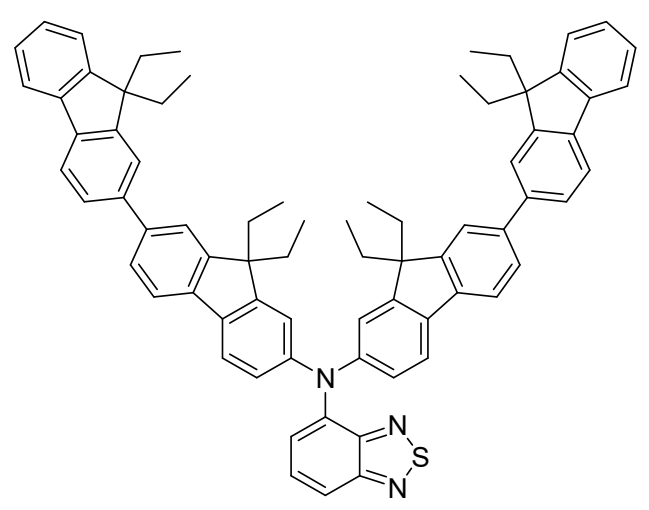

36

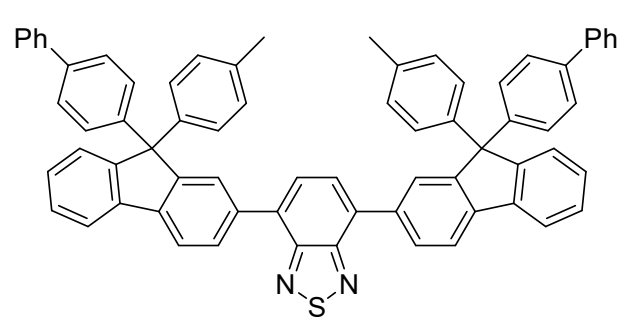

37

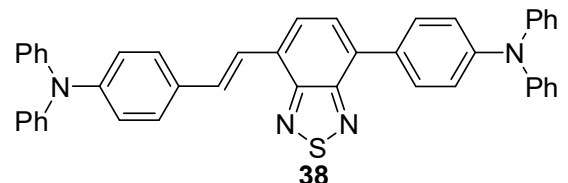

38
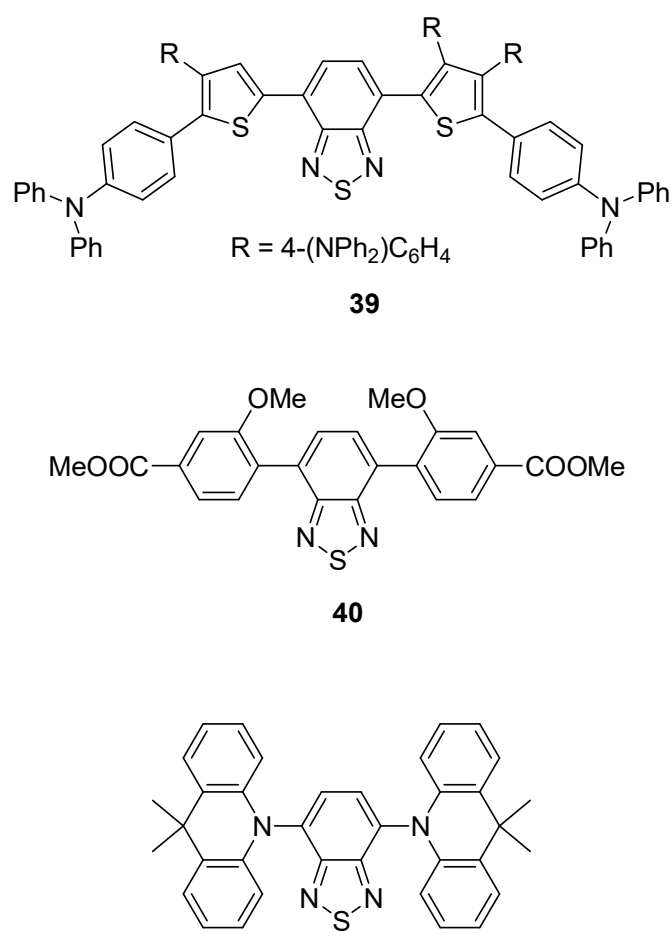

41

Figura 12: Derivados de BTD aplicados em OLED já descritos na literatura. 


\section{Objetivos}

Esse trabalho tem como objetivo central a produção e caracterização de novos derivados luminescentes de BTD arilóxi-substiuídos. Almeja-se compostos altamente emissivos que tenham características de TADF e possam levar a dispositivos OLEDs puramente orgânicos, com alta eficiência.

Abaixo estão listados os objetivos específicos:

- Fazer o planejamento de novos derivados de BTD com conjugação $\pi$ estendida, que tenham características D-A-A (doador-aceptor-aceptor) ou D-A-D (doador-aceptor-doador), tendo grupos arilóxi (ArO) como porção doadora.

- Sintetizar, via reações de acoplamento C-C, C-N e C-O, novos derivados de BTD arilóxi-substiuídos.

- Realizar a caracterização fotofísica dos novos luminóforos, determinandose: máximos de absorção e emissão, band gap óptico, deslocamento de Stokes, rendimento quântico de fluorescência em solução e em estado sólido.

- Determinar a energia e a distribuição dos orbitais HOMO e LUMO nos novos compostos via DFT.

- Determinar diferença de energia entre os estados singlete e triplete nos novos compostos via TD-DFT.

- Determinar o band gap eletroquímico dos compostos através de experimentos de voltametria cíclica.

- Realizar experimentos de fluorescência resolvida no tempo para avaliar a característica TADF dos novos compostos.

- Construir dispositivos OLEDs a partir dos derivados de BTD mais promissores (através de colaboração). 


\section{4 . Resultados}

Os resultados obtidos na presente dissertação estão divididos em duas partes. Na primeira parte (Seção 4.1) são descritas as condições reacionais para a obtenção dos novos derivados arilóxi-substituídos; é avaliada a arquitetura que leva a compostos com melhores características: fenóxi-BTD-aceptor ou fenóxiBTD-doador e; é descrita a construção de um OLED, como prova de conceito da aplicação desses fluoróforos como camadas emissoras de dispositivos eletroluminescentes. Na segunda parte do trabalho (Seção 4.2), desenvolve-se um estudo da relação estrutura-propriedade dos derivados de BTD arilóxisubstituídos, onde são avaliados os efeitos de diferentes substituintes nas características fotofísicas e eletroquímicas dos novos fluoróforos.

\subsection{Síntese do intermediário fenóxi-BTD e avaliação de grupos doadores e aceptores de elétrons}

\subsubsection{Síntese e caracterização estrutural}

Para a síntese dos derivados de BTD fenóxi-substituídos, inicialmente foram feitas otimizações da reação entre a dibromo-BTD e o 4-metóxifenol, onde foram testados diferentes solventes, bases e temperaturas (Tabela 2). No primeiro experimento foram aplicadas condições de condensação C-O de Ullmann ${ }^{68,69}$ (Entrada 1) e o produto desejado 42 foi obtido com 23\% de rendimento. Em seguida, a reação foi realizada na ausência de catalisador, levando a $15 \%$ de rendimento (Entrada 2). Ou seja, esses resultados indicaram que a reação pode ser produtiva na ausência de uma fonte de cobre. Desta forma, a otimização da reação foi continuada usando um protocolo livre de cobre. Na entrada 3 , quando $\mathrm{K}_{3} \mathrm{PO}_{4}$ foi substituído por $\mathrm{K}_{2} \mathrm{CO}_{3}$, obteve-se rendimento de $51 \%$. Alteração da base para $\mathrm{KOH}$ ou AcOK e alteração do solvente para $\mathrm{CH}_{3} \mathrm{CN}$ levaram a resultados onde não foi observada formação do produto de interesse (entradas 4-6). Por fim, aumentou-se a temperatura reacional para $120^{\circ} \mathrm{C}$, no entanto, esse aumento diminuiu o rendimento para $44 \%$. Cabe ressaltar que em temperatura mais elevadas, quantidades significativas de 3,6-dibromobenzeno-1,2-diamina, provenientes de extrusão do enxofre, foram observadas. 
Em termos de mecanismo, considerando o caráter eletro-deficiente do anel BTD e a boa nucleofilicidade do 4-metóxifenol, pode-se supor que a reação aconteça através de uma substituição nucleofílica aromática $\left(S_{N} A r\right)$.

Tabela 2: Dados de otimização da reação de formação do fenóxi-BTD.

\begin{tabular}{ccccccc}
\hline & & & & \\
\hline
\end{tabular}
desaerado $(6,5 \mathrm{~mL})$.

Na Figura 13, é mostrado o espectro de RMN ${ }^{1} \mathrm{H}$ do derivado de BTD fenóxisubstituído 42. Claramente pode-se observar o sinal da metila em $3,84 \mathrm{ppm}$ e os dois dubletes referentes aos $\mathrm{CHs}$ da porção 4-metóxifenol centrados em 6,96 e 7,13 ppm, integrando para dois hidrogênios. Adicionalmente, está destacada na figura a constante de acoplamento entre esses $\mathrm{CHs}$ aromáticos que apresentaram $J=9,05 \mathrm{~Hz}$. Já os dubletes integrando para um hidrogênio em 6,60 e em 7,66 ppm são referentes aos hidrogênios do núcleo BTD. 


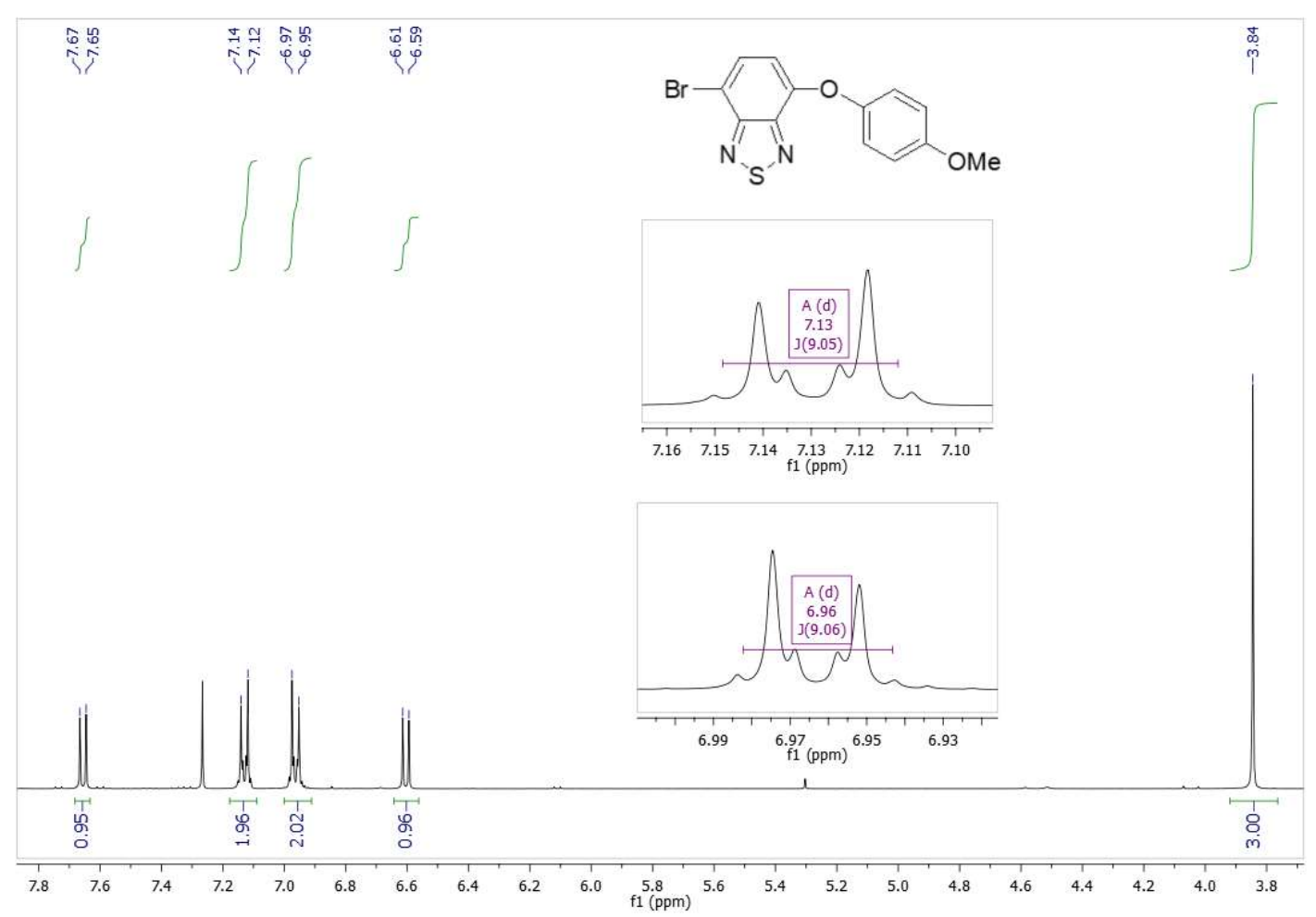

Figura 13: Espectro de $\mathrm{RMN}^{1} \mathrm{H}\left(400 \mathrm{MHZ}, \mathrm{CDCl}_{3}\right)$ do intermediário 42.

Para a obtenção dos fluoróforos desejados, o intermediário $\mathbf{4 2}$ foi submetido a condições de acoplamento cruzado de Suzuki com ácidos arilborônicos, levando aos compostos 43 e 44 com rendimentos de 96 e 77\%, respectivamente (Esquema 14). Considerando a característica doadora de elétrons do grupo metóxi, o composto 43 foi projetado para exibir uma arquitetura D-A-D (fenóxi-BTD-arila). Analogamente, considerando o efeito retirador de elétrons do átomo de flúor, 44 foi projetado como um luminóforo D-A-A (fenóxi-BTD-arila).

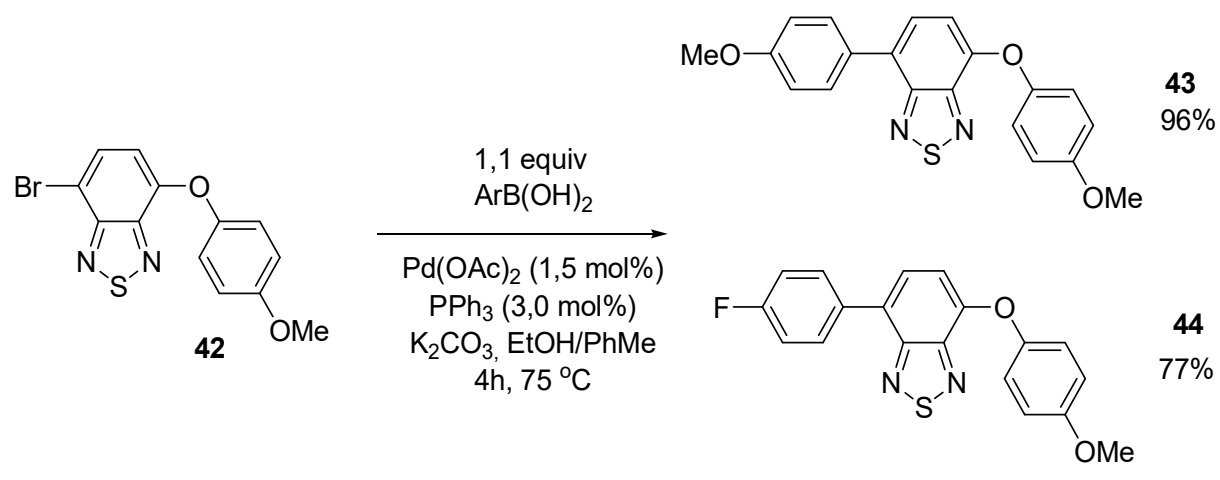

Esquema 14: Síntese dos derivados BTD fenóxi-substituídos 43 e 44.

Com o objetivo de ilustrar a caracterização desses fluoróforos, na Figura 14 é mostrado o espectro de $\mathrm{RMN}{ }^{1} \mathrm{H}$ do composto 43. Em 3,85 e 3,88 ppm pode-se 
observar os singletes referentes às duas metoxilas. Os dubletes centrados em 6,79 e 7,49 ppm, integrando para um hidrogênio, são referentes aos hidrogênios do núcleo BTD. Observa-se também na região aromática, quatro dubletes integrando para dois hidrogênios, referentes aos hidrogênios das duas arilas.

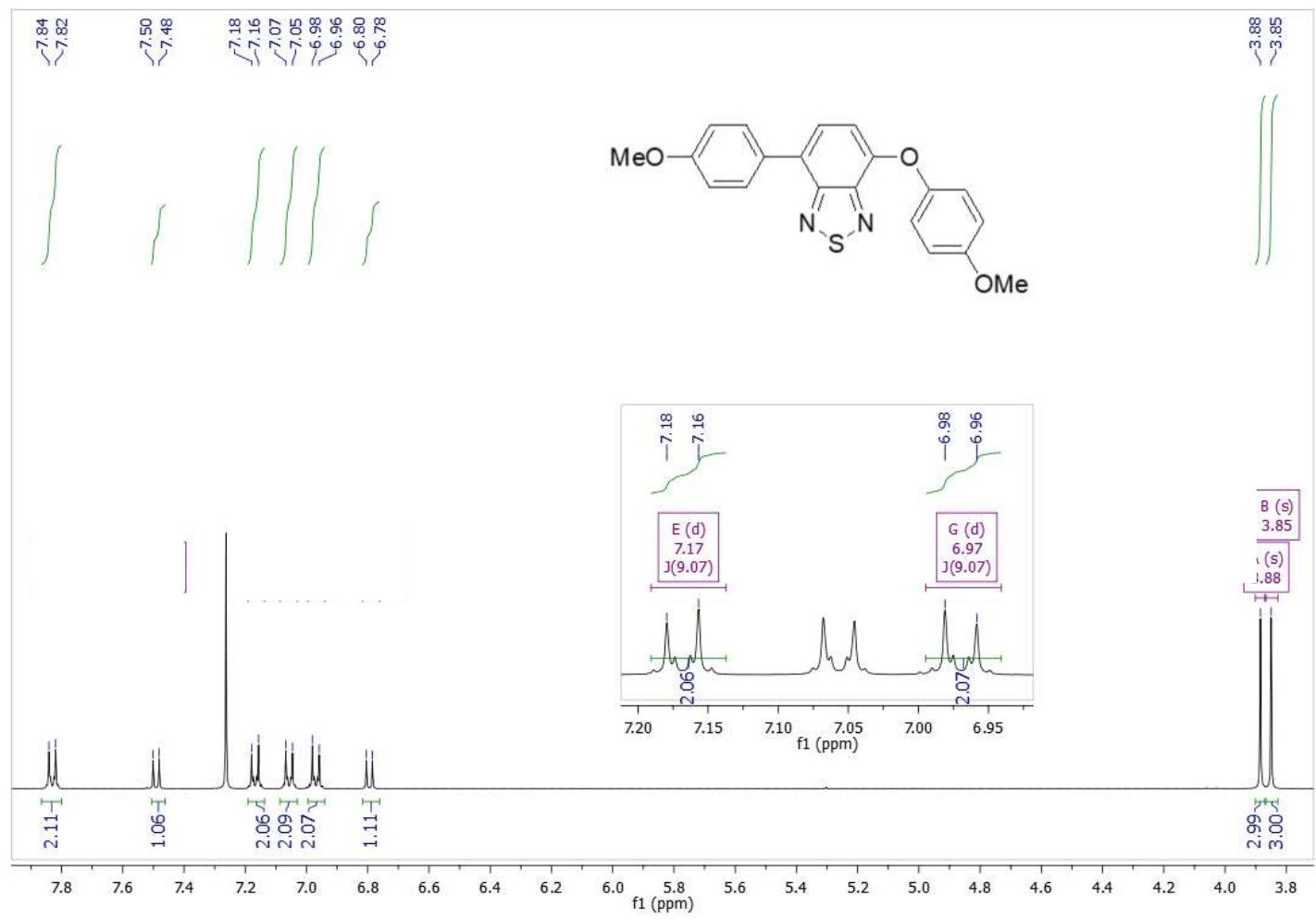

Figura 14: Espectro de $\mathrm{RMN}{ }^{1} \mathrm{H}\left(400 \mathrm{MHz}, \mathrm{CDCl}_{3}\right)$ do composto 43.

As estruturas do intermediário $\mathbf{4 2}$ e do fluoróforo $\mathbf{4 3}$ foram comprovadas através de análises de difratometria de raios $X$ em monocristal (Figura 15 eFigura 16). Em relação ao intermediário, pode-se observar que o ângulo de torção entre o anel BTD e o anel arilóxi é de $58,6^{\circ}$.

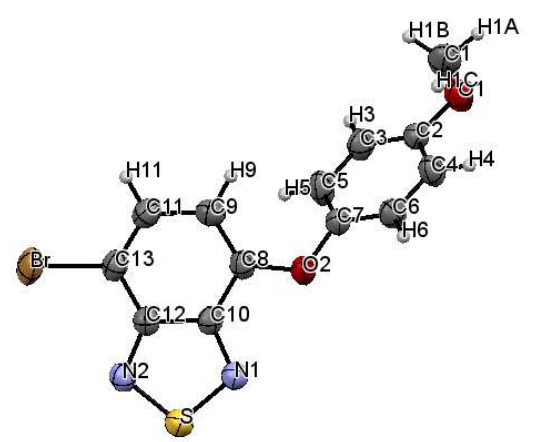

Figura 15: Estrutura molecular do intermediário 42. 
O composto 43 cristaliza com duas moléculas cristalograficamente independentes na unidade assimétrica (Figura 16). Em ambos, os grupos fenila e arilóxi são distorcidos em relação à porção BTD (ângulos diedros de 40,3\%/31,3 para o primeiro grupo e $67,2^{\circ} / 73,5^{\circ}$ para o segundo). Outro aspecto para ser destacado nas estruturas de $\mathbf{4 2}$ e de $\mathbf{4 3}$ é o caráter quinóide ${ }^{70,71}$ do núcleo BTD, uma vez que foram observados encurtamentos consideráveis das ligações C8-C9 e C11-C13.

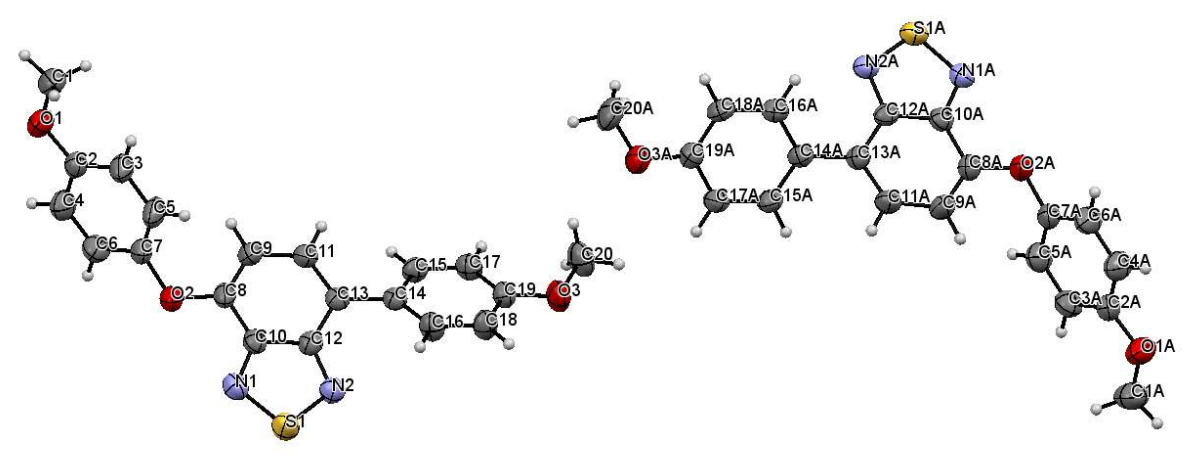

Figura 16: Estruturas moleculares do composto 43.

\subsubsection{Caracterização fotofísica dos compostos 43 e 44}

Para a caracterização fotofísica, inicialmente, os espectros de absorção dos compostos 43 e 44 foram obtidos em diferentes solventes $\left(30 \mu \mathrm{mol} \mathrm{L} \mathrm{L}^{-1}\right)$. Os resultados obtidos são mostrados na Figura 17 (topo) e os máximos de absorção $\left(\lambda_{\max }\right)$ estão resumidos na Tabela 3 . Ambos os compostos apresentam fortes bandas de absorção relacionadas as transições $\pi-\pi^{*}$. Os máximos de absorção estão localizados em torno de $401 \mathrm{~nm}$ para 43 e $388 \mathrm{~nm}$ para 44. As absortividades molares estimadas $(\varepsilon)$ foram $5760 \mathrm{~L} \mathrm{~mol}^{-1} \mathrm{~cm}^{-1}$ para 43 e $5190 \mathrm{~L}$ $\mathrm{mol}^{-1} \mathrm{~cm}^{-1}$ para 44. Os valores de band gap óptico foram 2,70 eV para 43 e 2,81 eV para 44, que estão na faixa apropriada para aplicação como camadas emissoras em OLEDs. Os espectros de absorção sofrem um efeito solvatocrômico muito pequeno, o que indica ausência de transferência de carga no estado fundamental para ambos os compostos. 

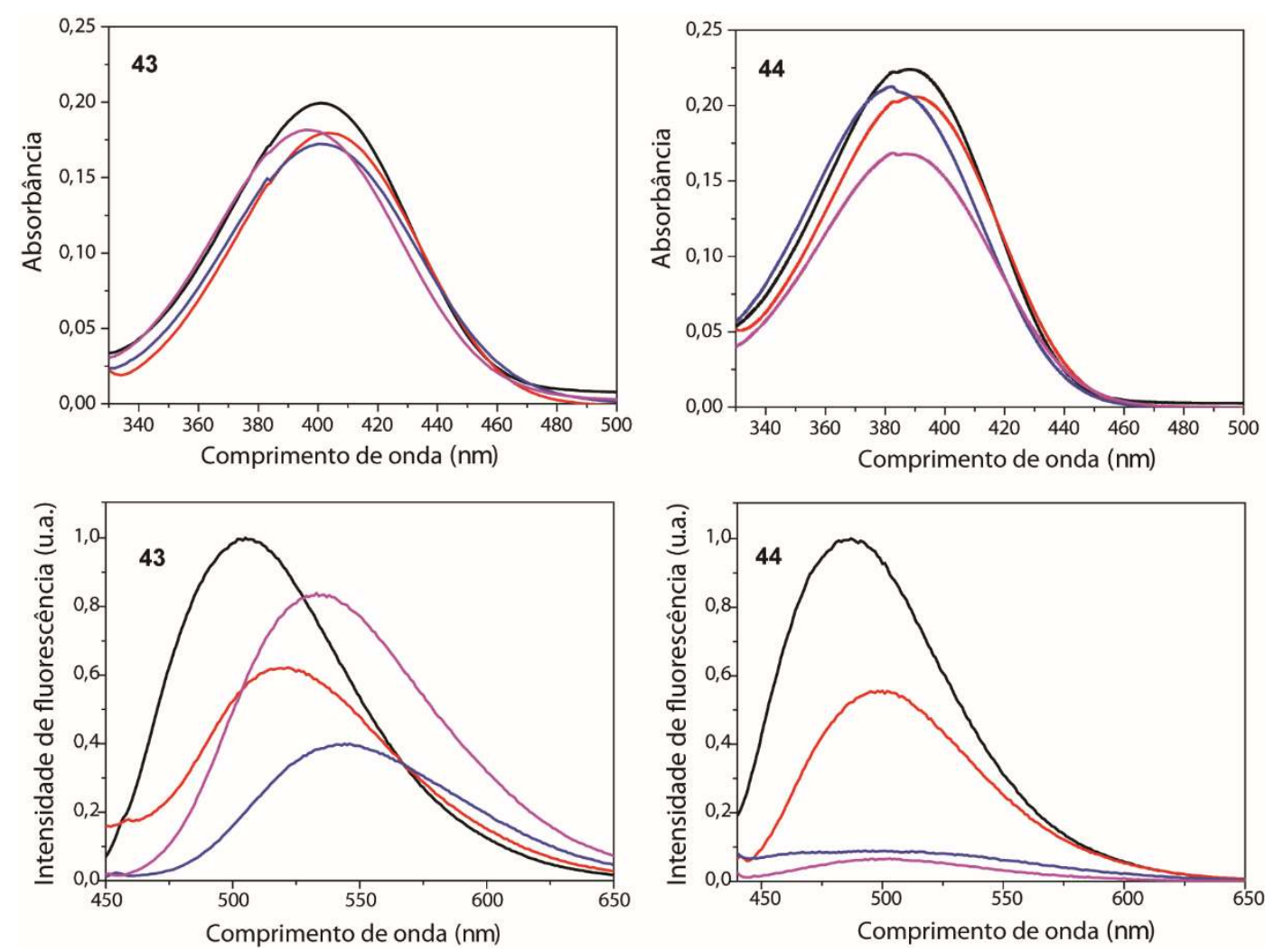

Figura 17: Absorção (superior) e espectro de emissão de fluorescência (inferior) dos compostos $\mathbf{4 3}$ e $\mathbf{4 4}$ em vários solventes. Ciclohexano $(-)$, tolueno $(-)$, acetona $(-)$ e acetato de etila (-).

Os espectros de emissão dos compostos 43 e $\mathbf{4 4}$ foram obtidos em diferentes solventes, sendo que os espectros foram obtidos excitando cada composto em seu comprimento de onda máximo de absorção de cada solvente, e os resultados são mostrados na Figura 17 (inferior) e na Tabela 3. Ambos os compostos apresentam altos valores de deslocamento de Stokes, que variou entre $103 \mathrm{~nm}$ e $153 \mathrm{~nm}$ para 43 e entre 93 nm e $138 \mathrm{~nm}$ para 44. Para 43, houve um desvio significativo (44 $\mathrm{nm}$ ) da emissão máxima para o vermelho à medida que a polaridade do solvente foi aumentada. Em contraste, para o 44, tal tendência não é claramente observada. Estes resultados sugerem uma maior deslocalização eletrônica no estado excitado para $\mathbf{4 3}$ e uma transferência de carga intramolecular (ICT) eficiente no estado excitado entre os grupos doadores (metoxifenila e metoxifenóxi) e o anel aceptor (BTD). 
Tabela 3: Comprimentos de onda máximo para absorção e emissão e os deslocamentos de Stokes de $\mathbf{4 3}$ e $\mathbf{4 4}$ em diferentes solventes.

\begin{tabular}{cccccccc}
\hline \multirow{2}{*}{ Solvente } & \multicolumn{2}{c}{$\lambda_{\text {abs }}(\mathrm{nm})$} & \multicolumn{2}{c}{$\lambda_{\text {em }}(\mathrm{nm})$} & \multicolumn{2}{c}{$\Delta \lambda_{S T}(\mathrm{~nm})$} & \multirow{2}{*}{$\Delta f$} \\
\cline { 2 - 6 } & $\mathbf{4 3}$ & $\mathbf{4 4}$ & $\mathbf{4 3}$ & $\mathbf{4 4}$ & $\mathbf{4 3}$ & $\mathbf{4 4}$ & \\
\hline $\mathrm{CH}_{3} \mathrm{CN}$ & 397 & 382 & 550 & 507 & 153 & 125 & 0,30542 \\
EtOH & 402 & 389 & 550 & 482 & 148 & 93 & 0,28869 \\
Acetona & 401 & 385 & 544 & 498 & 143 & 113 & 0,28431 \\
THF & 402 & 386 & 530 & 524 & 128 & 138 & 0,20957 \\
EtOAc & 398 & 388 & 533 & 501 & 135 & 113 & 0,19964 \\
PhMe & 403 & 389 & 519 & 498 & 116 & 109 & 0,01324 \\
Ciclohexano & 401 & 388 & 504 & 487 & 103 & 99 & $-0,00165$ \\
\hline
\end{tabular}

Em colaboração com o pesquisador Luis Maqueira realizou-se um estudo para entender melhor o comportamento desses luminóforos no estado excitado, plots de Lippert-Mataga (L-M) ${ }^{72}$ foram realizados e as mudanças nos momentos de dipolo foram calculadas. A inclinação do gráfico L-M (Figura 18) estima as mudanças nos momentos de dipolo $\left(\Delta \mu_{\mathrm{eg}}=\mu_{\mathrm{e}}-\mu_{\mathrm{g}}\right)$ entre o estado excitado e $\mathrm{O}$ estado fundamental usando a Equação $(1)^{73}$, onde "c" é a velocidade da luz, "h" é a constante de Planck, " $\Delta \lambda_{S T} 0$ " é o deslocamento de Stokes na ausência de solvente em $\mathrm{cm}^{-1}$ e "a" é o raio da cavidade de Onsager, que foram calculados como 7,94 Å para 43 e 7,67 Å para 44. 

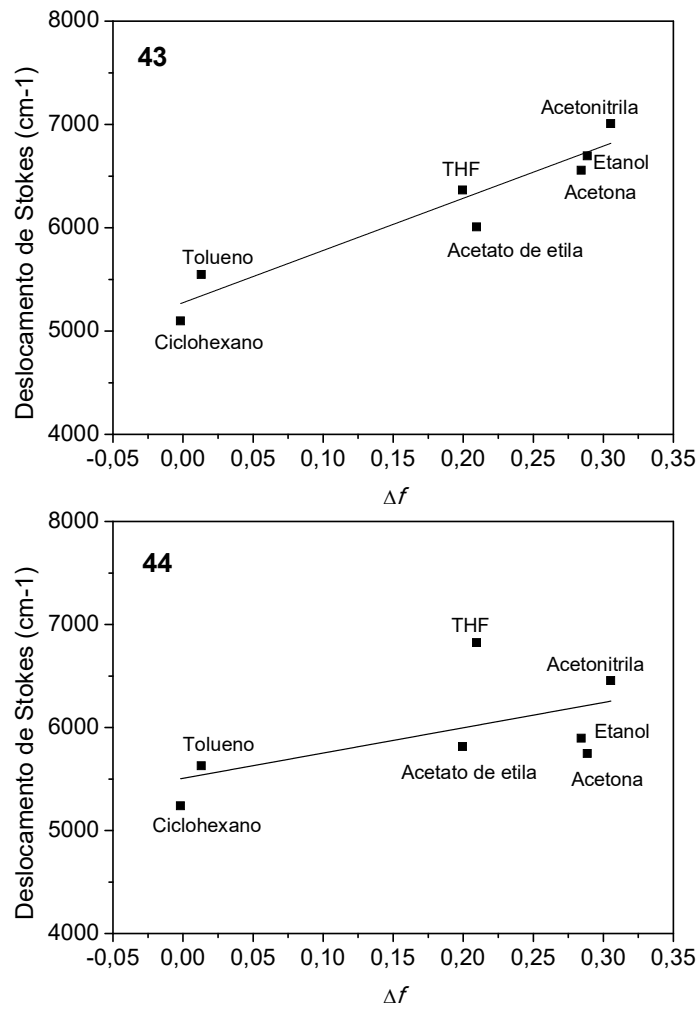

Figura 18: Deslocamento de Stokes $\left(\mathrm{cm}^{-1}\right)$ dos luminóforos 43 e $\mathbf{4 4}$ em função dos valores de $\Delta f$ para diferentes solventes. $43\left(R^{2}>0,88\right), 44\left(R^{2}>0,24\right)$. Concentração: 10 $\mu \mathrm{mol} \mathrm{L}{ }^{-1}$.

$$
\Delta \lambda_{S T}=\frac{2\left(\Delta \mu_{e g}\right)^{2}}{h c a^{3}} \Delta f+\Delta \lambda_{S T 0}
$$

As inclinações dos gráficos de Lippert-Mataga, bem como os valores de momento de dipolo no estado fundamental $\left(\mu_{\mathrm{g}}\right)$ e no estado excitado $\left(\mu_{\mathrm{e}}\right)$ para $\mathbf{4 3}$ e 44 estão resumidos na Tabela 4. A correlação positiva entre o deslocamento de Stokes e o fator de orientação da polarizabilidade $(\Delta f)$ indica um mecanismo de transferência de carga intramolecular (ICT) no estado excitado e as consideráveis mudanças nos valores do momento dipolar $\left(\Delta \mu_{\mathrm{eg}}=14,44 \mathrm{D}\right.$ para 43 e 10,42 D para 44) indicam que esses compostos são significativamente mais polares no estado excitado do que no estado fundamental. ${ }^{74}$ Portanto, com o aumento da polaridade do solvente, a interação luminóforo-solvente torna-se mais forte no estado excitado do que no estado fundamental com consequente extinção de fluorescência, ${ }^{74,75}$ como pode ser observado no espectro de emissão da Figura 17 , uma melhor correlação entre $\Delta f$ e o deslocamento de Stokes é observada para $\mathbf{4 3}$ $\left(R^{2}>0,88\right)$, sugerindo uma menor influência dos efeitos específicos do solvente na 
estabilidade do estado excitado e transferência de carga intramolecular (ICT) ${ }^{75}$. Em contraste, tal correlação é ruim para $44\left(R^{2}>0,24\right)$.

Tabela 4: Dados de inclinação Lippert-Mataga, mudança de dipolo no estado fundamental, no estado excitado e a diferença entre os estados (em Debye, D).

\begin{tabular}{|c|c|c|c|c|}
\hline Composto & Inclinação L-M & $\mu g^{a}$ & $\mu \mathrm{e}^{\mathrm{b}}$ & $\Delta \mu \mathrm{eg}^{\mathrm{c}}$ \\
\hline 43 & 5052 & $1,03 \mathrm{D}$ & $15,47 \mathrm{D}$ & $14,44 \mathrm{D}$ \\
\hline 44 & 2454 & $2,37 \mathrm{D}$ & $12,79 \mathrm{D}$ & $10,42 \mathrm{D}$ \\
\hline
\end{tabular}

Os rendimentos quânticos de fluorescência em solução $\left(\phi_{\text {solução }}\right)$ de 43 e 44 foram determinados em ciclohexano usando fluoresceína $\left(\phi_{\text {solução }}=0,93\right)$ como padrão ${ }^{76}$. Os valores obtidos foram 0,67 para 43 e 0,06 para 44. Estes resultados indicam que a presença de dois grupos doadores é importante para produzir derivados de BTD fenóxi-substituídos altamente luminescentes, indicando assim que uma arquitetura doador-BTD-fenóxi (D-A-D) é mais adequada que uma configuração aceptor-BTD-fenóxi (A-A-D) para a produção de derivados altamente emissivos.

\subsubsection{Estudo dos compostos 43 e 44 através da teoria funcional da densidade (DFT)}

As estruturas dos luminóforos foram também estudadas (através de colaboração com o pesquisador Luis Maqueira) pela teoria funcional da densidade (DFT). As estruturas moleculares foram otimizadas (no vácuo ou considerando ciclohexano como solvente). Em relação aos ângulos de torção entre o núcleo de BTD e os anéis fenóxi, obteve-se $59^{\circ}$ e $53^{\circ}$ para 43 e 44 , respectivamente. Torções consideráveis entre o BTD e os grupos arila também foram observados para ambos os compostos ( $36^{\circ}$ para 43 e $33^{\circ}$ para 44 ). Estes resultados estão de acordo com os ângulos medidos na estrutura de raios- $X$ de monocristal de 43 . A partir da Figura 19 pode-se concluir facilmente que, para ambos os compostos, os coeficientes orbitalares do LUMO estão quase totalmente concentrados no anel BTD, com o grupo fluorofenila não ampliando significativamente a capacidade aceptora elétrons do núcleo BTD. Em relação ao HOMO, para o 43 o orbital é distribuído principalmente sobre os grupos doadores metoxifenila e metoxifenóxi, com uma pequena porcentagem localizada sobre o anel de seis membros do BTD. $\mathrm{O}$ efeito do flúor no orbital de $\mathbf{4 4}$ se reflete como uma pequena densidade 
eletrônica HOMO no anel fluorofenila. A pequena distribuição orbitalar de HOMO sobre o grupo fluorfenila e o pequeno efeito do átomo de flúor sobre o LUMO em 44 podem explicar as diferenças de $\phi_{\text {solução }}$ para os fluoróforos, uma vez que ambos os efeitos podem levar a uma transferência de carga menos intensa no estado excitado.

номо

43

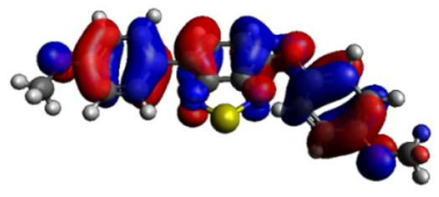

44

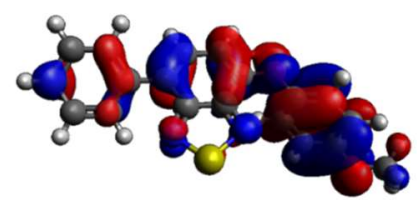

LUMO
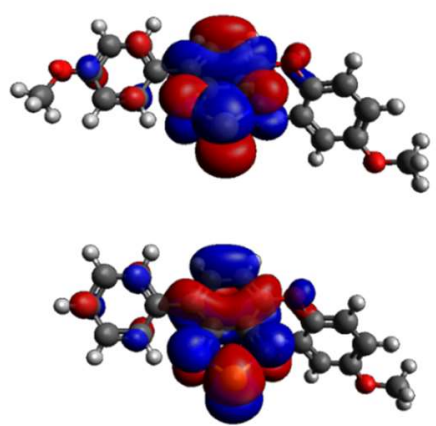

Figura 19: Distribuição HOMO e LUMO calculada para os estados fundamentais de 43 e 44.

Levando em consideração que (i) o rendimento quântico de fluorescência em solução de $\mathbf{4 3}$ foi maior que o de $\mathbf{4 4}$, (ii) que o composto 43 apresenta transferência de carga intramolecular (ICT) eficiente no estado excitado entre os dois grupos doadores (metoxifenila e metoxifenóxi) e o anel aceptor (BTD) e que essas características não foram observadas no composto 44 , e (iii) que 43 apresenta distribuição orbitalar mais apropriada para uma eficiente ICT, o composto 43, com arquitetura D-A-D foi escolhido para ser utilizado como camada emissora na construção de um OLED, como prova de conceito do potencial da aplicação de derivados de BTD arilóxi-substituídos em dispositivos eletroluminescentes.

\subsubsection{Aplicação do derivado de BTD 43 como camada emissora de OLED}

Recentemente, foram descritas a síntese e aplicações de dois interessantes derivados de BTD em OLEDs. O derivado de BTD N-di-hidroacridino-substituído ${ }^{6}$ 41 que apresenta fluorescência atrasada ativada termicamente (TADF) levou a um OLED vermelho altamente eficiente (Figura 12). Em outro trabalho, o derivado diarilado de $\mathrm{BTD}^{67} \mathbf{4 0}$ foi aplicado como camada emissora em um OLED branco, (Figura 12). Comparando a estrutura destes luminóforos com 43 e 44, pode-se ver 
características semelhantes. Assim como o derivado $\mathrm{N}$-substituído, os derivados de BTD arilóxi-substituídos possuem um átomo doador diretamente ligado ao núcleo BTD. Além disso, em 43 e 44 existe um grupo arila ligado à unidade aceptora, uma característica estrutural compartilhada com o luminóforo que levou a um OLED branco.

Tendo em vista estas semelhanças estruturais e os fatores abordados anteriormente, 43 foi escolhido para estudos eletroquímicos e fotoquímicos adicionais na forma de um filme fino para ser testado como camada emissora em OLEDs. Para fins de comparação, juntamente com o composto 43, a aplicação de 32 (Figura 20) em um OLED também foi estudada. O luminóforo 32 exibiu ICT, altos deslocamentos de Stokes (em solução e estado sólido) e um rendimento quântico de fluorescência em solução consideravelmente alto $\left(\phi_{\text {solução }}=0,49\right)^{3}$. Além disso, comparando os dispositivos eletroluminescentes fabricados usando estes compostos, a influência do grupo arilóxi no desempenho do OLED pode ser investigada.

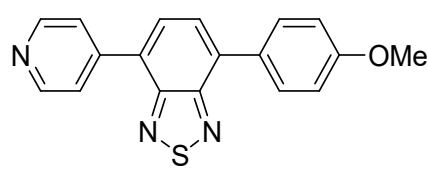

Figura 20: Estrutura do composto 32 sintetizado por Pazini e colaboradores (2017).

O comportamento eletroquímico de $\mathbf{4 3}$ e 32 foi estudado usando voltametria cíclica em $\mathrm{CH}_{2} \mathrm{Cl}_{2}$, usando TBAPF 6 como eletrólito de suporte e o par ferroceno/ferrocênio como uma referência externa (Figura 21). Ambos os compostos exibem picos de oxidação que foram atribuídos à oxidação dos grupos doadores metóxi. Os níveis de energia do HOMO foram calculados a partir do potencial de oxidação, sendo obtidos valores de $-5,7$ e $-5,9$ eV para 43 e 32, respectivamente. Os valores de LUMO foram estimados utilizando-se o band gap óptico (

Tabela 5$)^{77}$ e o valor determinado foi $-3.0 \mathrm{eV}$ para ambos os compostos. 

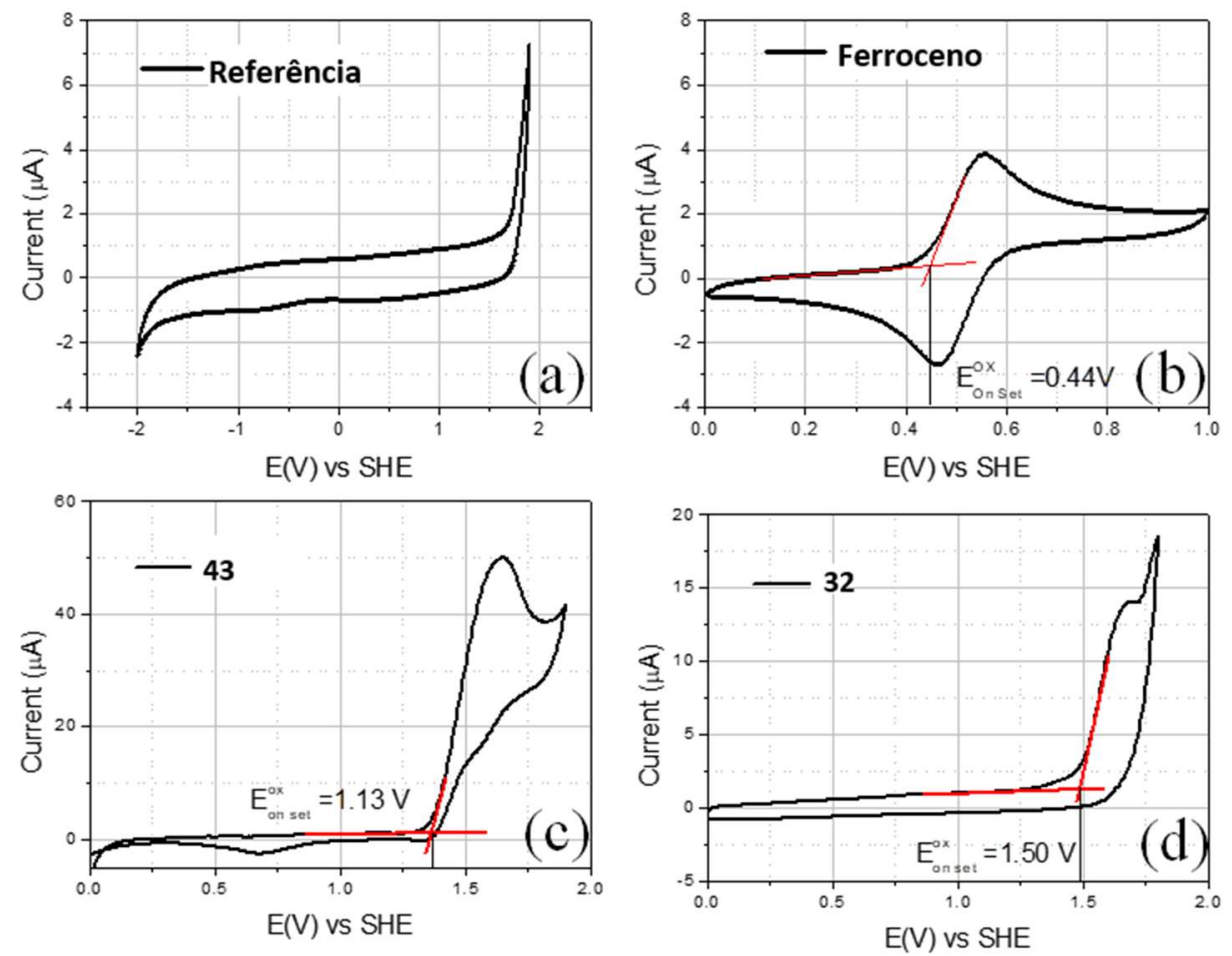

Figura 21: Voltamogramas cíclicos de (a) medição de referência; (b) ferroceno; (c) 43; e (d) 32 .

Tabela 5: Níveis de energia HOMO e LUMO para os compostos 43 e 32.

\begin{tabular}{cccc}
\hline Composto & $\mathrm{HOMO}(\mathrm{eV})$ & LUMO $(\mathrm{eV})$ & Band gap $(\mathrm{eV})$ \\
\hline $\mathbf{4 3}$ & $-5,7$ & $-3,0$ & $-2,7$ \\
$\mathbf{3 2}$ & $-5,9$ & $-3,0$ & $-2,9$ \\
\hline
\end{tabular}

Dispositivos OLED com a estrutura ITO / PEDOT: PSS (40 nm) / derivados de BTD (30 nm) / TPBi $(25 \mathrm{~nm}) / \mathrm{LiF}(0,1 \mathrm{~nm}) / \mathrm{Al}(100 \mathrm{~nm})$ foram construídos através de colaboração com o Prof. Marco Cremona, do Departamento de Física da PUC-Rio; o dispositivo A com o composto 43 como camada emissora e o dispositivo B com o composto 32. O diagrama de nível de energia para estes dispositivos (Figura 22) foi elaborado com base nos valores de HOMO e LUMO dos derivados de BTD. Os níveis de HOMO para os luminóforos 43 e 32 (5,7 e 5,9 ev), indicam uma barreira de energia de 0,7 e 0,9 eV, respectivamente, para a injeção de buracos quando comparado com o PEDOT:PSS. Além disso, uma barreira de elétrons de cerca de $0,5 \mathrm{eV}$ está presente entre o eletrodo LiF/Al e os níveis de LUMO do TPBi, indicando que, para ambos os OLEDs produzidos neste estudo, os elétrons podem ser mais eficientemente injetados do que os buracos. 


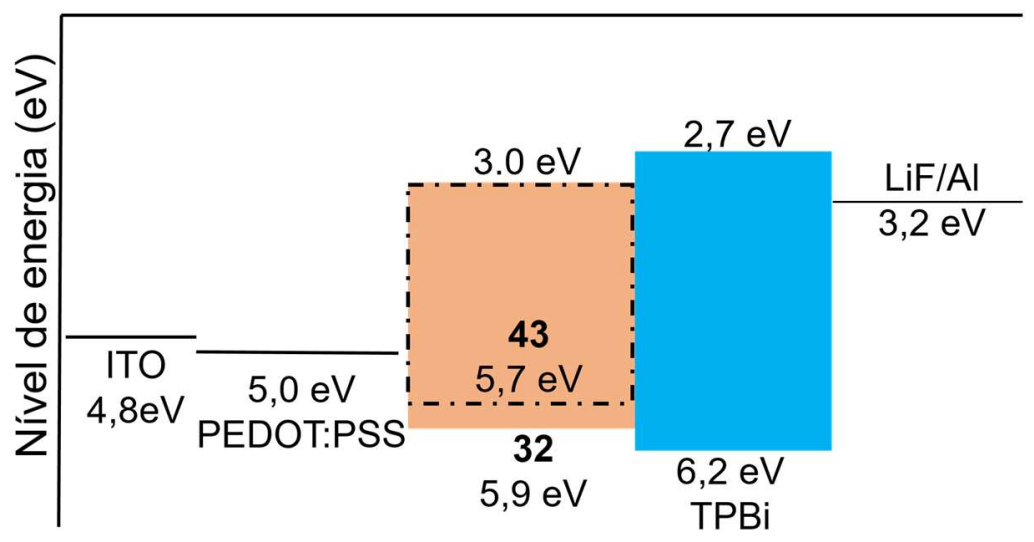

Figura 22: Diagrama de energia do dispositivo construído com a seguinte estrutura: ITO/PEDOT:PSS $(40 \mathrm{~nm}) / \mathbf{4 3}$ ou $32(30 \mathrm{~nm}) / \mathrm{TPBi}(25 \mathrm{~nm}) / \mathrm{LiF}(0.1 \mathrm{~nm}) / \mathrm{Al}(100 \mathrm{~nm})$.

Na Figura 23a são mostrados os espectros de eletroluminescência (EL) dos OLEDs A e B em função da tensão aplicada e corrente. As curvas de irradiância versus densidade de corrente estão representadas na Figura 23b. Já na Figura 23c tem-se a informação sobre a densidade de corrente obtida versus a voltagem aplicada e, por último, gráficos comparativos entre a fotoluminescência (PL) em filme fino e a eletroluminescência (Figura 23d).

O dispositivo A apresentou uma emissão de EL centrada em $547 \mathrm{~nm}$ quando medida em correntes de 0,8, 1,1 e 2,4 mA, correspondendo à transferência de carga dos grupos arila/arilóxi para o núcleo BTD. O espectro de EL de $A$ apresenta máximo de emissão igual ao máximo do espectro de fotoluminescência $(\mathrm{PL})$ de 43 na forma de um filme fino (Figura 23d). A tensão de acendimento $\left(V_{\text {on }}\right)$ do dispositivo foi de $6 \mathrm{~V}$ e a irradiância máxima observada foi de $0,40 \mu \mathrm{W} \mathrm{cm} \mathrm{cm}^{-2} \mathrm{com}$ uma densidade de corrente $(\mathrm{J})$ de $115 \mathrm{~mA} \mathrm{~cm}^{-2}$ a $8,0 \mathrm{~V}$.

Para o dispositivo B (com 32), a emissão de EL é centralizada em 527 nm, ligeiramente deslocado para o azul em comparação com A. A tensão de acendimento $\left(V_{\text {on }}\right)$ foi de $8 \mathrm{~V}$ e uma irradiância máxima de $0,31 \mu \mathrm{W} \mathrm{cm} \mathrm{cm}^{-2}$ com uma densidade de corrente $(\mathrm{J})$ de $332 \mathrm{~mA} \mathrm{~cm}^{-2}$ em 8,2 $\mathrm{V}$ foram obtidos.

Estes resultados indicam o desempenho superior do grupo fenóxi em comparação com o grupo 4-piridil na estrutura do derivado BTD, uma vez que o OLED A operou com menor densidade de corrente e levou a maior irradiância e estabilidade elétrica. Vale ressaltar que, diferentemente de $\mathbf{A}$, para o dispositivo B, o espectro de EL está deslocado para o vermelho em torno de $17 \mathrm{~nm}$ em comparação com o espectro de emissão de PL (Figura 23d). Isso pode ser atribuído à redistribuição espacial de cargas como resposta à mudança do momento dipolar na excitação eletrônica. As coordenadas da Comissão 
Internacional de L'Eclairage $\left(\mathrm{ClE}_{\mathrm{x}, \mathrm{y}}\right)$ para os OLEDs verdes foram determinadas como $(x=0,40, y=0,55)$ para o dispositivo $\mathbf{A}$ (Figura 24$)$, e $(x=0,33, y=0,53)$ para o dispositivo B.

a)

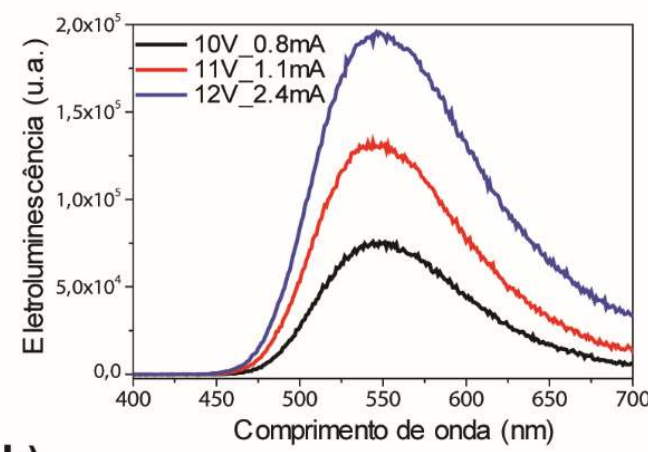

b)

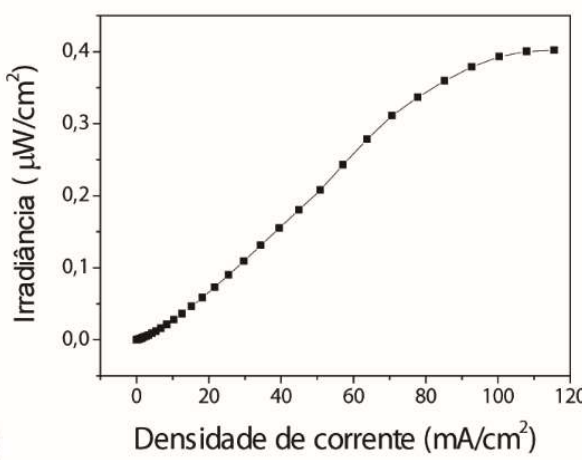

c)

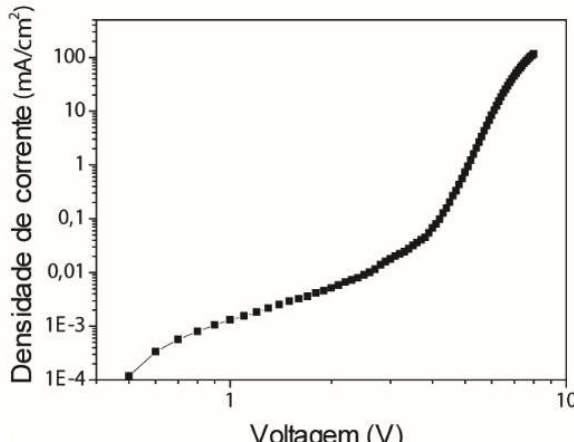

d)

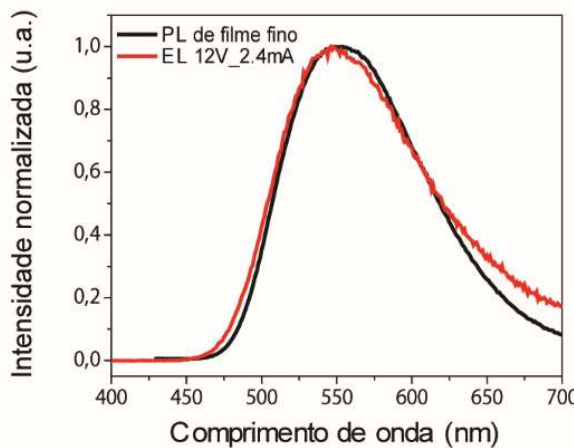

OLED B
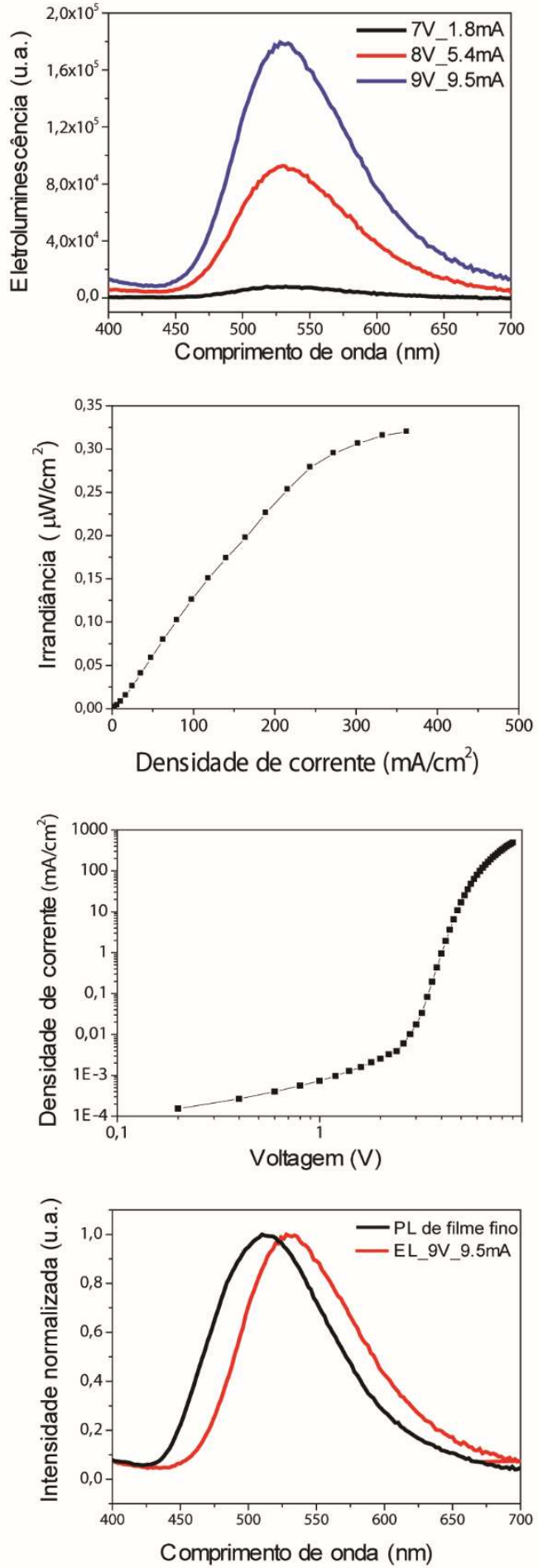

Figura 23: Caracterização OLEDs A e B. 


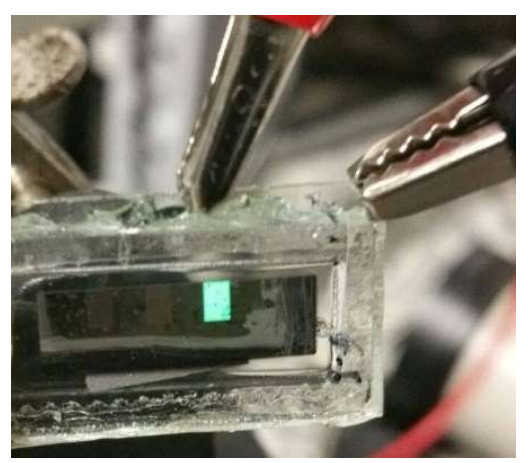

Figura 24: OLED verde fabricado utilizando o composto 43 como camada emissora.

Os resultados descritos indicam o potencial promissor de derivados de BTD fenóxi-substituídos para aplicações em dispositivos eletroluminescentes. Cabe ressaltar que os resultados descritos nessa Seção são uma prova de conceito e que tanto a estrutura do emissor orgânico quanto a estrutura do OLED devem ser otimizadas para a obtenção de um dispositivo com maior brilho, estabilidade e eficiência. Os resultados descritos na Seção 4.1 foram publicados em 2018 na revista Tetrahedron Letters ${ }^{3}$. 


\subsection{Otimização estrutural de derivados de BTD arilóxi-substituídos para aplicação em camadas emissoras de OLEDs}

Levando em consideração os resultados promissores do emprego do derivado de BTD fenóxi-substiuído 43 , com característica D-A-D, como camada emissora em OLEDs, foi realizada uma otimização estrutural mais abrangente do luminóforo, gerando derivados de segunda geração. Nessa otimização foram avaliados: (i) a natureza do substituinte fenóxi, (ii) o padrão de substituição dos grupos arila, e (iii) a substituição de grupos arila por heterocilos nitrogenados, conforme mostrado na Figura 25.
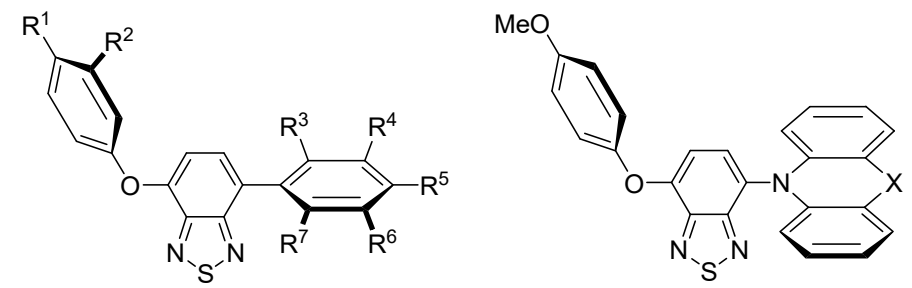

Figura 25: Estrutura geral dos derivados de BTD arilóxi-substituídos de segunda geração.

Cabe ressaltar que o planejamento desses compostos foi realizado buscando-se a não-coplanaridade entre as porções doadoras das extremidades e a porção aceptora central, o que pode levar à separação entre os orbitais HOMO e LUMO, com decréscimo de $\Delta \mathrm{E}_{\mathrm{ST}}$, podendo produzir luminóforos com características TADF.

\subsubsection{Síntese de novos derivados BTD substituídos}

Para a síntese dos novos derivados, inicialmente, foram realizados acoplamentos de Suzuki utilizando o intermediário 4-metóxi-fenóxi substituído (42) e ácidos arilborônicos com diferentes padrões de substituição. As condições reacionais empregadas foram as mesmas utilizadas na síntese de 43 . Dessa forma, os compostos 45-48 foram obtidos com ótimos rendimentos (92 a 99\%).

$\mathrm{Na}$ Tabela 6 estão demonstrados o esquema de reação, os ácidos arilborônicos utilizados e as estruturas dos produtos obtidos. Em termos de planejamento, o objetivo foi a inserção de grupos volumosos nas posições 2 e 3 no anel arílico, de modo a tentar evitar a coplanaridade entre esse anel e o núcleo BTD. 
Tabela 6: Acoplamento de Suzuki entre o intermediário 42 e ácidos arilborônicos.

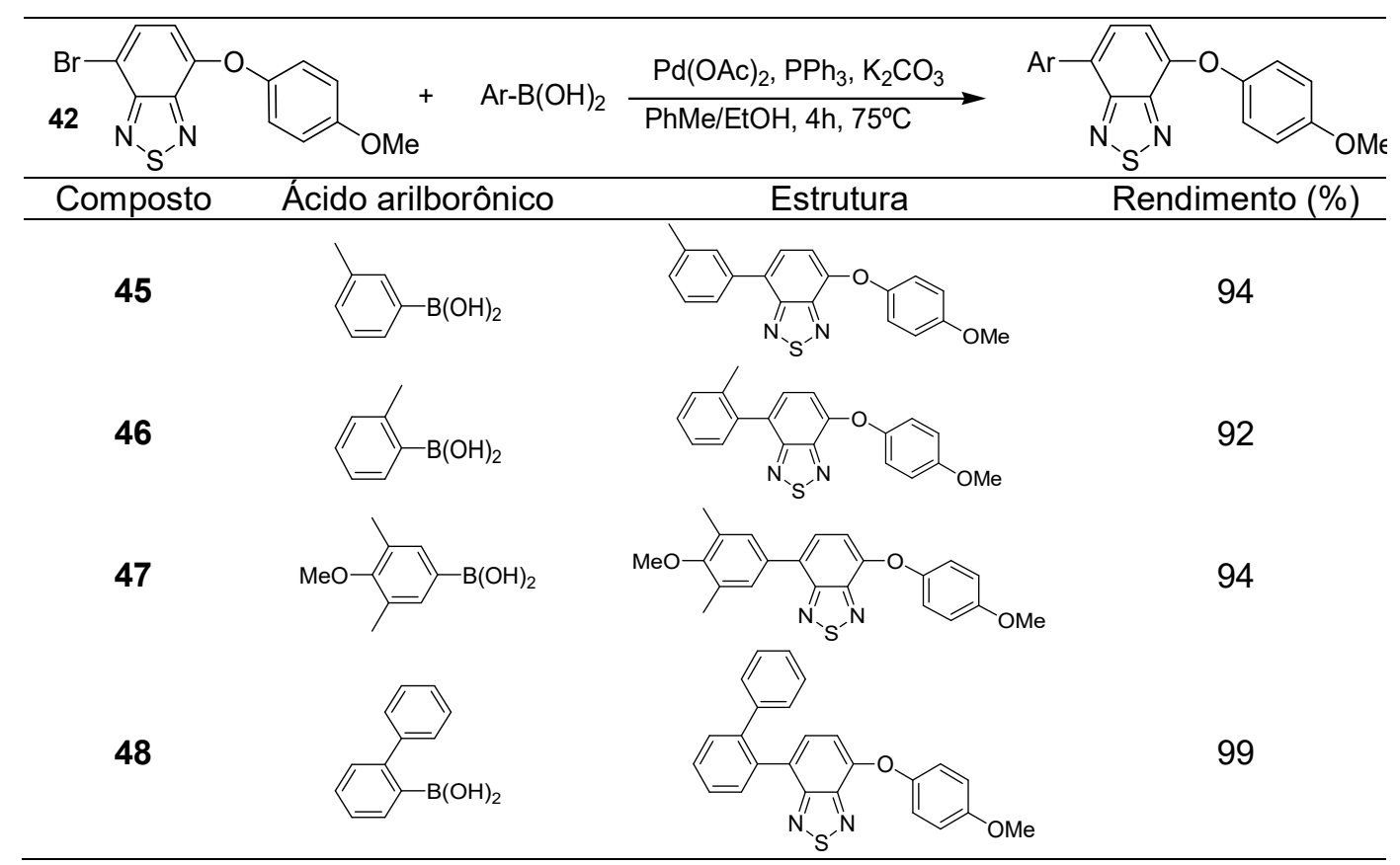

Todos os compostos sintetizados foram caracterizados por RMN ${ }^{1} \mathrm{H}$ e ${ }^{13} \mathrm{C}$ (Anexo 9.1). Para exemplificar a caracterização dessa classe de compostos, na Figura 26 está apresentado o RMN ${ }^{1} \mathrm{H}$ do composto 47. Nele pode-se observar um singlete em 2,39 ppm, integrando para 6 hidrogênios, referente às duas metilas equivalentes da arila inserida via Suzuki. Em 3,79 e 3,85 ppm são observados dois singletes integrando para 3 hidrogênios referentes às duas metoxilas. Na região aromática são observados os dois dubletes referentes aos hidrogênios do substituinte metóxi-fenóxi ( $2 \mathrm{H}$ cada), os dubletes referentes aos hidrogênios do anel BTD (1H cada) e o singlete referente aos hidrogênios da posição orto da arila $(2 \mathrm{H})$. 


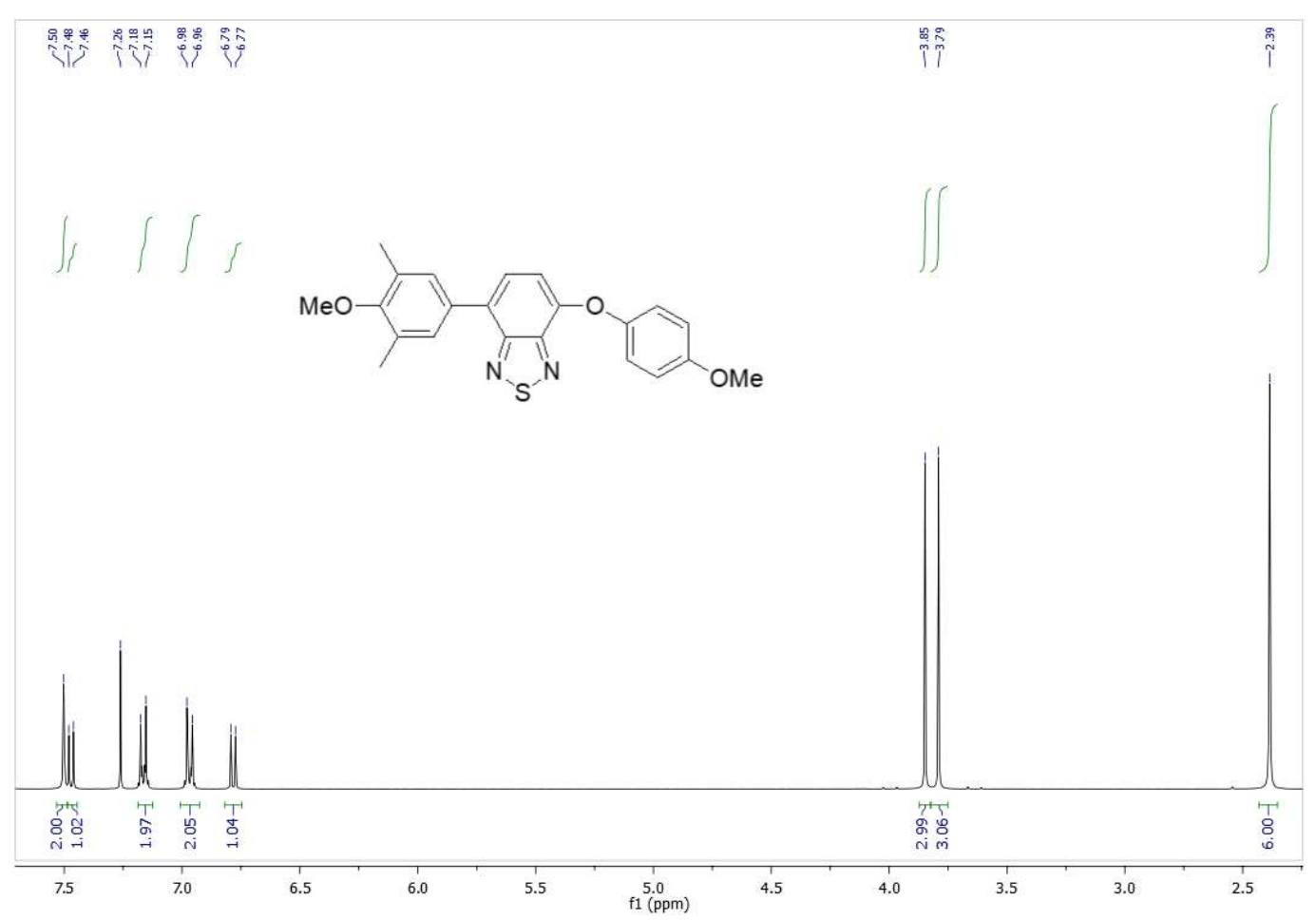

Figura 26: Espectro de $\mathrm{RMN}^{1} \mathrm{H}\left(400 \mathrm{MHz}, \mathrm{CDCl}_{3}\right)$ do produto 47.

O intermediário monobromado $\mathbf{4 2}$ também foi utilizado como substrato para reações de aminação de Buchwald-Hartwig, de modo a produzir derivados de BTD $\mathrm{N}$ - e O-substituídos. Nessas reações, $\mathbf{4 2}$ foi acoplado com a iminodibenzila e a fenoxazina utilizando um sistema baseado em $\mathrm{Pd}(\mathrm{OAc})_{2},\left(t-\mathrm{Bu}_{3} \mathrm{PH}\right) \mathrm{BF}_{4}, t-\mathrm{BuONa}$, em tolueno (Esquema 15). ${ }^{6}$ Nessas condições, o produto 49 e o produto 50 foram obtidos com rendimentos de 55 e $85 \%$, respectivamente, após $24 \mathrm{~h}$ de reação. A inserção desses heterociclos nitrogenados na estrutura do luminóforo é baseada em resultados já descritos na literatura, onde o derivado de BTD $N$-dihidroacridino-substituído ${ }^{6} 41$ (Figura 12) apresentou características de TADF e levou a um OLED com alto EQE. Outra justificativa da utilização desses heterociclos nitrogenados é a presença do grupo fenoxazina em compostos que apresentam características TADF e são, inclusive, comercializados como materiais para camadas emissoras de OLEDs ${ }^{78,79}$ (Figura 27). 


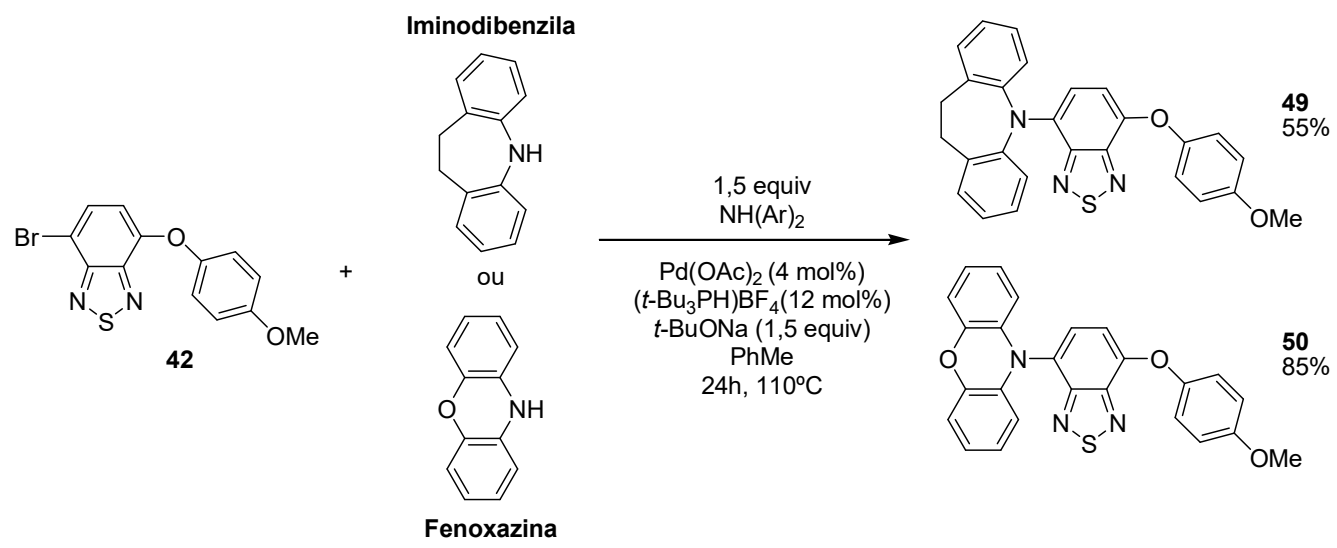

Esquema 15: Síntese de derivados de BTD N-e O-substituídos via acoplamento de Buchwald-Hartwig.
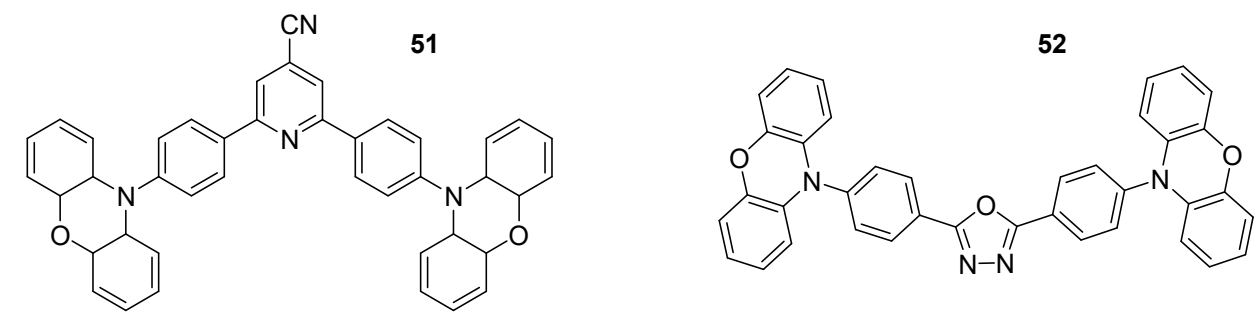

Figura 27: Materiais TADF que possuem o grupo fenoxazina e são comercializados como materiais para camadas emissoras de OLEDs.

Na Figura 28 está apresentado o RMN ${ }^{1} \mathrm{H}$ do composto 50. Nele pode-se observar um singlete em 3,87 ppm, integrando para três hidrogênios, referente aos hidrogênios da metoxila. Na região aromática, os duplos dubletes centrados em 5,82 e 6,75 ppm, integrando para 2 hidrogênios, são referentes aos hidrogênios em posição orto em relação ao do nitrogênio da fenoxazina. Além disso, podem ser observados dois triplos dubletes integrando para dois hidrogênios, o primeiro centrado em 6,54 ppm e o segundo em 6,67 ppm ambos com $J=7,7$ e $1,5 \mathrm{~Hz}$, referentes aos outros hidrogênios da fenoxazina. Também pode-se observar os dubletes centrados em 6,78 e 7,53 ppm, integrando para um hidrogênio e com $J=8,0 \mathrm{~Hz}$, que são referentes aos hidrogênios do anel BTD. E por último, dois dubletes centrados em 7,01 e 7,23 ppm, integrando para dois hidrogênios, referentes aos hidrogênios da arila metóxi-fenóxi-substituída. 


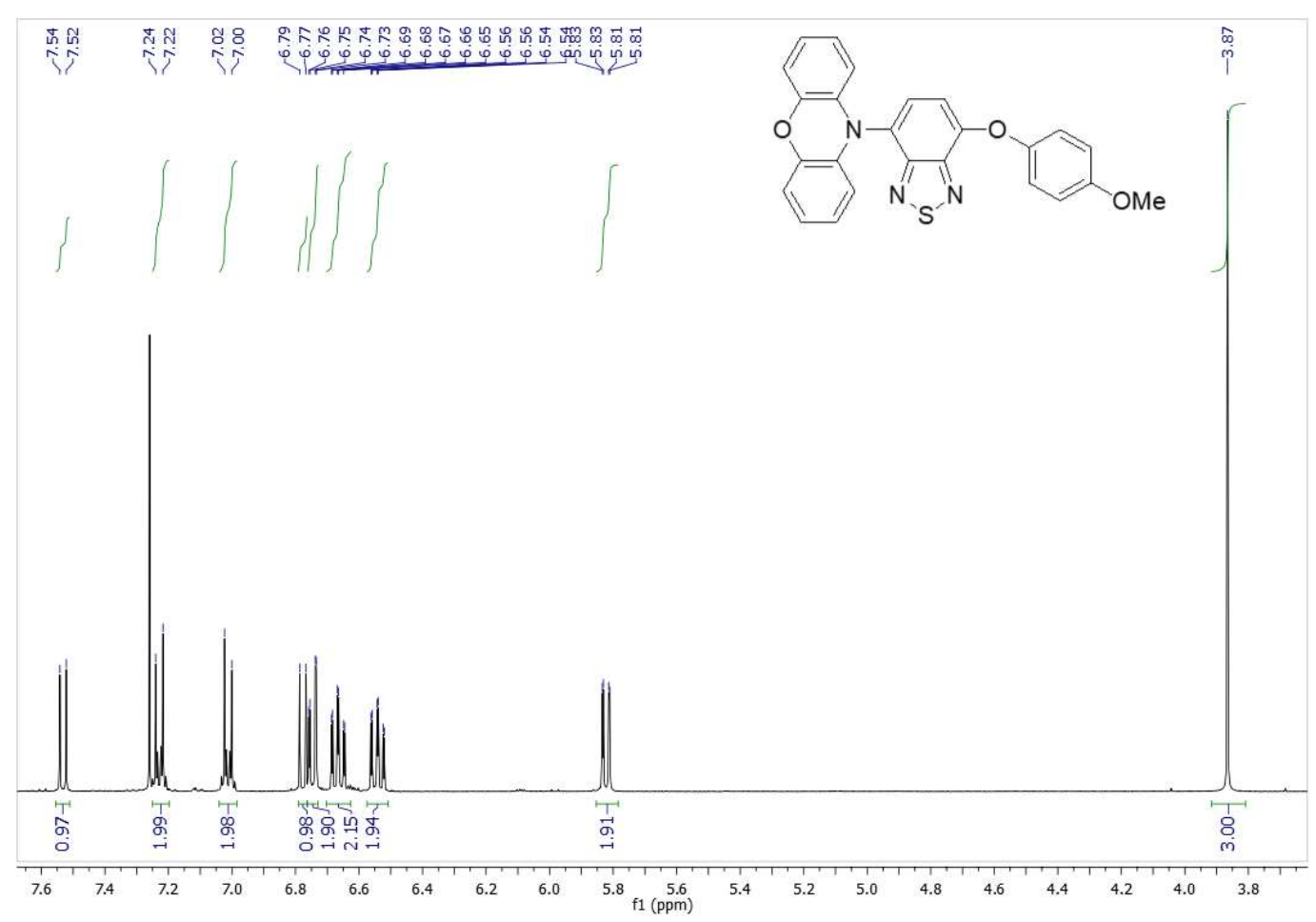

Figura 28: Espectro de $\mathrm{RMN}{ }^{1} \mathrm{H}\left(400 \mathrm{MHz}, \mathrm{CDCl}_{3}\right)$ do produto 50.

Com o objetivo de avaliar outros grupos arilóxi ligados ao anel BTD, foram realizadas reações da 4,7-dibromo-BTD (9) com diferentes fenóis. Quando ocresol ou resorcinol (Figura 29) foram utilizados, não se observou a formação dos produtos desejados.
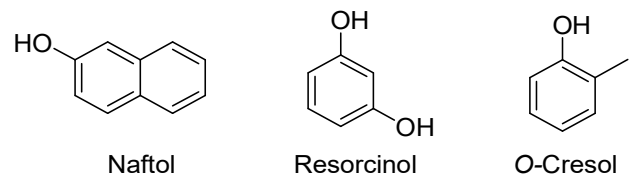

Figura 29: Fenóis testados para a síntese de novos derivados de BTD.

Quando o $\beta$-naftol foi aplicado, o produto monobromado 53 foi obtido com $10 \%$ de rendimento (Tabela 7 , entrada 1 ). Considerando o baixo rendimento dessa reação, novas tentativas de otimização foram realizadas (entradas 2-5). No entanto, infelizmente, nenhum dos solventes testados levou a melhores resultados. 
Tabela 7: Dados de otimização da reação de formação do segundo intermediário BTDnaftóxi (53).

\begin{tabular}{ccc}
\hline & & \\
\hline Entrada & Solvente & Rendimento $(\%)$ \\
\hline 1 & $\mathrm{DMF}$ & 10 \\
2 & $\mathrm{MeCN}$ & 7 \\
3 & $\mathrm{THF}$ & 0 \\
4 & $\mathrm{DMSO}$ & 8 \\
5 & Dioxano & 0 \\
\hline
\end{tabular}

Apesar do baixo rendimento, o intermediário $\mathbf{5 3}$ também foi aplicado em acoplamentos de Suzuki. Para isso, foram utilizados o ácido 2-toluilborônico e o ácido 4-metóxi-3,5-dimetifenilborônico e as mesmas condições descritas para o acoplamento do intermediário 43 (Esquema 16). Dessa forma, os compostos 54 e 55 foram obtidos com 63 e $53 \%$ de rendimento, respectivamente.

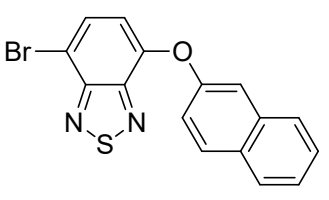

53

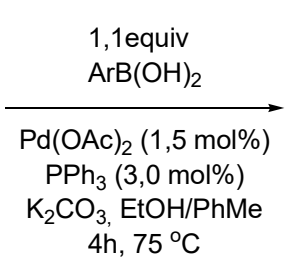

$4 \mathrm{~h}, 75^{\circ} \mathrm{C}$
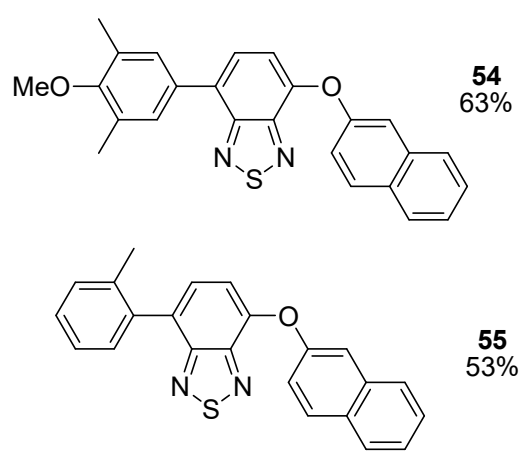

Esquema 16: Acoplamento de Suzuki no intermediário 53.

Na Figura 30 é mostrado o espectro de RMN ${ }^{1} \mathrm{H}$ do produto 54. Pode-se observar um singlete em 2,40 ppm, integrando para seis hidrogênios, que é

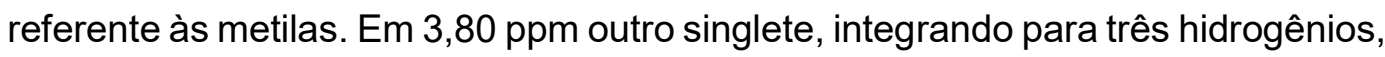
referente aos hidrogênios da metoxila. Na região aromática destaca-se o dublete em 6,99 ppm referente ao hidrogênio da posição orto vizinha ao oxigênio do naftóxi e o dublete em 7,93, referente a um dos hidrogênios do anel BTD. Além disso, a integral relativa dos sinais, está de acordo com o esperado para o composto. 


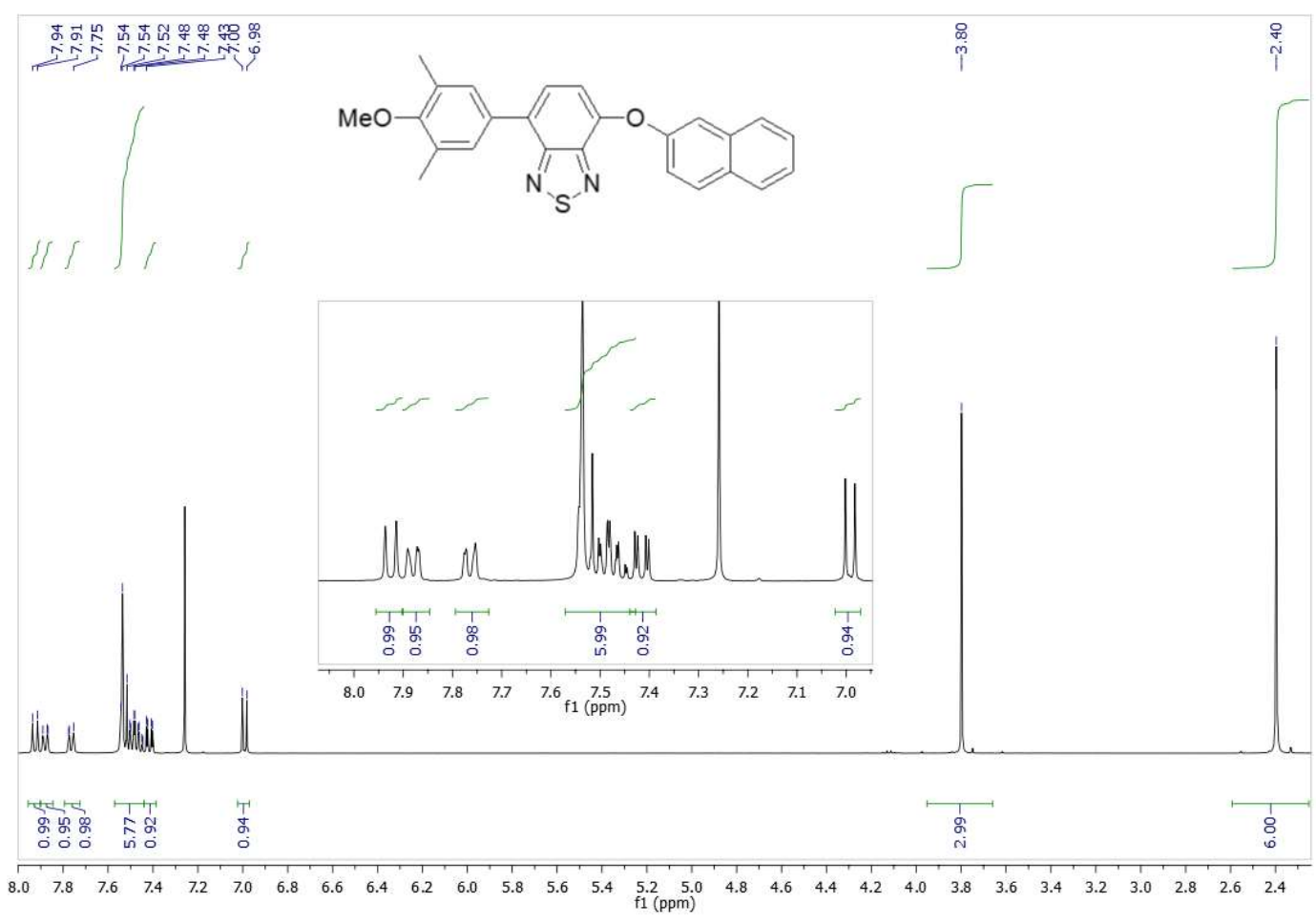

Figura 30: Espectro de $\mathrm{RMN}^{1} \mathrm{H}\left(400 \mathrm{MHz}, \mathrm{CDCl}_{3}\right)$ do produto 54.

Para poder avaliar melhor o efeito de grupos fenóxi/naftóxi nas propriedades fotofísicas e eletroquímicas de derivados de BTD, compostos simétricos diarilados e diaminados foram sintetizados com a finalidade de comparação. Para a obtenção dos derivados de BTD diarilados foram realizados acoplamentos de Suzuki entre a dibromo-BTD 9, e os ácidos 3-toluilborônico e 4-metoxi-3,5dimetifenilborônico, utilizando-se as condições padrões (Esquema 17). Os produtos foram obtidos com ótimos rendimentos de 90\% para 56 e 83\% para 57 . Pela comparação das propriedades fotofísicas e eletroquímicas de 56 e $57 \mathrm{com}$ 45, 47 e 54 o efeito dos grupos naftóxi e 4-metóxifenóxi pode ser avaliado. Além da questão comparativa, na estrutura dos compostos diarilados há grupos metila que podem forçar a não coplanaridade entre as arilas e o anel BTD, podendo levar a separação espacial entre HOMO e LUMO e, consequentemente, propriedades TADF. 


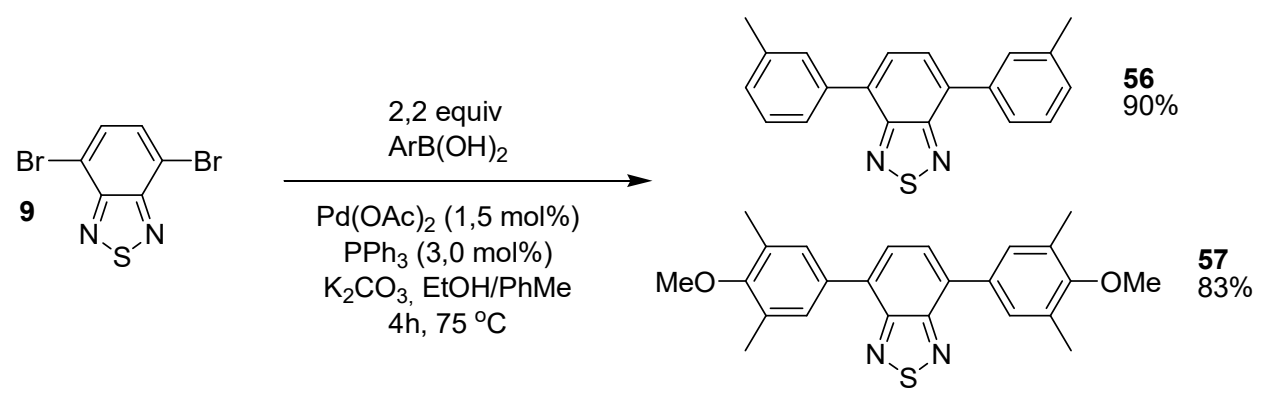

Esquema 17: Acoplamento de Suzuki na síntese de derivados simétricos em 9.

Na Figura 31 é mostrado o espectro de RMN ${ }^{1} \mathrm{H}$ do produto 57 . Nele podese observar um singlete em 2,41 ppm, integrando para 12 hidrogênios, referente as quatro metilas das arilas e o singlete em 3,81 ppm, integrando para seis hidrogênios, referente às metoxilas. Já o singlete em 7,60 ppm, integrando para quatro hidrogênios, referente aos hidrogênios das arilas e outro singlete em 7,69 ppm, integrando para dois hidrogênios, refere-se aos hidrogênios do núcleo BTD.

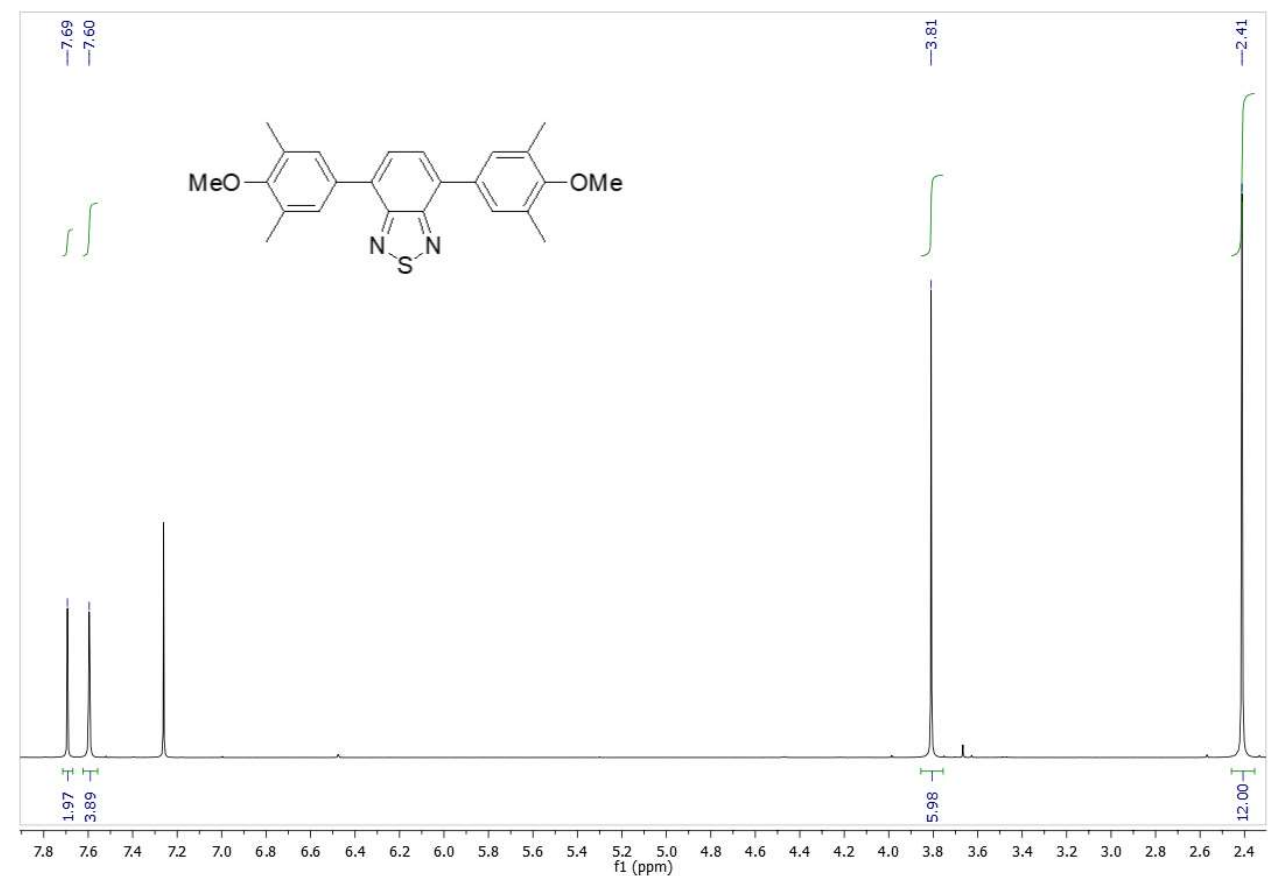

Figura 31: Espectro de $\mathrm{RMN}^{1} \mathrm{H}\left(400 \mathrm{MHz}, \mathrm{CDCl}_{3}\right)$ do produto 57.

Para a obtenção de derivados simétricos diaminados, o acoplamento de Buchwald-Hartwig foi realizado no composto 9 utilizando as aminas iminodibenzila e fenoxazina (Esquema 18). Foram aplicadas as mesmas condições usadas na aminação do intermediário 42 , porém utilizou-se três equivalentes das aminas. A reação ocorreu durante $24 \mathrm{~h}$ a $110^{\circ} \mathrm{C}$. Dessa forma, os produtos 58 e 59 foram obtidos com rendimentos de 38 e $51 \%$, respectivamente. A obtenção desses 
compostos teve dois objetivos, comparar as propriedades fotofíscas e eletroquímicas de 58 e 59 com 49 e 50, além de produzir compostos com estruturas muito semelhantes a $\mathbf{4 1}$, único derivado de BTD com características TADF já descrito na literatura.
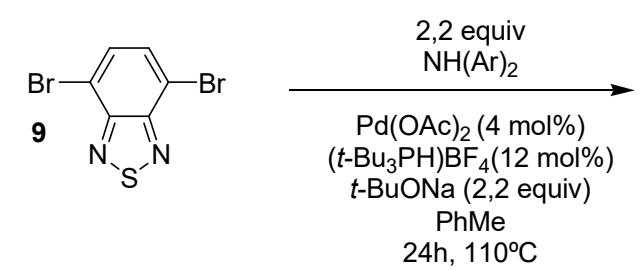

58

$38 \%$

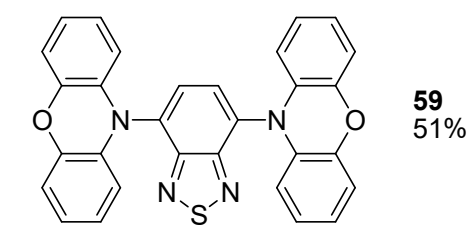

Esquema 18: Reação de aminação Buchwald-Hartwig para obtenção de derivados simétricos no dibromo-BTD.

Na Figura 32 está demonstrado o espectro de RMN ${ }^{1} \mathrm{H}$ do produto 59. Nele pode-se observar dois duplos dubletes integrando para quatro hidrogênios, o primeiro centrado em 5,90 ppm e o segundo centrado em 6,81 ppm referentes aos hidrogênios nas posições vizinhas ao nitrogênio e ao oxigênio, respectivamente. Além disso, dois triplos dubletes integrando para quatro hidrogênios, o primeiro centrado em 6,62 ppm e o segundo em 6,74, referentes aos outros hidrogênios da fenoxazina são observados. Por fim, um sinal 7,90 ppm correspondendo a um singlete integrando para dois que são referentes aos hidrogênios do núcleo BTD. 


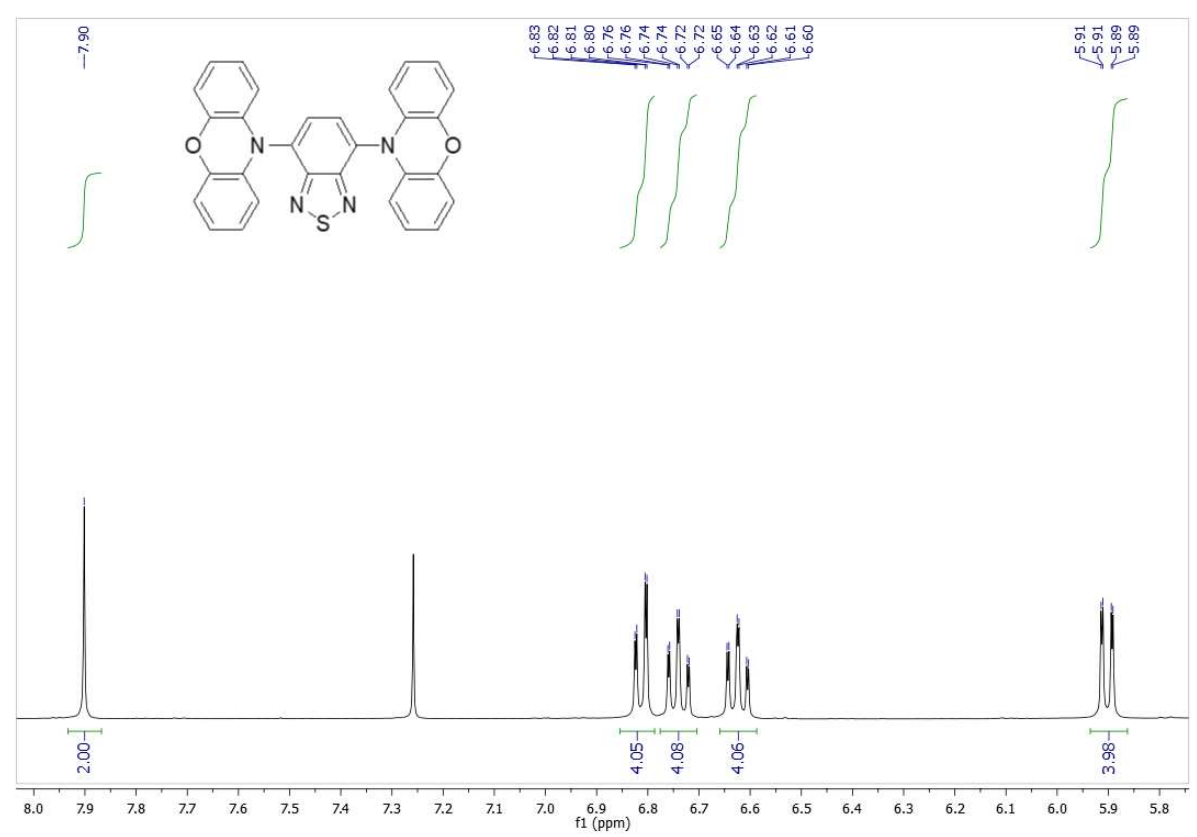

Figura 32: Espectro de $\mathrm{RMN}{ }^{1} \mathrm{H}\left(400 \mathrm{MHz}, \mathrm{CDCl}_{3}\right)$ do produto 59.

\subsubsection{Caracterização fotofísica e eletroquímica dos novos derivados de BTD}

O comportamento eletroquímico dos novos derivados de BTD sintetizados foi estudado em $\mathrm{CH}_{2} \mathrm{Cl}_{2}$, utilizando voltametria cíclica (Anexo 9.2). Na porção anódica do voltamograma, todos os compostos exibem picos de oxidação, que foram atribuídos à oxidação dos grupos doadores arilóxi, metóxi ou amino. Em regiões catódicas são observados picos referentes à redução da porção aceptora (BTD). Os níveis de energia do HOMO foram calculados a partir do potencial de oxidação $\left(\mathrm{E}_{\text {onset }}^{o x}\right.$ ), sendo obtidos valores entre -4,80 e -6,08 eV. Os valores de LUMO foram calculados a partir do potencial de redução $\left(\mathrm{E}_{\text {onset }}^{\text {red }}\right)$, sendo obtidos valores entre -2,93 e -3,16 eV. Dessa forma, o band gap eletroquímico dos compostos variou entre 1,90 a 3,12 eV (

Tabela 8).

Para exemplificar os dados obtidos, na Figura 33 está mostrado o voltamograma do composto $\mathbf{5 0}$. Na esquerda observa-se o potencial de redução e na direita o potencial de oxidação que foram utilizados para calcular o LUMO e HOMO, respectivamente. 

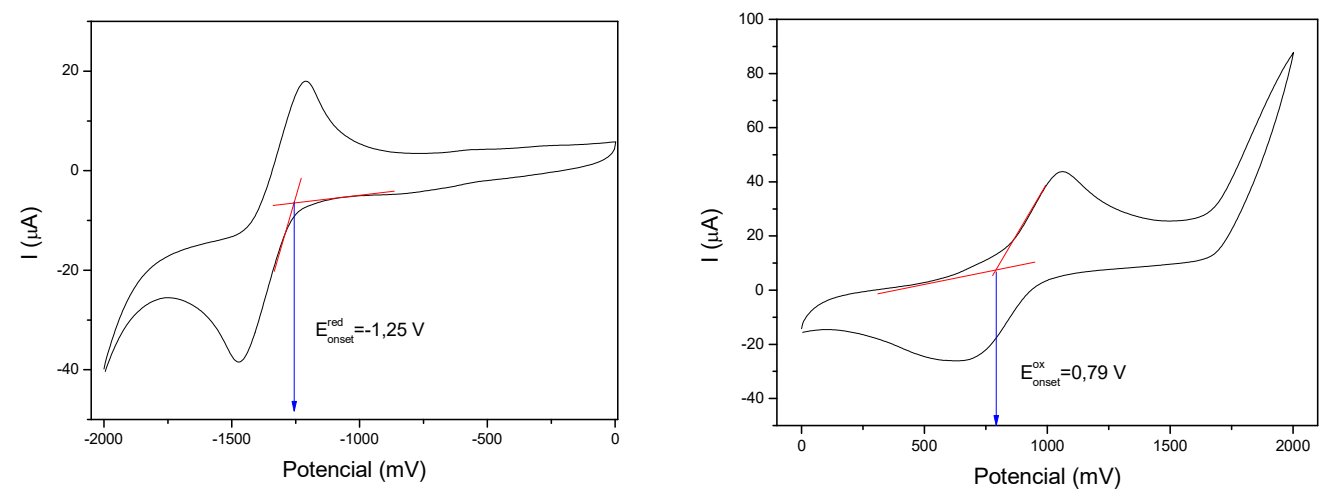

Figura 33: Voltamograma cíclico do composto 50.

Tabela 8: Dados eletroquímicos de oxidação e redução dos compostos 45-50 e 54-59.

\begin{tabular}{cccccc}
\hline Compostos & $\mathrm{E}_{\text {onset }}^{\text {ox }}(\mathrm{V})$ & $\mathrm{E}_{\text {onset }}^{\text {red }}(\mathrm{V})$ & $\mathrm{HOMO}(\mathrm{eV})$ & $\mathrm{LUMO}(\mathrm{eV})$ & $E_{\text {gap }}(\mathrm{eV})$ \\
\hline $\mathbf{4 5}$ & 1,54 & $-1,34$ & $-5,90$ & $-3,01$ & 2,89 \\
$\mathbf{4 6}$ & 1,52 & $-1,39$ & $-5,88$ & $-2,97$ & 2,91 \\
$\mathbf{4 7}$ & 1,37 & $-1,40$ & $-6,08$ & $-2,96$ & 3,12 \\
$\mathbf{4 8}$ & 1,35 & $-1,39$ & $-5,71$ & $-2,96$ & 2,75 \\
$\mathbf{4 9}$ & 0,65 & $-1,42$ & $-5,01$ & $-2,93$ & 2,08 \\
$\mathbf{5 0}$ & 0,79 & $-1,25$ & $-5,15$ & $-3,10$ & 2,05 \\
$\mathbf{5 4}$ & 1,41 & $-1,33$ & $-5,77$ & $-3,02$ & 2,75 \\
$\mathbf{5 5}$ & 1,56 & $-1,35$ & $-5,92$ & $-3,01$ & 2,91 \\
$\mathbf{5 6}$ & 1,65 & $-1,35$ & $-6,01$ & $-3,01$ & 3,00 \\
$\mathbf{5 7}$ & 1,42 & $-1,38$ & $-5,78$ & $-2,98$ & 2,80 \\
$\mathbf{5 8}$ & 0,44 & $-1,46$ & $-4,80$ & $-2,90$ & 1,90 \\
$\mathbf{5 9}$ & 0,88 & $-1,20$ & $-5,24$ & $-3,16$ & 2,08 \\
\hline
\end{tabular}

Os espectros de absorção dos compostos 45-50, 54 e 55 foram registrados em diferentes solventes e são apresentados na Figura 34. Além disso, os comprimentos de onda máximos de absorção, os coeficientes de absortividade molar e os valores de band gap óptico estão resumidos na Tabela 9. Todos os compostos apresentam intensas bandas de absorção localizadas entre 375 e 493 $\mathrm{nm}$, com valores de $\varepsilon$ na ordem de $10^{3} \mathrm{~L} \mathrm{~mol}^{-1} \mathrm{~cm}^{-1}$, relacionadas a transições $\pi$ $\pi^{*}$. Os espectros de absorção desses compostos apresentam efeito solvatocrômico no estado fundamental muito pequeno ( $\Delta \lambda_{\text {abs }}$ entre 2 e $6 \mathrm{~nm}$ ), o que indica transferência de carga quase nula para os compostos nesse estado. Uma exceção foi observada para o composto 50 , que apresentou uma variação de $18 \mathrm{~nm}$ no máximo de absorção e um valor de $\varepsilon$ de $4 \times 10^{2} \mathrm{~L} \mathrm{~mol}^{-1} \mathrm{~cm}^{-1}$. Acreditase que o comportamento observado se deve à presença do grupo altamente doador fenoxazina, o que gera uma maior deslocalização de elétrons entre a porção doadora e aceptora no estado fundamental. Cabe ressaltar que esse efeito também foi observado para o derivado não arilóxi-substituído 59 , que possui grupos fenoxazina ligados ao anel BTD. Em relação aos band gaps ópticos, 
valores entre 2,13 e 2,92 eV foram determinados. Sendo valores adequados para a construção de dispositivos OLED ${ }^{6}$.
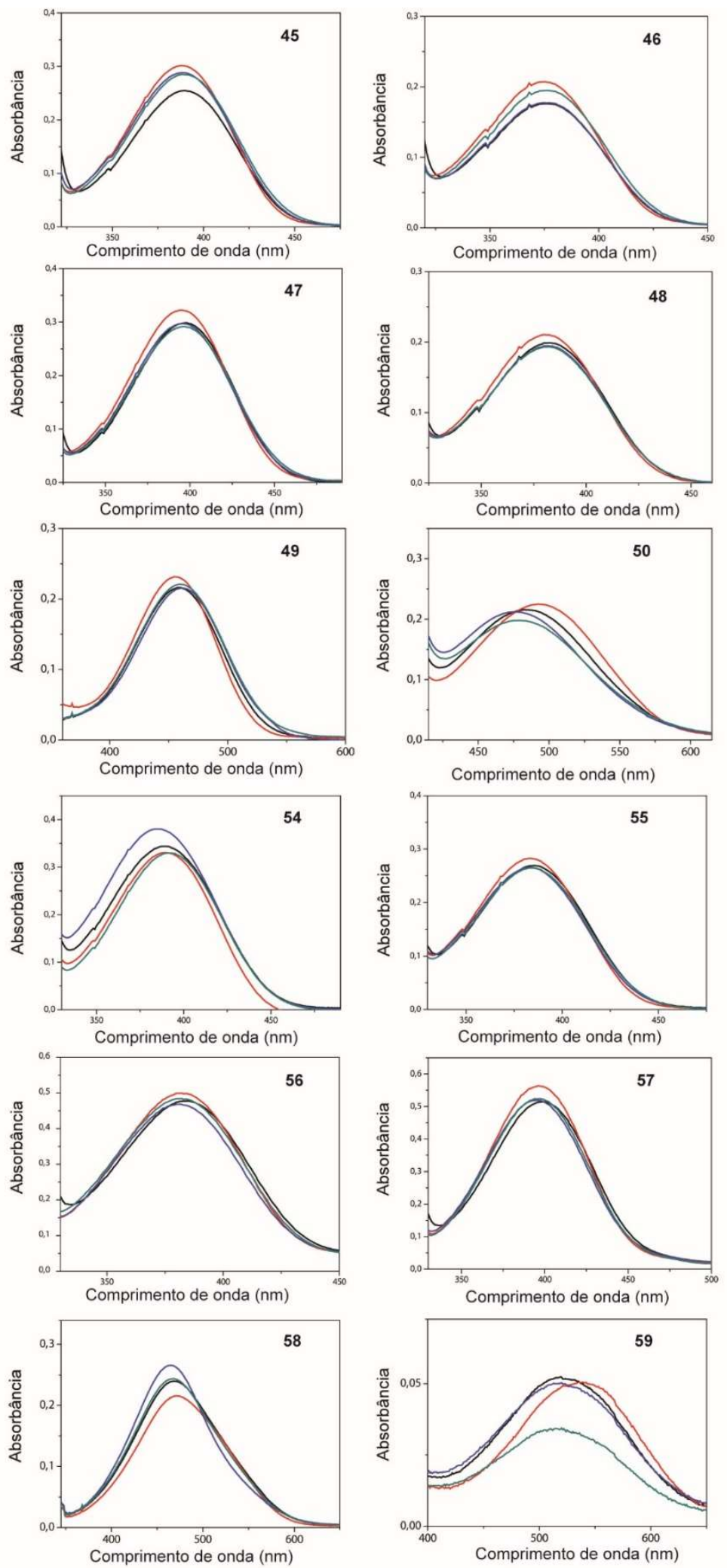

Figura 34: Espectros UV-Vis dos derivados de BTD arilóxi-substituídos. Tolueno (-), ciclohexano (-), diclorometano (-) e isopropanol (-). 
A partir dos dados relevantes compilados dos espectros de UV-Vis (Tabela 9), percebe-se que as propriedades relacionadas ao espectro de absorção apresentam dependência com o padrão de substituição do derivado de BTD. Em geral, derivados com arquitetura Ar-BTD-OAr ou Ar-BTD-ONaft possuem máximos de absorção semelhantes a derivados do tipo Ar-BTD-Ar. Comparando-se os derivados de BTD fenóxi-substituídos com seus análogos diarilados, os primeiros apresentaram absortividade molar ligeiramente menor ( $47<57$ e $45<56)$. Além disso, para ambas arquiteturas, a presença do grupo doador metoxila na arila parece causar um leve deslocamento batocrômico. Outro efeito observado foi um deslocamento para o azul do máximo de absorção dos compostos substituídos com metila ou fenila na posição 2 da arila (compostos 46 e 48). Isso pode ser interpretado como uma diminuição da conjugação do grupo arila com o anel BTD causada pela torção imposta pelos substituintes volumosos. Comparando-se $49 \mathrm{e}$ 50 com derivados de arquitetura Ar-BTD-OAr ou Ar-BTD-ONaft, percebe-se que a substituição de uma arila por doadores nitrogenados fortes, como a fenoxazina e a iminodibenzila, gera um forte deslocamento para o vermelho. Um deslocamento ainda mais acentuado para o vermelho é observado quando o grupo fenóxido é substituído por uma segunda unidade do doador nitrogenado (58 versus 49 e 59 versus 50). A presença desses heterociclos nitrogenados também causou um efeito significativo nos valores de band gap óptico, uma vez que para os compostos 49 e $\mathbf{5 0}$ houve uma diminuição considerável, e em 58 e 59 esse efeito foi ainda mais acentuado.

Tabela 9: Dados do máximo de absorção ( $\left.\lambda_{\text {abs }}\right)$, absortividade molar $(\varepsilon)$ e band gap óptico (em eV) dos compostos estudados.

\begin{tabular}{|c|c|c|c|c|c|c|}
\hline \multirow{2}{*}{ Composto } & \multicolumn{4}{|c|}{$\lambda_{\text {abs }}(\mathrm{nm})$} & \multirow{2}{*}{$\begin{array}{c}\log \varepsilon(\varepsilon)^{\mathrm{a}} \\
\mathrm{L} \mathrm{mol}^{-1} \mathrm{~cm}^{-1}\end{array}$} & \multirow{2}{*}{$E_{g a p}^{o p t, b}$} \\
\hline & $\mathrm{PhMe}$ & Ciclohexano & $\mathrm{CH}_{2} \mathrm{Cl}_{2}$ & iPrOH & & \\
\hline 45 & 390 & 388 & 388 & 388 & $3,76(5706)$ & 2,82 \\
\hline 46 & 375 & 377 & 375 & 376 & $3,59(3870)$ & 2,92 \\
\hline 47 & 398 & 395 & 396 & 397 & $3,75(5612)$ & 2,76 \\
\hline 48 & 383 & 380 & 382 & 380 & 3,59 (3871) & 2,88 \\
\hline 49 & 460 & 455 & 461 & 460 & $3,64(4332)$ & 2,38 \\
\hline 50 & 483 & 493 & 475 & 479 & $2,60(401)$ & 2,13 \\
\hline 54 & 389 & 389 & 384 & 391 & $3,82(6651)$ & 2,80 \\
\hline 55 & 385 & 383 & 383 & 385 & $3,72(5256)$ & 2,84 \\
\hline 56 & 385 & 382 & 381 & 382 & 3,97 (9249) & 2,83 \\
\hline 57 & 399 & 396 & 395 & 397 & $3,94(8762)$ & 2,73 \\
\hline 58 & 469 & 470 & 465 & 469 & 3,69 (4933) & 2,12 \\
\hline 59 & 519 & 539 & 520 & 520 & $2,89(786)$ & 1,96 \\
\hline
\end{tabular}


Com relação aos dados dos compostos no estado excitado, todos os derivados de BTD fenóxi- ou naftóxi-substituídos apresentaram emissão de fluorescência (Figura 35). Dependendo do padrão de substituição do derivado, foram observadas emissões na região do azul, verde, amarelo e vermelho, uma vez que os máximos de emissão variaram entre 468 e 632 nm (Tabela 10). Em relação ao efeito solvatocrômico, de modo geral, observou-se a mesma tendência que foi observada para o composto 43 , onde o aumento da polaridade do solvente foi acompanhado de deslocamento para o vermelho. Isso sugere o mecanismo de transferência de carga, com os solventes mais polares estabilizando mais significativamente o estado excitado. Outra propriedade que corrobora a estabilidade dos derivados de BTD fenóxi- e naftóxi-substituídos no estado excitado é o deslocamento de Stokes (Tabela 11), que para esses compostos varia entre 90 e $158 \mathrm{~nm}$.

Tabela 10: Comprimento de onda máximo $(\lambda$ em $)$ para emissão dos novos derivados de BTD em diferentes solventes.

\begin{tabular}{ccccccccccccc}
\hline \multirow{2}{*}{ Solvente } & \multicolumn{10}{c}{$\lambda_{\text {em }}(\mathrm{nm})$} \\
\cline { 2 - 12 } & $\mathbf{4 5}$ & $\mathbf{4 6}$ & $\mathbf{4 7}$ & $\mathbf{4 8}$ & $\mathbf{4 9}$ & $\mathbf{5 0}$ & $\mathbf{5 4}$ & $\mathbf{5 5}$ & $\mathbf{5 6}$ & $\mathbf{5 7}$ & $\mathbf{5 8}$ & $\mathbf{5 9}$ \\
\hline PhMe & 502 & 484 & 496 & 497 & 594 & - & 512 & 497 & 479 & 510 & 650 & - \\
Ciclohexano & 490 & 468 & 485 & 485 & 574 & 632 & 502 & 486 & 470 & 497 & 630 & - \\
$\mathrm{CH}_{2} \mathrm{Cl}_{2}$ & 514 & 511 & 510 & 509 & 619 & - & 535 & 509 & 492 & 524 & 639 & - \\
$i \mathrm{PrOH}$ & 518 & 489 & 510 & 507 & 614 & - & 546 & 519 & 494 & 529 & 641 & - \\
\hline
\end{tabular}

Tabela 11: Deslocamentos de Stokes $\Delta \lambda$ st dos novos derivados de BTD em diferentes solventes.

\begin{tabular}{ccccccccccccc}
\hline \multirow{2}{*}{ Solvente } & \multicolumn{10}{c}{$\Delta \lambda \mathrm{st}(\mathrm{nm})$} \\
\cline { 2 - 13 } & $\mathbf{4 5}$ & $\mathbf{4 6}$ & $\mathbf{4 7}$ & $\mathbf{4 8}$ & $\mathbf{4 9}$ & $\mathbf{5 0}$ & $\mathbf{5 4}$ & $\mathbf{5 5}$ & $\mathbf{5 6}$ & $\mathbf{5 7}$ & $\mathbf{5 8}$ & $\mathbf{5 9}$ \\
\hline PhMe & 112 & 109 & 98 & 114 & 119 & - & 123 & 112 & 94 & 111 & 181 & - \\
Ciclohexano & 101 & 91 & 90 & 105 & 134 & 139 & 113 & 103 & 88 & 101 & 160 & - \\
$\mathrm{CH}_{2} \mathrm{Cl}_{2}$ & 126 & 136 & 114 & 127 & 158 & - & 151 & 126 & 111 & 129 & 174 & - \\
$\quad \mathrm{PrOH}$ & 130 & 113 & 113 & 127 & 154 & - & 155 & 134 & 112 & 132 & 172 & - \\
\hline
\end{tabular}



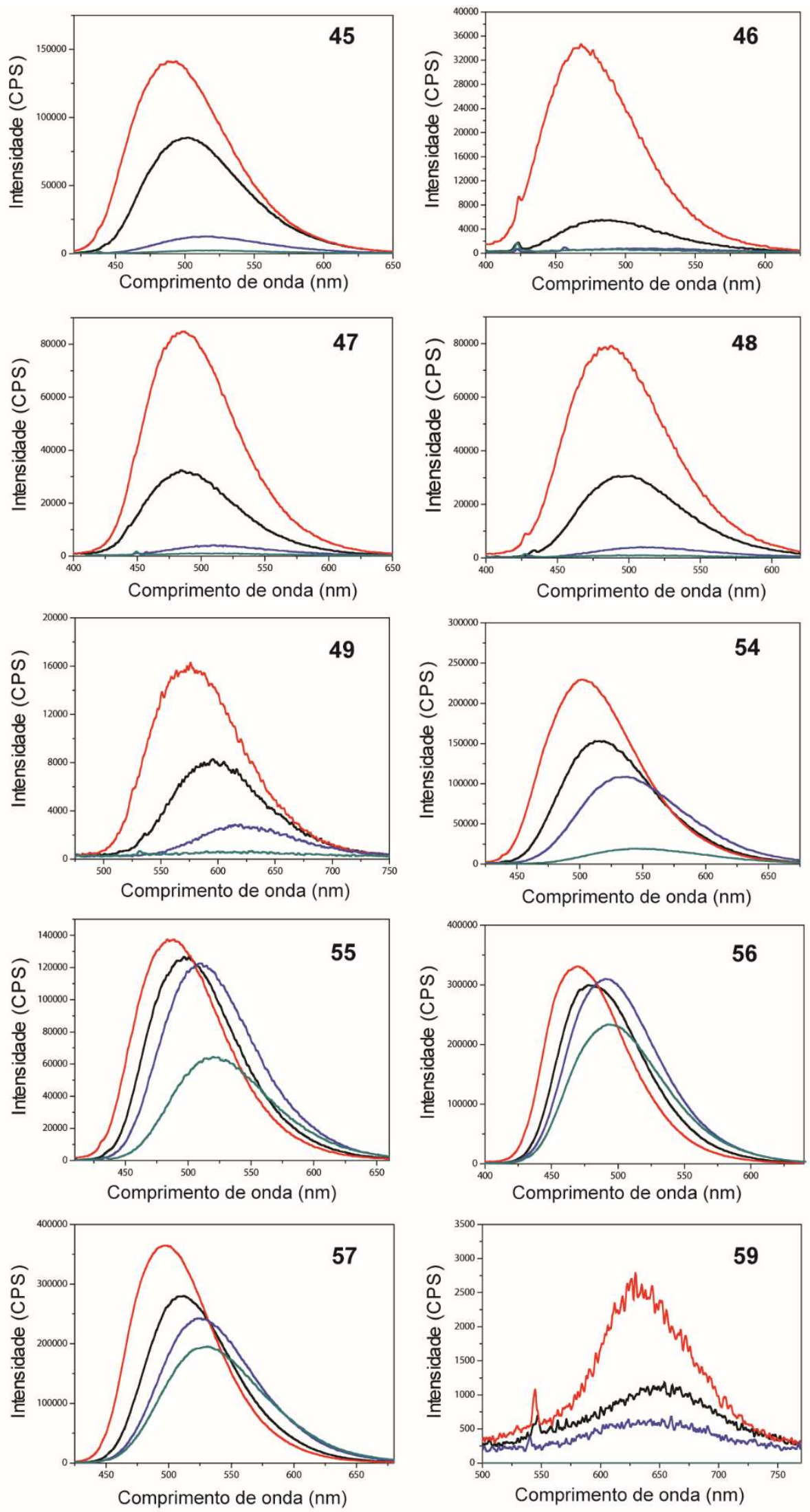

Figura 35: Espectros de fluorescência dos novos derivados de BTD. Tolueno (-), ciclohexano (-), diclorometano $(-)$ e isopropanol $(-)$. 
O rendimento quântico de fluorescência em solução $\left(\phi_{\text {solução }}\right)$ foi determinado em ciclohexano para os compostos 45-49 e 54-58 (Tabela 12). Para os derivados de BTD arilóxi-substituídos, valores de rendimento quântico de fluorescência em solução variaram entre 0,27 e 0,74. Esses valores são mais elevados que os valores já descritos na literatura para derivados de BTD tiofenóxisubstituídos, sintetizados através de acoplamentos C-S, ( $\phi_{\text {solução }}$ entre 0,02 e $0,37)^{9}$. Além disso, observa-se semelhança entre os valores obtidos para derivados do tipo Ar-BTD-OAr e os valores descritos na literatura para derivados de BTD diarilados $\left(\phi_{\text {solução }} \text { entre } 0,17 \text { e } 0,80\right)^{5}$. Pode ser ressaltado, ainda, que os compostos diarilados 56 e 57 apresentaram $\phi_{\text {solução }}$ tão elevados quanto os melhores compostos diarilados previamente descritos ${ }^{5}$.

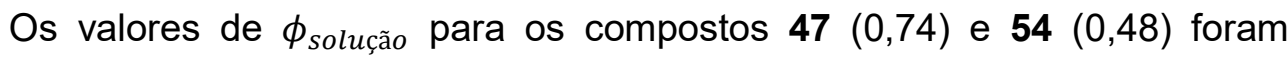
menores do que o seu análogo diarilado $57(0,84)$. A mesma tendência foi observada comparando-se o composto $45(0,65)$ com o análogo diarilado 56 $(0,71)$. Esses resultados indicam fluorescência mais intensa em solução para compostos do tipo Ar-BTD-Ar que para derivados de BTD arilóxi-substituídos. A substituição do grupo arila por grupos nitrogenados (fenoxazina ou iminodibenzila) em compostos de arquitetura ArO-BTD diminuiu significativamente a desativação radiativa do estado excitado desses compostos, uma vez que 49 apresentou $\phi_{\text {solução }}$ de 0,27 e o composto 50 não apresentou fluorescência. Outra relação interessante entre a estrutura do fluoróforo e a intensidade de emissão pode ser observada comparando-se os compostos 47 e 46 ( $\phi_{\text {solução de }}$ 0,74 e 0,60, respectivamente) com seus análogos naftóxi-substituídos 54 e $\quad \mathbf{5 5}$

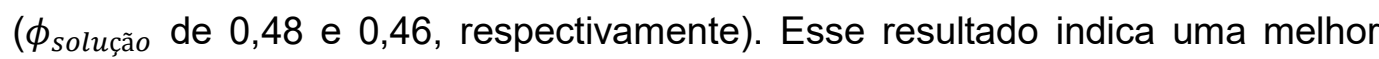
performance emissiva em solução de derivados de BTD fenóxi-substituídos que de seus análogos naftóxi-substituídos. No que diz respeito ao padrão de substituição da arila, não foi observada uma relação clara entre a natureza e a posição dos grupos substituintes do anel (OMe, $\mathrm{Me}, \mathrm{Ph})$ e o rendimento quântico de florescência em solução.

Tabela 12: Rendimento quântico de fluorescência em solução ${ }^{80-82}$ em ciclohexano.

\begin{tabular}{ccccccccccc}
\hline Composto & $\mathbf{4 5}^{\mathrm{a}}$ & $\mathbf{4 6}^{\mathrm{a}}$ & $\mathbf{4 7}^{\mathrm{a}}$ & $\mathbf{4 8}^{\mathrm{a}}$ & $\mathbf{4 9}^{\mathrm{b}}$ & $\mathbf{5 4}^{\mathrm{a}}$ & $\mathbf{5 5}^{\mathrm{a}}$ & $\mathbf{5 6}^{\mathrm{a}}$ & $\mathbf{5 7}^{\mathrm{a}}$ & $\mathbf{5 8}^{\mathrm{b}}$ \\
$\phi_{\text {solução }}$ & 0,65 & 0,60 & 0,74 & 0,71 & 0,27 & 0,48 & 0,46 & 0,71 & 0,84 & 0,02
\end{tabular}

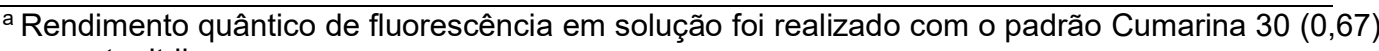
em acetonitrila.

${ }^{\mathrm{b}}$ Rendimento quântico de fluorescência em solução foi realizado com o padrão Cumarina $153(0,53)$ em etanol. 
Com o objetivo de avaliar a característica TADF dos derivados de BTD, três técnicas foram aliadas: (i) DFT, que dá informações acerca da separação dos orbitais HOMO e LUMO em diferentes porções do fluoróforos; (ii) TD-DFT, através do qual pode-se estimar a diferença energética entre os estados $S_{1}$ e $T_{1}$; e (iii) emissão de fluorescência resolvida no tempo, com a qual pode-se obter os respectivos tempos de vida das espécies presentes no estado excitado.

Os cálculos de DFT e TD-DFT foram realizados através de colaboração com - Dr. Luis Maqueira. Em relação ao DFT, as estruturas moleculares foram otimizadas no vácuo ou considerando ciclohexano como solvente. Os cálculos foram realizados por o método da Teoria Funcional da Densidade (DFT) com o funcional B3LYP e a base $6-31 \mathrm{G}^{* *}$, usando os pacotes de programas Gaussian $03^{83}$ e ORCA 3.0. ${ }^{84} \mathrm{O}$ mesmo funcional e base foram usados para o cálculo das energias do estado singleto $\left(S_{1}\right)$ e tripleto $\left(T_{1}\right)$ das moléculas no vácuo em experimentos de TD-DFT.

Considerando a arquitetura D-A-D dos fluoróforos, o esperado caso os compostos tenham característica TADF é uma alta separação dos orbitais HOMO e LUMO, com alto coeficiente orbitalar HOMO nas porções doadoras e alto coeficiente orbitalar LUMO na porção aceptora (anel BTD). A distribuição orbitalar obtida é mostrada na Figura 36. Para todos os derivados de BTD arilóxisubstituídos, o orbital LUMO está concentrado no anel BTD. Em contraste, o fluoróforo diarilado 56 apresentou pequeno coeficiente orbitalar LUMO também nas arilas. Nos compostos do tipo Ar-BTD-OAr, alto coeficiente orbitalar HOMO encontra-se nas porções doadoras fenóxi ou naftóxi. No entanto, observa-se também distribuição desse orbital no anel de seis membros da BTD. Cabe ressaltar que no quesito separação orbitalar HOMO-LUMO, os compostos arilóxisubstituídos apresentaram melhores resultados que os compostos diarilados, já que esses exibem alto coeficiente de HOMO também na porção aceptora. 
HOMO

45

46

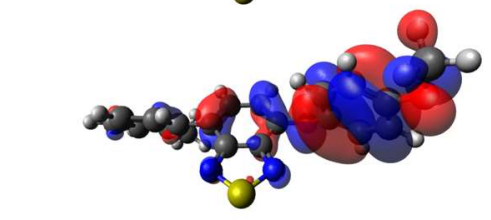

47

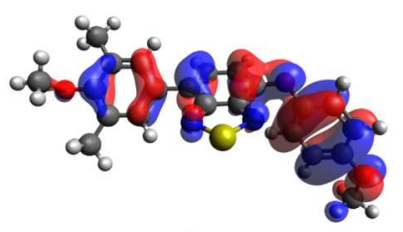

48

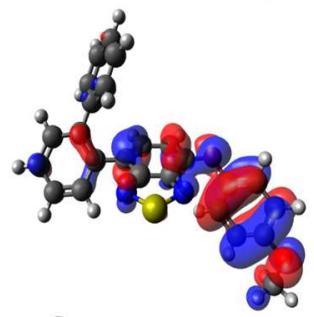

49

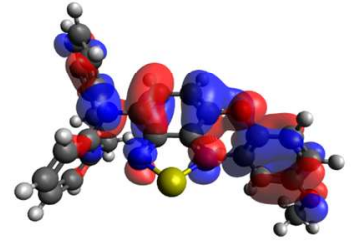

54

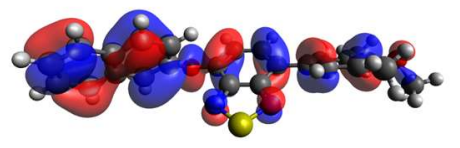

55

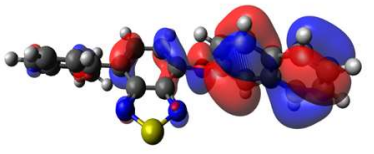

56

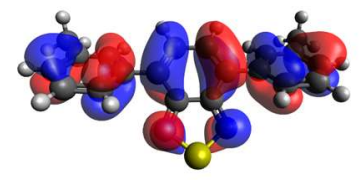

57

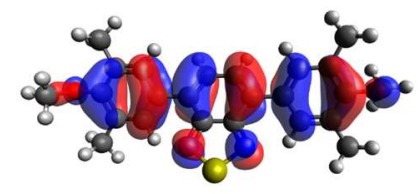

58

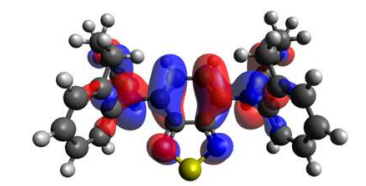

LUMO
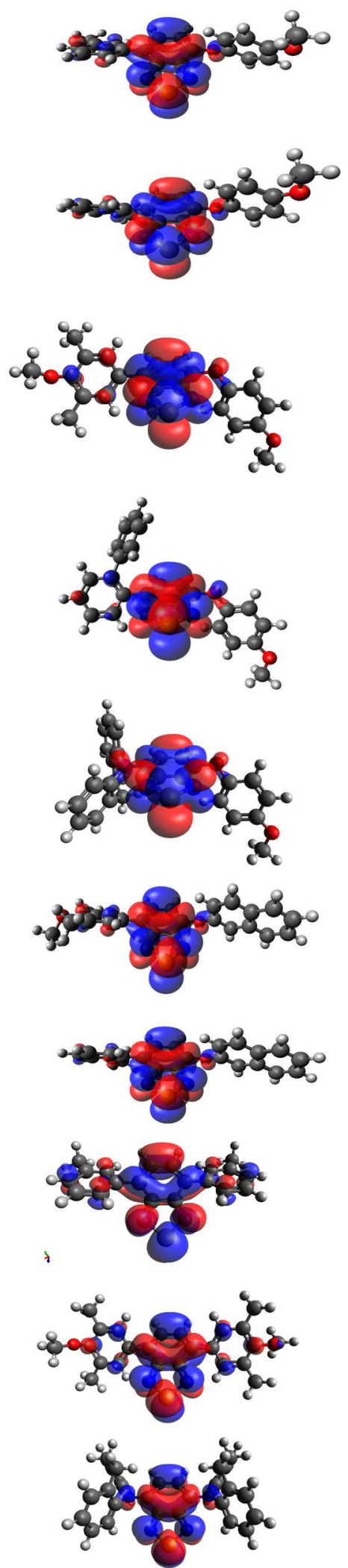

Figura 36: Distribuição eletrônica do HOMO e LUMO dos novos derivados de BTD através de cálculos teóricos de DFT. 
A diferença energética entre os estados $\mathrm{S}_{1}$ e $\mathrm{T}_{1}\left(\Delta \mathrm{E}_{\mathrm{ST}}\right)$ foi estimada através de TD-DFT (time-dependent density functional theory) e os resultados são mostrados na Tabela 13. Um baixo valor de $\Delta \mathrm{E}_{\mathrm{ST}}$ possibilita cruzamento reverso intersistema e, consequentemente, característica TADF. Para compostos TADFs descritos na literatura, essa diferença tem variado entre 0,008 e 0,32 eV. , $^{63,64}$ Para os compostos estudados, os valores calculados variaram entre 0,64 e 1,03 eV, indicando um valor inadequado de $\Delta \mathrm{E}_{\text {sт }}$ para ocorrência de cruzamento reverso intersistema. Além disso, a tendência de $\Delta \mathrm{E}_{\text {St }}$ para os compostos avaliados foi $\mathrm{Ar}$ BTD-OAr < Ar-BTD-ONaft < Ar-BTD-Ar.

Tabela 13: Estimativas da diferença energética (eV) entre os estados $\mathrm{S}_{1}$ e $\mathrm{T}_{1}$ por TDDFT.

\begin{tabular}{ccccccccccc}
\hline Compostos & $\mathbf{4 5}$ & $\mathbf{4 6}$ & $\mathbf{4 7}$ & $\mathbf{4 8}$ & $\mathbf{4 9}$ & $\mathbf{5 4}$ & $\mathbf{5 5}$ & $\mathbf{5 6}$ & $\mathbf{5 7}$ & $\mathbf{5 8}$ \\
$\Delta$ EsT & 0,68 & 0,64 & 0,69 & 0,68 & - & 0,75 & 0,78 & 1,03 & 0,95 & - \\
\hline
\end{tabular}

Em relação à fluorescência resolvida no tempo, quando o fluoróforo apresenta características de TADF, na ausência de oxigênio, são observados decaimentos referentes a duas espécies, um decaimento mais rápido com tempo de vida na ordem de nanossegundos, característico de fluorescência; e um decaimento mais lento, com tempo de vida na ordem de microssegundos ou até milissegundos, atribuído ao cruzamento intersistema reverso, característico de materiais que apresentam TADF. ${ }^{63}$

$\mathrm{Na}$ Tabela 14, são mostrados os dados do tempo de decaimento de fluorescência $(\tau)$ em ciclohexano e em tolueno para os compostos 45-49 e 54-58, além dos valores de $\chi^{2}$, que fornece a informação sobre a qualidade do ajuste exponencial, onde valores entre 0,8 e 1,2 são aceitáveis. Na Figura 37 é mostrado o comportamento de cada composto em relação ao tempo de decaimento de fluorescência. A partir dos resultados obtidos, observa-se que os compostos testados apresentam um único decaimento de fluorescência, na escala de nanossegundos (2,21-23,96 ns), característico de transições do tipo $S_{1} \rightarrow S_{0}$. Além disso, não se observou uma clara tendência de aumento ou diminuição dos valores de $\tau$ ao variar-se o solvente.

Zhang e colaboradores (2012) concluíram que a proporção do componente de decaimento lento diminui com um aumento no $\Delta \mathrm{E}_{\mathrm{ST}}$ dos compostos. Esse dado está em concordância com o observado para os compostos testados, que apresentaram valores altos de $\Delta \mathrm{E}_{\mathrm{ST}} \mathrm{e}$, por consequência, não possuem a componente lenta de decaimento radiativo, típica de materiais TADF. 
Componentes lentas de decaimentos radiativos de compostos descritos na literatura que possuem cruzamento reverso intersistema tem variado entre 29-270 $\mu \mathrm{s} .^{6,63,65}$

Tabela 14: Dados da fluorescência resolvida no tempo, onde $\tau$ é o tempo de decaimento de fluorescência.

\begin{tabular}{ccccccccccc}
\hline Composto & $\mathbf{4 5}$ & $\mathbf{4 6}$ & $\mathbf{4 7}$ & $\mathbf{4 8}$ & $\mathbf{4 9}$ & $\mathbf{5 4}$ & $\mathbf{5 5}$ & $\mathbf{5 6}$ & $\mathbf{5 7}$ & $\mathbf{5 8}$ \\
\hline$\tau_{\text {ciclohexano }}$ & 13,02 & 9,72 & 13,83 & 14,99 & 23,96 & 9,40 & 8,16 & 6,77 & 7,47 & 5,47 \\
$\chi^{2}$ & 1,17 & 1,03 & 1,13 & 1,08 & 1,14 & 1,18 & 1,14 & 1,08 & 1,09 & 1,14 \\
$\tau_{\text {tolueno }}$ & 9,37 & 2,21 & 13,58 & 7,80 & 23,04 & 13,20 & 10,42 & 7,22 & 8,18 & 2,49 \\
$\chi^{2}$ & 1,15 & 1,19 & 1,14 & 1,09 & 1,18 & 1,08 & 1,04 & 1,12 & 1,12 & 1,18 \\
\hline
\end{tabular}

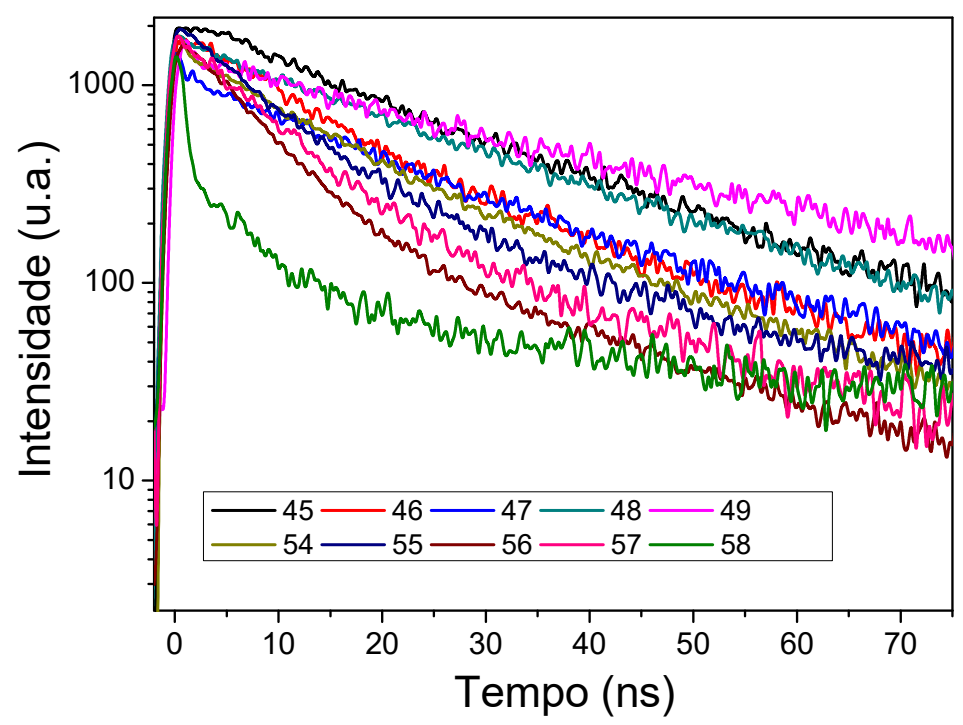

Figura 37: Curvas de decaimento de fluorescência resolvida no tempo dos compostos em ciclohexano.

Com o propósito de complementar as caracterizações fotofísicas e, considerando a necessidade de avaliação dos fluoróforos no estado sólido para aplicação em dispositivos eletroluminescentes, foram determinados os rendimentos quânticos de fluorescência no estado sólido ( $\phi_{\text {sólido }}$ ) para os compostos 45-49 e 54-58 (Tabela 15). Para os derivados de BTD arilóxisubstituídos, valores entre 0,27 e 0,83 foram observados. Além disso, de uma forma geral, os valores de rendimentos quânticos no estado sólido foram menores que os observados em solução, tanto para compostos do tipo Ar-BTD-OAr, quanto compostos com estrutura Ar-BTD-Ar. O efeito de supressão de fluorescência causada pela agregação é um fenômeno muito conhecido em compostos aromáticos, principalmente quando há a formação de intensas interações intermoleculares do tipo $\pi$-stacking, onde o estado excitado dos agregados 
formados por essas interações geralmente decai para o estado fundamental via processos não radiativos. ${ }^{85,86} \mathrm{Um}$ comportamento diferente foi observado para os compostos 55 e 46, visto que os rendimentos quânticos no estado sólido foram maiores que em solução. Para 55 , o valor passou de 0,46 , para 0,56 , enquanto que para 46, o valor passou de 0,60 para 0,83 .

Quando um material apresenta fluorescência mais intensa na forma agregada que em solução, diz-se que ele possui Emissão Induzida por Agregação (EIA). Em termos gerais, para que o material tenha essa propriedade, alguns canais de desativação não radiativa atuantes em solução devem ser suprimidos ou desfavorecidos. ${ }^{86}$ Esses canais estão relacionados com a vibração e rotação intramoleculares. Associado a isso, compostos ElAgênicos ${ }^{86}$ apresentam também estrutura não-planar, o que dificulta as interações intermoleculares do tipo $\pi$ stacking, que levariam à supressão de fluorescência. Ao comparar as estruturas dos compostos 55 e 46, percebe-se semelhanças estruturais. Ambos possuem um grupo 2-toluila e um grupo arilóxi ligados ao anel BTD. Pode ser proposto que a metila na posição 2 atue evitando a planaridade do composto e, consequentemente, evitando $\pi$-stacking no estado sólido. Esse efeito, em conjunto com a restrição de rotação intramolecular do grupo arilóxi imposta pelo

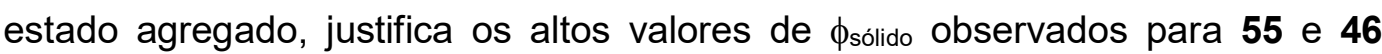
(Figura 38). Para o composto 2-fenil-substituído 48 observou-se decréscimo no rendimento quântico no estado sólido. Esse resultado pode estar associado à capacidade do substituinte fenila realizar interações intermoleculares do tipo $\pi$ stacking. Outra relação importante entre a estrutura e a intensidade de emissão pode ser obtida comparando-se os compostos 47 e 57, que possuem o mesmo anel arila. Para o derivado de BTD fenóxi-substituído um alto valor de $\phi_{\text {sólido }}$ foi observado $(0,60)$, enquanto que para o derivado diarilado o valor foi de 0,24 . Essa comparação reforça a importância do grupo arilóxi e da presença de grupos volumosos na porção arila para que o composto seja altamente emissivo no estado sólido.

Tabela 15: Rendimento quântico de fluorescência no estado sólido. 87,88

\begin{tabular}{ccccccccccc}
\hline Compostos & $\mathbf{4 5}$ & $\mathbf{4 6}$ & $\mathbf{4 7}$ & $\mathbf{4 8}$ & $\mathbf{4 9}$ & $\mathbf{5 4}$ & $\mathbf{5 5}$ & $\mathbf{5 6}$ & $\mathbf{5 7}$ & $\mathbf{5 8}$ \\
$\phi_{\text {sólido }}$ & 0,28 & 0,83 & 0,60 & 0,27 & - & 0,30 & 0,56 & 0,27 & 0,24 & - \\
\hline
\end{tabular}

*Utilizando o padrão salicilato de sódio $(0,55)$. 


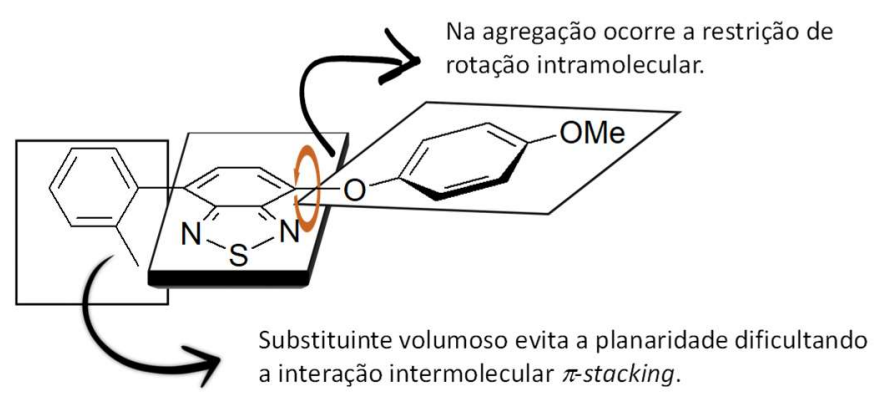

Figura 38: Requisitos estruturais propostos para derivados de BTD arilóxi-substituídos apresentarem EIA.

Para confirmar a propriedade de emissão induzida por agregação (EIA) dos derivados de BTD arilóxi-substituídos, determinou-se a intensidade de fluorescência dos compostos mais emissivos no estado sólido (46 e 47) em misturas acetona/água com frações crescentes do solvente aquoso (Figura 39). Esses dados foram comparados com a emissão dos compostos diarilados $57 \mathrm{e}$ 56, nas mesmas condições. Para os derivados de BTD arilóxi-substituídos, quando aconteceu a agregação (fração de água de aproximadamente $80 \%$ ) observou-se um aumento significativo na fluorescência, indicando que ambos são EIAgênicos. Por outro lado, para os compostos do tipo Ar-BTD-Ar, supressão de emissão de fluorescência foi observada com o aumento da proporção de água no solvente. Esses dados reforçam a importância do grupo arilóxi para que esses derivados sejam altamente emissivos na forma agregada.

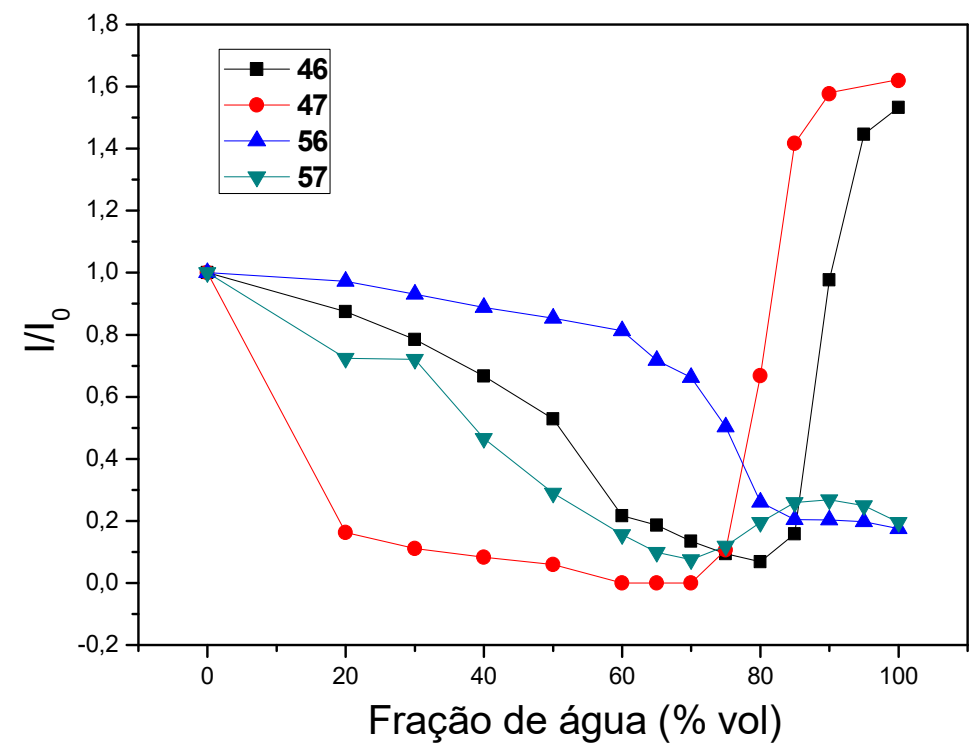

Figura 39: Variação da intensidade de fluorescência dos compostos 46, 47, 56 e 57 em diferentes frações de água. 


\section{5 . Conclusões}

Em resumo, a síntese de derivados de BTD arilóxi-substituídos foi descrita pela primeira vez. Os luminóforos sintetizados exibiram forte transferência de carga intramolecular (ICT) durante a fotoexcitação. O composto 43 , possuindo um grupo 4-metoxifenóxi e um grupo 4-metoxifenila ligados ao núcleo BTD, apresentou melhores propriedades fotofísicas que o derivado 4-fluorfenilsubstituído. Entre elas: (i) maior rendimento quântico de fluorescência em solução; (ii) transferência de carga intramolecular mais eficiente no estado excitado; e (iii) distribuição orbitalar mais apropriada para um eficiente ICT. Esses resultados indicaram que a arquitetura D-BTD-D é preferencial para estes compostos.

O OLED verde de três camadas construído com 43 como camada emissora operou usando menor densidade de corrente e levou a uma maior irradiância e estabilidade elétrica do que a observada para o dispositivo feito com o derivado de BTD 4-piridil-substituído (32). Estes resultados indicaram o potencial promissor de derivados BTD arilóxi-substituídos para aplicações eletroluminescentes.

Com base nos resultados obtidos na primeira parte do trabalho, foi realizada uma otimização estrutural mais abrangente onde 12 novos derivados foram sintetizados e caracterizados. Seis desses compostos com arquitetura Ar-BTDOAr, dois desses compostos com design NHet-BTD-OAr e outros quatro compostos com arquitetura Ar-BTD-Ar ou NHet-BTD-NHet, para fins comparativos

Os compostos arilóxi-substituídos apresentaram intensas bandas de absorção centradas entre 375 a $493 \mathrm{~nm}$, com valores de $\varepsilon$ na ordem de $10^{3} \mathrm{~L} \mathrm{~mol}^{-1} \mathrm{~cm}^{-1}$. Em relação aos band gaps ópticos, valores entre 2,13 e 2,92 eV foram observados. Já nos espectros de fluorescência os máximos de emissão variaram entre 468 e $632 \mathrm{~nm}$.

Para esses fluoróforos, altos valores de rendimento quântico de fluorescência em solução foram observados ( $\phi_{\text {solução }}$ entre 0,27 e 0,74 ). Resultados de DFT mostraram que o orbital LUMO está concentrado no anel BTD e alto coeficiente orbitalar HOMO encontra-se nas porções doadoras arilóxi. No quesito separação orbitalar HOMO-LUMO, os derivados de BTD arilóxisubstituídos apresentaram melhores resultados que os compostos diarilados e diaminados, já que esses exibem um maior grau de sobreposição entre os orbitais. 
A diferença energética entre os estados $S_{1}$ e $T_{1}\left(\Delta E_{S T}\right)$ foi estimada e infelizmente, os valores calculados variaram entre 0,64 e 1,03 eV, indicando um valor inadequado de $\Delta \mathrm{E}_{\mathrm{st}}$ para ocorrência de cruzamento reverso intersistema o que seria um dos requisitos dos compostos para apresentarem característica TADF. Outro requisito para se chegar a esse objetivo é a presença de dois decaimentos de fluorescência: um na ordem de ns e outro na ordem de $\mu$ s. Contudo, os compostos testados apresentaram um único decaimento de fluorescência, na escala de nanossegundos (2,21-23,96 ns), característico de compostos fluorescentes não TADFs. Em relação ao rendimento quântico de fluorescência no estado sólido, a maioria dos compostos apresentaram supressão de fluorescência. Entretanto, os compostos 46 e 55 apresentaram valores superiores que em solução. As justificativas para isso foram a não-planaridade induzida pela metila na posição dois da arila e também a restrição de rotação do grupo arilóxi no estado sólido. Os testes de emissão induzida por agregação desses compostos confirmaram a característica EIAgênica desses derivados de BTD arilóxi-substituídos.

Apesar do objetivo inicial de desenvolvimento de novos materiais TADFs não ter sido alcançado, o presente trabalho permitiu o desenvolvimento de uma nova classe de compostos puramente orgânicos altamente emissivos no estado sólido. Assim sendo, chegou-se na estrutura do composto líder 46, que apresentou alto valor de absortividade molar, boa separação entre HOMO e LUMO, band gap adequado para aplicação em OLEDs, emissão no azul, rendimento quântico de fluorescência de 0,83 no estado sólido e emissão induzida por agregação. 


\section{6 . Perspectivas}

- Avaliar as propriedades termogravimétricas do composto líder 46.

- Fabricar, através de colaboração, dispositivos OLEDs utilizando o composto líder 46 como camada emissora.

- Avaliar as propriedades de emissão induzida por agregação de todos os derivados de BTD arilóxi-substituídos sintetizados.

- Utilizar intermediários ArO-BTD-Br na síntese de novos luminóforos.

- Sintetizar derivados de BTD arilóxi-substituídos utilizando fenóis substituídos com grupos volumosos. 


\section{Procedimentos experimentais}

\subsection{Materiais e métodos}

Os reagentes para este trabalho foram adquiridos da Sigma-Aldrich Co ou da Oakwood Chemical Co e utilizados como recebidos. Os solventes utilizados foram obtidos de fontes comerciais (Vetec Química Fina Ltda., Sigma-Aldrich Co. e Hexis.Científica). Para as reações de Suzuki, tolueno e etanol, foram desaerados através de fluxo de nitrogênio. Para a aminação de Buchwald-Hartwig houve o tolueno foi seco sob $\mathrm{Na/Benzofenona} \mathrm{e} \mathrm{destilado} \mathrm{sob} \mathrm{atmosfera} \mathrm{de}$ nitrogênio.

Para identificação dos compostos sintetizados, os espectros de RMN ${ }^{1} \mathrm{H}$ e $\mathrm{RMN}{ }^{13} \mathrm{C}$ em solução foram obtidos em espectrômetro Bruker Avance III HD-400 $\mathrm{MHz}$ da Central Analítica do Departamento de Química da PUC-Rio. Os espectros de massas de alta resolução (ESI-(+) HRMS - Electron spray ionization highresolution mass spectrometric) foram obtidos em espectrômetro de massa Q-TOF (Micromass) da Waters (USA) do Laboratório de Catálise Molecular da UFRGS.

A difratometria de raios-X em monocristal foi realizada pelo Prof. Davi Back no Departamento de Química da UFSM através de um difratômetro Bruker D8 Venture Photon 100. As estruturas foram obtidas por métodos diretos utilizando o software SHELXS e os desenhos gráficos obtidos utilizando o software ORTEP3 para Windows.

Os espectros de absorção (UV-Vis) foram obtidos por meio de um espectrofotômetro Perkin-Elmer Lambda 35, utilizando velocidade de 1200 $\mathrm{nm} \cdot \mathrm{min}^{-1}$, spectral bandpass de $10 \mathrm{~nm}$ e cubetas de quartzo de caminho óptico de $1 \mathrm{~cm}$. Para obtenção de espectros de fotoluminescência, utilizou-se um fluorímetro da marca Horiba modelo FluoroMax 4. O scanning foi realizado em velocidade de $1500 \mathrm{~nm} \cdot \mathrm{min}^{-1}$ e uma cubeta de $1 \mathrm{~cm}$ de caminho óptico.

Os experimentos de rendimento quântico de fluorescência no estado sólido foram realizados em parceira com o professor do Instituto de Química da UFRGS, Fabiano Rodembusch. As medidas de Espectroscopia de Emissão de Fluorescência no estado sólido foram realizadas em espectrofluorímetro Shimadzu RF-5301PC utilizando suporte para sólidos. 
Os experimentos fluorescência resolvida no tempo foram realizados em colaboração com o Prof. Fabiano Rodembusch do Instituto de Química da UFRGS. Curvas de fluorescência resolvidas no tempo foram realizadas usando um espectrofotômetro EasyLife V (Optical Building Blocks). Todas as medições foram efetuadas à temperatura ambiente. As curvas de decaimento foram analisadas usando o software EasyLife $V(\mathrm{OBB})$. Um método de mínimos quadrados não lineares foi empregado para o ajuste do decaimento a uma soma de exponenciais. O valor de $\chi^{2}$ dos respectivos resíduos e a função de autocorrelação foram utilizados para determinar a qualidade do ajuste proposto.

Os experimentos de Voltametria Cíclica foram realizados em um potenciostato Ivium Compact Stat disponível no laboratório LEEA da PUC-Rio. Já os cálculos teóricos, foram executados por ORCA 3.0.3 ${ }^{84}$ e Gaussian03 ${ }^{83}$. As estruturas otimizadas foram obtidas por método de DFT utilizando o funcional B3LYP.

\subsection{Síntese dos intermediários ArO-BTD-Br (compostos 42 e 53)}

Em um frasco de Schlenk selado foi adicionado 4,7-dibromo-2,1,3benzotiadiazola 1 (1,00 mmol, $294 \mathrm{mg})$, 4-metoxifenol ou 2-naftol (2,00 mmol), $\mathrm{K}_{2} \mathrm{CO}_{3}(3,00 \mathrm{mmol}, 415 \mathrm{mg})$ e DMF desaerado $(6,5 \mathrm{~mL})$. E, então, sob atmosfera de nitrogênio a reação foi agitada a $100^{\circ} \mathrm{C}$ durante $24 \mathrm{~h}$. Após, esperou-se a mistura atingir a temperatura ambiente e foi diluída com $15 \mathrm{~mL}$ de água e extraída com acetato de etila $(3 \times 15 \mathrm{~mL})$. As frações orgânicas foram combinadas e foi adicionado $\mathrm{Na}_{2} \mathrm{SO}_{4}$ anidro, filtrou-se e a mistura foi concentrada sob pressão reduzida. A purificação do composto 42 se deu por meio da adição de aproximadamente $5 \mathrm{~mL}$ de metanol onde houve a precipitação de um subproduto, com a solução resultante foi utilizada a técnica de cromatografia em coluna com sílica gel, hexano/acetato de etila (100:1) foram empregados como fase móvel. Para o composto 53 foi aplicado somente cromatografia em coluna nas mesmas condições descritas acima. Os intermediários obtidos foram caracterizados por ponto de fusão e RMN ${ }^{1} \mathrm{H}$, RMN ${ }^{13} \mathrm{C}$ e HRMS.

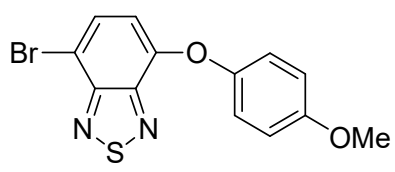

4-(4-metoxifenol)-7-

bromobenzo[c][1,2,5]tiadiazola (81): Sólido

branco, $51 \%$ de rendimento, ponto de fusão: 119$121^{\circ} \mathrm{C} . \mathrm{RMN}^{1} \mathrm{H}\left(400 \mathrm{MHz}, \mathrm{CDCl}_{3}\right) \delta$ (ppm) 7,66 (d, J $=8,1 \mathrm{~Hz}, 1 \mathrm{H}) ; 7,13(\mathrm{~d}, J=9,1 \mathrm{~Hz}, 2 \mathrm{H}) ; 6,96(\mathrm{~d}, J=$ 
9,1 Hz, 2H); 6,60 (d, J = 8,1 Hz, 1H); 3,84 (s, 3H). $\mathrm{RMN}{ }^{13} \mathrm{C}\left(101 \mathrm{MHz}, \mathrm{CDCl}_{3}\right) \delta$ (ppm) 157,1; 154,4; 150,$7 ; 148,1 ; 147,8 ; 132,2 ; 121,7 ; 115,2 ; 111,4$; 105,8; 55,7. HRMS (m/Z) para $\mathrm{C}_{13} \mathrm{H}_{10} \mathrm{BrN}_{2} \mathrm{O}_{2} \mathrm{~S}$ $(\mathrm{M}+\mathrm{H})^{+}$: calculado: 336,9646 ; encontrado: 336,9641 .

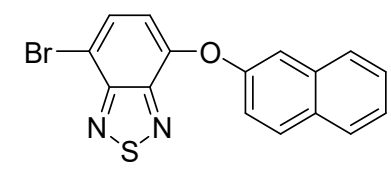

\section{4-bromo-7-(naftaleno-3-}

iloxi)benzo[c][1,2,5]tiadiazola (53); Sólido amarelo, $10 \%$ de rendimento; $\mathrm{RMN}{ }^{1} \mathrm{H}\left(400 \mathrm{MHz}, \mathrm{CDCl}_{3}\right) \delta$ (ppm) $7,95(\mathrm{~d}, J=8,9 \mathrm{~Hz}, 1 \mathrm{H}) ; 7,92-7,87(\mathrm{~m}, 1 \mathrm{H})$; $7,81-7,77(\mathrm{~m}, 1 \mathrm{H}) ; 7,73(\mathrm{~d}, J=8,1 \mathrm{~Hz}, 1 \mathrm{H}) ; 7,58-$ $7,50(\mathrm{~m}, 3 \mathrm{H}) ; 7,39$ (dd, $J=8,9,2,4 \mathrm{~Hz}, 1 \mathrm{H}) ; 6,82(\mathrm{~d}, J$ $=8,1 \mathrm{~Hz}, 1 \mathrm{H}) \cdot \mathrm{RMN}{ }^{13} \mathrm{C}\left(101 \mathrm{MHz}, \mathrm{CDCl}_{3}\right) \delta(\mathrm{ppm})$ 154,$5 ; 152,9 ; 149,5 ; 148,0 ; 134,2 ; 132,2 ; 131,0$; 130,$4 ; 127,9 ; 127,4 ; 126,9 ; 125,6 ; 120,0 ; 116,3$; 113,$5 ;$ 106,9. HRMS (m/Z) para $\mathrm{C}_{16} \mathrm{H}_{9} \mathrm{BrN}_{2} \mathrm{OS}$ $(\mathrm{M}+\mathrm{H})^{+}$: calculado: 356,9697 ; encontrado: 356,9711 .

\subsection{Síntese dos cromóforos fenóxi e naftóxi-substituídos via acoplamento de Suzuki $(43-48,54$ e 55)}

Em um frasco de Schlenk seco e selado foi adicionado $1(0,30 \mathrm{mmol}, 100 \mathrm{mg})$, $\mathrm{Pd}(\mathrm{OAc})_{2}\left(4,4 \times 10^{-3} \mathrm{mmol}, 1,0 \mathrm{mg}\right), \mathrm{PPh}_{3}\left(8,8 \times 10^{-3} \mathrm{mmol}, 2,3 \mathrm{mg}\right), \mathrm{K}_{2} \mathrm{CO}_{3}(0,60$ $\mathrm{mmol}, 83 \mathrm{mg})$, o ácido arilborônico apropriado $(0,36 \mathrm{mmol})$, etanol $(1 \mathrm{~mL})$ e tolueno $(1 \mathrm{~mL})$. A reação foi agitada a $75^{\circ} \mathrm{C}$ durante $4 \mathrm{~h}$ e foi deixada esfriar até a temperatura ambiente. A mistura foi filtrada, o sólido resultante no recipiente foi lavado com tolueno $(2 \times 5 \mathrm{~mL})$ e as frações foram unidas e a solução foi concentrada sob pressão reduzida. $O$ material bruto foi purificado por cromatografia em coluna utilizando sílica gel e aplicando hexano/acetato de etila (100:1) como fase móvel. Desse modo, foram sintetizados e caracterizados por ponto de fusão, RMN ${ }^{1} \mathrm{H}, \mathrm{RMN}{ }^{13} \mathrm{C}$ e HRMS os produtos 43-48, 54 e 55. 


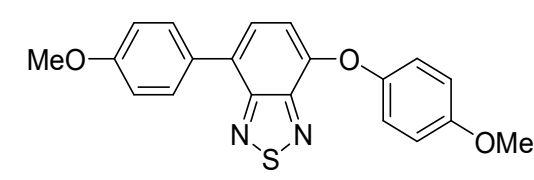

\section{4-(4-metoxifenoxi)-7-(4-metoxifenil)}

benzo[c][1,2,5]tiadiazola (43): sólido amarelo,

96\% de rendimento, ponto de fusão: 109-

$111^{\circ} \mathrm{C}$. RMN ${ }^{1} \mathrm{H}\left(400 \mathrm{MHz}, \mathrm{CDCl}_{3}\right) \delta(\mathrm{ppm}) 7,83$

(d, J = 8,9 Hz, 2H); 7,49 (d, J = 7,9 Hz,; 1H);

$7,17(\mathrm{~d}, \mathrm{~J}=9,1 \mathrm{~Hz}, 2 \mathrm{H}) ; 7,06(\mathrm{~d}, \mathrm{~J}=8,9 \mathrm{~Hz}, 2 \mathrm{H})$;

6,97 (d, J = 9,1 Hz, 2H); 6,79 (d, J = 7,9 Hz, 1H);

$3,88$ (s; $3 \mathrm{H}) ; 3,85$ (s, 3H), RMN ${ }^{13} \mathrm{C}(101 \mathrm{MHz}$,

$\left.\mathrm{CDCl}_{3}\right) \delta(\mathrm{ppm}) 159,4 ; 156,7 ; 154,8 ; 149,5$;

148,6; 148,5; 130,0; 129,8; 127,9; 127,5; 121,6;

115,$0 ; 114,0 ; 111,3 ; 55,6 ; 55,3$. HRMS (m/Z)

para $\mathrm{C}_{20} \mathrm{H}_{17} \mathrm{~N}_{2} \mathrm{O}_{3} \mathrm{~S}\left(\mathrm{M}+\mathrm{H}^{+}\right)$: calculado:

365,0960; encontrado: 365,0966.

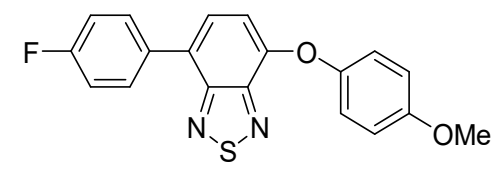

4-(4-metoxifenoxi)-7-(4-fluorfenil)

benzo[c][1,2,5]tiadiazola (44): sólido amarelo,

rendimento $77 \%$, ponto de fusão: $139-141^{\circ} \mathrm{C}$.

RMN ${ }^{1} \mathrm{H}\left(400 \mathrm{MHz}, \mathrm{CDCl}_{3}\right) \delta(\mathrm{ppm}) 7,85$ (dd, J

$=8,9 ; 5,4 \mathrm{~Hz}, 2 \mathrm{H}) ; 7,49$ (d, J = 7,9 Hz, 1H); 7,24-

7,15 (m, 4H); 6,97 (d, J = 9,1 Hz, 2H); 6,78 (d, $\mathrm{J}=7,9 \mathrm{~Hz}, 1 \mathrm{H}) ; 3,84$ (s, 3H). RMN ${ }^{13} \mathrm{C}(101$

$\left.\mathrm{MHz}, \mathrm{CDCl}_{3}\right) \delta$ (ppm) 164,0; 161,4; 156,9; 154,$8 ; 150,2 ; 148,6 ; 148,4 ; 133,3 ; 130,6 ; 130,6$; 128,$3 ; 127,1 ; 121,7 ; 115,7 ; 115,5 ; 115,1 ; 111,0$; 55,7. HRMS ( $\mathrm{m} / \mathrm{Z})$ para $\mathrm{C}_{19} \mathrm{H}_{14} \mathrm{FN}_{2} \mathrm{O}_{2} \mathrm{~S}\left(\mathrm{M}+\mathrm{H}^{+}\right)$: calculado: 353,0760; encontrado: 353,0776.

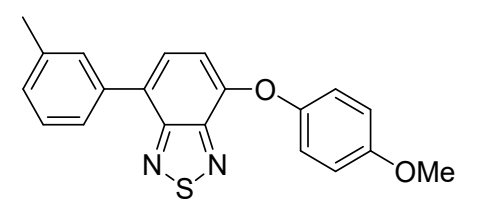

\section{4-(4-metoxifenoxi)-7-( $m$ -}

tolilbenzo[c][1,2,5]tiadiazola (45): sólido amarelo, ponto de fusão: $97-100{ }^{\circ} \mathrm{C}$, rendimento $94 \%$. RMN ${ }^{1} \mathrm{H}\left(400 \mathrm{MHz}, \mathrm{CDCl}_{3}\right) \delta$ (ppm) 7,70 - 7,63 (m, 2H); 7,52 (d, J = 7,8 Hz, $1 \mathrm{H}) ; 7,40(\mathrm{t}, \mathrm{J}=8,0 \mathrm{~Hz}, 1 \mathrm{H}) ; 7,23(\mathrm{~m}, 1 \mathrm{H}) ; 7,17$ (d, J = 9,1 Hz, 2H); 6,97 (d, J = 9,1 Hz, 2H); 6,79 (d, J = 7,8 Hz, 1H); 3,85 (s, 3H); 2,46 (s, 3H). $\mathrm{RMN}{ }^{13} \mathrm{C}\left(101 \mathrm{MHz}, \mathrm{CDCl}_{3}\right) \delta$ (ppm) 156,8; 154,$9 ; 150,0 ; 148,6 ; 138,2 ; 137,3 ; 129,7 ; 128,7$; 128,$5 ; 128,4 ; 128,4 ; 126,1 ; 121,7 ; 55,7 ; 21,6$. 

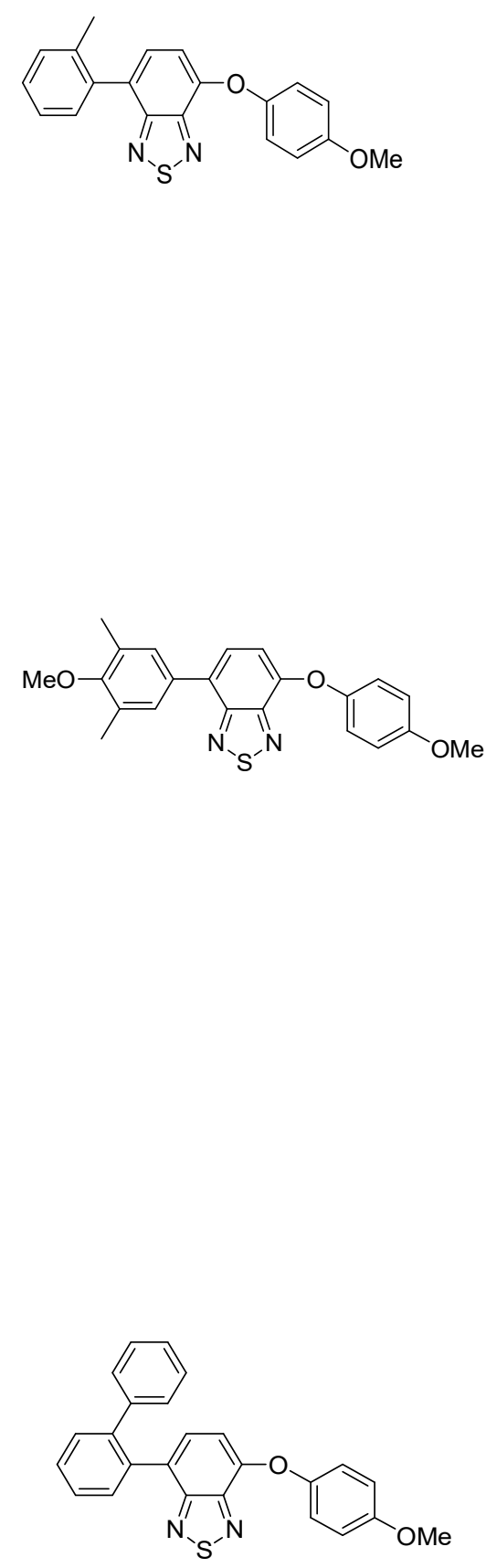

4-(4-metoxifenoxi)-7-(o-

tolilbenzo[c][1,2,5]tiadiazola (46): sólido amarelo, rendimento $92 \%$, ponto de fusão: 75 $77^{\circ} \mathrm{C}$. RMN ${ }^{1} \mathrm{H}\left(400 \mathrm{MHz}, \mathrm{CDCl}_{3}\right) \delta$ (ppm) 7,38 - 7,27 (m, 5H); 7,20 (d, J = 9,0 Hz, 2H); 6,98 (d, $\mathrm{J}=9,0 \mathrm{~Hz}, 2 \mathrm{H}) ; 6,77$ (d, J = 7,7 Hz, 1H); 3,85 (s, 3H); 2,17 (s, 3H). RMN ${ }^{13} \mathrm{C}(101 \mathrm{MHz}$, $\left.\mathrm{CDCl}_{3}\right) \delta(\mathrm{ppm}) 156,2 ; 155,4 ; 150,1 ; 148,4$; 148,0; 137,2; 136,7; 130,4; 129,7; 128,9; 128,3; 125,$8 ; 121,8 ; 115,1 ; 110,6 ; 55,7 ; 20,5$.

4-(4-metoxifenoxi)-7-(4-fluorfenil) benzo[c][1,2,5]tiadiazola (47): sólido amarelo, ponto de fusão: $120{ }^{\circ} \mathrm{C}$ rendimento $94 \%$. RMN ${ }^{1} \mathrm{H}\left(400 \mathrm{MHz}, \mathrm{CDCl}_{3}\right) \delta$ (ppm) 7,50 (s, 2H); 7,47 (d, J = 7,8 Hz, 1H); 7,16 (d, J = 9,1 Hz, 2H); 6,97 (d, J = 9,1 Hz, 2H); 6,78 (d, J = 7,8 Hz, 1H); 3,85 (s, 3H), 3,79 (s, 3H); 2,39 (s, 6H). RMN ${ }^{13} \mathrm{C}(101$ $\left.\mathrm{MHz}, \mathrm{CDCl}_{3}\right) \delta$ (ppm) 157,0; 156,8; 154,9; 149,$6 ; 148,6 ; 148,6 ; 132,8 ; 131,1 ; 129,4 ; 128,2$; 128,$0 ; 121,6 ; 115,1 ; 111,3 ; 59,8 ; 55,7 ; 16,3$. HRMS (m/Z) para $\mathrm{C}_{22} \mathrm{H}_{20} \mathrm{~N}_{2} \mathrm{O}_{3} \mathrm{~S}\left(\mathrm{M}+\mathrm{H}^{+}\right)$: calculado: 393,1273; encontrado: 393,1264.

\section{4-(4-metoxifenoxi)-7-o}

bifenil[c][1,2,5]tiadiazola (48): sólido amarelo, ponto de fusão: $125^{\circ} \mathrm{C}$, rendimento $99 \%$. RMN ${ }^{1} \mathrm{H}\left(400 \mathrm{MHz}, \mathrm{CDCl}_{3}\right) \delta$ (ppm) 7,61 - 7,55 (m, $1 \mathrm{H}) ; 7,51(\mathrm{~m}, 3 \mathrm{H}) ; 7,18-7,03(\mathrm{~m}, 8 \mathrm{H}) ; 6,94(\mathrm{~d}$, $\mathrm{J}=9,1 \mathrm{~Hz}, 2 \mathrm{H}) ; 6,60(\mathrm{~d}, \mathrm{~J}=7,8 \mathrm{~Hz}, 1 \mathrm{H}) ; 3,83$ (s, 3H). RMN ${ }^{13} \mathrm{C}\left(101 \mathrm{MHz}, \mathrm{CDCl}_{3}\right) \delta(\mathrm{ppm})$ 156,$8 ; 155,4 ; 149,7 ; 148,5 ; 147,9 ; 141,8 ; 141,5$; 135,$9 ; 131,2 ; 130,8 ; 130,6 ; 129,2 ; 128,5 ; 128,4$; 127,$8 ; 127,3 ; 126,5 ; 121,6 ; 115,0 ; 110,7 ; 55,7$. 

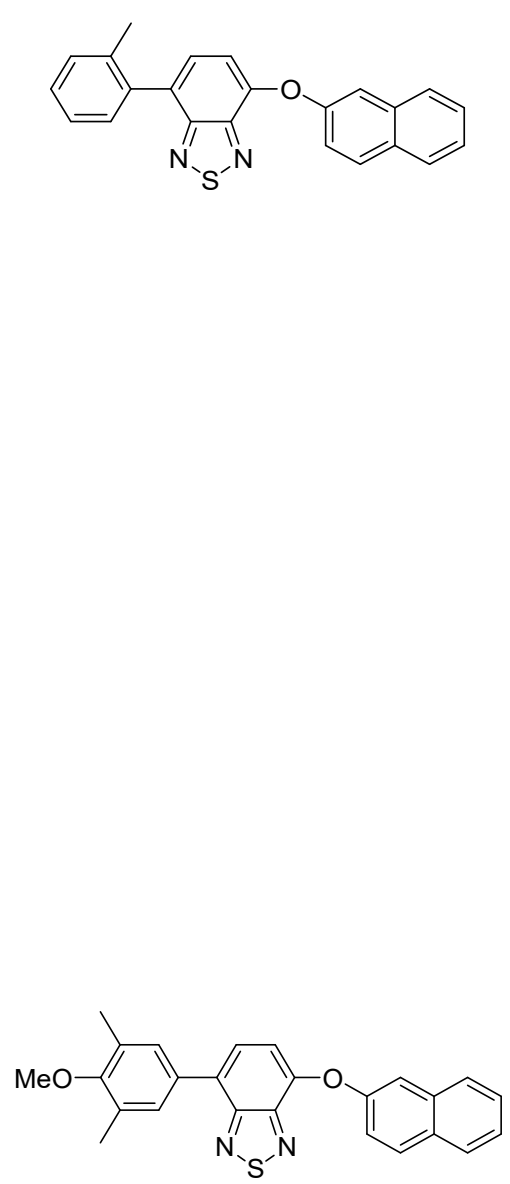

4-(4-metoxi-3,5-dimetilfenil)-7-(naftaleno-3iloxi)benzo[c][1,2,5]tiadiazola (54): sólido amarelo, rendimento $63 \%$, ponto de fusão: $132-$ $135^{\circ} \mathrm{C} . \mathrm{RMN}{ }^{1} \mathrm{H}\left(400 \mathrm{MHz}, \mathrm{CDCl}_{3}\right) \delta$ (ppm) 7,93 $(\mathrm{d}, \mathrm{J}=8,9 \mathrm{~Hz}, 1 \mathrm{H}) ; 7,90-7,85(\mathrm{~m}, 1 \mathrm{H}) ; 7,79-$ ,73 (m, 1H); 7,57 - 7,44 (m, 6H); 7,42 (dd, J = 8,9, 2,4 Hz, 1H); 6,99 (d, J = 7,8 Hz, 1H); 3,80 (s, 3H); 2,40 (s, 6H). RMN ${ }^{13} \mathrm{C}(101 \mathrm{MHz}$, $\left.\mathrm{CDCl}_{3}\right) \delta(\mathrm{ppm}) 157,1 ; 155 ; 153,6 ; 148,9 ; 148,3$; 134,$3 ; 132,8 ; 131,1 ; 130,9 ; 130,2 ; 129,5 ; 129,2$; 127,$9 ; 127,9 ; 127,4 ; 126,7 ; 125,3 ; 120,1 ; 115,8$; 113,7; 59,8; 16,4. HRMS (m/Z) para $\mathrm{C}_{25} \mathrm{H}_{20} \mathrm{~N}_{2} \mathrm{O}_{2} \mathrm{~S}\left(\mathrm{M}+\mathrm{H}^{+}\right)$: calculado: 413,1324; encontrado: 413,1318.

\subsection{Síntese dos derivados de BTD arilóxi-substiuidos via aminação de Buchwald-Hartwig (49 e 50)}

Foram aplicadas as condições da aminação de Buchwald-Hartwig ${ }^{6}$ no intermediário 42, onde colocou-se (0,32 mmol, 109,4 mg), fenoxazina ou iminodenzila $(1,5 \mathrm{mmol}), 4 \mathrm{~mol} \%$ de $\mathrm{Pd}(\mathrm{OAc})_{2}, 12 \mathrm{~mol} \%$ de tetrafluroborato de tri-terc-butilfosfônio e terc-butóxi de sódio $(0,48 \mathrm{mmol}, 46,1 \mathrm{mg})$ em um tubo Schlenk, sob atmosfera inerte. Tolueno seco e desaerado foi utilizado como 
solvente da reação. A reação foi agitada por um período de 24 horas a uma temperatura de $110^{\circ} \mathrm{C}$. Após o fim esse tempo, a mistura foi resfriada e particionada com água e extraída com diclorometano $(3 \times 10 \mathrm{~mL})$. As frações orgânicas foram unidas, secas com sulfato de sódio anidro, filtradas e posteriormente fez-se a secagem do produto em rota-evaporador. A técnica utilizada para a obtenção dos produtos puros foi cromatografia em coluna, utilizando hexano e acetato de etila em diferentes proporções (1 até $5 \%$ ). Assim, foram sintetizados os derivados de BTD's não simétricos 49 e 50 que foram caracterizados por ponto de fusão, RMN ${ }^{1} \mathrm{H}, \mathrm{RMN}{ }^{13} \mathrm{C}$. e HRMS

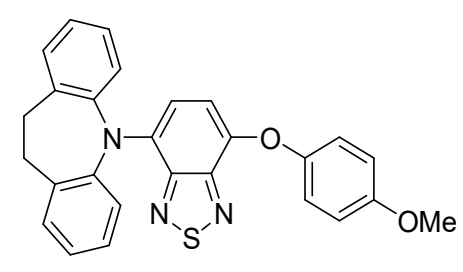

4-(4-metoxifenoxi)-7- $N$ -

iminodibenzil[c][1,2,5]tiadiazola (49): sólido laranja, ponto de fusão: $120{ }^{\circ} \mathrm{C}$, rendimento $55 \%$.

$\mathrm{RMN}{ }^{1} \mathrm{H}\left(400 \mathrm{MHz}, \mathrm{CDCl}_{3}\right) \delta(\mathrm{ppm}) 7,43-7,36(\mathrm{~m}$, $2 \mathrm{H}$ ); 7,19 (td, J = 9,4; 4,8 Hz, 6H); 7,03 (d, J = 9,1 $\mathrm{Hz}, 2 \mathrm{H}) ; 6,87(\mathrm{~d}, \mathrm{~J}=9,1 \mathrm{~Hz}, 2 \mathrm{H}) ; 6,72$ (m, sistema $\mathrm{AB}, 2 \mathrm{H}) ; 3,79$ (s, 3H); 3,13 (s, 4H). RMN ${ }^{13} \mathrm{C}(101$ $\left.\mathrm{MHz}, \mathrm{CDCl}_{3}\right) \delta(\mathrm{ppm}) 155.9,150.4,149.8,149.7$, 145.2 , 142.6, 137.4, 136.3, 130.3, 128.8, 126.6, 126.5, 120.1, 114.9, 114.8, 112.9, 55.7, 31.4. HRMS $(\mathrm{m} / \mathrm{Z})$ para $\mathrm{C}_{27} \mathrm{H}_{21} \mathrm{~N}_{3} \mathrm{O}_{2} \mathrm{~S}\left(\mathrm{M}+\mathrm{H}^{+}\right)$: calculado: 452,1433; encontrado: 452,1428.

\section{0-(4-(4-metoxifenoxi)benzo[c][1,2,5]}

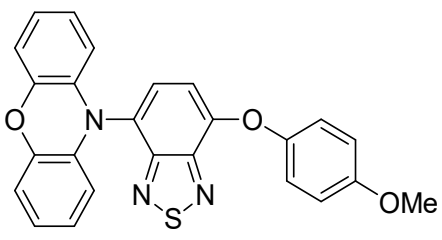
tiadiazol-7-yl)-10H-fenoxazina (50): sólido vermelho, ponto de fusão: 134 , rendimento $85 \%$. $\mathrm{RMN}^{1} \mathrm{H}\left(400 \mathrm{MHz}, \mathrm{CDCl}_{3}\right) \delta(\mathrm{ppm})$ 7,53 (d, J = 8,0 $\mathrm{Hz}, 1 \mathrm{H}) ; 7,23$ (d, J = 9,1 Hz, 2H); 7,01 (d, J = 9,1 Hz, $2 \mathrm{H}) ; 6,78(\mathrm{~d}, \mathrm{~J}=8,0 \mathrm{~Hz}, 1 \mathrm{H}) ; 6,75(\mathrm{dd}, \mathrm{J}=8,0 ; 1,4$ $\mathrm{Hz}, 2 \mathrm{H}) ; 6,67$ (td, J = 7,7; 1,5 Hz, 2H); 6,54 (td, J = 7,7; $1,5 \mathrm{~Hz}, 2 \mathrm{H}$ ); 5,82 (dd, J = 8,0; 1,4 Hz, 2H); 3,87 (s, 3H). RMN ${ }^{13} \mathrm{C}\left(101 \mathrm{MHz}, \mathrm{CDCl}_{3}\right) \delta$ (ppm) 157,3; 153,$4 ; 151,6 ; 149,5 ; 147,7 ; 144,1 ; 133,7 ; 133,6$; 124,$0 ; 123,2 ; 122,1 ; 121,8 ; 115,8 ; 115,3 ; 113,2$; 110,$0 ; 55,7$. HRMS (m/Z) para $\mathrm{C}_{25} \mathrm{H}_{17} \mathrm{~N}_{3} \mathrm{O}_{3} \mathrm{~S}(\mathrm{M}+$ $\mathrm{H}^{+}$): calculado: 440,1069 ; encontrado: 440,1073 . 


\subsubsection{Síntese dos compostos diarilados 56 e 57 via acoplamento de Suzuki}

O composto 9 foi submetido a condições clássicas de acoplamento de Suzuki. Em um frasco de Schlenk seco e selado foi adicionado 9 (0,50 mmol, 147 $\mathrm{mg})$, o ácido arilborônico apropriado (1,10 mmol), $\mathrm{Pd}(\mathrm{OAc})_{2}\left(1,8 \times 10^{-2} \mathrm{mmol}, 4,0\right.$ $\mathrm{mg}), \mathrm{PPh}_{3}\left(3,0 \times 10^{-2} \mathrm{mmol}, 8,0 \mathrm{mg}\right), \mathrm{K}_{2} \mathrm{CO}_{3}(2 \mathrm{mmol}, 276 \mathrm{mg})$, etanol $(1 \mathrm{~mL}) \mathrm{e}$ tolueno $(1 \mathrm{~mL})$. A reação foi agitada a $75^{\circ} \mathrm{C}$ durante $4 \mathrm{~h}$ sob atmosfera inerte de nitrogênio. Posteriormente, a mistura resultante foi deixada esfriar até a temperatura ambiente e então foi filtrada, o sólido que ainda permaneceu no recipiente foi lavado com tolueno $(2 \times 5 \mathrm{~mL})$, as frações foram unidas e a solução foi concentrada sob pressão reduzida. O material bruto foi purificado por cromatografia em coluna utilizando sílica gel e aplicando hexano/acetato de etila (100:1) como fase móvel. Desse modo, derivados de BTD diarilados e simétricos (56 e 57) foram sintetizados e caracterizados por ponto de fusão, RMN ${ }^{1} \mathrm{H}$, RMN ${ }^{13} \mathrm{C}$ e HRMS.

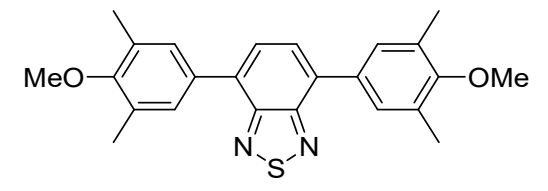

4,7-bis(4-metoxi-3,5-

dimetilfenil)benzo[c][1,2,5]tiadiazola $(57)$ :

sólido amarelo, rendimento $83 \%$, ponto de fusão: $205^{\circ} \mathrm{C}$. $\mathrm{RMN}^{1} \mathrm{H}\left(400 \mathrm{MHz}, \mathrm{CDCl}_{3}\right) \delta$ (ppm) 7,69 (s, 2H); 7,60 (s, 4H); 3,81 (s, 6H); 2,41 (s, 12H). RMN ${ }^{13} \mathrm{C}\left(101 \mathrm{MHz}, \mathrm{CDCl}_{3}\right) \delta$ (ppm) 157,3; 154,2; 133,1; 132,8; 131,1; 129,7; 127,9; 59,8; 16,4. HRMS (m/Z) para $\mathrm{C}_{24} \mathrm{H}_{24} \mathrm{~N}_{2} \mathrm{O}_{2} \mathrm{~S} \quad(\mathrm{M}+\mathrm{H})^{+}$: calculado: 405,1637; encontrado: 405,1637.

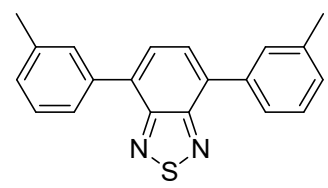

4,7-dim-tolilbenzo[c][1,2,5]tiadiazola (56): sólido amarelo, rendimento $90 \%$, ponto de fusão: $80^{\circ} \mathrm{C}$. RMN ${ }^{1} \mathrm{H}\left(400 \mathrm{MHz}, \mathrm{CDCl}_{3}\right) \delta(\mathrm{ppm})$ 7,82 - 7,68 (m, 6H); 7,44 (t, J = 7,9 Hz, 2H); 7,28 (d, J = 7,9 Hz, 2H); 2,49 (s, 6H). RMN ${ }^{13} \mathrm{C}$ $\left(101 \mathrm{MHz}, \mathrm{CDCl}_{3}\right) \delta$ (ppm) 154,1; 138,2; 137,4; 133,$4 ; 129,9 ; 129,1 ; 128,5 ; 128,1 ; 126,4 ; 21,6$. HRMS (m/Z) para $\mathrm{C}_{20} \mathrm{H}_{16} \mathrm{~N}_{2} \mathrm{~S} \quad(\mathrm{M}+\mathrm{H})^{+}$: calculado: 317,1112 ; encontrado: 317,1120 . 


\subsection{Síntese dos compostos simétricos 58 e 59 via Aminação de Buchwald-Hartwig}

Visando a síntese de derivados de BTDs nitrogenados utilizou-se das condições clássicas da aminação de Buchwald-Hartwig ${ }^{6}$. Em um tubo Schlenk, sob atmosfera inerte, foi adicionado o composto $1(0,5 \mathrm{mmol}, 147 \mathrm{mg})$, amina (2,2 equiv), $4 \mathrm{~mol} \%$ de $\operatorname{Pd}(\mathrm{OAc})_{2}, 12 \%$ de tetrafluroborato de tri-terc-butilfosfônio e terc-butóxi de sódio (1,1 mmol, 105,7 mg). Foram dissolvidos em $10 \mathrm{~mL}$ de tolueno seco e desaerado. O Schlenk foi devidamente selado e a mistura reacional foi agitada a uma temperatura de $110^{\circ} \mathrm{C}$ por um período de 24 horas. A mistura foi então resfriada e foi feita uma extração com água e diclorometano $(3 \times 10 \mathrm{~mL})$. As frações orgânicas foram unidas e secas com sulfato de sódio anidro, filtrou-se e após o solvente foi evaporado com pressão reduzida. A técnica utilizada para a obtenção dos produtos puros foi cromatografia em coluna, utilizando hexano e acetato de etila em diferentes proporções (1 até $33 \%$ ). Para o composto 59 , após a cromatografia em coluna foi necessária uma purificação adicional usando hexano para precipitar o produto. O resultado foram os produtos simétricos $58 \mathrm{e}$ 59, que foram caracterizados por ponto de fusão, $R M N{ }^{1} \mathrm{H}, \mathrm{RMN}{ }^{13} \mathrm{C}$ e HRMS.

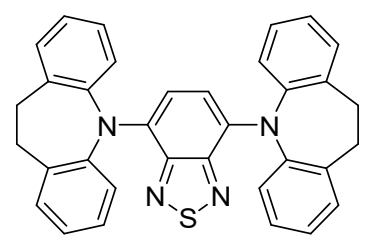

\section{1,4-N-diiminodibenzilbenzo[c][1,2,5]tiadiazola}

(58): sólido roxo, ponto de fusão: $210{ }^{\circ} \mathrm{C}$, rendimento $38 \%$. RMN ${ }^{1} \mathrm{H}\left(400 \mathrm{MHz}, \mathrm{CDCl}_{3}\right) \delta$ (ppm) 7,34 - 7,27 (m, 4H); 7,17 (dd, J = 6,9; 2,2 Hz, $4 \mathrm{H}), 7,13-7,03(\mathrm{~m}, 8 \mathrm{H}) ; 6,97$ (s, 2H); 3,18 (s, 8H). $\mathrm{RMN}{ }^{13} \mathrm{C}\left(101 \mathrm{MHz}, \mathrm{CDCl}_{3}\right) \delta$ (ppm) 151,4; 145,6; 136,$5 ; 134,6 ; 130,2 ; 127,4 ; 126,4 ; 125,2 ; 118,6$; 32,2. HRMS $(\mathrm{m} / \mathrm{Z})$ para $\mathrm{C}_{34} \mathrm{H}_{26} \mathrm{~N}_{4} \mathrm{~S}\left(\mathrm{M}+\mathrm{H}^{+}\right)$: calculado: 523,1956; encontrado: 523,1965.

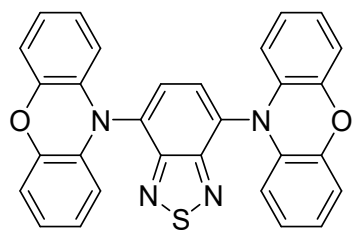

\section{0-(4-(10H-fenoxazine-10-}

\section{yl)benzo[c][1,2,5]tiadiazola-7-yl) $10 \mathrm{H}$-fenoxazina}

(59): sólido roxo, ponto de fusão: $324{ }^{\circ} \mathrm{C}$, rendimento $51 \%$. RMN ${ }^{1} \mathrm{H}\left(400 \mathrm{MHz}, \mathrm{CDCl}_{3}\right) \delta$ (ppm) 7,90 (s, 2H); 6,81 (dd, J = 7,9, 1,5 Hz, 4H); $6,74(\mathrm{td}, \mathrm{J}=7,7,1,4 \mathrm{~Hz}, 4 \mathrm{H}) ; 6,62(\mathrm{td}, \mathrm{J}=7,7,1,4$ $\mathrm{Hz}, 4 \mathrm{H}) ; 5,90$ (dd, J = 7,9, 1,5 Hz, 4H). RMN ${ }^{13} \mathrm{C}(101$ $\left.\mathrm{MHz}, \mathrm{CDCl}_{3}\right) \delta(\mathrm{ppm}) 154,2 ; 144,2 ; 133,4 ; 133,2$; 131,$7 ; 123,3 ; 122,4 ; 116,2 ; 113,3$. HRMS (m/Z) para 
$\mathrm{C}_{30} \mathrm{H}_{18} \mathrm{~N}_{4} \mathrm{O}_{2} \mathrm{~S}\left(\mathrm{M}+\mathrm{H}^{+}\right)$: calculado: 499,1229;

encontrado: 499,1232.

\subsection{Preparo de soluções}

\subsubsection{Soluções para experimento de absorção}

Para as análises de UV-Vis dos compostos sintetizados foram preparadas soluções-mãe dos produtos em isopropanol na concentração de aproximadamente $5.10^{-4} \mathrm{~mol} \mathrm{~L}^{-1}$. Escolheu-se isopropanol pois é um solvente de difícil evaporação. A partir destas soluções-mãe, com o intuito de analisar o máximo de absorção e a absortividade molar, foram preparadas 4 soluções em concentração de $5.10^{-5} \mathrm{~mol} \mathrm{~L}^{-1}$ em diferentes solventes (isopropanol, diclorometano, tolueno e ciclohexano) e estas foram analisadas em espectrofotômetro.

\subsubsection{Soluções para experimento de emissão}

As soluções de derivados de BTD previamente preparadas nas concentrações de $5.10^{-4} \mathrm{~mol} \mathrm{~L}^{-1}$ foram utilizadas para a diluição até uma concentração de aproximadamente $5.10^{-6} \mathrm{~mol} \mathrm{~L}^{-1}$ de cada composto, onde essas foram preparadas em isopropanol, diclorometano, tolueno e ciclohexano e analisadas no fluorímetro. Assim, foram observados o máximo de emissão de cada composto nos diferentes solventes e a influência do efeito da polaridade dos solventes na fluorescência dos compostos.

\subsubsection{Soluções para rendimento quântico de fluorescência}

Utilizando soluções de fluoresceína, Cumarina 30 ou Cumarina 153, como referência, foram calculados os valores de rendimento quântico dos compostos em questão. Preparou-se soluções dos padrões e de cada um dos compostos estudados de modo a obter valores de absorbância em um intervalo de 0,01 a $0,1.89$

\subsection{Cálculo de Rendimento quântico em solução}

Após registro dos espectros de fluorescência de cada uma das soluções anteriormente citadas, obteve-se um gráfico de reta a partir da integral do espectro 
de fluorescência versus absorbância. Por último, foi calculado o rendimento quântico segundo a equação (2) em que $\phi_{f}=$ rendimento quântico do padrão, $m_{c h}=$ inclinação da reta obtida no gráfico do composto, $m_{f}=$ inclinação da reta obtida no gráfico do padrão, $n_{f}=$ índice de refração do solvente da solução do padrão, $n_{c h}=$ índice de refração do solvente da solução dos compostos. As medidas foram realizadas com o auxílio inicial do Dr. Luis Maqueira do Departamento de Química da PUC-Rio.

$$
\phi_{\text {solução }}=\phi_{f} \cdot\left(\frac{m_{c h}}{m_{f}}\right)\left(\frac{n_{f}}{n_{c h}}\right)
$$

\subsection{Experimentos de Voltametria Cíclica}

Os experimentos foram realizados utilizando três eletrodos: um eletrodo de trabalho de carbono-vítreo, um eletrodo de referência de $\mathrm{Ag} / \mathrm{AgCl}\left(\mathrm{KCl}_{\text {(sat) }}\right)$ e um eletrodo auxiliar de $\mathrm{Pt}$. As soluções foram preparadas a $10^{-3} \mathrm{~mol} \mathrm{~L}^{-1} \mathrm{em}$ diclorometano utilizando $\mathrm{TBAPF}_{6}$ (hexafluorofosfato de tetrabutilamônio) como eletrólito suporte. Uma célula eletroquímica sem os produtos de análise foi utilizada como referência, além de ferroceno para calibração. Os experimentos foram conduzidos em uma extensão de 0 a 2,0V a $50 \mathrm{mV} \cdot \mathrm{s}^{-1} \mathrm{e}$ as medidas foram realizadas 3 vezes com o auxílio inicial da pós-doutoranda Joseany de Almeida do Departamento de Química da PUC-Rio. Os cálculos de HOMO e LUMO foram obtidos segundo as equações (3) e (4), em que $e$ é a carga eletrônica e $\phi$ é o fator de correção entre o valor obtido na literatura e o observado nas análises para ferroceno.

$$
\begin{gathered}
E_{\text {номо }}(e V)=-e . \mathrm{E}_{\text {onset }}^{\text {oxi }}(V)-4,4(e V)+e . \phi(V) \\
E_{\text {LUмо }}(e V)=-e . \mathrm{E}_{\text {onset }}^{\text {red }}(V)-4,4(e V)+e . \phi(V)
\end{gathered}
$$




\section{Referências bibliográficas}

1. Neto BAD, Lapis AAM, da Silva Júnior EN, Dupont J. European J Org Chem. 2013; 2013: 228-255.

2. Neto BAD, Carvalho PHPR, Correa JR. Acc Chem Res. 2015; 48: 15601569.

3. Pazini A, Maqueira L, Stieler R, Aucélio RQ, Limberger J. J Mol Struct. 2017; 1131: 181-189.

4. Fang Q, Xu B, Jiang B, Fu H, Chen X, Cao A. Chem Commun. 2005: 1468.

5. DaSilveira Neto BA, Lopes AS, Ebeling G, Gonçalves RS, Costa VEU, Quina FH, Dupont J. Tetrahedron. 2005; 61: 10975-10982.

6. Ni F, Wu Z, Zhu Z, Chen T, Wu K, Zhong C, An K, Wei D, Ma D, Yang C. J Mater Chem C. 2017; 5: 1363-1368.

7. da Cruz EHG, Carvalho PHPR, Corrêa JR, Silva DAC, Diogo EBT, de Souza Filho JD, Cavalcanti BC, Pessoa C, de Oliveira HCB, Guido BC, da Silva Filho DA, Neto BAD, da Silva Júnior EN. New J Chem. 2014; 38: 2569.

8. Neto BAD, Carvalho PHPR, Santos DCBD, Gatto CC, Ramos LM, Vasconcelos NM de, Corrêa JR, Costa MB, de Oliveira HCB, Silva RG. RSC Adv. 2012; 2: 1524-1532.

9. Balaguez RA, Ricordi VG, Duarte RC, Toldo JM, Santos CM, Schneider PH, Gonçalves PFB, Rodembusch FS, Alves D. RSC Adv. 2016; 6: 4961349624.

10. Yamashita Y, Ono K, Tomura M, Tanaka S. Tetrahedron. 1997; 53: 10169_ 10178.

11. Echavarren AM, Crdenas DJ. In Metal-Catalyzed Cross-Coupling Reactions Wiley-VCH Verlag GmbH: Weinheim, Germany, pp 1-40.

12. Heravi MM, Hajiabbasi P. Monatshefte für Chemie - Chem Mon. 2012; 143: 1575-1592.

13. Marion N, Nolan SP. Acc Chem Res. 2008; 41: 1440-1449.

14. Batalha PN, Sagrillo FS, Gama IL. Rev Virtual Química. 2014; 6.

15. Heck RF, Nolley JP. J Org Chem. 1972; 37: 2320-2322.

16. Tamao K, Sumitani K, Kumada M. J Am Chem Soc. 1972; 94: 4374-4376.

17. Kiso Y, Yamamoto K, Tamao K, Kumada M. J Am Chem Soc. 1972; 94: 
4373-4374.

18. Sonogashira K, Tohda Y, Hagihara N. Tetrahedron Lett. 1975; 16: 44674470.

19. Baba S, Negishi E. J Am Chem Soc. 1976; 98: 6729-6731.

20. Milstein D, Stille JK. J Am Chem Soc. 1978; 100: 3636-3638.

21. Miyaura N, Yamada K, Suzuki A. Tetrahedron Lett. 1979; 20: 3437-3440.

22. Colby DA, Tsai AS, Bergman RG, Ellman JA. Acc Chem Res. 2012; 45: 814-825.

23. Wendlandt AE, Suess AM, Stahl SS. Angew Chemie Int Ed. 2011; 50: 11062-11087.

24. Fürstner A, Leitner A, Méndez M, Krause H. J Am Chem Soc. 2002; 124: 13856-13863.

25. Cifuentes JMC, Ferreira BX, Esteves PM, Buarque CD. Top Catal. 2018; 61: 689-698.

26. Miyaura N. In Metal-Catalyzed Cross-Coupling Reactions Wiley-VCH Verlag GmbH: Weinheim, Germany, pp 41-123.

27. Biajoli AFP, Schwalm CS, Limberger J, Claudino TS, Monteiro AL. J Braz Chem Soc. 2014.

28. Larsen RD, King AO, Chen CY, Corley EG, Foster BS, Roberts FE, Yang C, Lieberman DR, Reamer RA, Tschaen DM, Verhoeven TR, Reider PJ, Lo YS, Rossano LT, Brookes AS, Meloni D, Moore JR, Arnett JF. J Org Chem. 1994; 59: 6391-6394.

29. Chiusoli GP, Maitlis PM, Eds. Metal-catalysis in Industrial Organic Processes, Royal Society of Chemistry: Cambridge, 2007.

30. Volovych I, Neumann M, Schmidt M, Buchner G, Yang J-Y, Wölk J, Sottmann T, Strey R, Schomäcker R, Schwarze M. RSC Adv. 2016; 6: 58279-58287.

31. Colacot TJ. Platin Met Rev. 2011; 55: 84-90.

32. Jiang L, Buchwald SL. In Metal-Catalyzed Cross-Coupling Reactions WileyVCH Verlag GmbH: Weinheim, Germany, pp 699-760.

33. Kosugi M, Kameyama M, Migita T. Chem Lett. 1983; 12: 927-928.

34. Boger DL, Duff SR, Panek JS, Yasuda M. J Org Chem. 1985; 50: 57905795.

35. Guram AS, Buchwald SL. J Am Chem Soc. 1994; 116: 7901-7902.

36. Guram AS, Rennels RA, Buchwald SL. Angew Chemie Int Ed English. 1995; 34: 1348-1350.

37. Louie J, Hartwig JF. Tetrahedron Lett. 1995; 36: 3609-3612. 
38. Wolfe JP, Buchwald SL. J Org Chem. 1996; 61: 1133-1135.

39. Louie J, Driver MS, Hamann BC, Hartwig JF. J Org Chem. 1997; 62: 12681273.

40. Wolfe JP, Buchwald SL. Angew Chemie Int Ed. 1999; 38: 2413-2416.

41. Kawatsura M, Hartwig JF. J Am Chem Soc. 1999; 121: 1473-1478.

42. Ruiz-Castillo P, Buchwald SL. Chem Rev. 2016; 116: 12564-12649.

43. Goodyear A, Linghu X, Bishop B, Chen C, Cleator E, McLaughlin M, Sheen FJ, Stewart GW, Xu Y, Yin. J. Org Process Res Dev. 2012; 16: 605-611.

44. Lee CW, Kim J-K, Joo SH, Lee JY. ACS Appl Mater Interfaces. 2013; 5: 2169-2173.

45. Volz D, Wallesch M, FI?chon C, Danz M, Verma A, Navarro JM, Zink DM, Br?se S, Baumann T. Green Chem. 2015; 17: 1988-2011.

46. Jiang H, Sun J, Zhang J. Curr Org Chem. 2012; 16: 2014-2025.

47. Lavis LD, Raines RT. ACS Chem Biol. 2014; 9: 855-866.

48. Wu J, Lai G, Li Z, Lu Y, Leng T, Shen Y, Wang C. Dye Pigment. 2016; 124 : 268-276.

49. Culzoni MJ, Muñoz de la Peña A, Machuca A, Goicoechea HC, Babiano R. Anal Methods. 2013; 5: 30-49.

50. Wu Y, Zhu W. Chem Soc Rev. 2013; 42: 2039-2058.

51. Mancilha FS, DaSilveira Neto BA, Lopes AS, Moreira PF, Quina FH, Gonçalves RS, Dupont J. European J Org Chem. 2006; 2006: 4924-4933.

52. Misra R, Gautam P, Jadhav T, Mobin SM. J Org Chem. 2013; 78: 49404948.

53. Volz D, Wallesch M, Fléchon C, Danz M, Verma A, Navarro JM, Zink DM, Bräse S, Baumann T. Green Chem. 2015; 17: 1988-2011.

54. Thejo Kalyani N, Dhoble SJ. Renew Sustain Energy Rev. 2012; 16: 26962723.

55. Chen H-W, Lee J-H, Lin B-Y, Chen S, Wu S-T. Light Sci Appl. 2018; 7: 17168.

56. Yang Y, Zhou Y, He Q, He C, Yang C, Bai F, Li Y. J Phys Chem B. 2009; 113: 7745-7752.

57. Thangthong A, Prachumrak N, Sudyoadsuk T, Namuangruk S, Keawin T, Jungsuttiwong S, Kungwan N, Promarak V. Org Electron. 2015; 21: 117125.

58. Pu Y-J, Higashidate M, Nakayama K, Kido J. J Mater Chem. 2008; $18: 4183$.

59. Zhang ST, Wang ZJ, Zhao JM, Zhan YQ, Wu Y, Zhou YC, Ding XM, Hou XY. Appl Phys Lett. 2004; 84: 2916-2918. 
60. Smith T, Guild J. Trans Opt Soc. 1931; 33: 73-134.

61. Mueller G. Electroluminescence. I, Academic Press, 2000.

62. Tsutsui T, Aminaka E, Lin CP, Kim D-U. Philos Trans R Soc A Math Phys Eng Sci. 1997; 355: 801-814.

63. Zhang Q, Li J, Shizu K, Huang S, Hirata S, Miyazaki H, Adachi C. J Am Chem Soc. 2012; 134: 14706-14709.

64. Méhes G, Nomura H, Zhang Q, Nakagawa T, Adachi C. Angew Chemie Int Ed. 2012; 51: 11311-11315.

65. Zhang $Q$, Kuwabara H, Potscavage WJ, Huang S, Hatae $\mathrm{Y}$, Shibata $\mathrm{T}$, Adachi C. J Am Chem Soc. 2014; 136: 18070-18081.

66. Ku S-Y, Chi L-C, Hung W-Y, Yang S-W, Tsai T-C, Wong K-T, Chen Y-H, Wu C-I. J Mater Chem. 2009; 19: 773-780.

67. Angioni E, Chapran M, Ivaniuk K, Kostiv N, Cherpak V, Stakhira P, Lazauskas A, Tamulevičius S, Volyniuk D, Findlay NJ, Tuttle T, Grazulevicius J V., Skabara PJ. J Mater Chem C. 2016; 4: 3851-3856.

68. Monnier F, Taillefer M. Angew Chemie Int Ed. 2009; 48: 6954-6971.

69. Sambiagio C, Marsden SP, Blacker AJ, McGowan PC. Chem Soc Rev. 2014; 43: 3525-3550.

70. Suzuki T, Tsuji T, Okubo T, Okada A, Obana Y, Fukushima T, Miyashi T, Yamashita Y. J Org Chem. 2001; 66: 8954-8960.

71. Tomura M, Yamashita Y. Zeitschrift für Krist - New Cryst Struct. 2003; 218.

72. Patra D, Barakat C. Spectrochim Acta Part A Mol Biomol Spectrosc. 2011; 79: 1034-1041.

73. Mishra A, Sahu S, Tripathi S, Krishnamoorthy G. Photochem Photobiol Sci. 2014; 13: 1476-1486.

74. Gülseven Sıdır Y, Sıdır İ. Spectrochim Acta Part A Mol Biomol Spectrosc. 2013; 102: 286-296.

75. Manning SJ, Bogen W, Kelly LA. J Org Chem. 2011; 76: 6007-6013.

76. Sjöback R, Nygren J, Kubista M. Spectrochim Acta Part A Mol Biomol Spectrosc. 1995; 51: L7-L21.

77. L. M, F. N, I. H. J Solid State Electrochem. 2002; 7: 55-59.

78. Sasabe H, Onuma N, Nagai Y, Ito T, Kido J. Chem - An Asian J. 2017; 12: 648-654.

79. Lee J, Shizu K, Tanaka H, Nomura H, Yasuda T, Adachi C. J Mater Chem C. $2013 ; 1: 4599$.

80. Jones G, Jackson WR, Choi CY, Bergmark WR. J Phys Chem. 1985; 89: 294-300. 
81. Grabolle M, Spieles M, Lesnyak V, Gaponik N, Eychmüller A, Resch-Genger U. Anal Chem. 2009; 81: 6285-6294.

82. Würth C, Grabolle M, Pauli J, Spieles M, Resch-Genger U. Nat Protoc. 2013; 8: 1535-1550.

83. Frisch MJ, Trucks GW, Schlegel HB, Scuseria GE, Robb MA, Cheeseman JR, Montgomery JA, Vreven T, Kudin KN, Burant JC, Millam JM, lyengar SS, Tomasi J, Barone V, Mennucci B, Cossi M, Scalmani G, Rega N, Petersson GA, Nakatsuji H, Hada M, Ehara M, Toyota K, Fukuda R, Hasegawa J, Ishida M, Nakajima T, Honda Y, Kitao O, Nakai H, Klene M, Li $X$, Knox JE, Hratchian HP, Cross JB, Bakken V, Adamo C, Jaramillo J, Gomperts R, Stratmann RE, Yazyev O, Austin AJ, Cammi R, Pomelli C, Ochterski JW, Ayala PY, Morokuma K, Voth GA, Salvador P, Dannenberg JJ, Zakrzewski VG, Dapprich S, Daniels AD, Strain MC, Farkas O, Malick DK, Rabuck AD, Raghavachari K, Foresman JB, Ortiz J V., Cui Q, Baboul AG, Clifford S, Cioslowski J, Stefanov BB, Liu G, Liashenko A, Piskorz P, Komaromi I, Martin RL, Fox DJ, Keith T, Laham AMA, Peng CY, Nanayakkara A, Challacombe M, Gill PMW, Johnson B, Chen W, Wong MW, Gonzalez C, Pople JA. Gaussian 03, Revision C.02, 2003.

84. Neese F. Orca 4.0 Manual ORCA - An Ab Initio, Density Functional and Semi-empirical Program Package, Version 3.0.3, 2017.

85. Bünau G v. Berichte der Bunsengesellschaft für Phys Chemie. 1970; 74: 1294-1295.

86. Mei J, Leung NLC, Kwok RTK, Lam JWY, Tang BZ. Chem Rev. 2015; 115: 11718-11940.

87. Kirkbright GF, Spillane DEM, Anthony K, Brown RG, Hepworth JD, Hodgson KW, West MA. Anal Chem. 1984; 56: 1644-1647.

88. Ramasamy SM, Senthilnathan VP, Hurtubise RJ. Anal Chem. 1986; 58: 612-616.

89. Allen MW. Measurement of Fluorescence Quantum Yields, 2010. 


\section{Anexos}

\subsection{Espectros de $\mathrm{RMN}{ }^{1} \mathrm{H}$ e ${ }^{13} \mathrm{C}$}

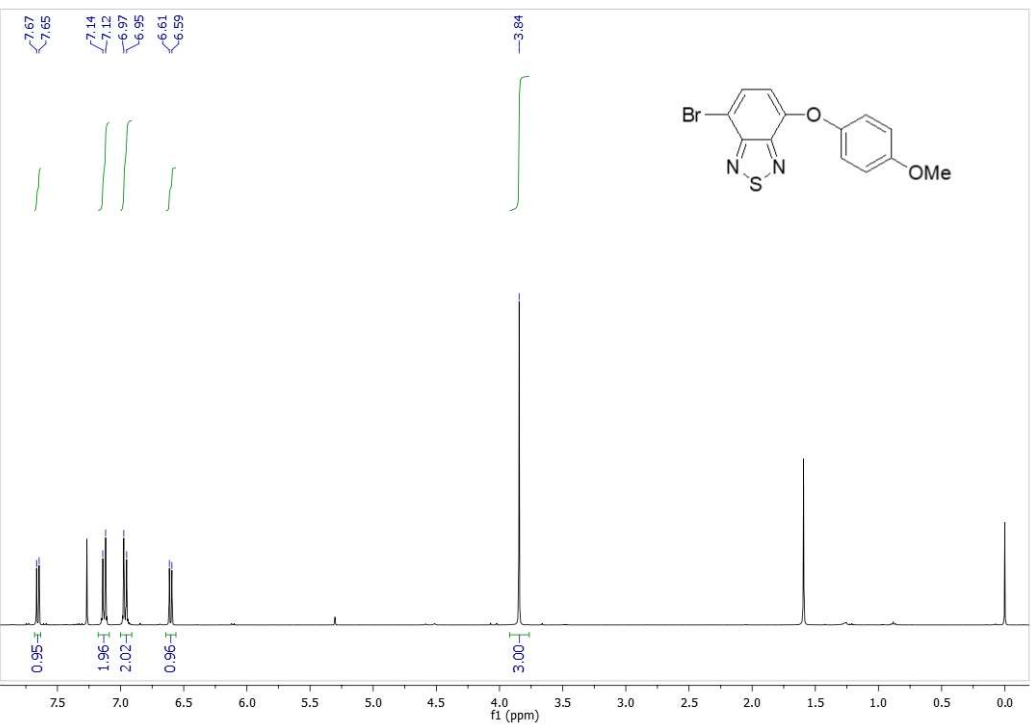

Figura S1. Espectro de $\mathrm{RMN}^{1} \mathrm{H}\left(400 \mathrm{MHz}, \mathrm{CDCl}_{3}\right)$ do composto 42.

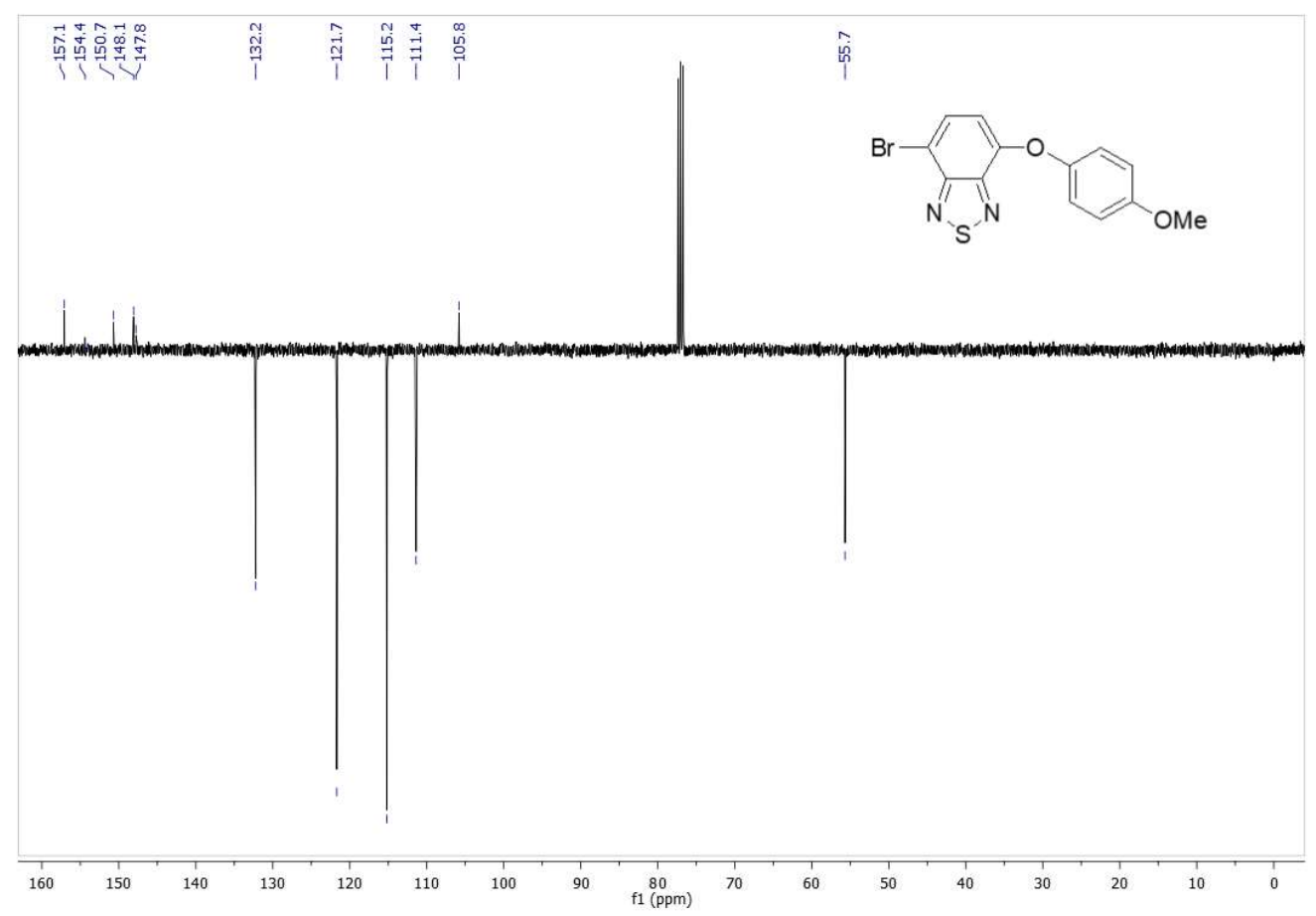

Figura S2. Espectro de RMN ${ }^{13} \mathrm{C}\left(100 \mathrm{MHz}, \mathrm{CDCl}_{3}\right)$ do composto 42. 


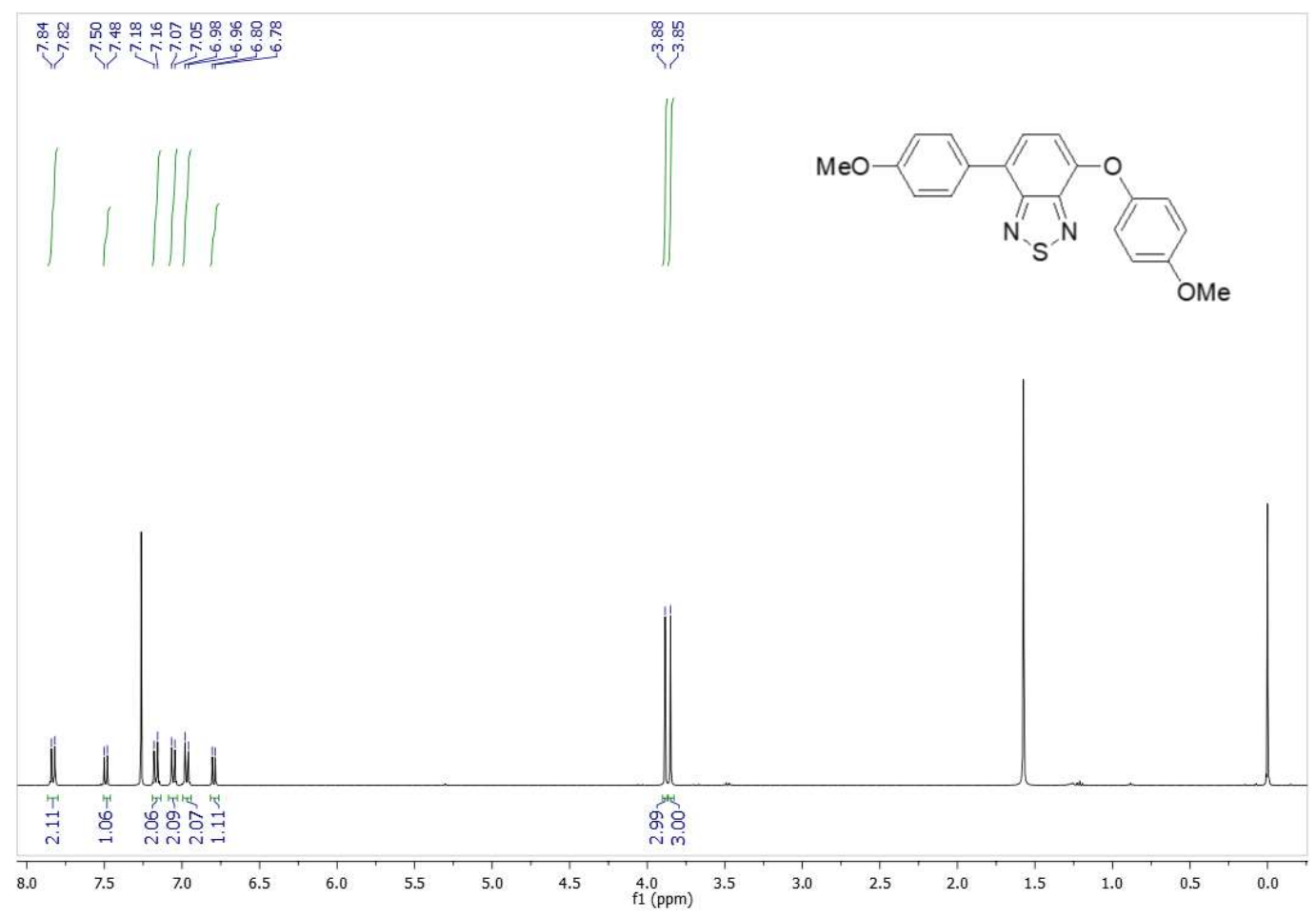

Figura S3. Espectro de $\mathrm{RMN}^{1} \mathrm{H}\left(400 \mathrm{MHz}, \mathrm{CDCl}_{3}\right)$ do composto 43.

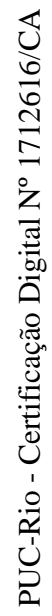

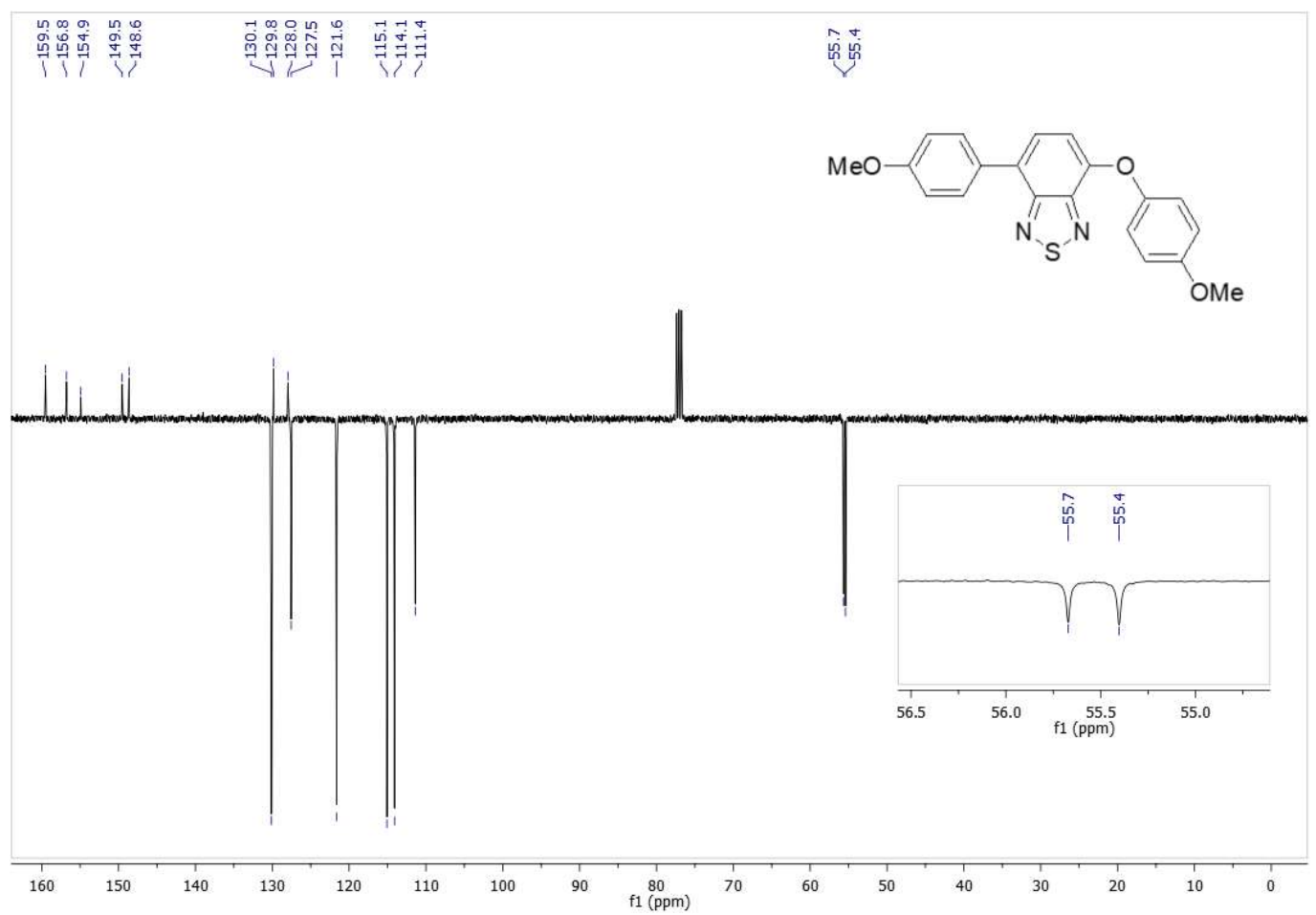

Figura S4. Espectro de $\mathrm{RMN}^{13} \mathrm{C}\left(100 \mathrm{MHz}, \mathrm{CDCl}_{3}\right)$ do composto 43. 


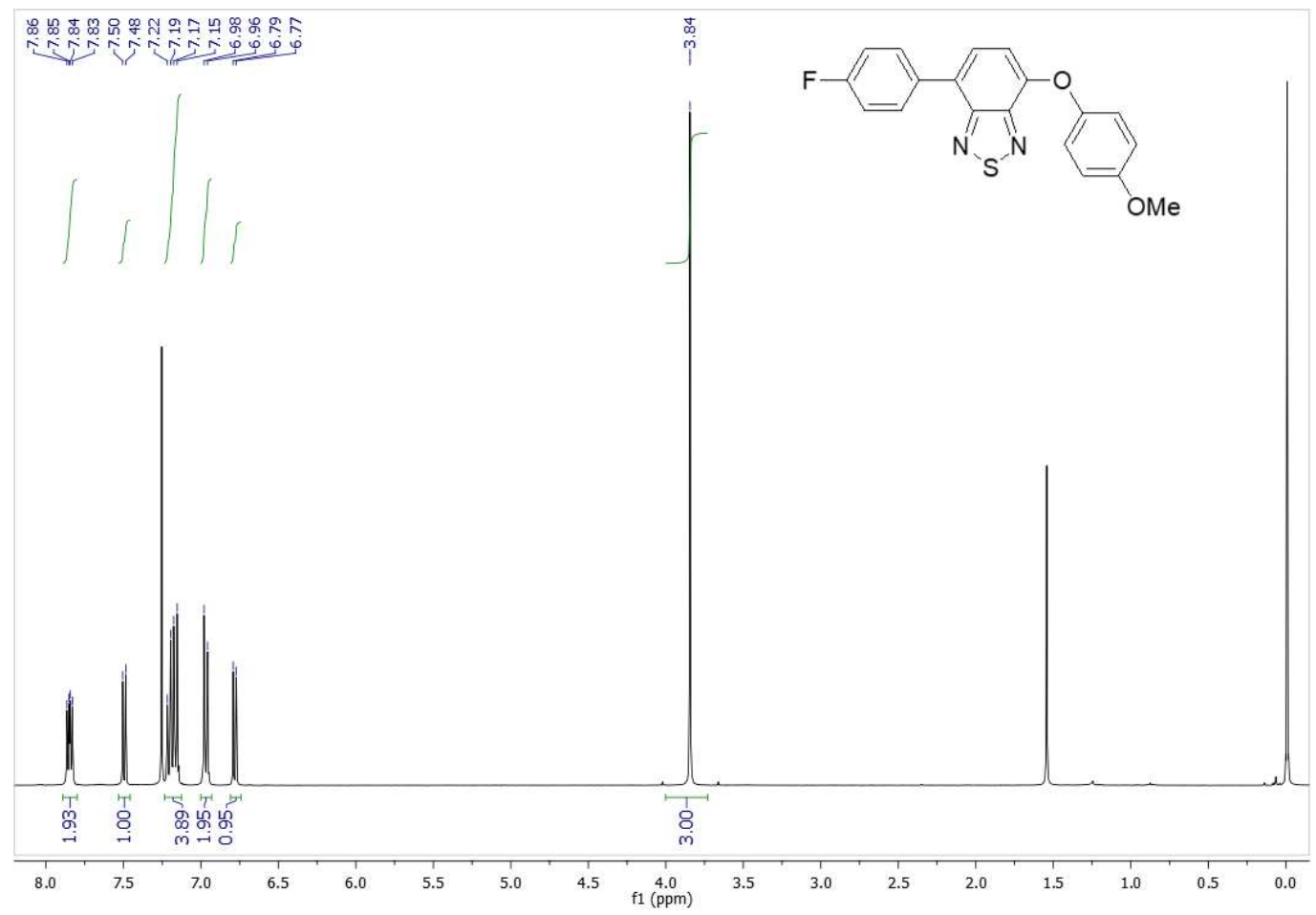

Figura S5. Espectro de RMN ${ }^{1} \mathrm{H}(400 \mathrm{MHz}, \mathrm{CDCl} 3)$ do composto 44.

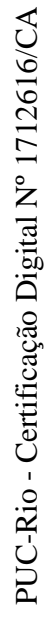

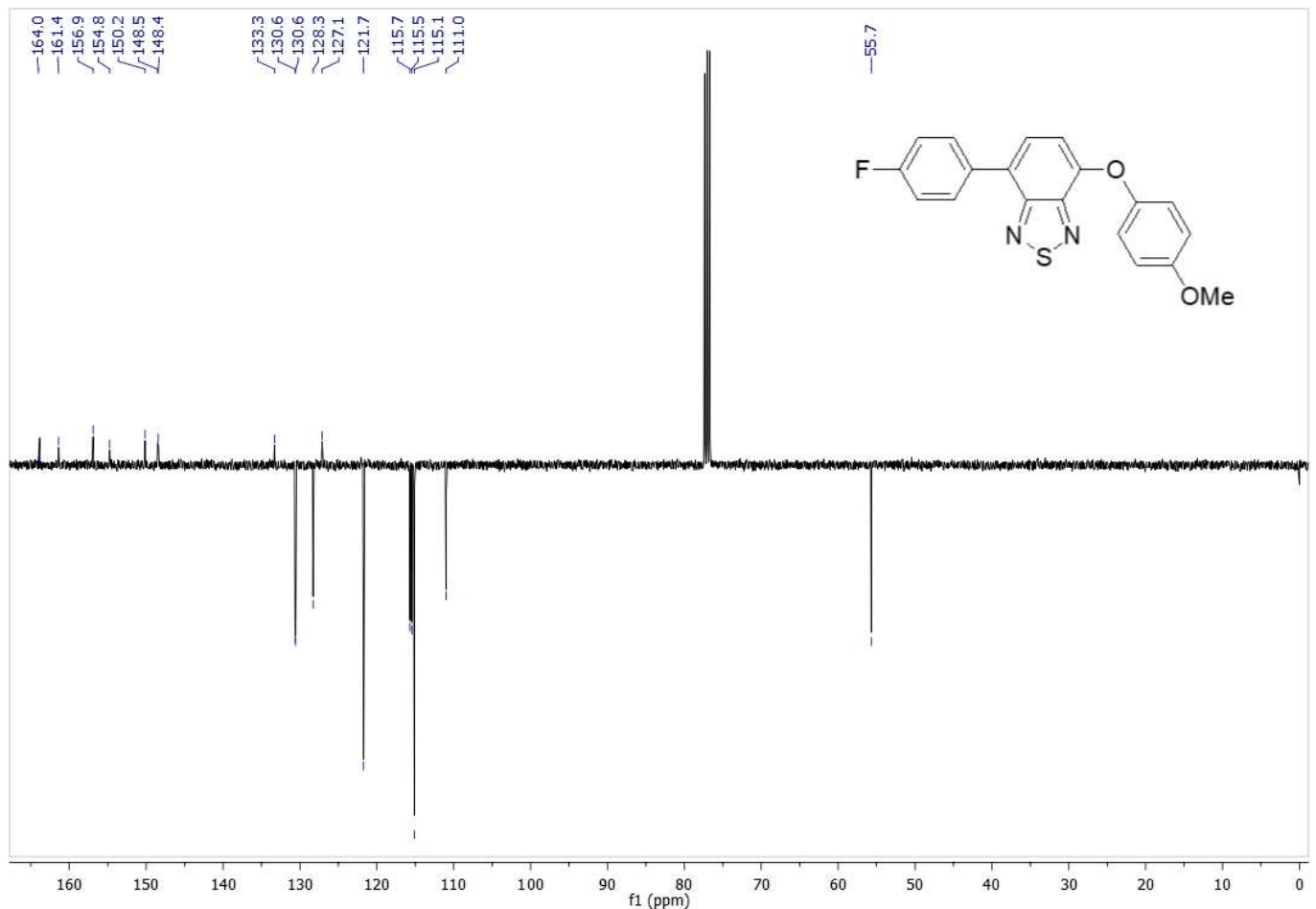

Figura S6. Espectro de $\mathrm{RMN}{ }^{13} \mathrm{C}\left(100 \mathrm{MHz}, \mathrm{CDCl}_{3}\right)$ do composto 44. 


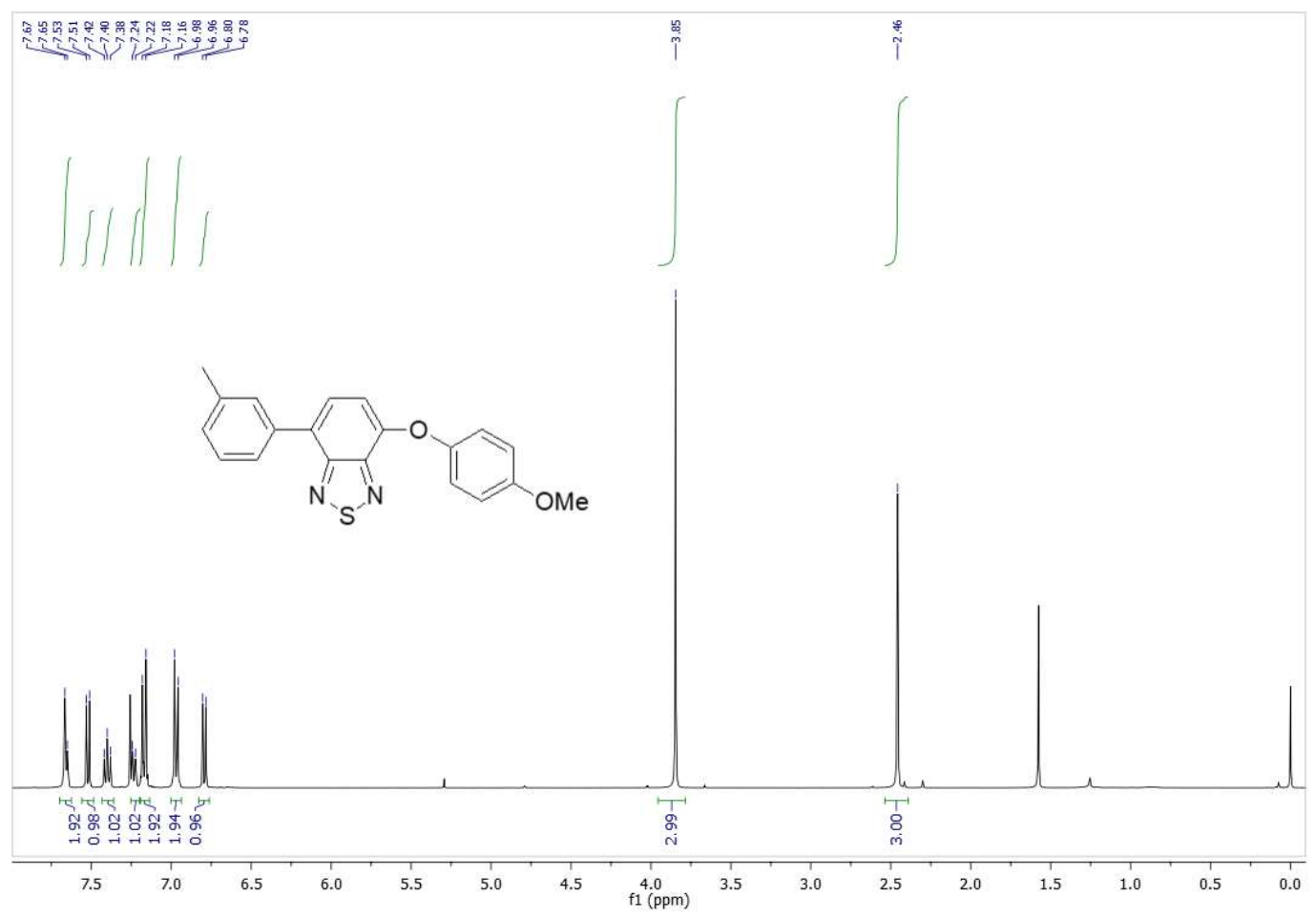

Figura S7. Espectro de $\mathrm{RMN}^{1} \mathrm{H}\left(400 \mathrm{MHz}, \mathrm{CDCl}_{3}\right)$ do composto 45.

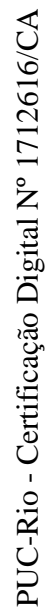

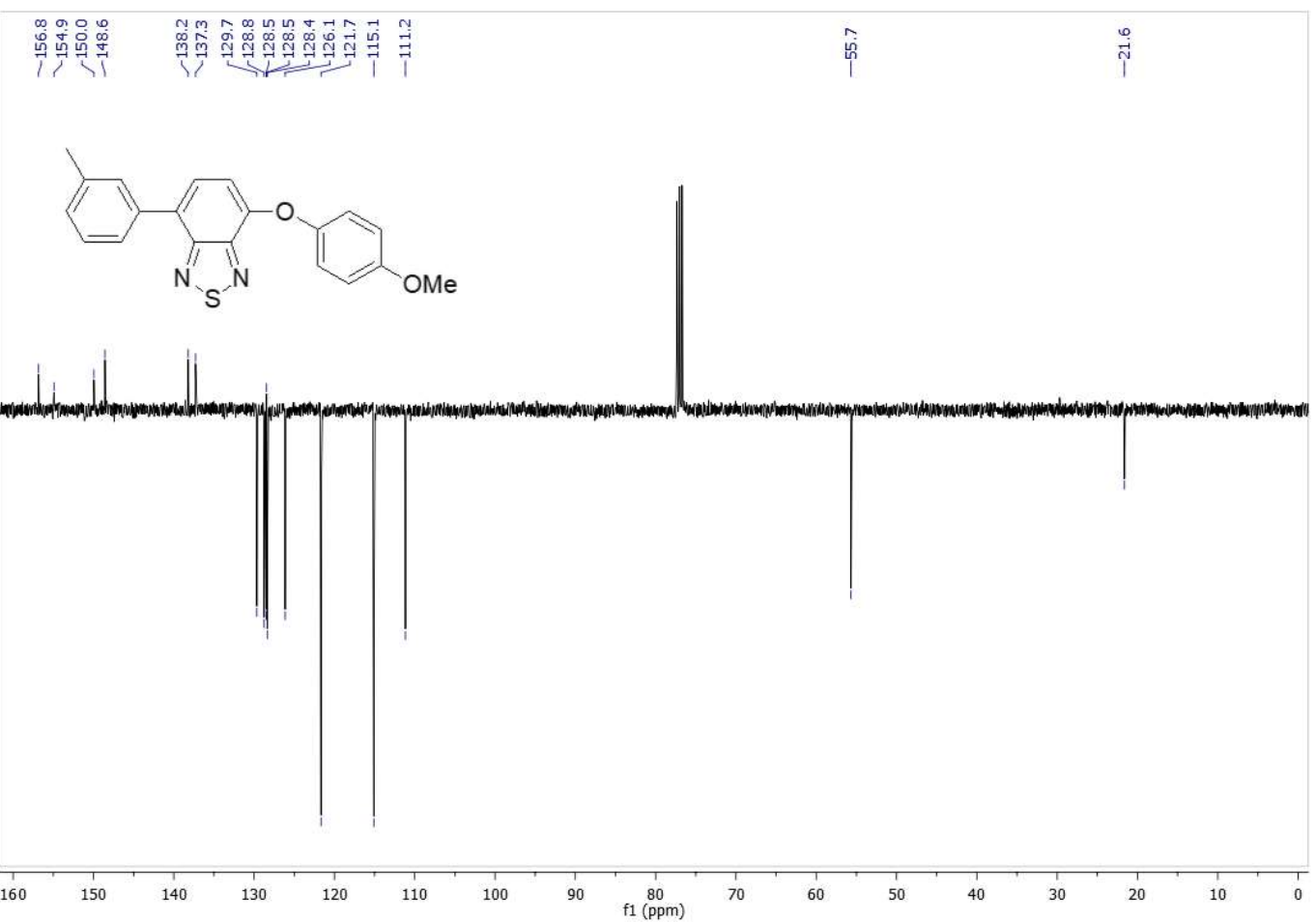

Figura S8. Espectro de $\mathrm{RMN}{ }^{13} \mathrm{C}\left(100 \mathrm{MHz}, \mathrm{CDCl}_{3}\right)$ do composto 45. 


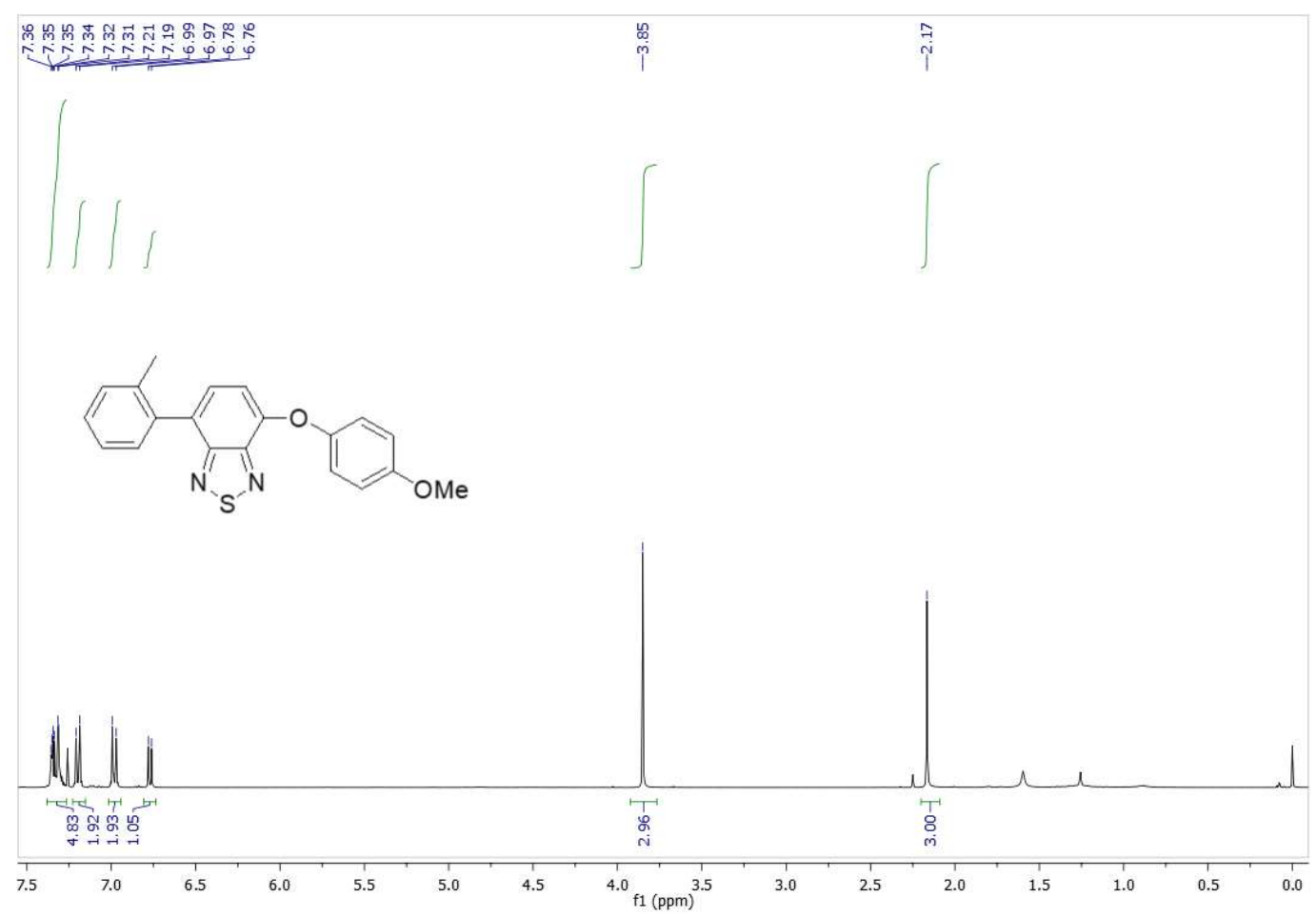

Figura S9. Espectro de $\mathrm{RMN}^{1} \mathrm{H}\left(400 \mathrm{MHz}, \mathrm{CDCl}_{3}\right)$ do composto 46.

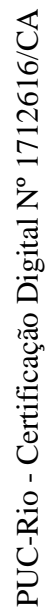

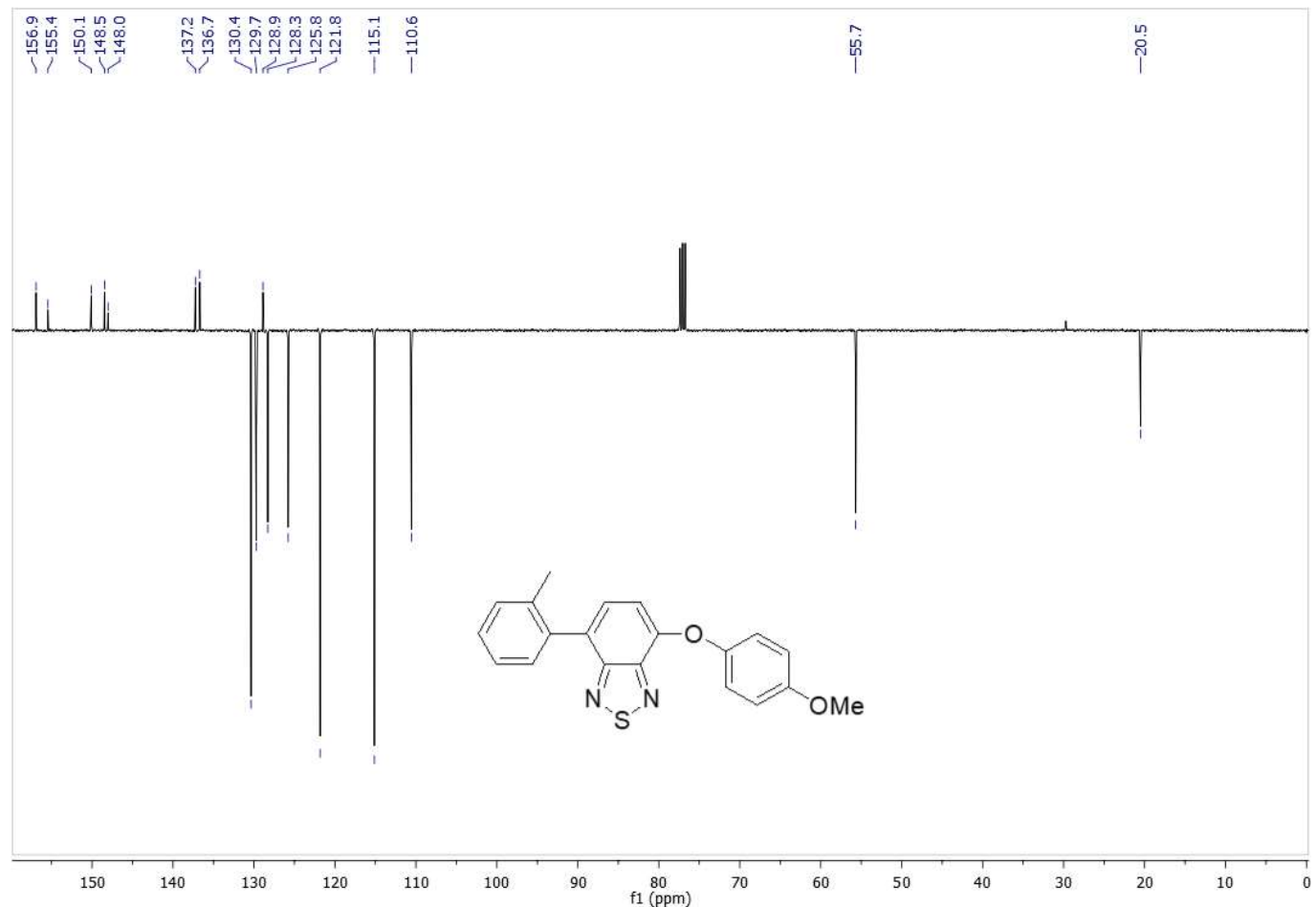

Figura S10. Espectro de RMN ${ }^{13} \mathrm{C}\left(100 \mathrm{MHz}, \mathrm{CDCl}_{3}\right)$ do composto 46. 


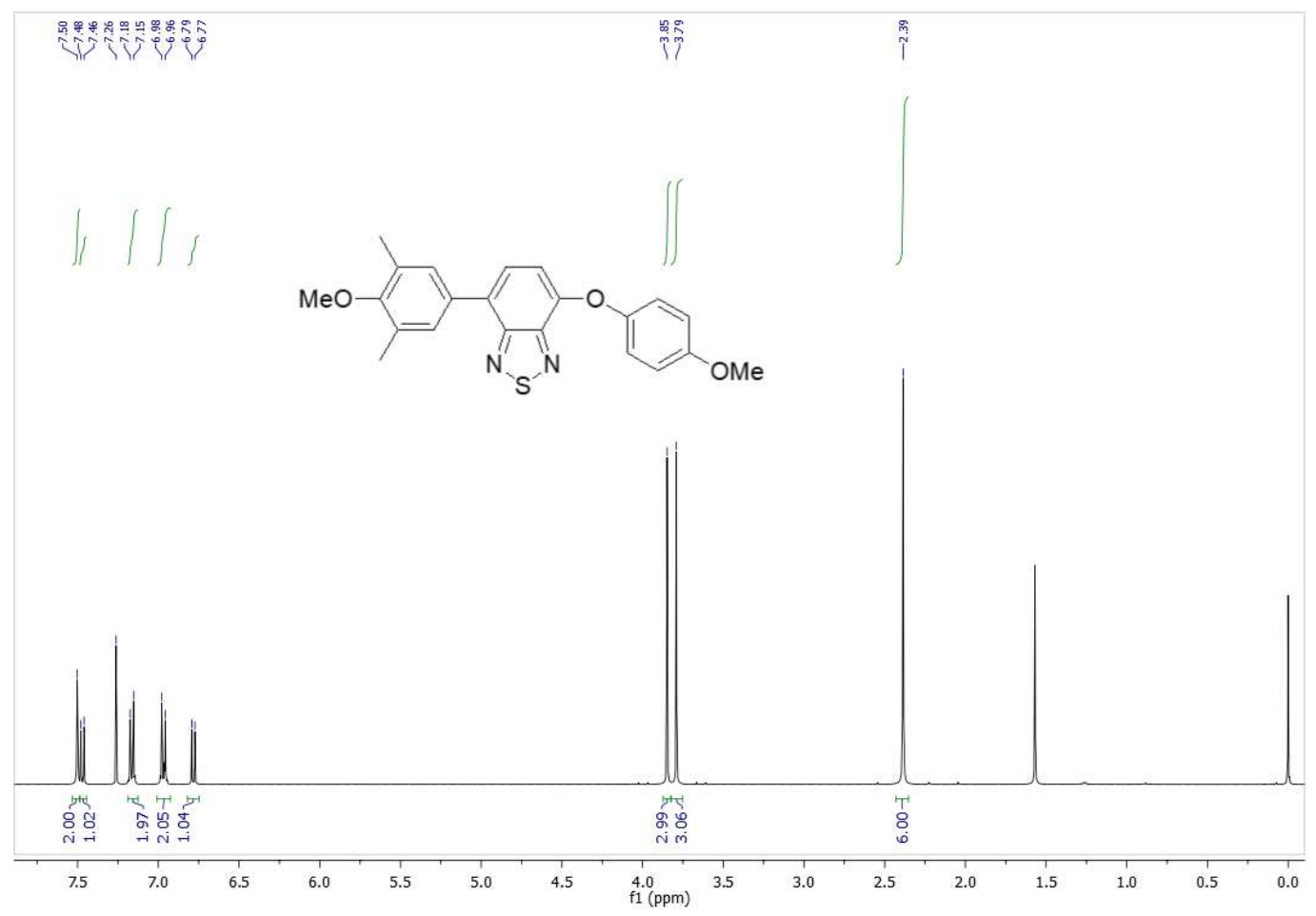

Figura S11. Espectro de RMN ${ }^{1} \mathrm{H}\left(400 \mathrm{MHz}, \mathrm{CDCl}_{3}\right)$ do composto 47.

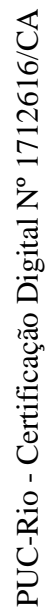

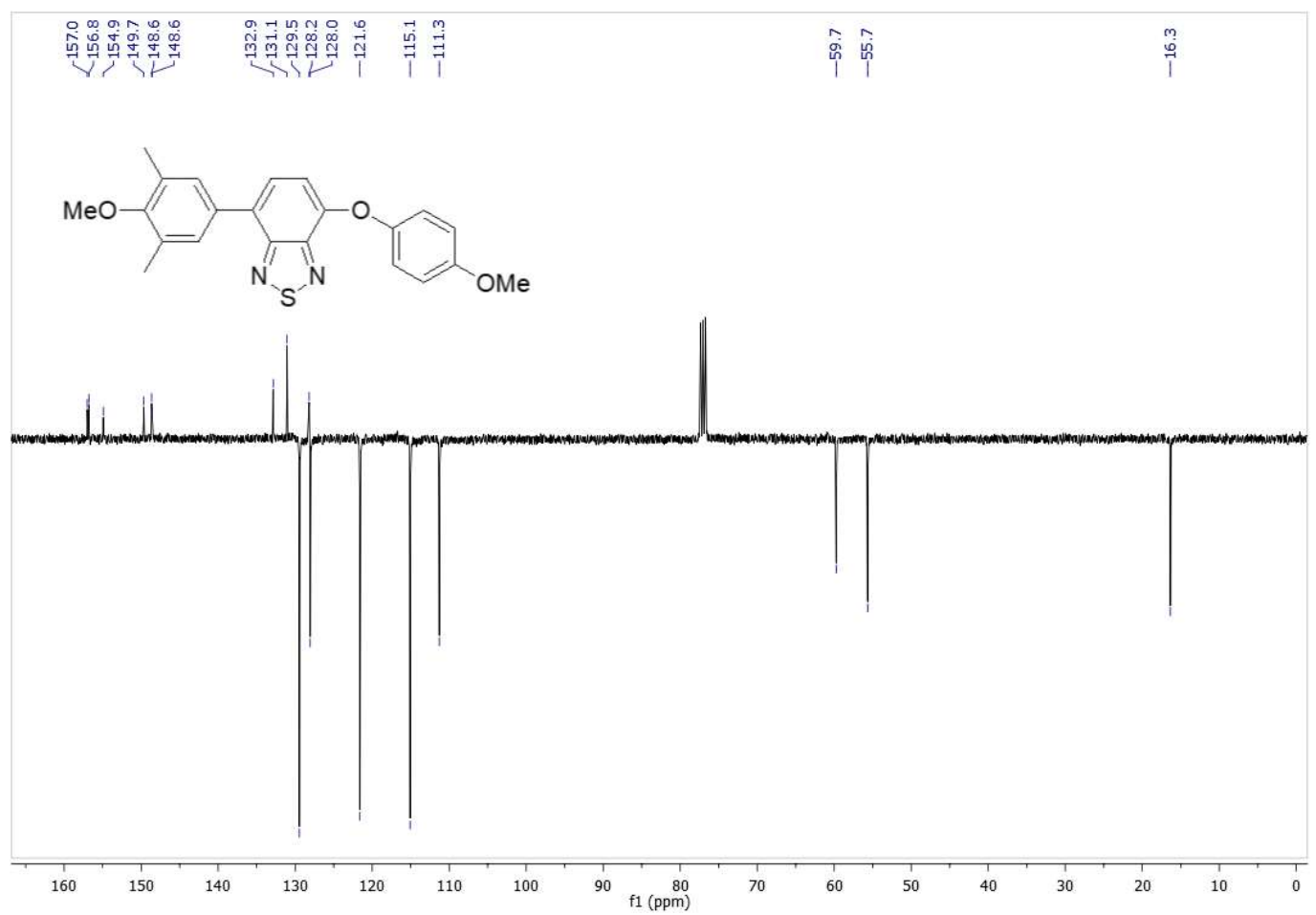

Figura S12. Espectro de RMN ${ }^{13} \mathrm{C}\left(100 \mathrm{MHz}, \mathrm{CDCl}_{3}\right)$ do composto 47. 


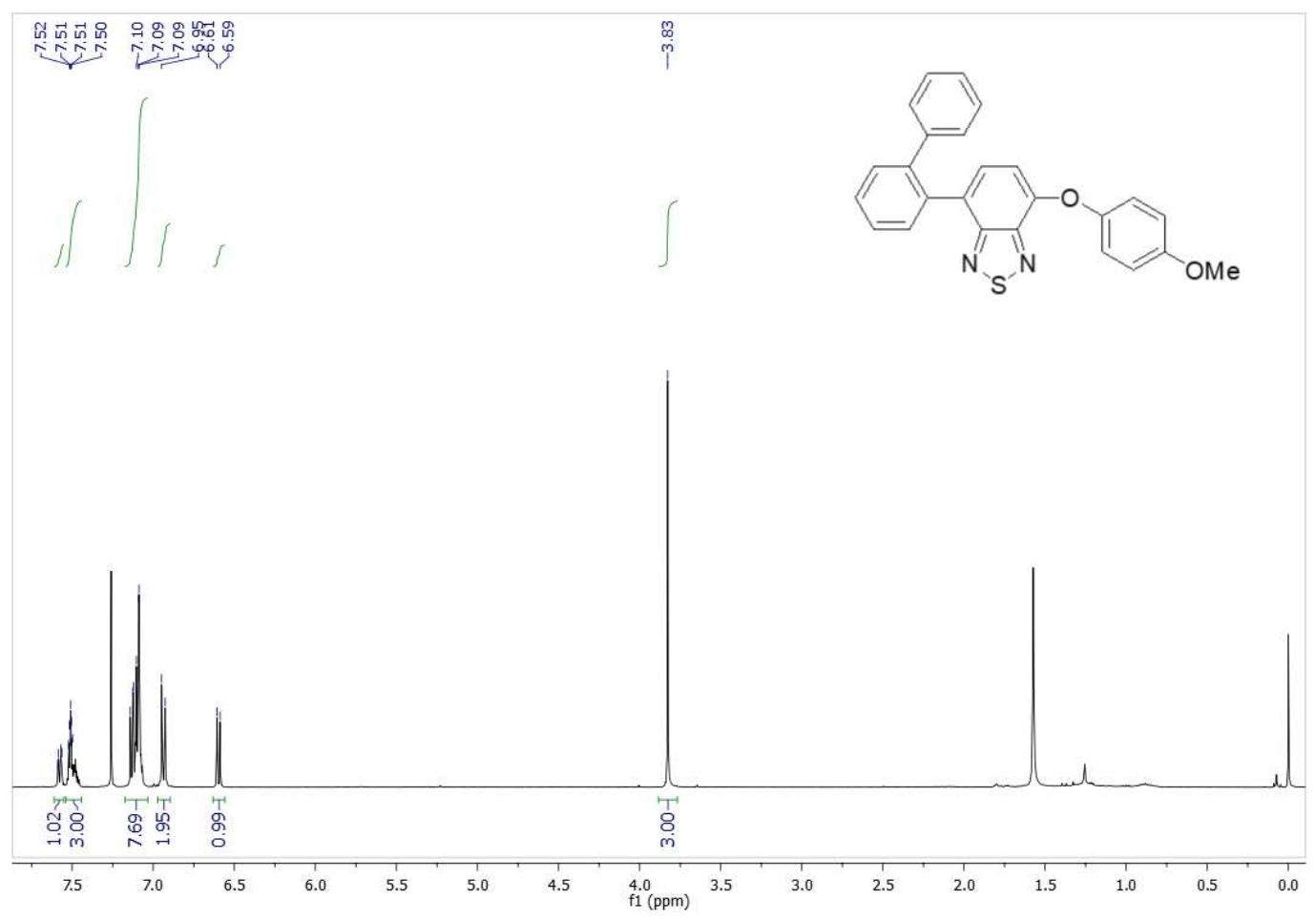

Figura S13. Espectro de RMN ${ }^{1} \mathrm{H}\left(400 \mathrm{MHz}, \mathrm{CDCl}_{3}\right)$ do composto 48.

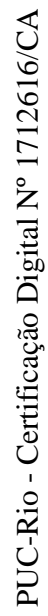

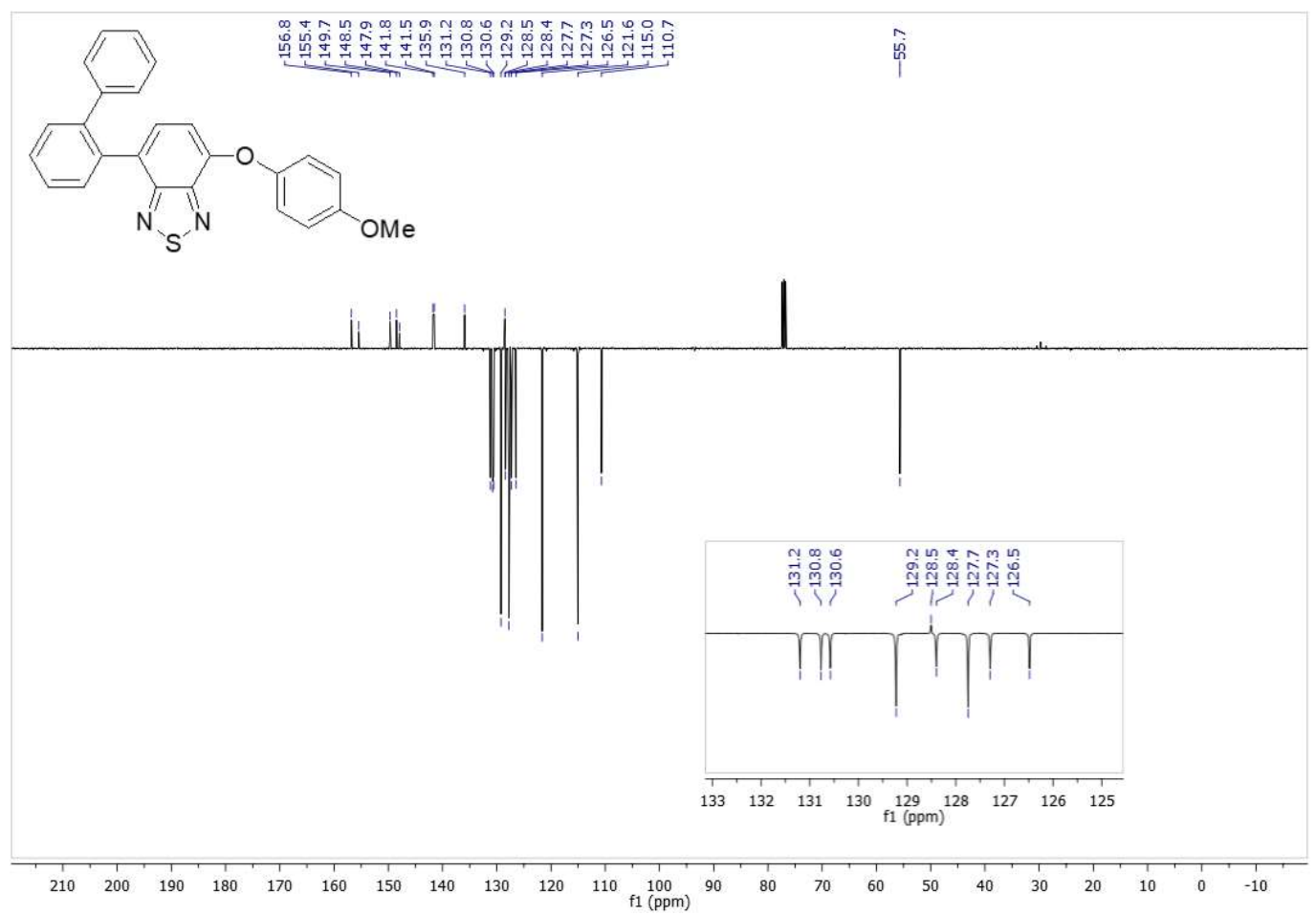

Figura S14. Espectro de RMN ${ }^{13} \mathrm{C}\left(100 \mathrm{MHz}, \mathrm{CDCl}_{3}\right)$ do composto 48. 


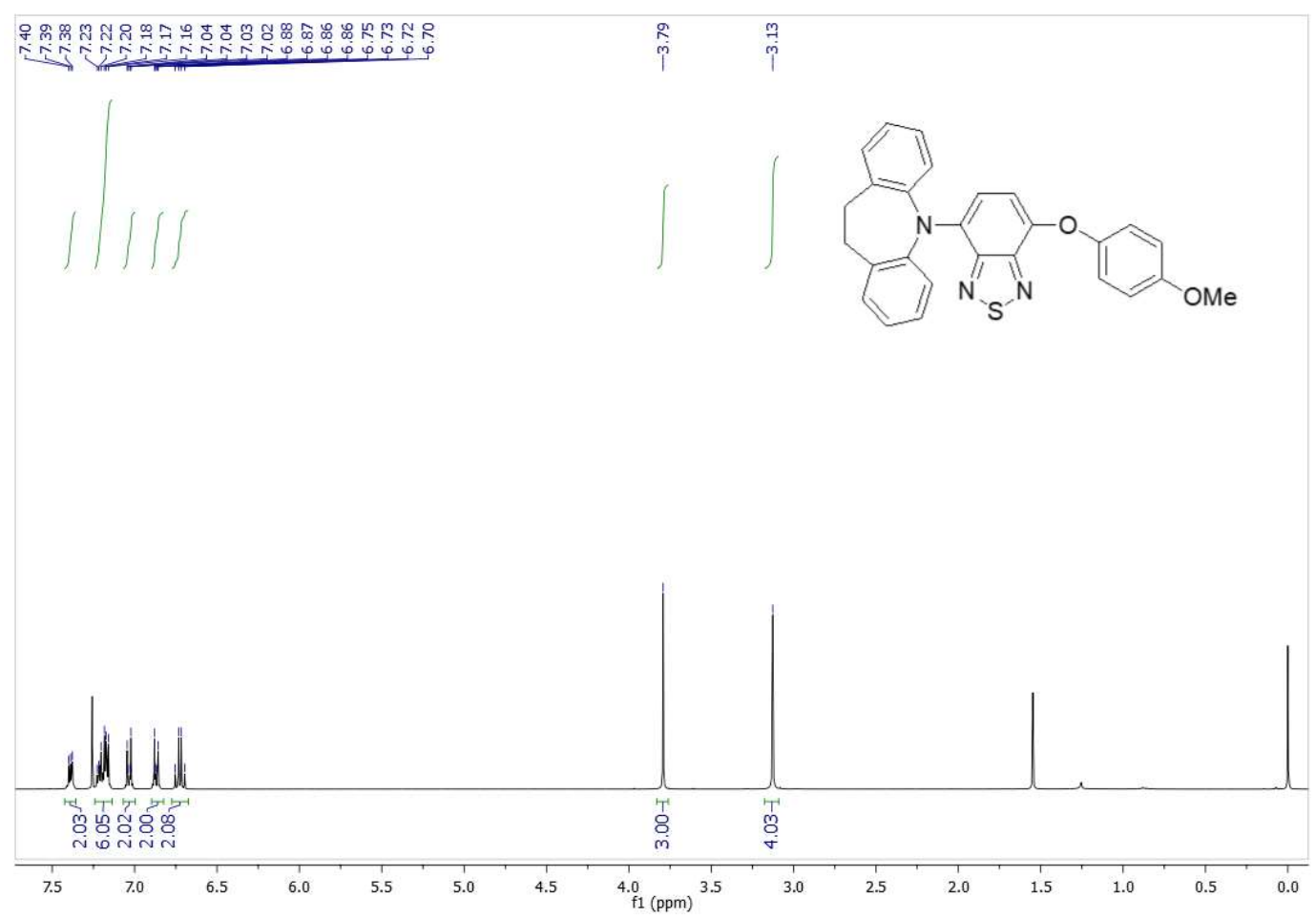

Figura S15. Espectro de RMN ${ }^{1} \mathrm{H}\left(400 \mathrm{MHz}, \mathrm{CDCl}_{3}\right)$ do composto 49.

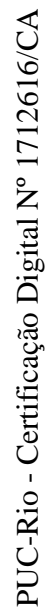

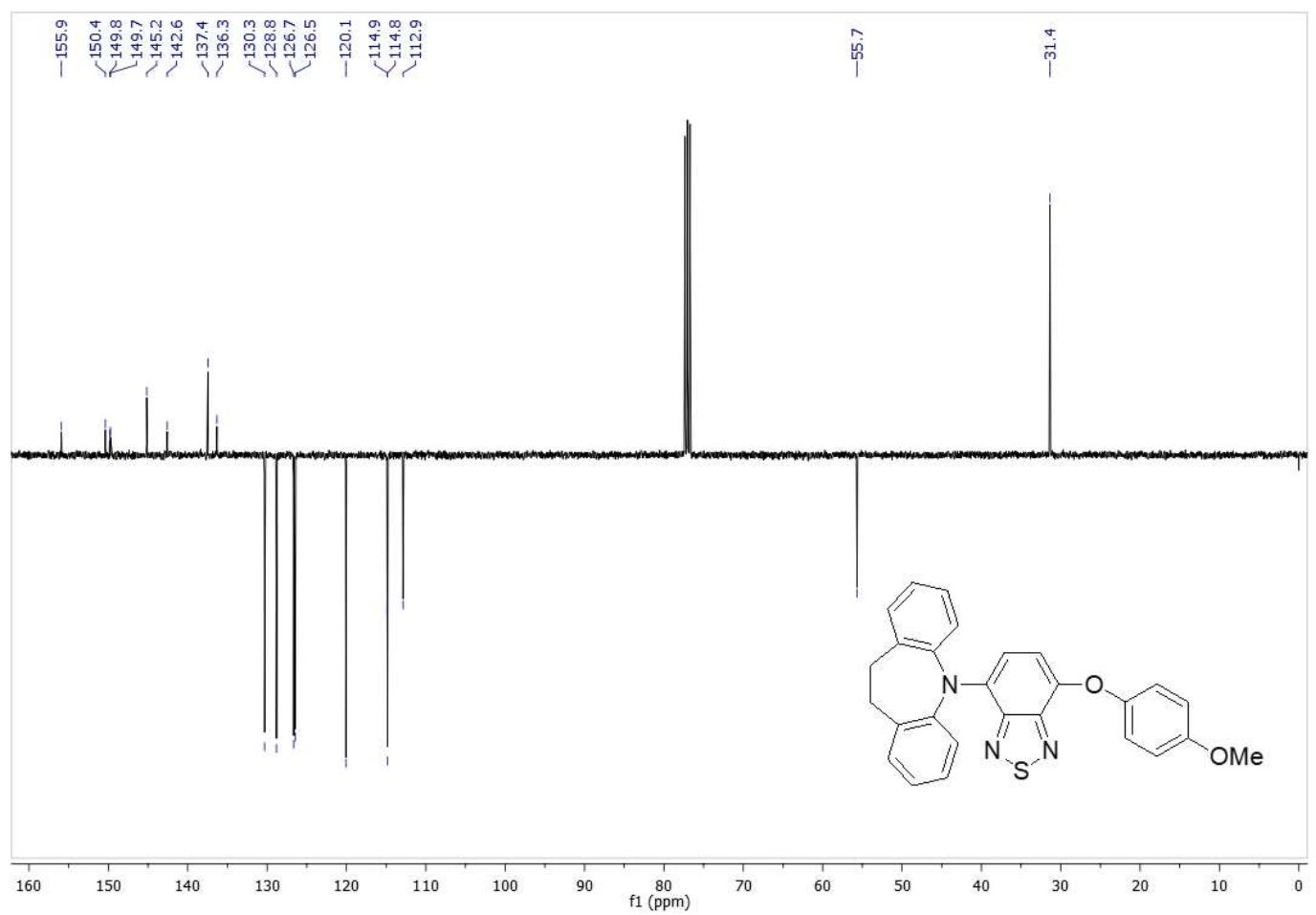

Figura S16. Espectro de RMN ${ }^{13} \mathrm{C}\left(100 \mathrm{MHz}, \mathrm{CDCl}_{3}\right)$ do composto 49. 


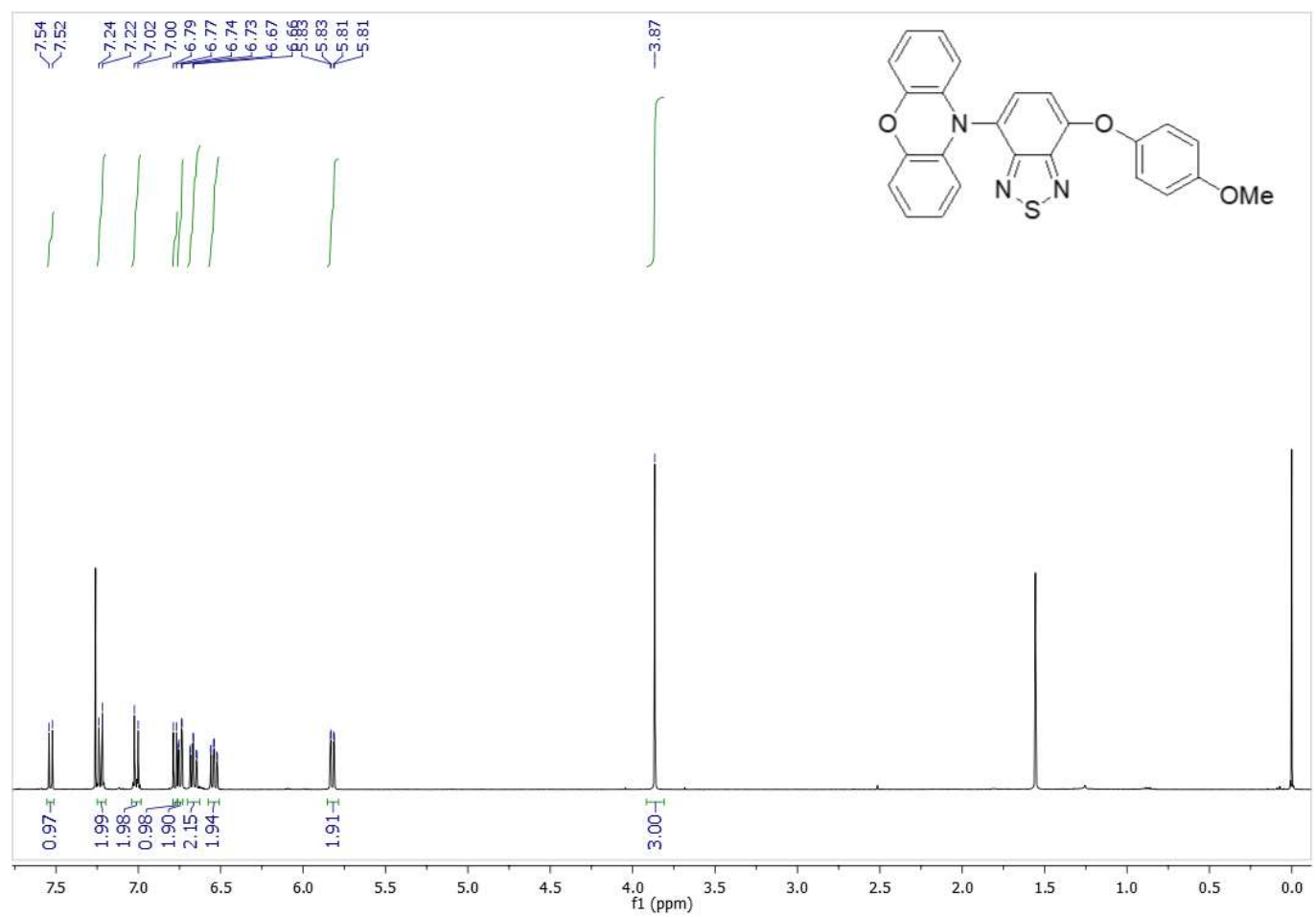

Figura S17. Espectro de RMN ${ }^{1} \mathrm{H}\left(400 \mathrm{MHz}, \mathrm{CDCl}_{3}\right)$ do composto 50.

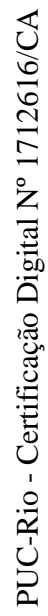

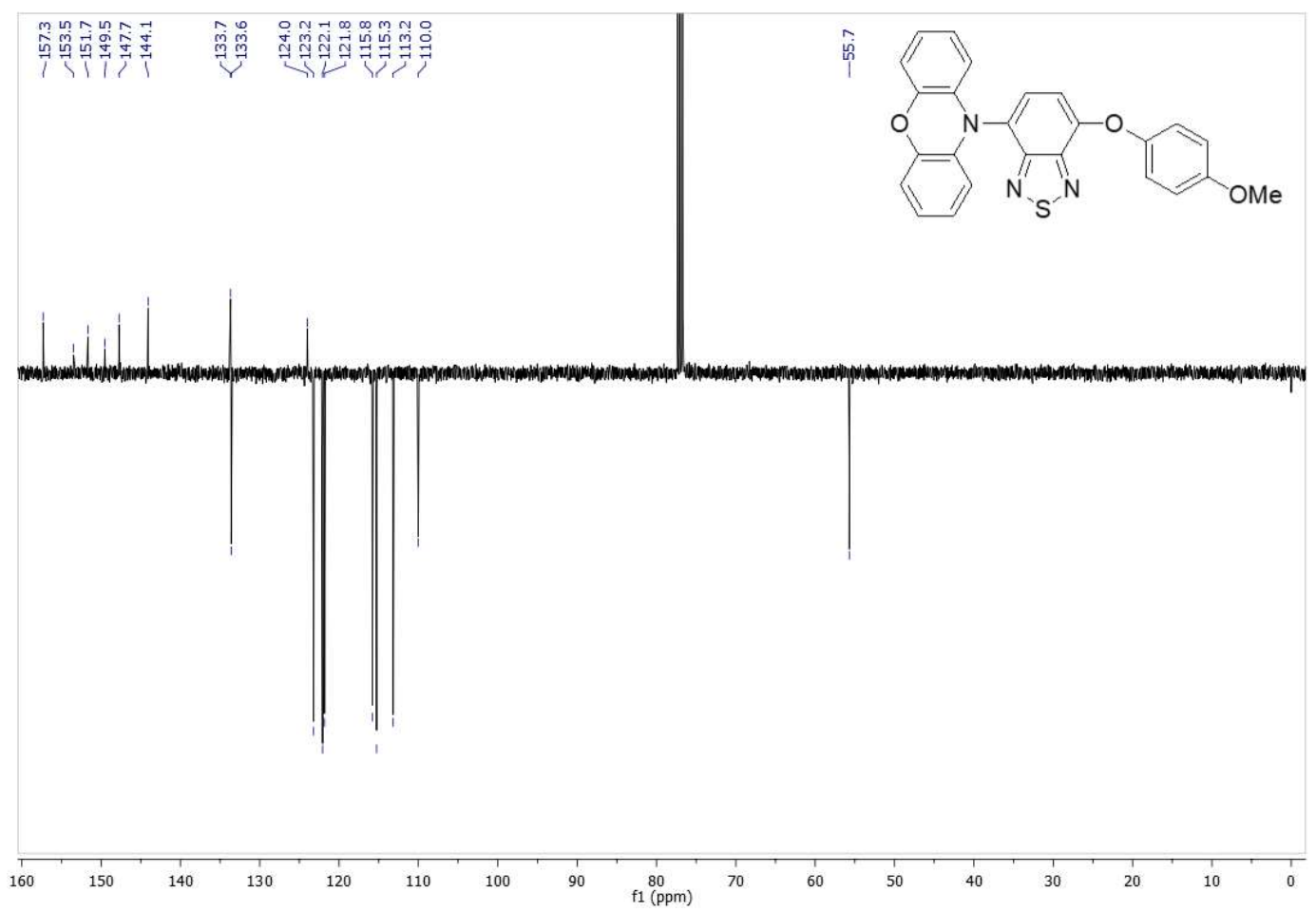

Figura S18. Espectro de RMN ${ }^{13} \mathrm{C}\left(100 \mathrm{MHz}, \mathrm{CDCl}_{3}\right)$ do composto 50. 


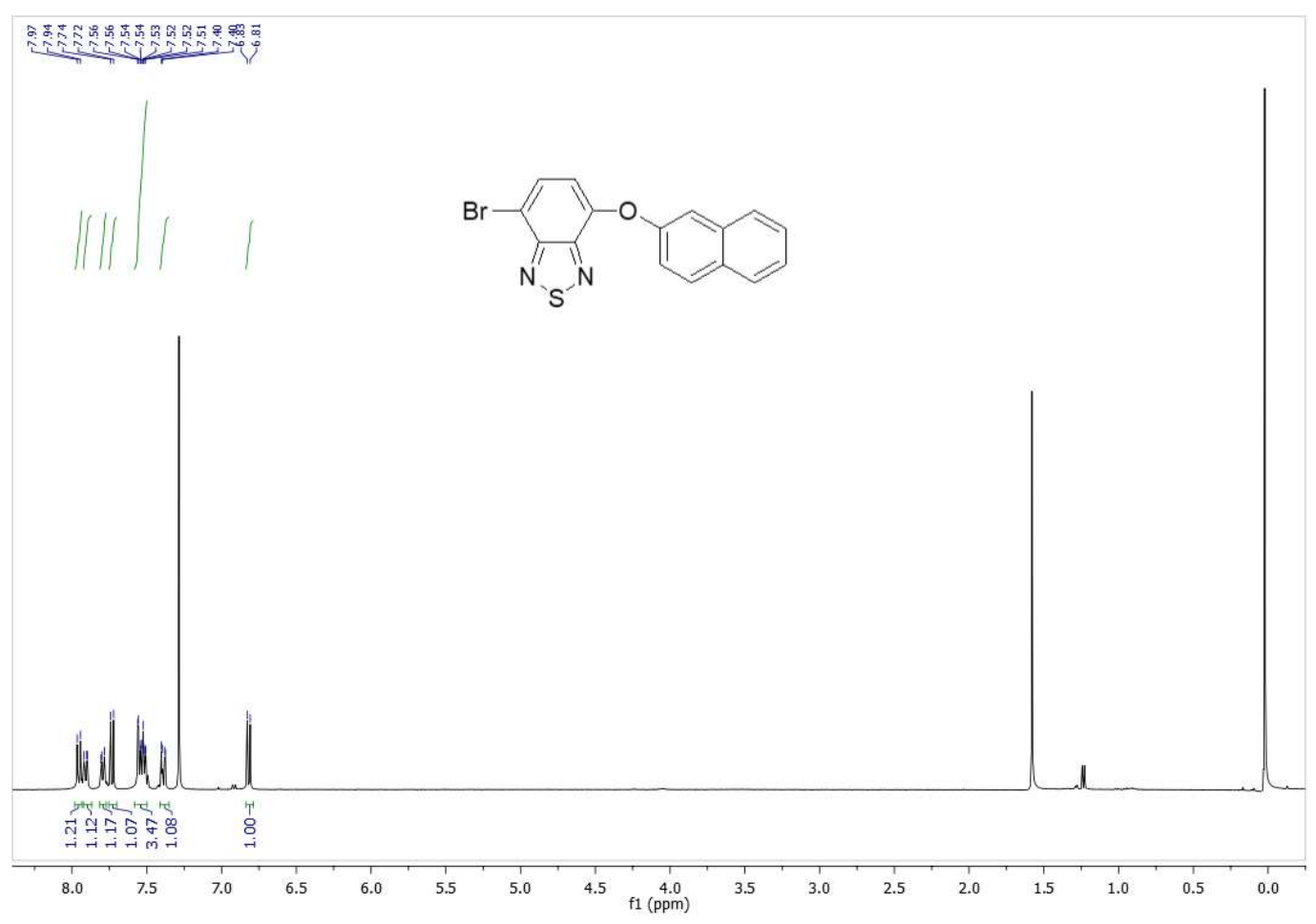

Figura S19. Espectro de $\mathrm{RMN}^{1} \mathrm{H}\left(400 \mathrm{MHz}, \mathrm{CDCl}_{3}\right)$ do composto 53.

Uీ

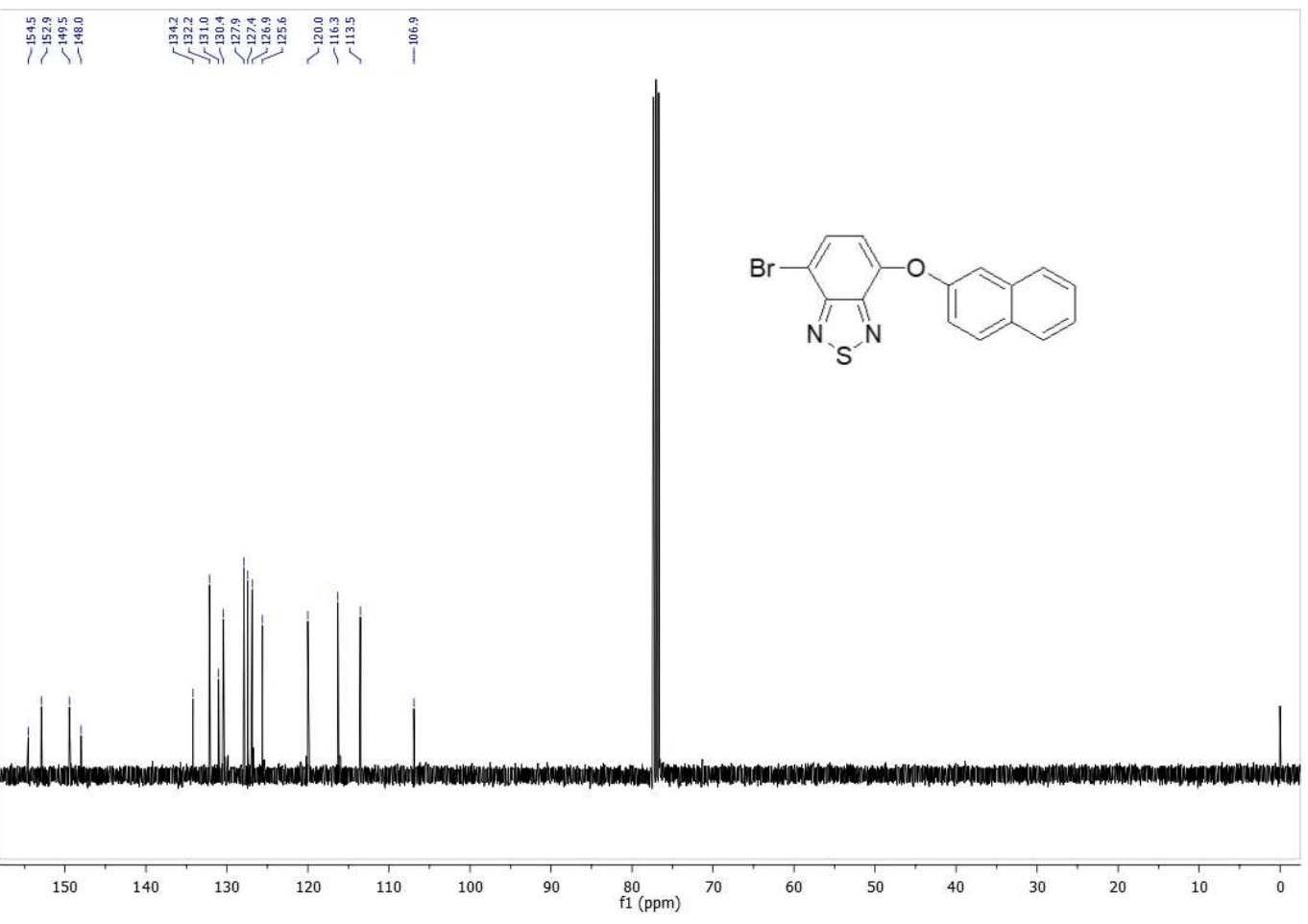

Figura S20. Espectro de RMN ${ }^{13} \mathrm{C}\left(100 \mathrm{MHz}, \mathrm{CDCl}_{3}\right)$ do composto 53. 


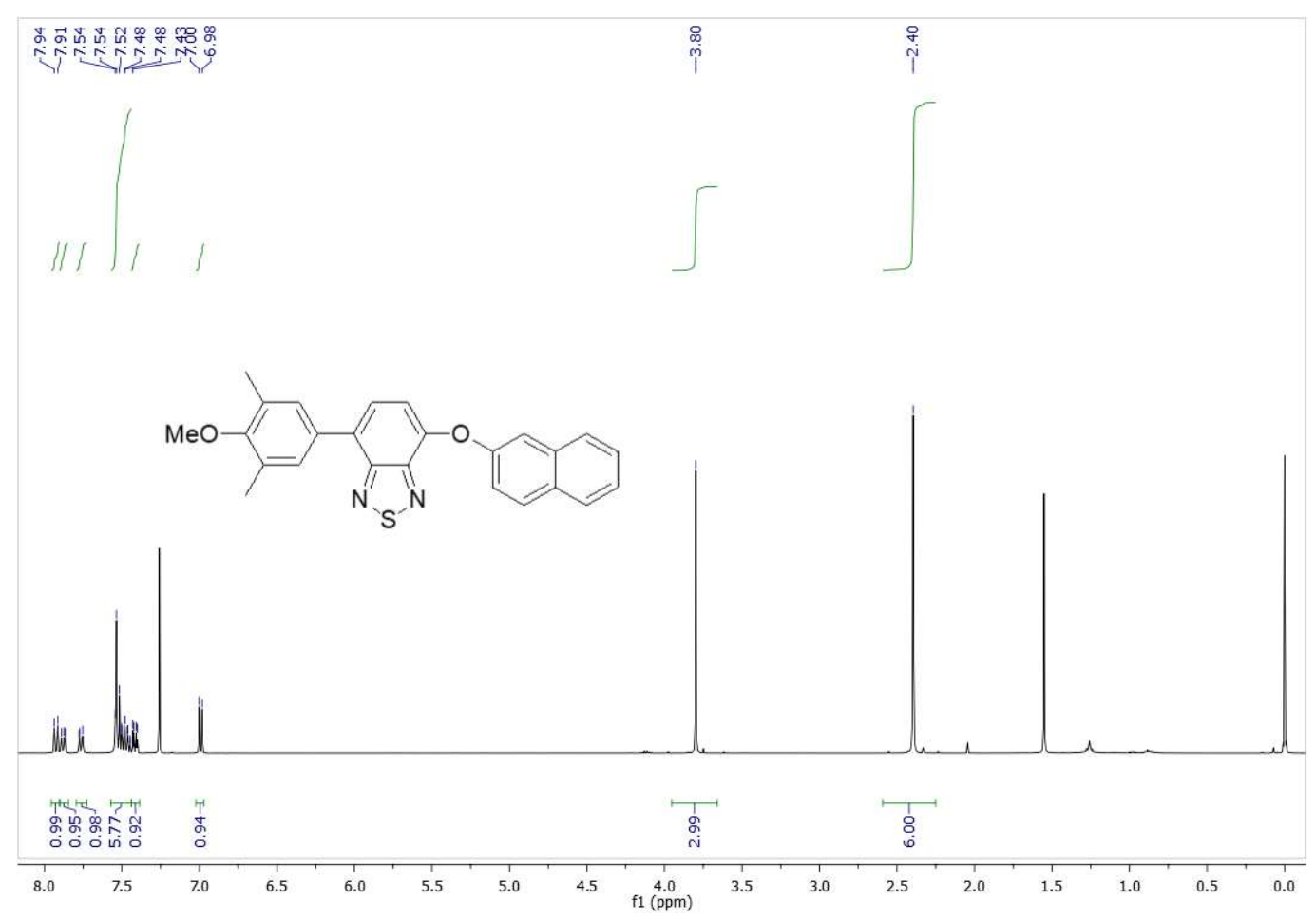

Figura S21. Espectro de RMN ${ }^{1} \mathrm{H}(400 \mathrm{MHz}, \mathrm{CDCl} 3)$ do composto 54.

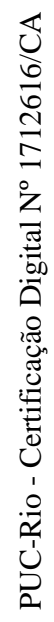

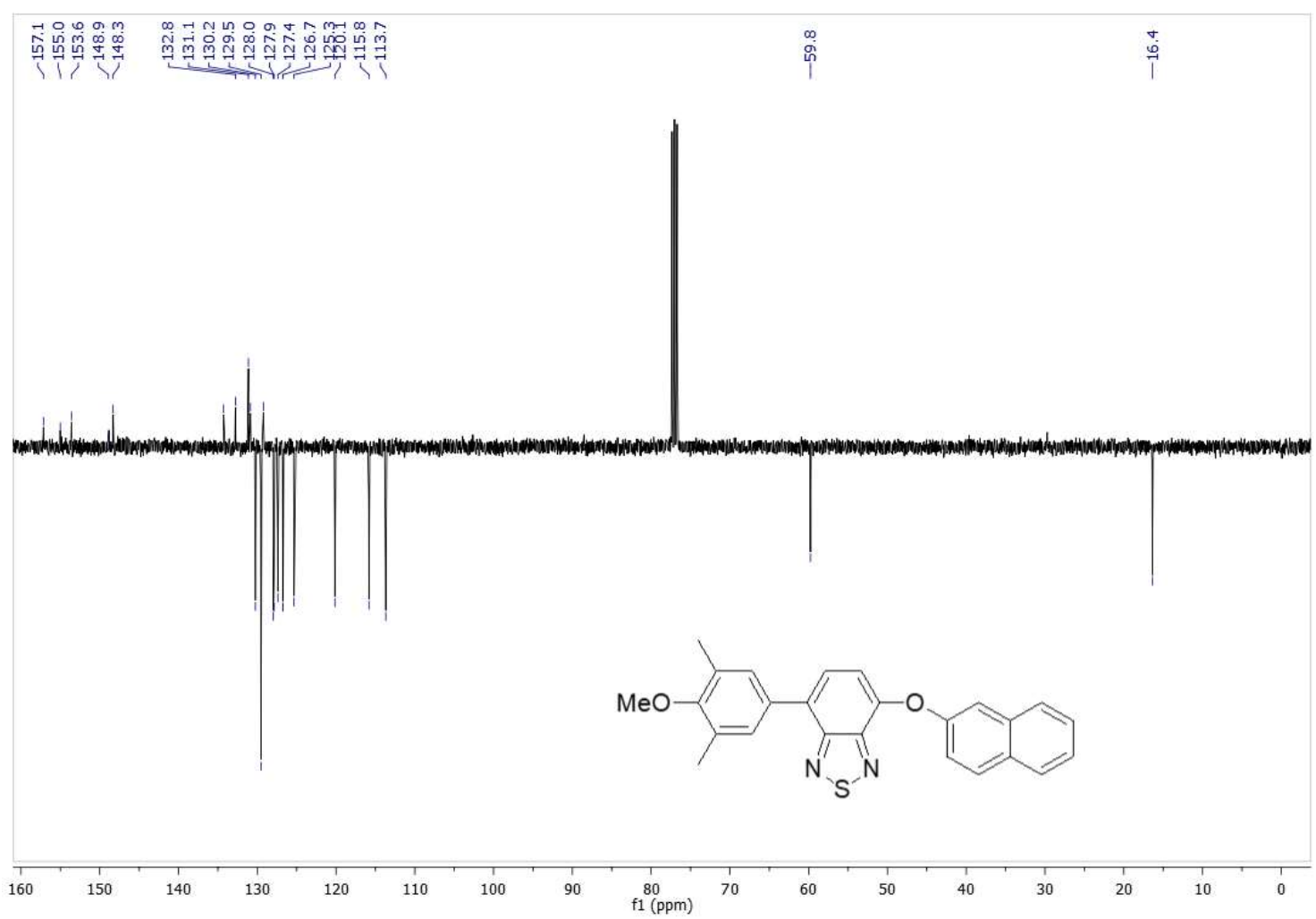

Figura S22. Espectro de $\mathrm{RMN}{ }^{13} \mathrm{C}\left(100 \mathrm{MHz}, \mathrm{CDCl}_{3}\right)$ do composto 54. 


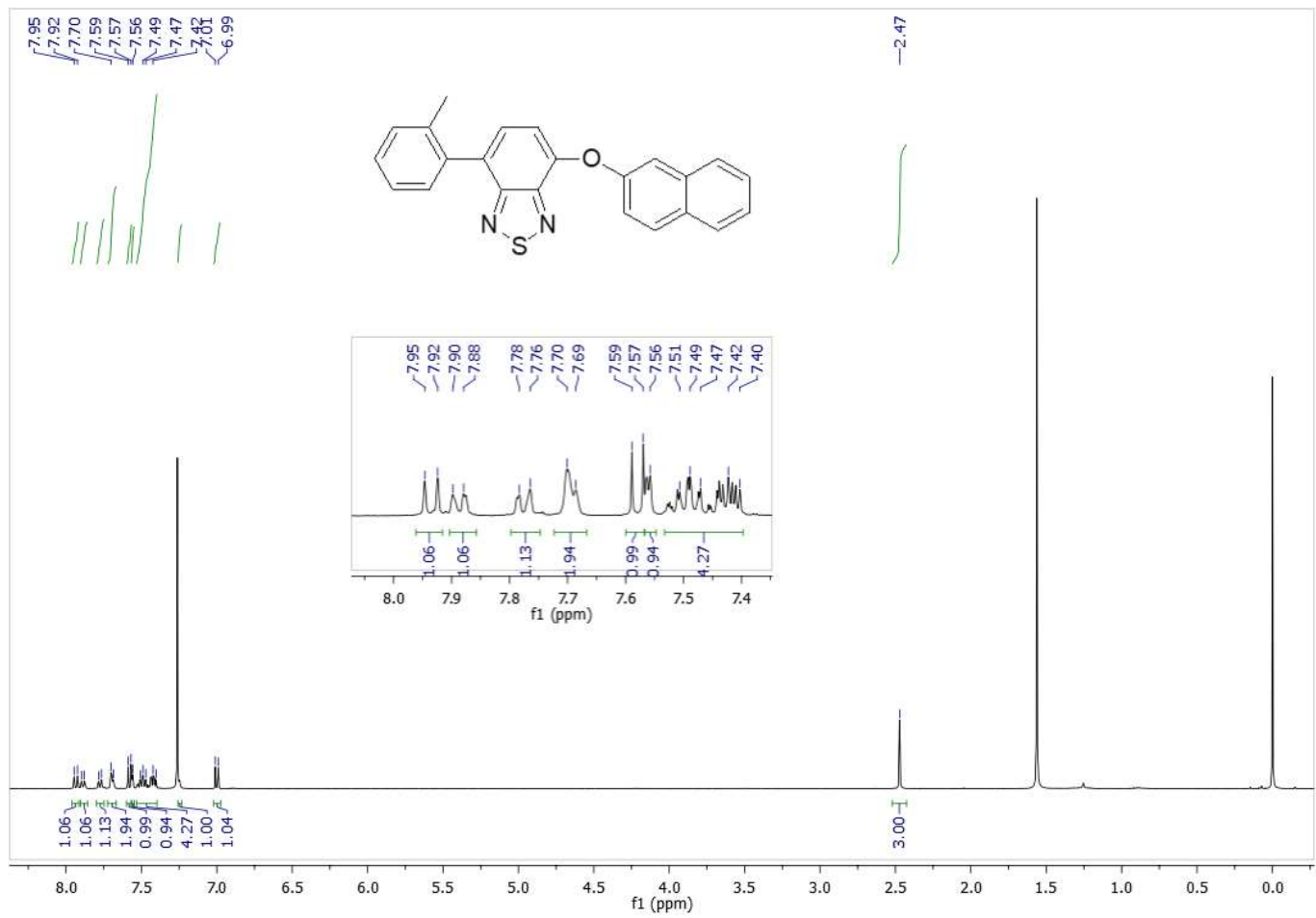

Figura S23. Espectro de RMN ${ }^{1} \mathrm{H}(400 \mathrm{MHz}, \mathrm{CDCl} 3)$ do composto 55.

Uీ

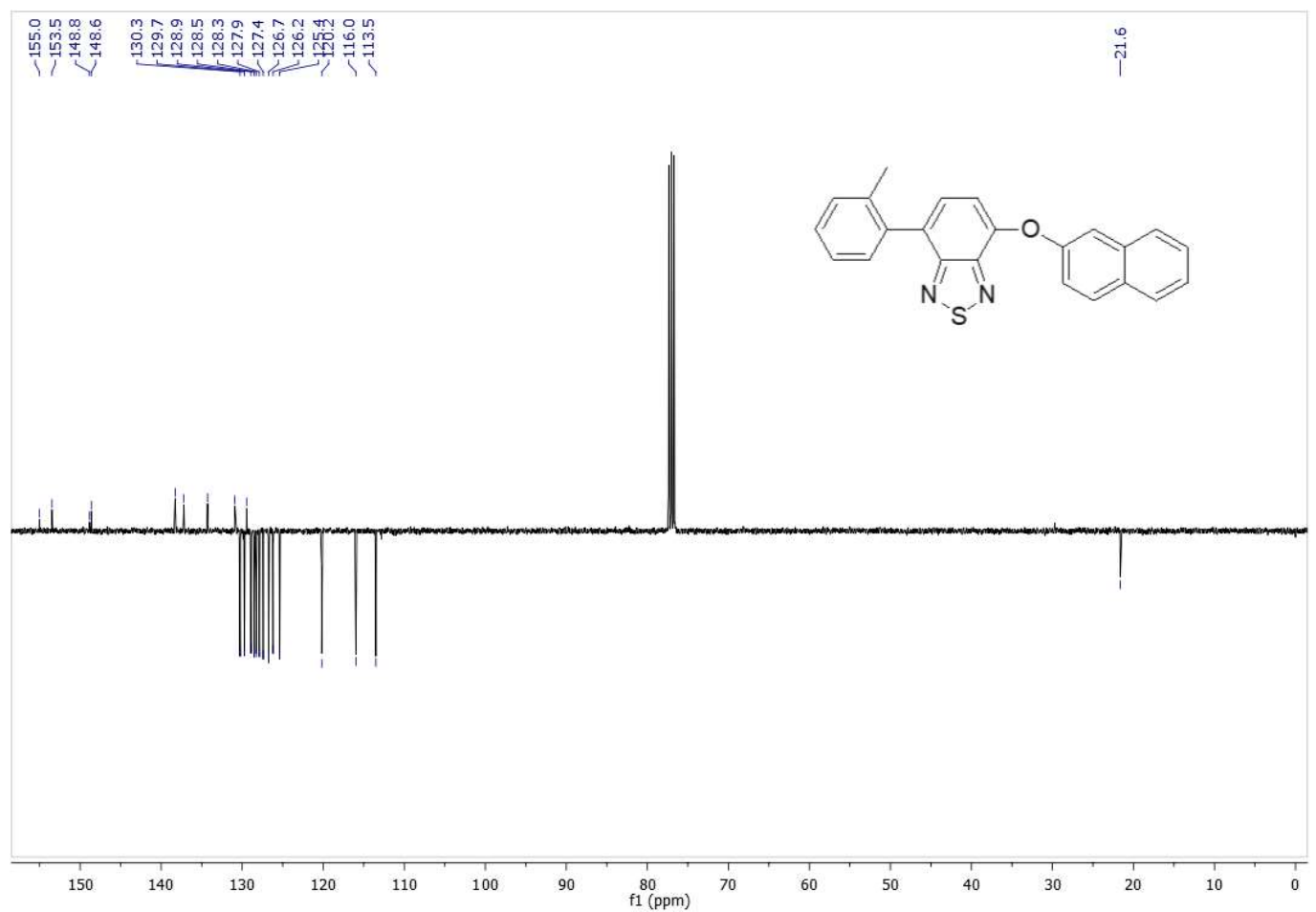

Figura S24. Espectro de RMN ${ }^{13} \mathrm{C}\left(100 \mathrm{MHz}, \mathrm{CDCl}_{3}\right)$ do composto 55. 


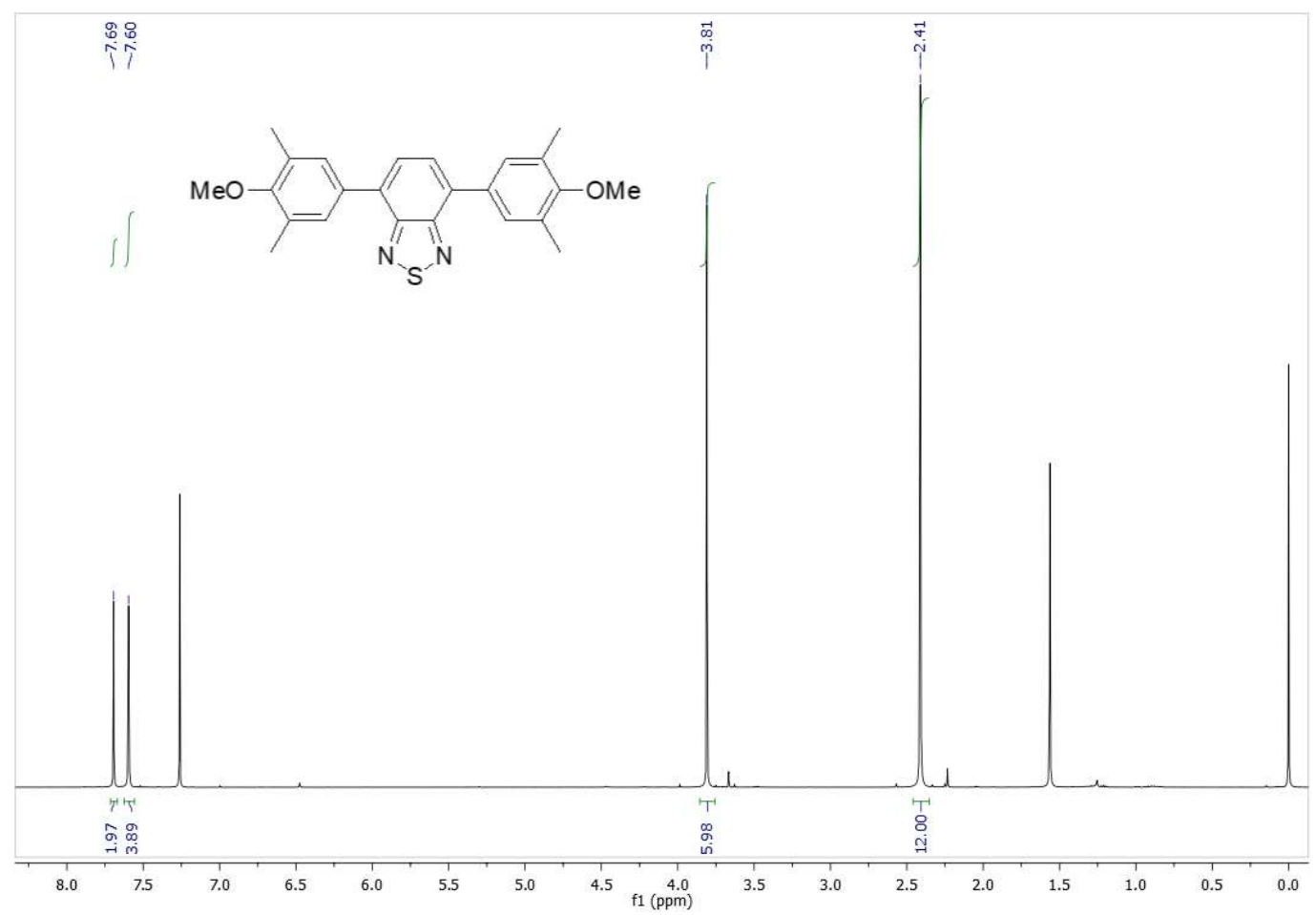

Figura S25. Espectro de RMN ${ }^{1} \mathrm{H}\left(400 \mathrm{MHz}, \mathrm{CDCl}_{3}\right)$ do composto 57.

Uీ

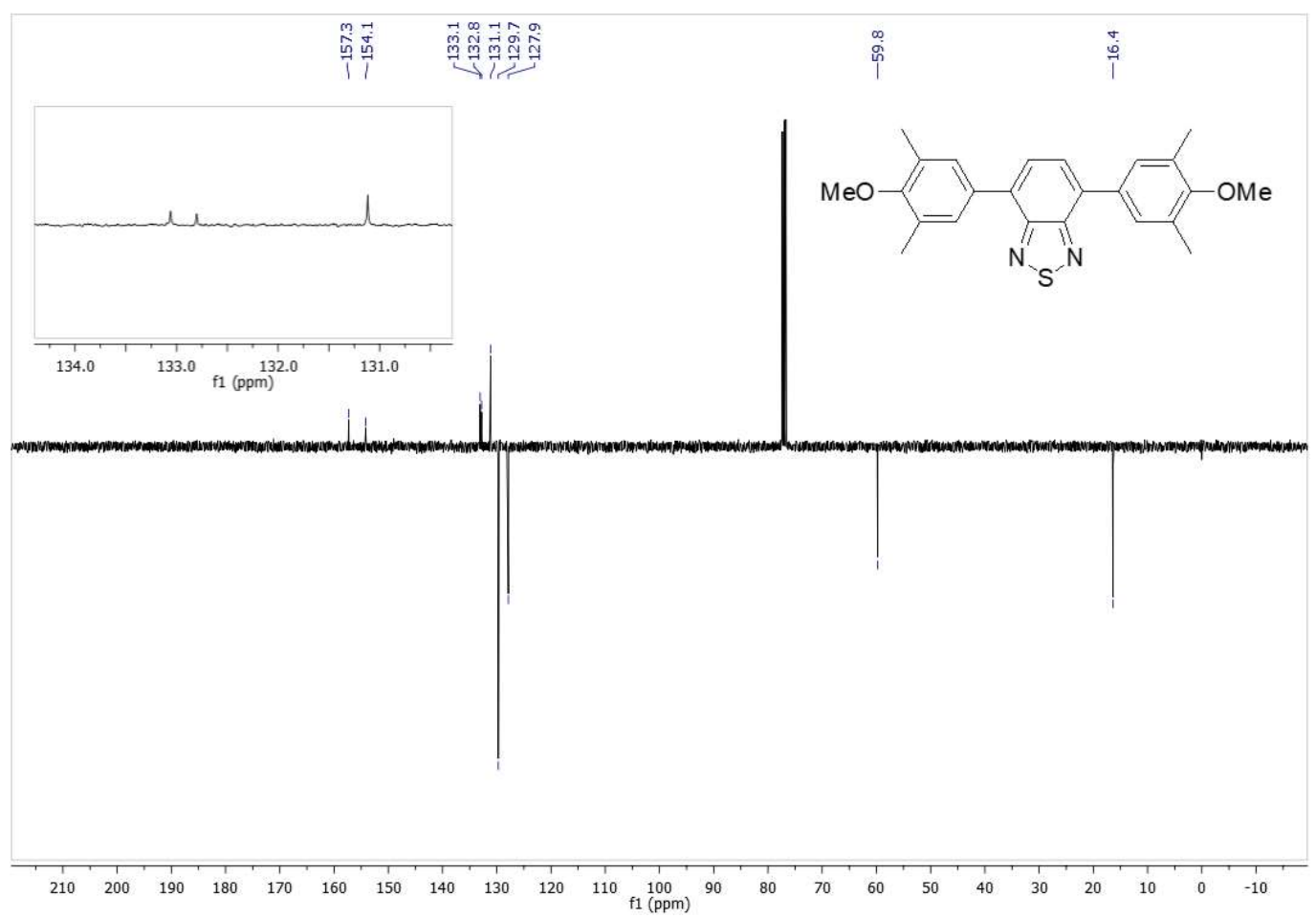

Figura S26. Espectro de RMN ${ }^{13} \mathrm{C}\left(100 \mathrm{MHz}, \mathrm{CDCl}_{3}\right)$ do composto 57. 


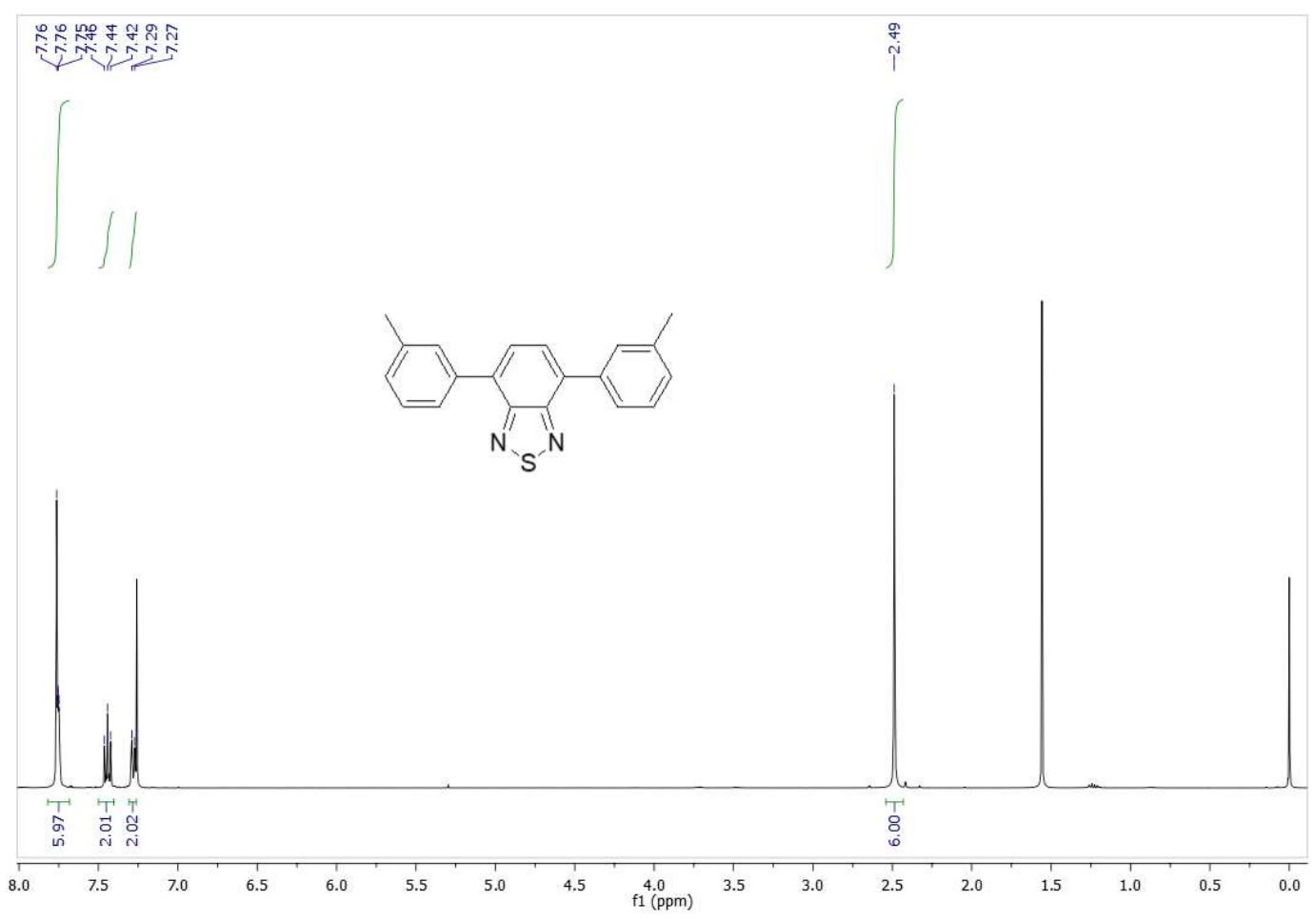

Figura S27. Espectro de RMN ${ }^{1} \mathrm{H}\left(400 \mathrm{MHz}, \mathrm{CDCl}_{3}\right)$ do composto 56.

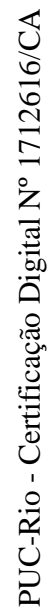

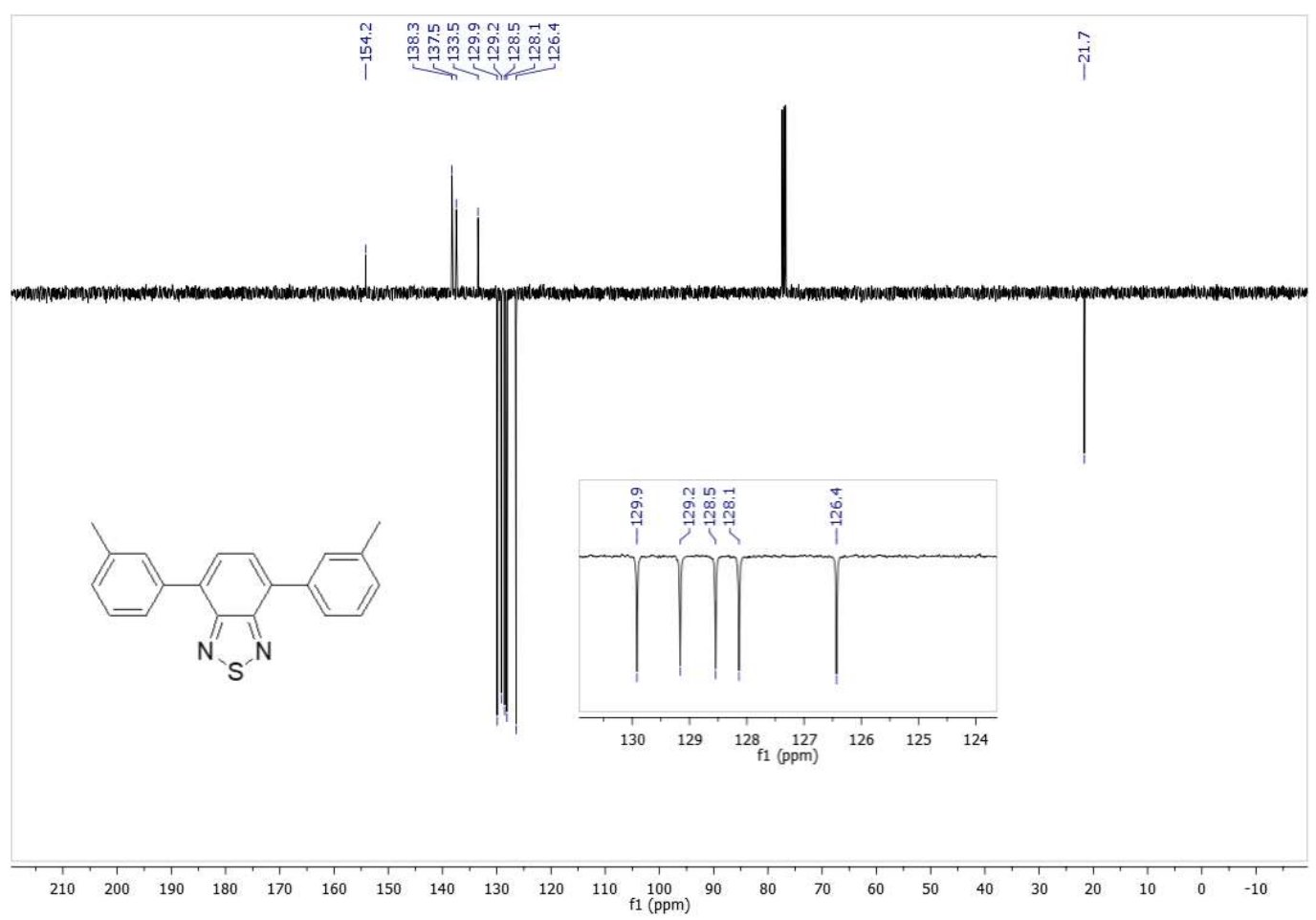

Figura S28. Espectro de $\mathrm{RMN}{ }^{13} \mathrm{C}\left(100 \mathrm{MHz}, \mathrm{CDCl}_{3}\right)$ do composto 56. 


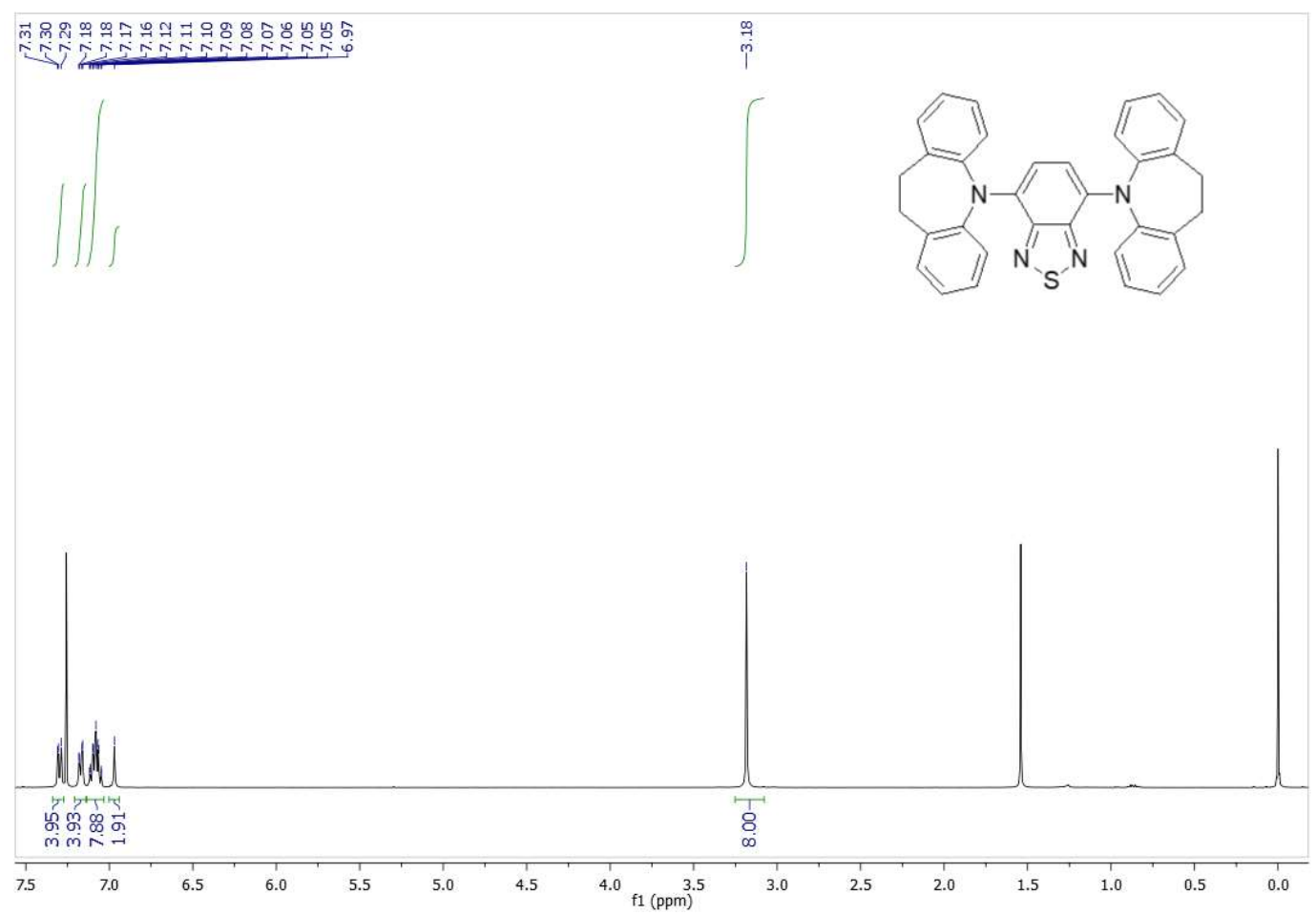

Figura S29. Espectro de RMN ${ }^{1} \mathrm{H}\left(400 \mathrm{MHz}, \mathrm{CDCl}_{3}\right)$ do composto 58 .

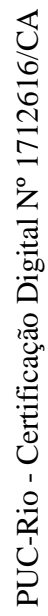

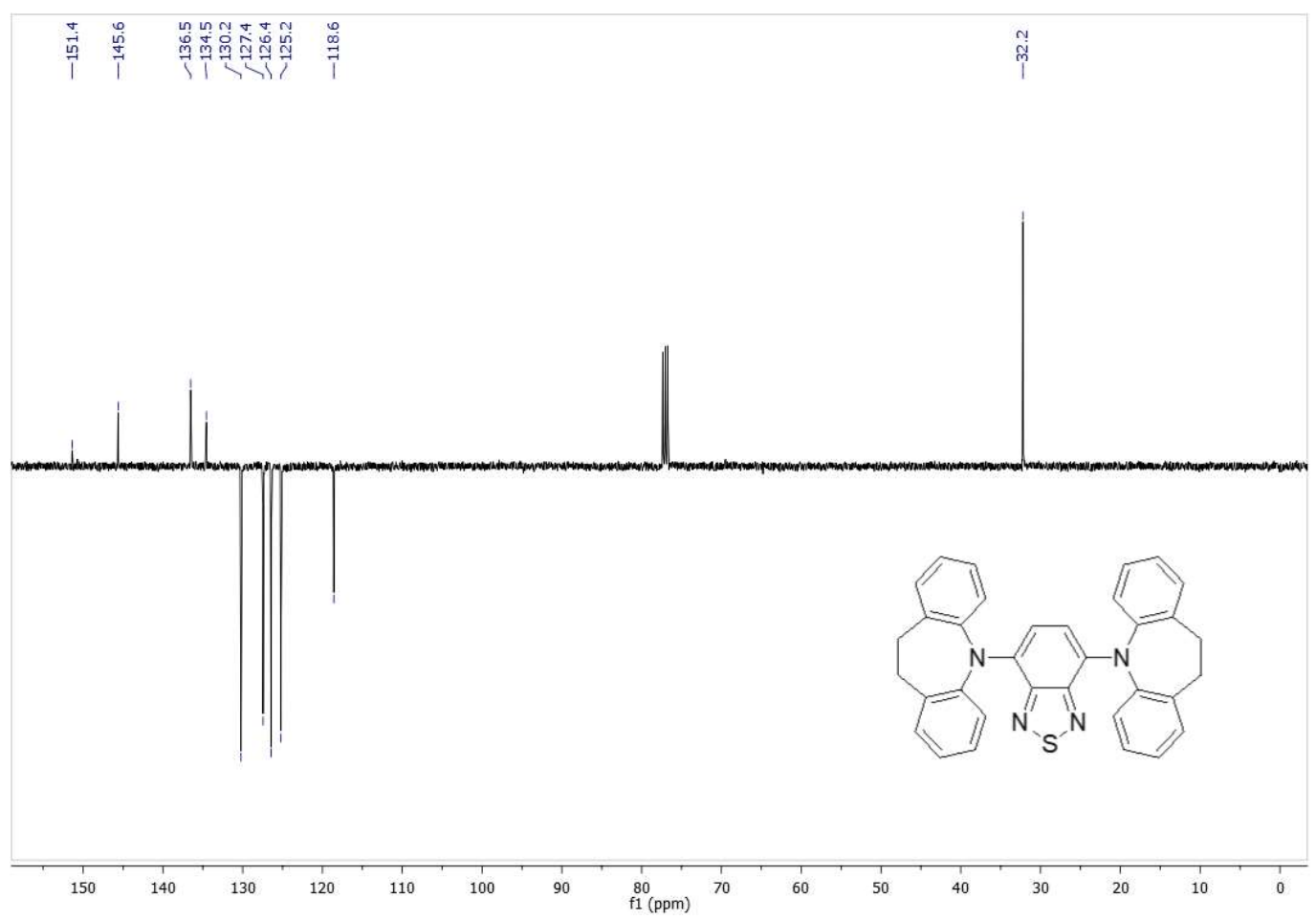

Figura S30. Espectro de RMN ${ }^{13} \mathrm{C}\left(100 \mathrm{MHz}, \mathrm{CDCl}_{3}\right)$ do composto 58. 


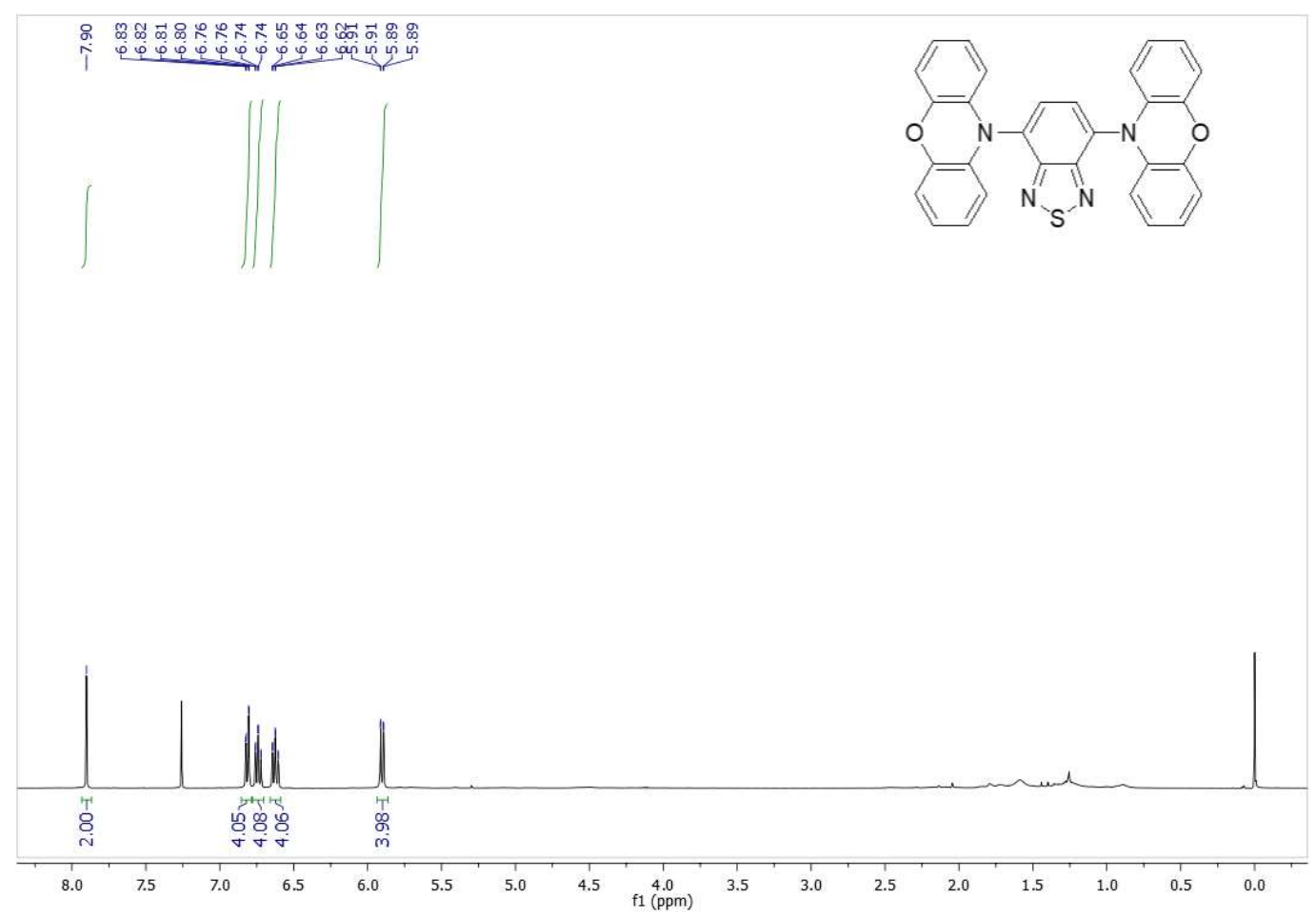

Figura S31. Espectro de $\mathrm{RMN}^{1} \mathrm{H}\left(400 \mathrm{MHz}, \mathrm{CDCl}_{3}\right)$ do composto 59.

Ũ

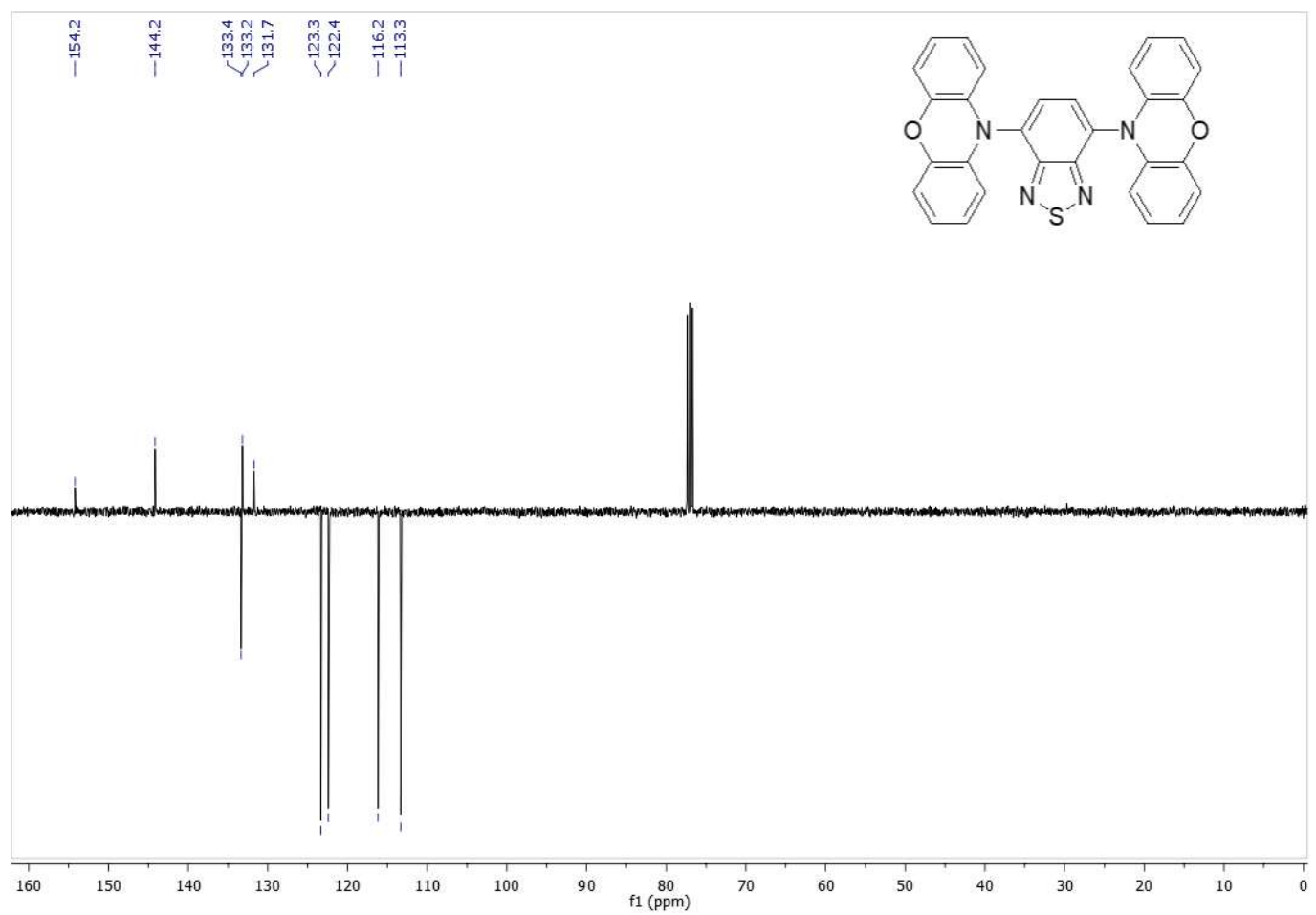

Figura S32. Espectro de $\mathrm{RMN}{ }^{13} \mathrm{C}\left(100 \mathrm{MHz}, \mathrm{CDCl}_{3}\right)$ do composto 59. 


\subsection{Voltametria cíclica}

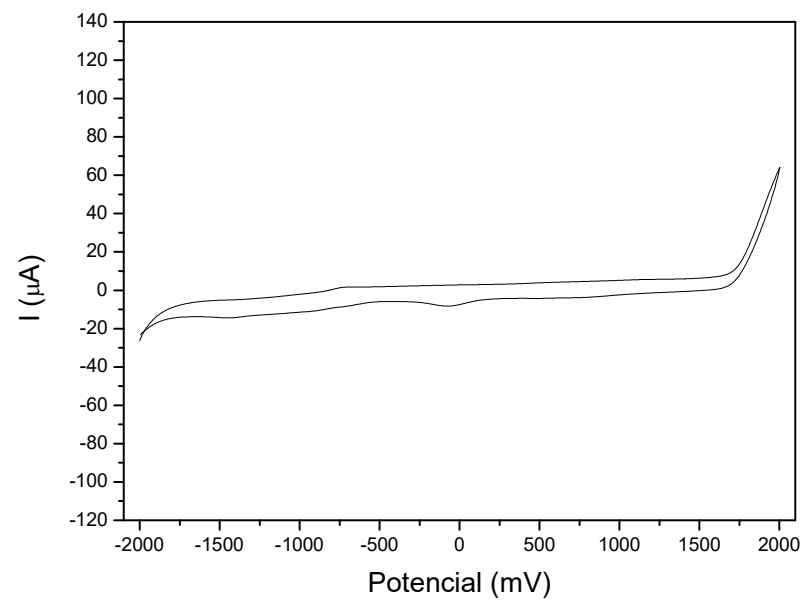

Figura S33. Voltamograma do branco.

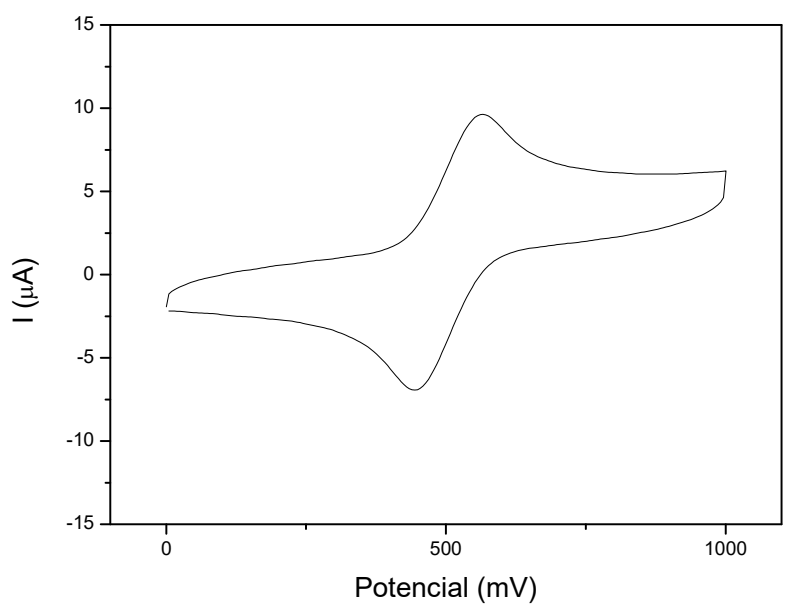

Figura S34. Voltamograma ferroceno.
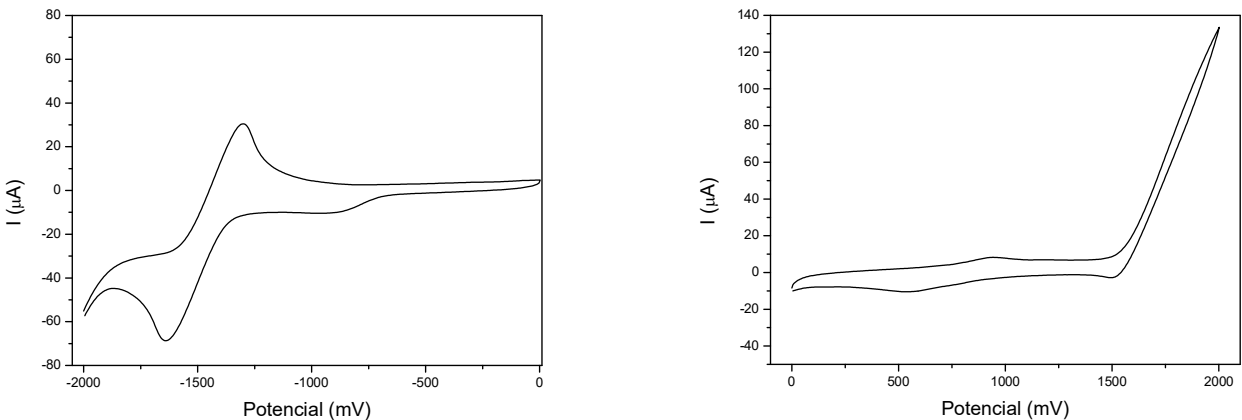

Figura S 35. Voltamogramas do composto 45. 

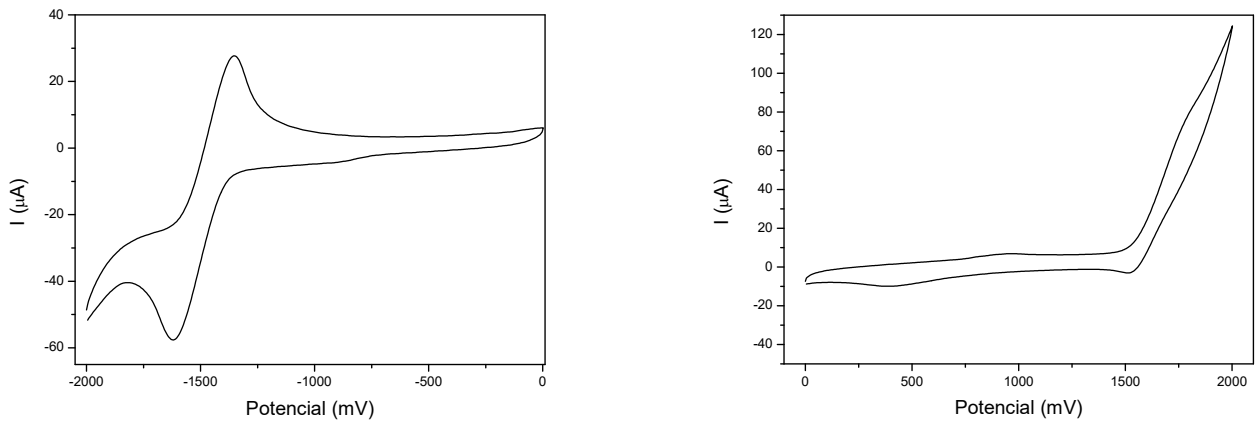

Figura S36. Voltamogramas do composto 46.
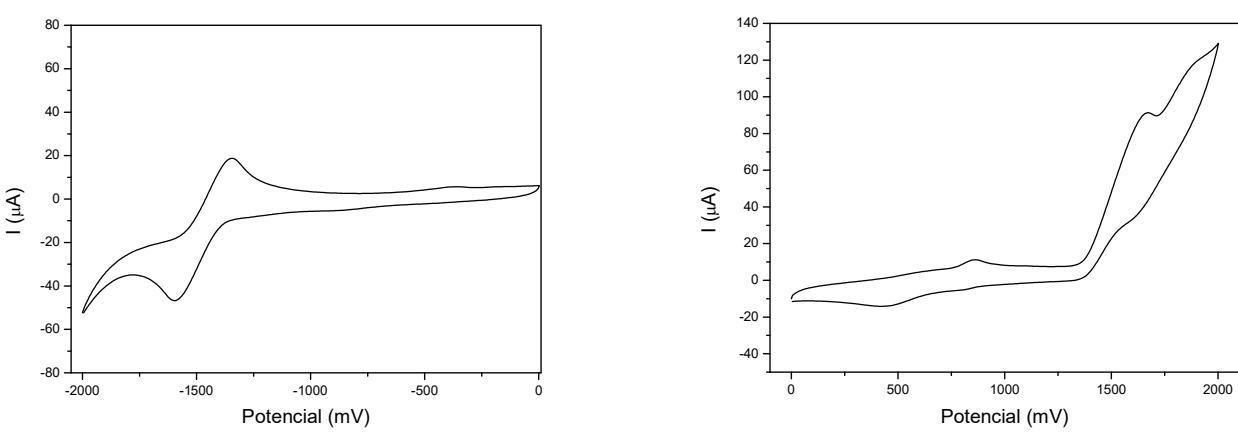

Figura S37. Voltamogramas do composto 47.
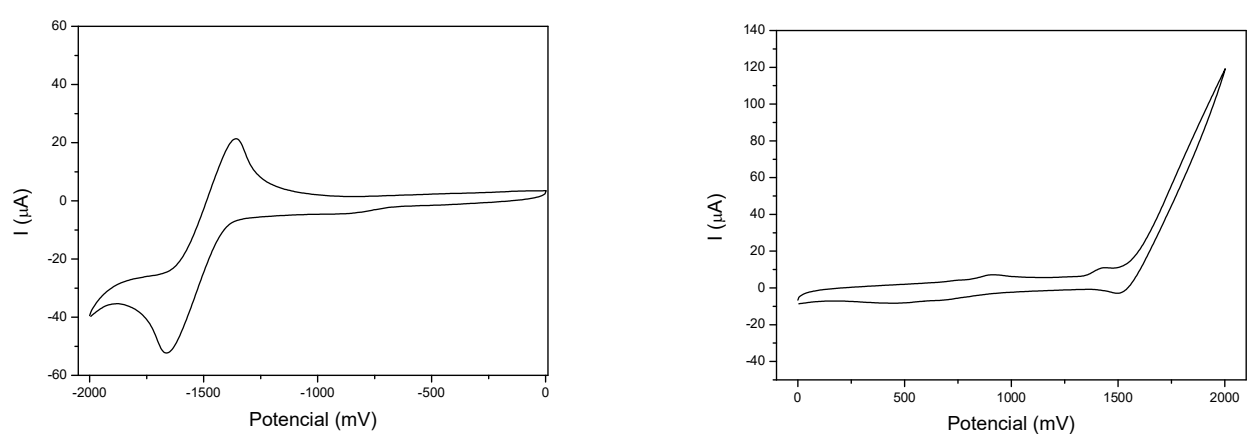

Figura S38. Voltamogramas do composto 48.
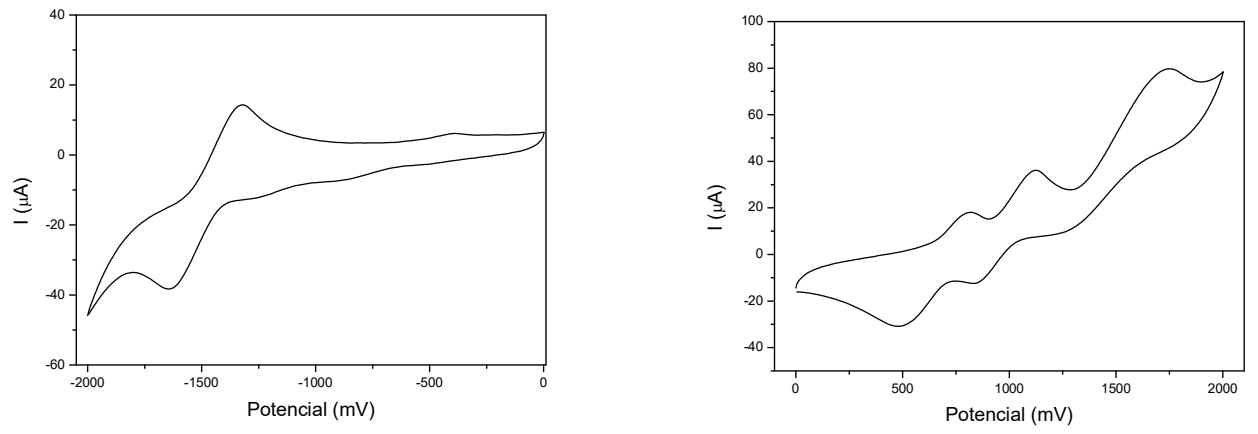

Figura S39. Voltamogramas do composto 49. 

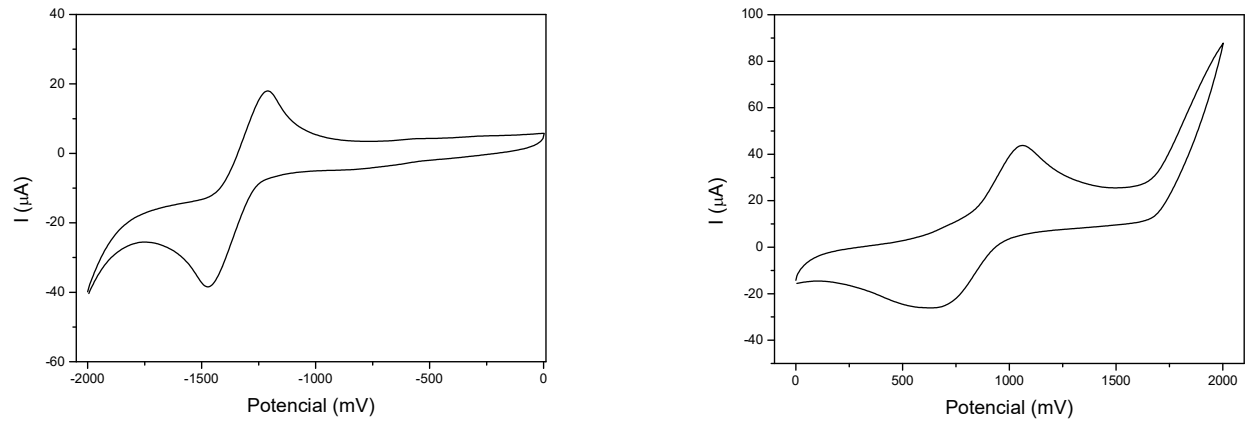

Figura S40. Voltamogramas do composto $\mathbf{5 0 .}$
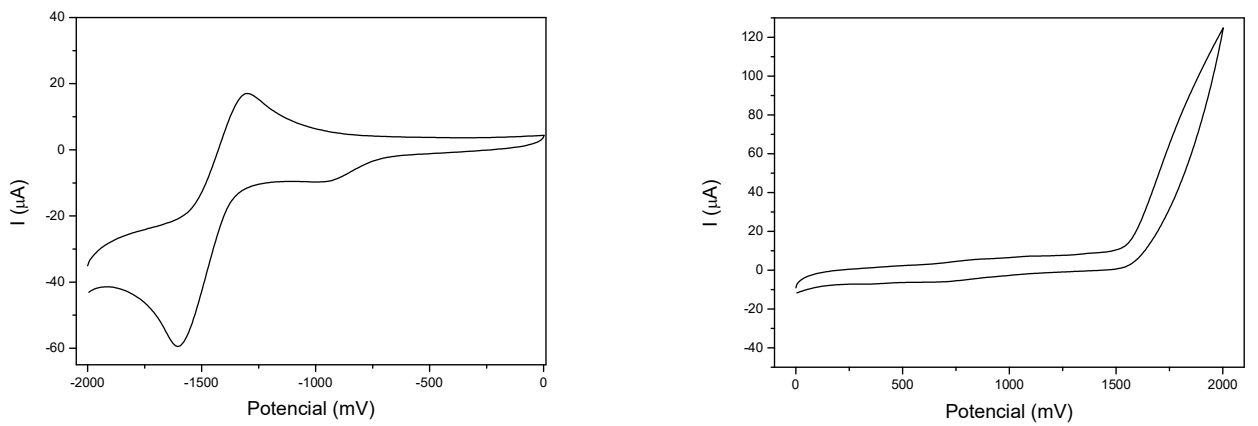

Figura S41. Voltamogramas do composto $5 \mathbf{5 .}$
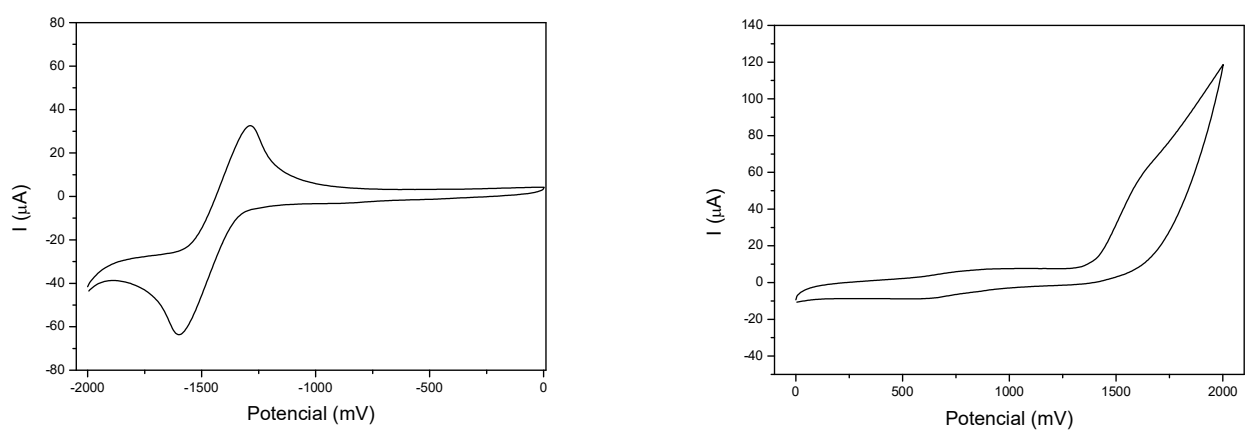

Figura S42. Voltamogramas do composto 54.
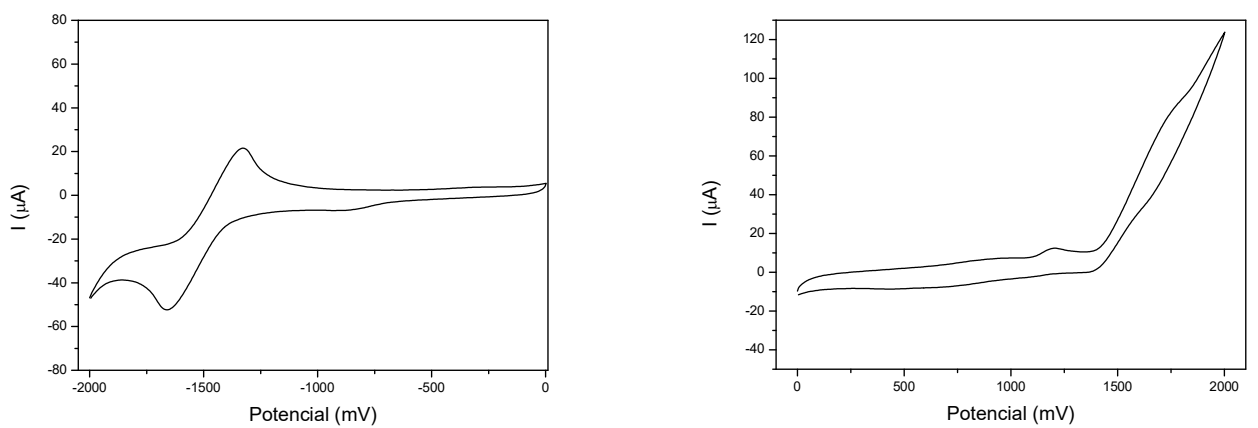

Figura S 43. Voltamogramas do composto 57. 

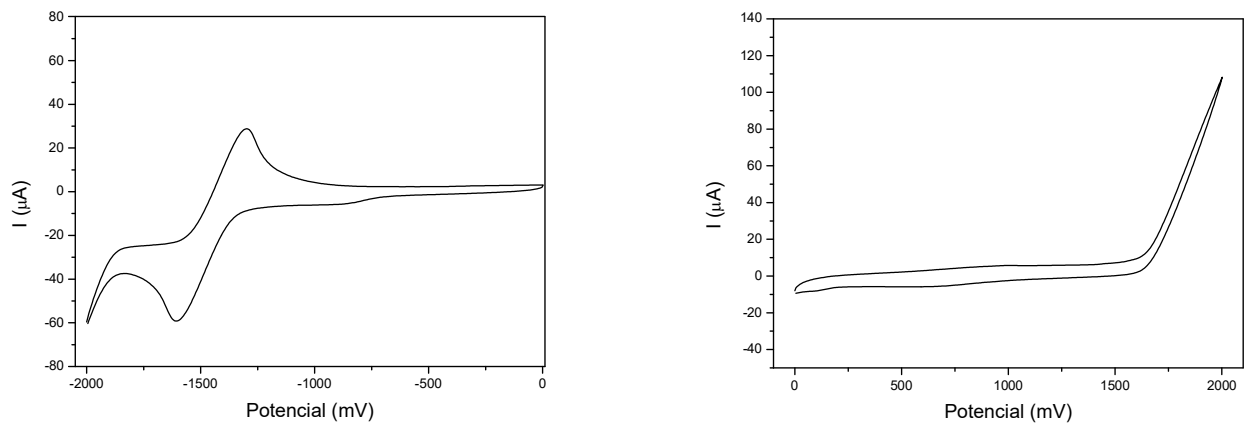

Figura S44. Voltamogramas do composto 56.

Uీ
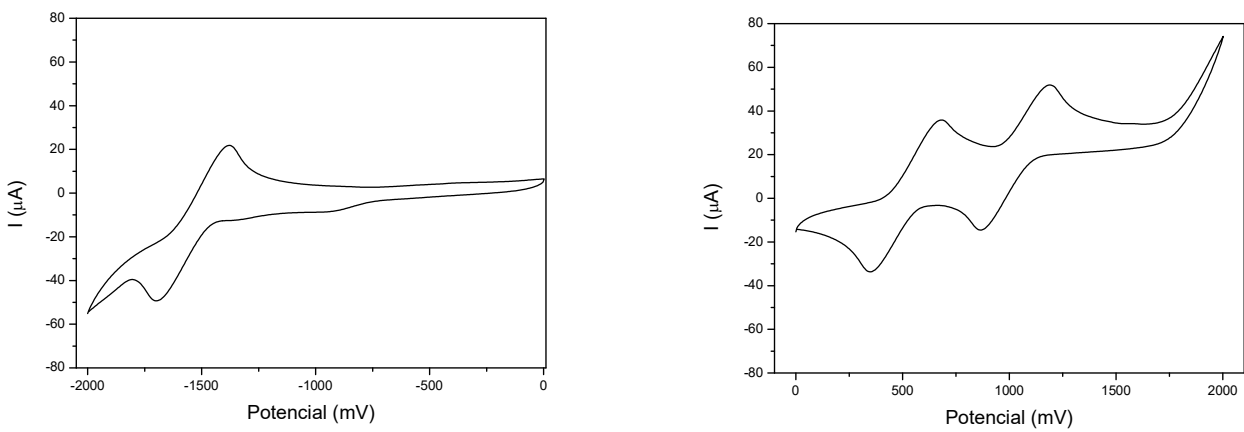

Figura S45. Voltamogramas do composto 58.
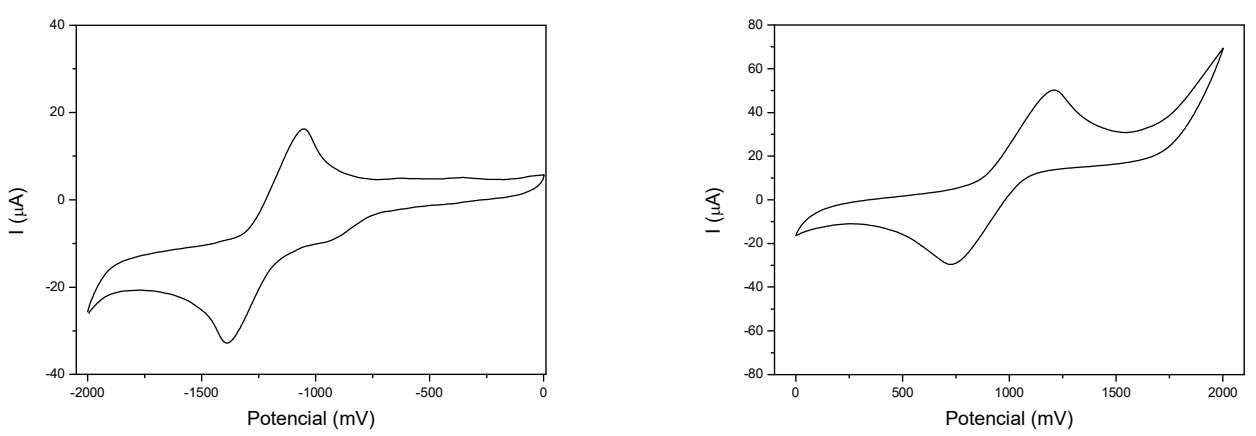

Figura S46. Voltamogramas do composto 59. 


\subsection{Dados de difratometria de raios $-\mathrm{X}$}

\begin{tabular}{|c|c|}
\hline Identification code & Composto 42 \\
\hline Empirical formula & C13H9BrN2O2S \\
\hline Formula weight & 337.19 \\
\hline Temperature & $100(2) \mathrm{K}$ \\
\hline Wavelength & $0.71073 \mathrm{~A}$ \\
\hline Crystal system, space group & Monoclinic, P21/c \\
\hline Unit cell dimensions & $\begin{aligned} \mathrm{a}= & 4.4218(2) \mathrm{A} \\
& \text { alpha }=90 \mathrm{deg} . \\
\mathrm{b}= & 28.1414(11) \mathrm{A} \\
& \text { beta }=97.8990(10) \mathrm{deg} . \\
\mathrm{c}= & 10.3354(4) \mathrm{A} \\
& \text { gamma }=90 \mathrm{deg} .\end{aligned}$ \\
\hline Volume & $1273.89(9) \mathrm{A}^{\wedge} 3$ \\
\hline Z, Calculated density & $4,1.758 \mathrm{Mg} / \mathrm{m}^{\wedge} 3$ \\
\hline Absorption coefficient & $3.388 \mathrm{~mm}^{\wedge}-1$ \\
\hline $\mathrm{F}(000)$ & 672 \\
\hline Crystal size & $0.29 \times 0.17 \times 0.09 \mathrm{~mm}$ \\
\hline Theta range for data collection & 2.46 to $27.91 \mathrm{deg}$. \\
\hline Limiting indices & $-5<=\mathrm{h}<=4,-36<=\mathrm{k}<=37,-13<=\mid<=13$ \\
\hline Reflections collected / unique & $11276 / 3037[\mathrm{R}$ (int) $=0.0357]$ \\
\hline Completeness to theta $=27.91$ & $99.7 \%$ \\
\hline Absorption correction & Semi-empirical from equivalents \\
\hline Max. and min. transmission & 0.7602 and 0.4599 \\
\hline Refinement method & Full-matrix least-squares on $\mathrm{F}^{\wedge} 2$ \\
\hline Data / restraints / parameters & $3037 / 0 / 172$ \\
\hline Goodness-of-fit on $\mathrm{F}^{\wedge} 2$ & 1.078 \\
\hline Final $R$ indices [l>2sigma(I)] & $\mathrm{R} 1=0.0335, w R 2=0.0828$ \\
\hline $\mathrm{R}$ indices (all data) & $\mathrm{R} 1=0.0487, w R 2=0.0899$ \\
\hline Extinction coefficient & none \\
\hline Largest diff. peak and hole & 0.279 and -0.434 e. $A^{\wedge}-3$ \\
\hline
\end{tabular}

Tabela S 1: Dados do cristal e refinamento da estrutura para o composto 42. 


\begin{tabular}{|c|c|}
\hline Identification code & Composto 43. \\
\hline Empirical formula & $\mathrm{C}_{40} \mathrm{H}_{32} \mathrm{~N}_{4} \mathrm{O}_{6} \mathrm{~S}_{2}$ \\
\hline Formula weight & 728,82 \\
\hline Temperature & 295(2) K \\
\hline Wavelength & $0,71073 \mathrm{~A}$ \\
\hline Crystal system, space group & Monoclinic, P21/c \\
\hline Unit cell dimensions & $\begin{aligned} a= & 9,5330(4) \mathrm{A} \\
& \text { alpha }=90 \mathrm{deg} . \\
\mathrm{b}= & 36,5907(16) \mathrm{A} \\
& \text { beta }=101,2820(10) \mathrm{deg} . \\
\mathrm{c}= & 10,1464(4) \mathrm{A} \\
& \text { gamma }=90 \mathrm{deg} .\end{aligned}$ \\
\hline Volume & $3470,9(3) A^{\wedge} 3$ \\
\hline Z, Calculated density & $4,1 ., 95 \mathrm{Mg} / \mathrm{m}^{\wedge} 3$ \\
\hline Absorption coefficient & $0,209 \mathrm{~mm}^{\wedge}-1$ \\
\hline $\mathrm{F}(000)$ & 1520 \\
\hline Crystal size & $0.23 \times 0.15 \times 0.13 \mathrm{~mm}$ \\
\hline Theta range for data collection & 2.25 to $27.92 \mathrm{deg}$. \\
\hline Limiting indices & $-12<=\mathrm{h}<=12,-48<=\mathrm{k}<=48,-13<=\mathrm{l}<=13$ \\
\hline Reflections collected / unique & $50563 / 8293[R($ int $)=0,0600]$ \\
\hline Completeness to theta $=27.91$ & $=27,92 \quad 99,6 \%$ \\
\hline Absorption correction & Semi-empirical from equivalents \\
\hline Max. and min. transmission & 0.9833 and 0.9634 \\
\hline Refinement method & Full-matrix least-squares on $\mathrm{F}^{\wedge} 2$ \\
\hline Data / restraints / parameters & $8293 / 0 / 469$ \\
\hline Goodness-of-fit on $\mathrm{F}^{\wedge} 2$ & 1.014 \\
\hline Final $\mathrm{R}$ indices [l>2sigma(l)] & $\mathrm{R} 1=0,0487, \mathrm{wR} 2=0,1019$ \\
\hline $\mathrm{R}$ indices (all data) & $\mathrm{R} 1=0,1040, \mathrm{wR} 2=0,1200$ \\
\hline Extinction coefficient & none \\
\hline Largest diff. peak and hole & 0.206 and -0.341 e. $A^{\wedge}-3$ \\
\hline
\end{tabular}

Tabela S 2: Dados do cristal e refinamento da estrutura para o composto 43. 


\begin{tabular}{|c|c|c|c|}
\hline 42 & & & 43 \\
\hline Ligação & $\begin{array}{l}\text { Comprimento da } \\
\text { ligação }(\AA)\end{array}$ & Ligação & $\begin{array}{l}\text { Comprimento da } \\
\text { ligação }(\AA)\end{array}$ \\
\hline$C(8)-C(9)$ & $1,360(3)$ & $C(8)-C(9)$ & $\begin{array}{l}1,352(3) \\
1,356(3)\end{array}$ \\
\hline$C(8)-C(10)$ & $1,423(3)$ & $C(8)-C(10)$ & $\begin{array}{l}1,422(3) \\
1,421(3)\end{array}$ \\
\hline$C(9)-C(11)$ & $1,421(3)$ & $C(9)-C(11)$ & $\begin{array}{l}1,414(3) \\
1,415(3)\end{array}$ \\
\hline$C(10)-C(12)$ & $1,425(3)$ & $C(10)-C(12)$ & $\begin{array}{l}1,430(3) \\
1,430(3)\end{array}$ \\
\hline$C(11)-C(13)$ & $1,353(4)$ & $C(11)-C(13)$ & $\begin{array}{l}1,367(3) \\
1,368(3)\end{array}$ \\
\hline$C(12)-C(13)$ & $1,421(3)$ & $C(12)-C(13)$ & $\begin{array}{l}1,431(3) \\
1,432(3)\end{array}$ \\
\hline $\mathrm{S}-\mathrm{N}(1)$ & $1,614(2)$ & S-N(1) & $\begin{array}{l}1,6072(18) \\
1,6118(18)\end{array}$ \\
\hline $\mathrm{S}-\mathrm{N}(2)$ & $1,617(2)$ & $\mathrm{S}-\mathrm{N}(2)$ & $\begin{array}{l}1,6097(17) \\
1,6042(17)\end{array}$ \\
\hline$N(1)-C(10)$ & $1,343(3)$ & $N(1)-C(10)$ & $1,345(2)$ \\
\hline$N(2)-C(12)$ & $1,343(3)$ & $N(2)-C(12)$ & $\begin{array}{l}1,342(2) \\
1,349(2)\end{array}$ \\
\hline
\end{tabular}

Tabela S 3: Comprimento de ligação obtido a partir de análises de raios $X$ dos monocristais dos compostos dos compostos 42 e $43 . q 23$ 